\title{
2011 Triennial Surveillance Review - Health Check and Statistical Information
}




\section{INTERNATIONAL MONETARY FUND}

\section{Triennial Surveillance Review-Health Check and Statistical Information}

Prepared by the Strategy, Policy, and Review Department

August 26, 2011

Contents

Page

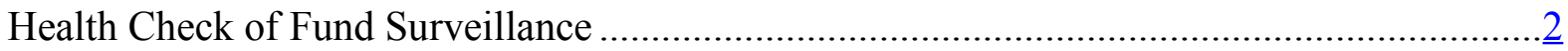

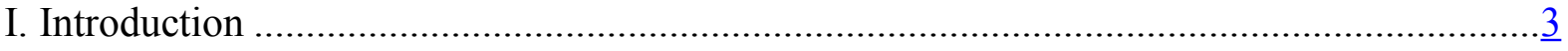

II. Overall Value-added of Surveillance, Traction, and Areas for Progress ........................... $\underline{3}$

III. Where We Stand on the Four Operational Priorities ................................................ 9

IV. Candor, "Silo" Mentality, and Evenhandedness..................................................

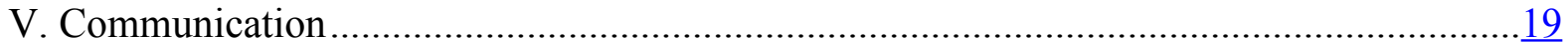

Statistical Appendix I: Article IV Staff Report Reviews.............................................21

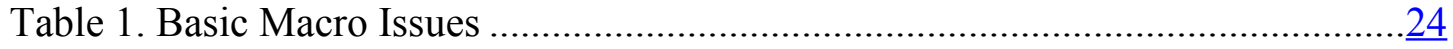

Table 2. Financial Sector Issues................................................................... $\frac{26}{28}$

Table 3. Exchange Rate and External Stability Issues ........................................... $\frac{28}{29}$

Table 4. Risk Assessment .................................................................................29

Table 5. Multilateral Perspective ........................................................................

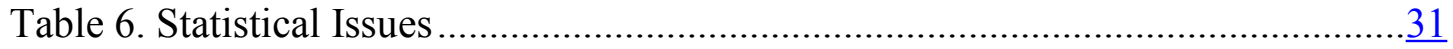

Table 7. Candor and Communication .............................................................

Statistical Appendix II: Stakeholder Surveys ............................................................ 33

Table 1. Country Authorities' Survey Results ..................................................... $\frac{36}{42}$

Table 2. Executive Directors' Survey Results .................................................. $\frac{42}{50}$

Table 3. Mission Chiefs' Survey Results ......................................................

Table 4. Financial Markets Survey Results ......................................................66

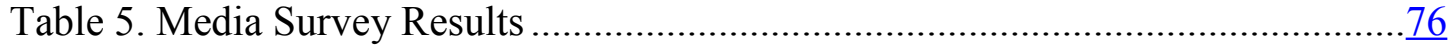

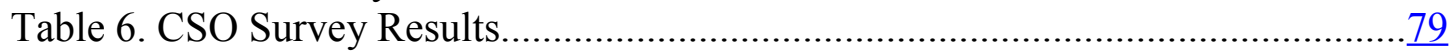

Table 7. Country Authorities' Survey Comments .................................................... $\frac{81}{94}$

Table 8. Executive Directors' Survey Comments................................................... $\frac{94}{98}$

Table 9. Mission Chiefs' Survey Comments ........................................................... $\frac{98}{1}$

Table 10. Financial Markets Survey Comments ................................................111

Table 11. Media Survey Comments..............................................................114

Table 12. CSO Survey Comments …............................................................ 


\section{HEALTH CHECK OF FUND'S SURVEILLANCE ${ }^{1}$}

\section{Key Messages}

$>$ Fund policy advice in recent years is generally viewed as timely and taking account of changing economic conditions and socio-political context. However, views among G-20 and Asian authorities are more mixed.

$>$ Perceived value added of Fund's surveillance is highest for low-income countries (LICs), relative to emerging and advanced economies. The same was observed in the 2008 TSR.

$>$ Perceived traction of Fund surveillance is high overall, but similarly varies across country groups. Overall more than 70 percent of country authority respondents indicate that recent Article IV consultations have generated policy debate to at least some extent, and more than 60 percent appropriate policy changes to at least some extent. But traction is higher for LICs than for emerging and advanced economies.

$>$ Perceived value added remains uneven across policy areas. The contribution of surveillance is perceived as highest on fiscal and macro-financial issues, and lowest on spillovers and exchange rate issues.

$>$ Progress against 2008 TSR operational priorities is mixed. Some progress is perceived in macro-financial issues and risk assessment, but less on exchange rate issues - despite technical improvements. Coverage and analytical depth of risk assessment, spillover, and cross-country analyses in recent Article IV reports are mixed. Country authority interviews by external experts indicate that more detailed discussions of risks stemming from international developments, their policy implications, and financial interconnectedness would be welcome.

$>$ Perception on evenhandedness differs among stakeholders. There is concern on the evenhandedness of policy advice expressed by country authorities, while perception among media and financial market participants is more positive.

$>$ Country authorities called for a greater focus on tailored policy advice and for more cross-country comparisons as key areas for progress in the future. An improvement in the quality of analysis and consistency of advice across countries are also ranked high, particularly by large countries — raising a possible tension with the desire for more tailored advice.

\footnotetext{
${ }^{1}$ Prepared by a staff team comprising Tetsuya Konuki, Wasima Rahman-Garrett, Nicolas Million, Sean Cogliardi, Olessia Korbut, and Era Dabla-Norris (all SPR).
} 


\section{INTRODUCTION}

1. Overview. This paper (a) provides a snapshot of the overall value added of Fund's surveillance perceived by stakeholders; (b) details where the Fund stands in terms of four operational priorities set out in the $2008 \mathrm{TSR}^{2}$ (c) examines key issues identified in the recent $\underline{I E O}$ paper on the IMF performance in the run up to the global crisis; ${ }^{3}$ and (d) discusses stakeholders' perception on the communication aspects of surveillance.

2. Methodology. This paper relies on various stakeholders' surveys (country authorities; Executive Directors, IMF mission chiefs; financial market participants, media and civil society organizations) and interviews by former senior Fund staff of country authorities (mainly at the time of the 2011 Spring Meetings) to analyze stakeholders' perception ( $\underline{T S R}$ External Report on Interviews with Country Authorities). ${ }^{4}$ The paper also relies on a review by staff of 50 Article IV staff reports issued from January 2010 through April 2011.5

\section{Overall Value-Added of Surveillance, Traction, and Areas for Progress}

3. Scope. This section provides a snapshot of perceptions related to effectiveness, value added, and areas for future progress in Fund surveillance. It also reports on the coverage of basic macro issues and the follow up on past policy advice in Article IV staff reports.

4. Policy advice during the global crisis. About 80 percent of respondents to the country authority and Executive Director surveys thought that the Fund's advice during the global crisis has taken into account changing economic conditions in the global economy and their own country (Chart 1). In addition, around 70 percent thought that Fund's advice has been timely, but this opinion varied across country groups. The timeliness of Fund advice was viewed more negatively in Asia than elsewhere (only 36 percent of respondents agreed that it was timely), and among G-20 countries (only 50 percent of respondents agreed that it was timely). (Statistical Appendix II, Table 1).

\footnotetext{
${ }^{2}$ In discussing the 2008 TSR, the Executive Board requested that progress related to the four operational priorities be reviewed in the 2011 TSR.

${ }^{3}$ See "IMF Performance in the Run Up to the Economic and Financial Crisis," IEO (1/10/2011).

${ }^{4}$ The sample of respondents to these surveys may not be fully representative of the original population targeted. Response rates for country authority surveys among Asian and European countries are noticeably higher than those among African countries (Statistical Appendix II, Table 1)

${ }^{5}$ Statistical Appendices I and II provide detailed explanations for methodology of Article IV staff report reviews and stakeholders' surveys, respectively.
} 


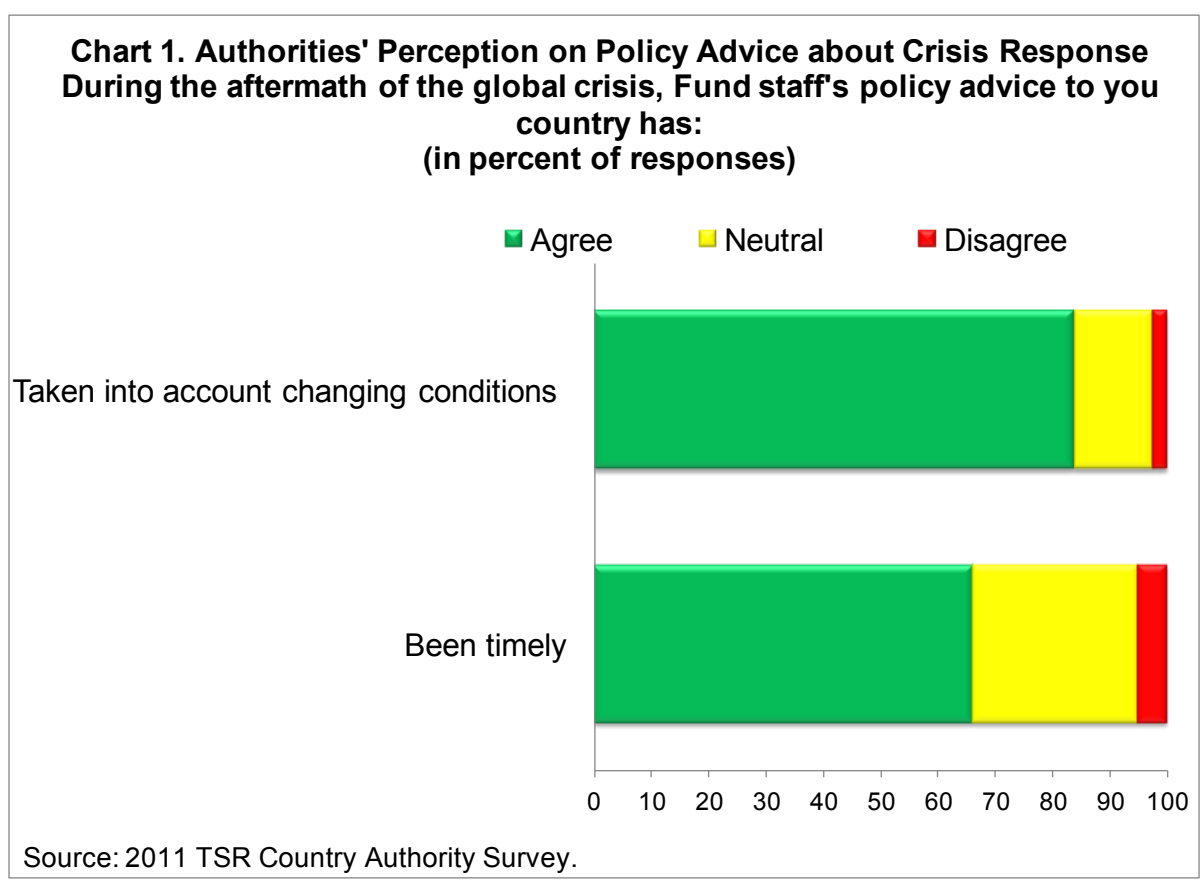

5. Coverage of basic macro issues in Article IV staff reports. Article IV staff report reviews found that all basic macro policy areas were covered in recent staff reports. Virtually all of the 50 sample reports provided a rationale and justification for recommended fiscal and monetary policy adjustments and stance; covered core financial sector issues; and provided a clear assessment of the exchange rate level (Tables 1 through 3, Statistical Appendix I). All sample staff reports clearly identified the baseline scenario and discussed key medium-term challenges. This represents progress compared with the 2008 TSR when about a quarter of the sample reports did not clearly describe the baseline medium-term scenario.

6. Follow up of past policy advice. Follow up of past policy advice in recent Article IV reports has been uneven. Fund advice was not followed in 64 percent of the cases. This may be due to a variety of reasons, including unexpected changes in country circumstances. Among countries where past Fund advice was not followed, more than half (around 56 percent) did not provide reasons why, despite the fact that the Bilateral Surveillance Guidance Note stipulates that staff reports should include follow up on previous policy recommendations. The lack of follow up of previous policy recommendations may be an impediment to the traction of surveillance.

7. Valued-added: country authorities' general perception. Many interviewees saw the main value-added of bilateral surveillance as the provision of an integrated view of the main economic and financial challenges currently facing the country; and they added that the assessments offered by surveillance provided new insights to policy interactions within their country. The authorities from small emerging markets and LICs noted in the interviews that Fund staff provided them with valuable specific technical inputs that helped domestic policy 
making, and supported internal policy coordination. Larger countries valued multilateral surveillance more than smaller ones.

8. Perceived value added across products. Different products seem to have different audiences, but among multilateral products, the WEO and GFSR appear to be the most frequently used products by virtually all stakeholders.

- Country authorities: Among the Fund's multilateral surveillance and related products, 85 percent of respondents noted that the WEO was the most helpful in sharpening their views, followed by the GFSR (69 percent) and REO (57 percent). Perceived value added of the REOs was particularly favorable among LICs, African, and Middle East countries. Less than 30 percent reported that the Fiscal Monitor, Early Warning/Vulnerability Exercises, and cross-country thematic reports were most helpful. Less favorable perception on Fiscal Monitor and Early Warning/Vulnerability exercises could be explained by the fact that the Fiscal Monitor is a relatively new product (first published in May 2010); and Early Warning/Vulnerability Exercises have a restricted audience. ${ }^{6}$

- $\quad$ Executive Directors: Almost all respondents reported that the WEO and GFSR were most helpful in strengthening their understanding of global stability risks, followed by the Fiscal Monitor (61 percent), Early Warning/Vulnerability Exercises (61 percent), and the REOs (50 percent). Less than 40 percent of them reported that way for crosscountry thematic reports (Statistical Appendix II, Table 2).

- $\quad$ Financial market participants: 85 percent of respondents rely on Article IV reports at least to some extent, followed by the WEO (81 percent) and GFSR (65 percent, Statistical Appendix II, Table 4). Over 90 percent of them considered comprehensiveness and analytical depth of surveillance reports as their main strength.

- Media: Almost all respondents to the media survey reported that the credibility of Article IV reports was satisfactory or very good (Statistical Appendix II, Table 5).

\section{Perception from the Civil Society Organizations (CSOs): 80 percent of CSO} survey respondents noted that they found analysis of developments and outlook the most valuable aspects of the Fund's surveillance products, while almost 70 percent of them perceived cross-country thematic aspects in that way (Statistical Appendix II, Table 6). In addition, 40 percent of CSO respondents considered the Fund's communications on surveillance as somewhat or much better than other comparable international financial institutions, government agencies and think tanks.

\footnotetext{
${ }^{6}$ The focus of Fiscal Monitor and Early Warning/Vulnerability Exercises on advanced and emerging market issues could also partly explain the lower perceived value added of these products among LICs.
} 


10. Perceived
relative value-added
differs across policy
areas. Country
authorities thought
that Fund's fiscal
analysis contributed
most in terms of
providing new
insights or improving
the understanding of
the issues, similar to
the 2008 TSR,
followed by the
analysis of macro-
financial and

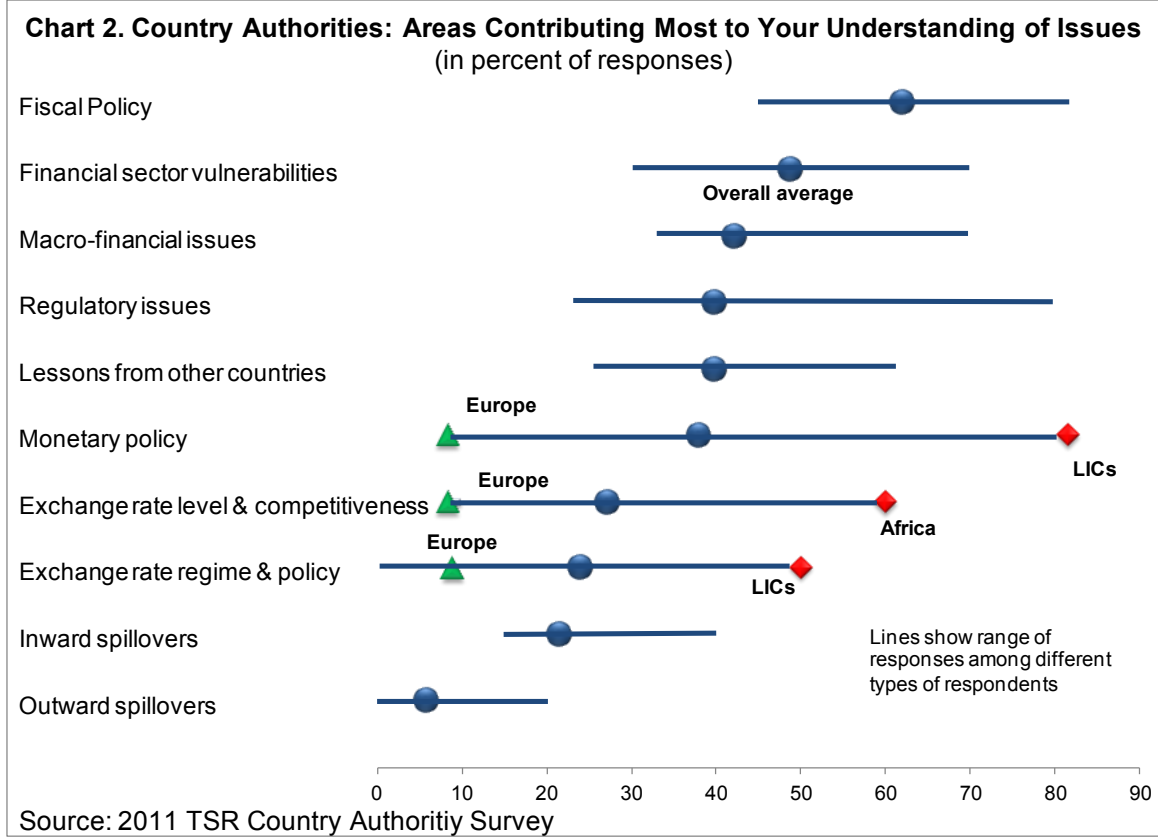

financial sector

policy issues (see Chart 2). The perceived contribution of surveillance in monetary policy ranked lower than for fiscal and financial policy issues, but this was driven downward by respondents from European members, many of which are in the euro area. ${ }^{7}$ The reported contribution from surveillance in the analysis of lessons from experiences in other countries (cross-country analysis) lagged fiscal and financial policy related areas. Finally, country authorities ranked the current contribution from Fund's surveillance of inward and outward spillovers and exchange rate and competitiveness issues lowest (discussed in section III below). ${ }^{8}$ In the 2008 TSR, while the question asked was different, the ordering of relative value added across policy areas perceived by country authorities was broadly similar to that in the 2011 TSR (see Chart 3). ${ }^{9}$

\footnotetext{
${ }^{7}$ Overall, 38 percent of country authority survey respondents reported that the Fund's analysis of monetary policy contributed strongly to their insights into this issue, with this figure rising to 58 percent outside of Europe. While the question was not specifically about bilateral surveillance, and the Euro area monetary policy gets covered as part of Euro area surveillance, respondents from countries with no independent monetary policy may have seen less value on this topic. The ordering of relative value added across policy areas changes when European countries are excluded, with monetary policy next to fiscal policy, followed by macro-financial and financial sector policy; the ordering of other policy areas remains the same as in the full sample.

${ }^{8}$ For exchange rate issues, overall, 27 percent of country authority survey respondents reported that the Fund's analysis contributed strongly to their insights into this issue, with this figure rising to 38 percent for nonEuropean members.

${ }^{9}$ These two results are not directly comparable. In the 2008 TSR survey, the authorities were asked to rate the contribution of surveillance in each policy area. In the 2011 TSR, they were asked to choose all policy areas where they saw the most contribution from surveillance.
} 


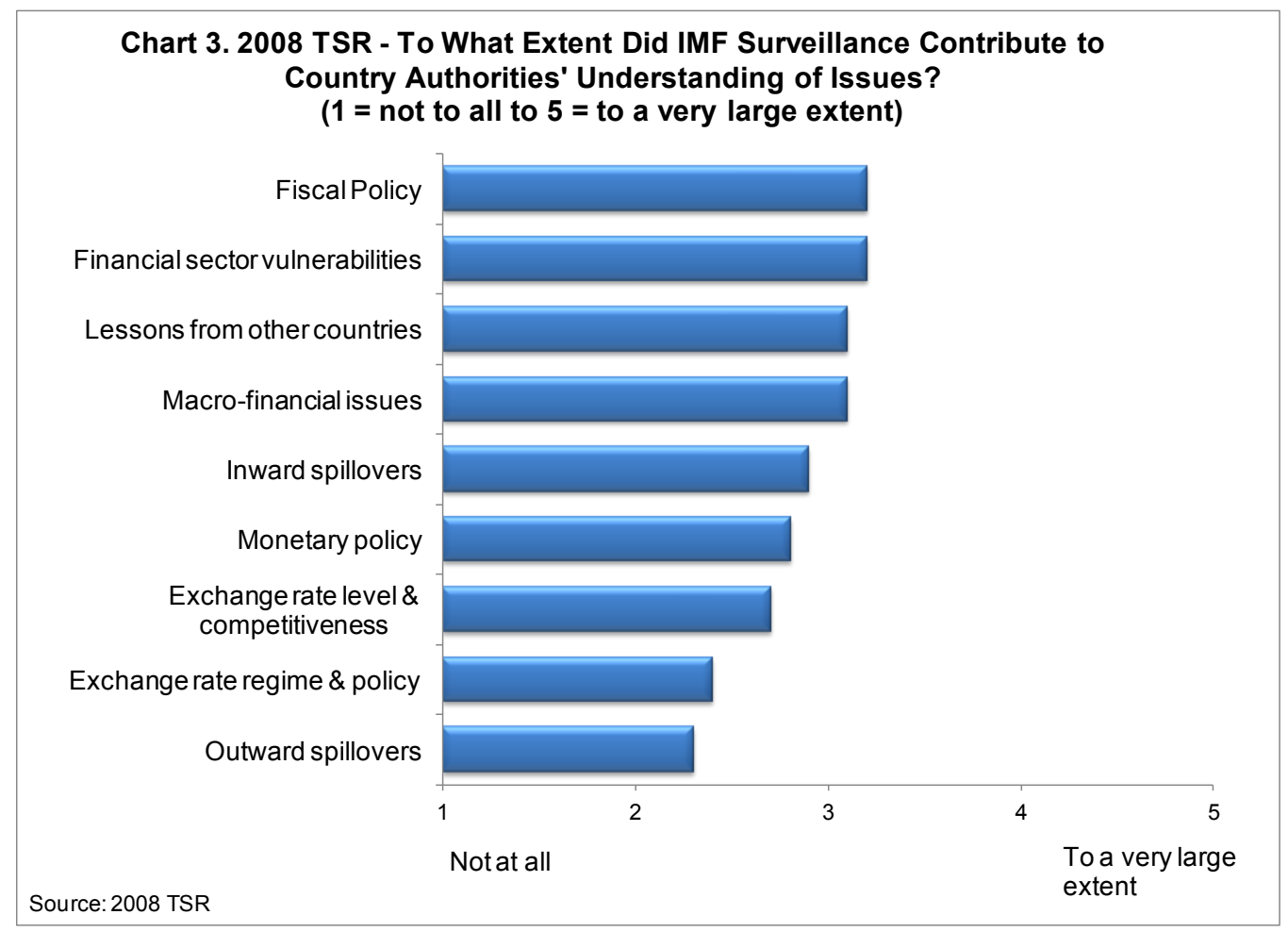

11. Perceived value-added also varied across the membership. Across the range of policy areas, higher value-added was perceived by African and Middle East country authorities compared to their European and Asian counterparts, by non-G-20 as compared to G-20 authorities, and by program compared to non-program countries. Similar to the 2008 TSR, LIC authorities saw the greatest value added in Fund's surveillance across policy areas, followed by emerging markets, and to a lesser extent for advanced countries. Likewise, Executive Directors perceived that surveillance was most valuable for LICs. These results were echoed by financial market participants.

\section{Perceived traction of Fund's bilateral surveillance was overall high, but varied} across groups. More than 70 percent of respondents to the country authority survey thought that recent Article IV consultations have generated policy debate at least to some extent, while more than 60 percent of them thought that they have fostered appropriate policy changes at least to some extent (Chart 4). Perceived traction of bilateral surveillance, however, varied across country groups: the highest traction was perceived among LICs and African countries, and the lowest among advanced economies and countries in Asia Pacific; less traction was perceived by G-20 compared to non-G-20 countries and by non-program versus program cases. Not surprisingly, this pattern is consistent with the perceived value added of bilateral surveillance across the membership. The 2009 IEO Report on $\underline{I M F}$ Interactions with Member Countries also found that the Fund got least traction with advanced and large emerging market economies, and most traction with PRGT-eligible countries. Some of the authorities interviewed noted that staff sometimes lacked the political savvy needed to gain traction for Fund advice among policy makers, other relevant 
stakeholders (e.g. parliamentarians, unions, and civil society), and public opinion more generally. As to the traction of multilateral surveillance, interviews indicated that representatives of larger, more systemic countries were interested in the Fund's analysis of cross-border spillover effects of national policies and related policy recommendations. In particular, many interviewees noted that the closed-door IMFC breakfast presentations had generated significant interest and attention of the senior policy makers attending them and had increased interest in the IMFC.

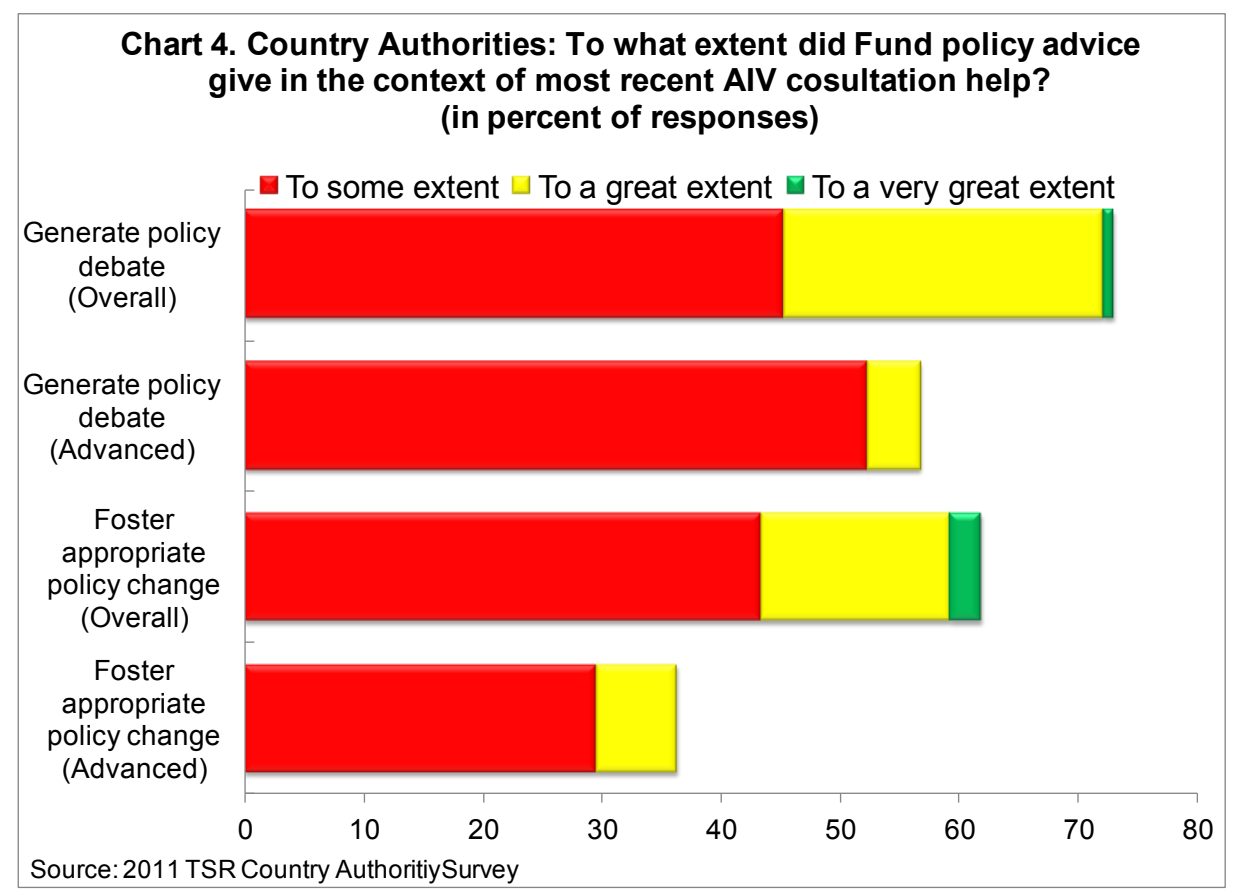

13. Area for future progress. Almost 70 percent of respondents to the country authority survey thought that the Fund's policy advice during the crisis has been appropriately informed by the political and social context. However, more than 60 percent of survey respondents saw the need for policy advice to be more tailored to country circumstances in order to further strengthen Fund's surveillance (Chart 5). Interviews found that many authorities would like country teams to be more familiar with the country's background, such as the legal and institutional framework. At the same time, the need for better consistency was also ranked high (around 40 percent). In addition, almost 50 percent of survey respondents indicated they would like to see greater use of cross-country comparisons in the future, and around 45 percent a better quality of analysis. Opinions on the most important areas for improvement differed across country types. Larger countries were mostly asking for improvements in the quality of analysis, while emphasizing the need for more consistency of advice (around 60 percent). 


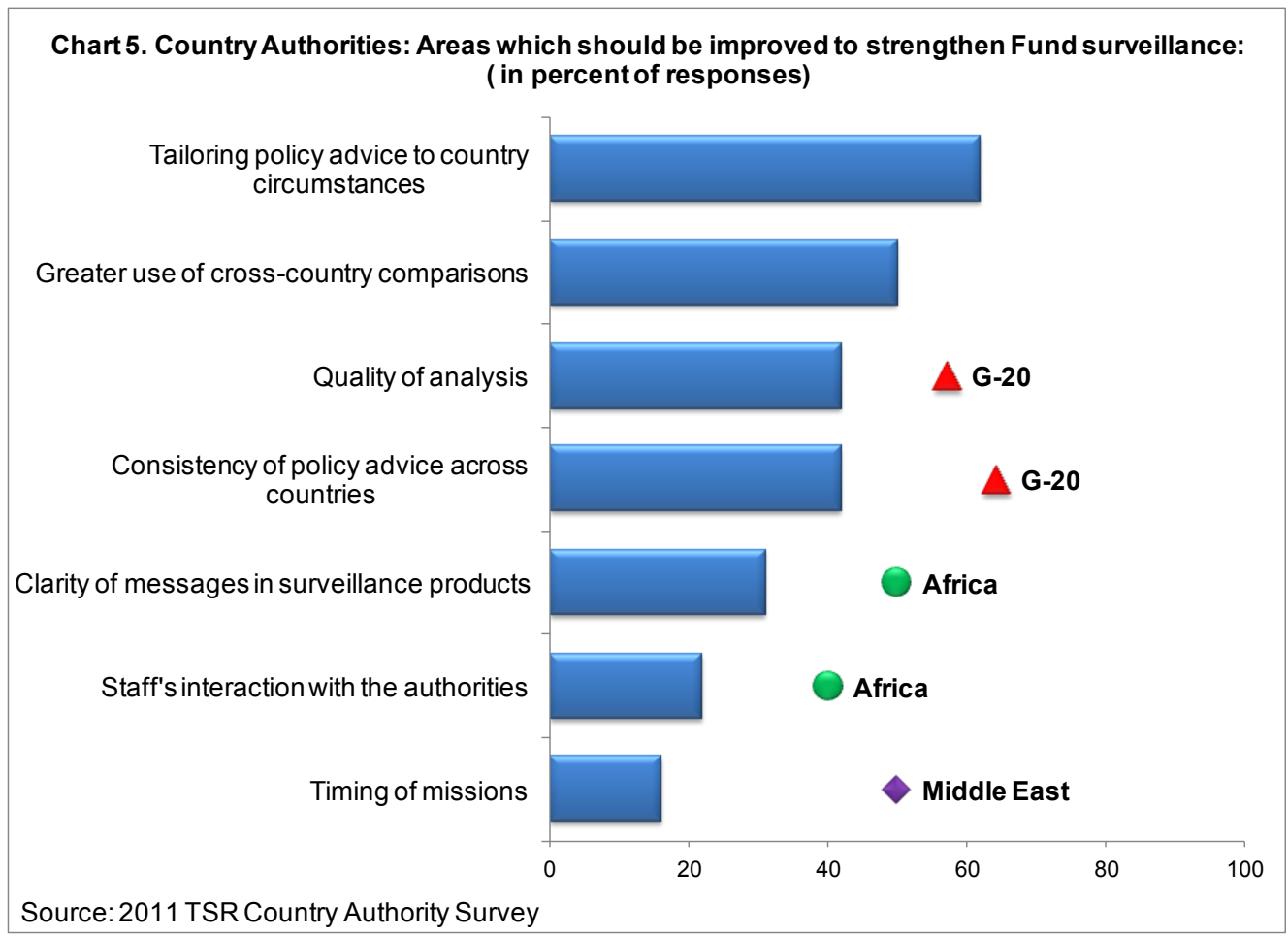

\section{Where We Stand on the Four Operational Priorities}

14. Scope. This section discusses where the Fund stands regarding the four operational priorities identified in the 2008 TSR: risk assessment; multilateral perspective; financial sector surveillance and real-financial linkages; and analysis of exchange rate and external stability risks. While a number of steps have been taken to address shortfalls in each area, this TSR suggests that there is scope for further improvement.

\section{Risk Assessment}

15. The 2008 TSR found insufficient attention to risks to the baseline scenario in Article IV staff reports. It called for (i) greater attention to risks around the baseline; (ii) an improved toolkit to quantify high probability risk assessment; and (iii) more systemic approach to tail risks in Article IV consultations.

16. The toolkit for risk detection has been enriched. The Fund has developed new vehicles to sharpen the focus on risks. Since 2008, the Fund and the Financial Stability Board (FSB) have initiated regular Early Warning Exercises (EWEs). The EWE examines tail risks to the global economy that would result in policy recommendations that could differ from those generated by the baseline scenario presented in the WEO, GFSR, and the Fiscal Monitor. It seeks to identify the vulnerabilities and triggers that could precipitate systemic crises, and identifies risk-mitigating policies including those that would require international cooperation. As part of the EWE, the scope of the vulnerability exercises was expanded to include advanced economies. Starting 2011, a Vulnerability Exercise for LICs has been introduced. 


\section{Greater attention has} been paid to risks around the baseline since 2008. More than 70 percent of the respondents to the country authority survey noticed an improvement in the quality of risk assessment at least to some extent compared with pre-global crisis Article IV consultations (Chart 6).$^{10}$ The Article IV staff report reviews found that the bottom-line messages took account of the major risks to the baseline scenario in 78 percent of the sample reports. This is an improvement from the 2008 TSR, where the comparable ratio was 54 percent. While a large majority of respondents to the country authority surveys thought that, in general, the discussion of risks was appropriate for their own country, this ratio dropped significantly when it comes to signaling risks for other countries (Chart 7). G-20, Asian, and

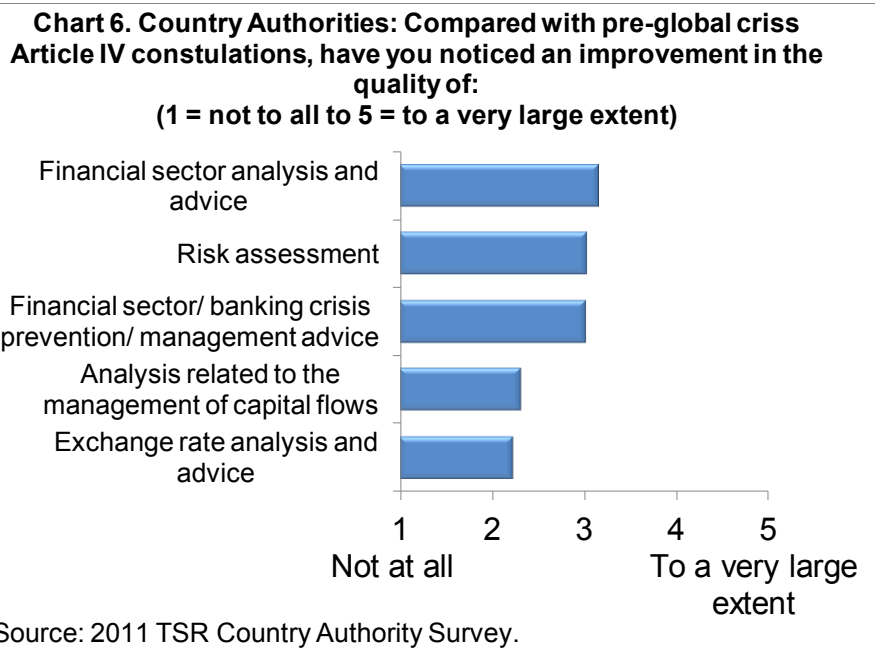

Chart 7. Percent who think that Fund advice adequately signals risks:

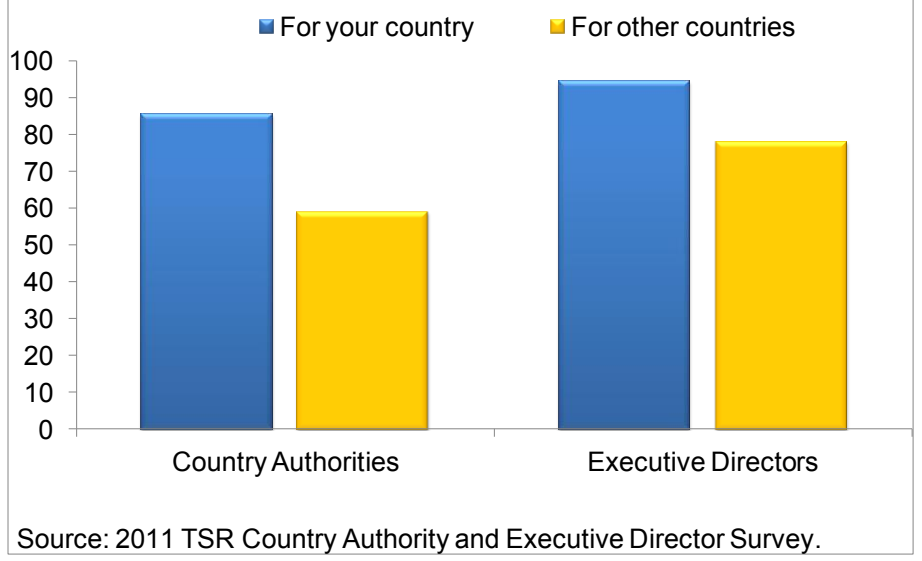

Western Hemisphere country authorities were particularly critical of the Fund's ability to adequately signal risks for other countries.

\footnotetext{
${ }^{10}$ Respondents from Asian countries were less convinced of progress in risk assessment: slightly over 50 percent of them reported no progress or progress only to a little extent.
} 
18. There is scope for improvement on transmission channels of risks. Risk transmission channels still seem to be insufficiently spelled out. 50 percent of Executive Director survey respondents indicated that the discussion of transmission channels of risks in the Article IV reports was insufficient, with more than 30 percent of respondents to the financial market survey sharing this view. In particular, as discussed below, despite some progress since 2008, the coverage of two-way macro-financial possible transmission channels was still uneven in the Article IV staff reports in recent years.

19. There is also scope for progress on tail risks.

Interviews by external experts indicated that the authorities welcomed the increased focus on the analysis of systemic risks, but felt there was a need for further progress not only in identifying tail risks, but also in tracing the effects of their

Chart 8. Coverage of Risk Transmission and Tail Risk (in percent of $\mathbf{5 0}$ sample Article IV reports) Risk transmission from
macro to financial

Risk transmission from financial to macro

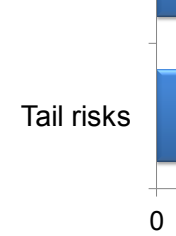

Source: Article IV Staff Report Reviews. possible realization (i.e., connecting the dots). More than a quarter of respondents to the Executive Director and financial market surveys indicated that the discussion of tail risks in the Article IV reports was insufficient. The review of 50 Article IV reports found that tail risks were discussed only in 16 percent of the sample (Chart 8, Statistical Appendix I, Table 4). Although more than 90 percent of respondents to the mission chief survey reported that authorities were open at least to some extent to discussing high probability risks, this ratio dropped below 70 percent when it pertained to a discussion of tail risks (Statistical Appendix II, Table 3).

\section{Multilateral perspective (spillover and cross-country analysis)}

20. The 2008 TSR reported that although spillover analysis should be mainstream practice it was not yet sufficiently covered, and there was insufficient policy-oriented crosscountry analyses in Article IV consultations. It called for (i) better integration of the WEO/GFSR into Article IV staff reports; (ii) more explicit discussion on inward spillover effects; (iii) more discussion of outward spillovers for systemic members; and (iv) better knowledge and information sharing within the Fund.

\section{Efforts to improve the integration of bilateral and multilateral surveillance and} inter-departmental knowledge sharing were stepped up. With a view to enhancing integration between multilateral surveillance and Article IV consultations, the Fund has introduced various new processes since 2008. Weekly cross-departmental surveillance meetings were initiated to improve knowledge and information sharing between functional and area departments. The briefing process for the Article IV consultation missions has been changed to enhance inter-departmental discussions and knowledge sharing. Regional units 
have been set up in all area departments to improve coverage of regional inter linkages. Spillover reports of five systemic economies have been prepared - though the surveys and analysis undertaken in this paper were conducted before they were released. Despite these efforts, the coverage and policy orientation of spillover and cross-country analyses are still uneven, as discussed below.

\section{Authorities still view} spillover analysis less favorably than other areas of Fund surveillance. Country authorities perceived that the current spillover analysis in Fund's surveillance contributed less to their insights compared with other areas. Only about 20 percent of country authority survey respondents mentioned inward spillovers, among the areas from which they gained the most contribution to their

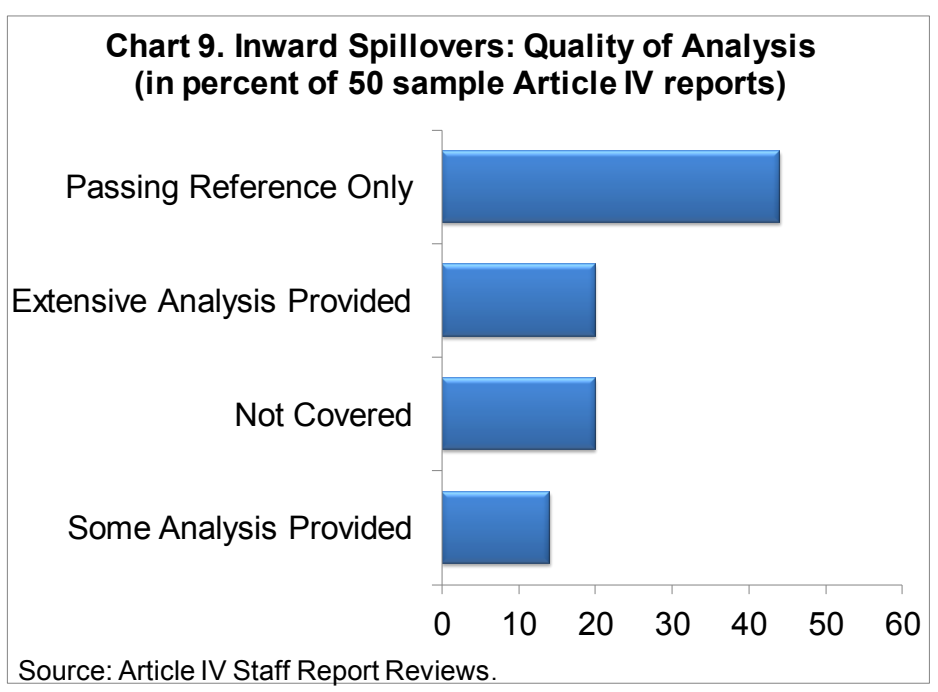
insights from Fund surveillance (see Chart 2). Respondents from advanced economies and LICs viewed the value added of Fund's surveillance in this area less favorably than emerging market countries. The perceived value added in the area of outward spillovers was the lowest - at six percent of overall respondents - relative to other policy areas across various types of countries, including respondents from G-20 and advanced countries.

23. Uneven coverage of spillovers. The lower perceived value added for current spillover analysis may reflect current uneven coverage, including the fact that this study was conducted before the spillover reports were available. Written comments by country authorities also called for greater attention to spillover analysis. Interviews indicated that country authorities would like a detailed discussion, based on quantified scenarios, of the risks posed by international economic developments (inward spillovers) and of the appropriate policy responses. They also wanted more analysis of transmission of financial disturbances "across borders." Regarding inward spillovers, while arguably a common set of external assumptions ensures that spillovers are implicitly taken into account, the Article IV staff report reviews found that while around three quarters of the sample reports explicitly covered inward spillover issues — a result is similar to the 2008 TSR — only 20 percent of them provided extensive analysis, such as possible scenarios and transmission mechanisms to document the possible implications and associated policy recommendations (Chart 9). Interviewees welcomed, in principle, the preparation of spillover reports of five systemic economies which were underway at that time (and have now been completed). 


\section{Uneven policy}

orientation of cross-country

analysis. Current cross-country analysis receives higher marks in terms of contribution than spillovers analysis - 40 percent of respondents to the country authority survey viewed Fund's surveillance in this area as contributing most to their insights (see Chart 2). But coverage and the relevance for policy discussions of such analysis remain uneven. The

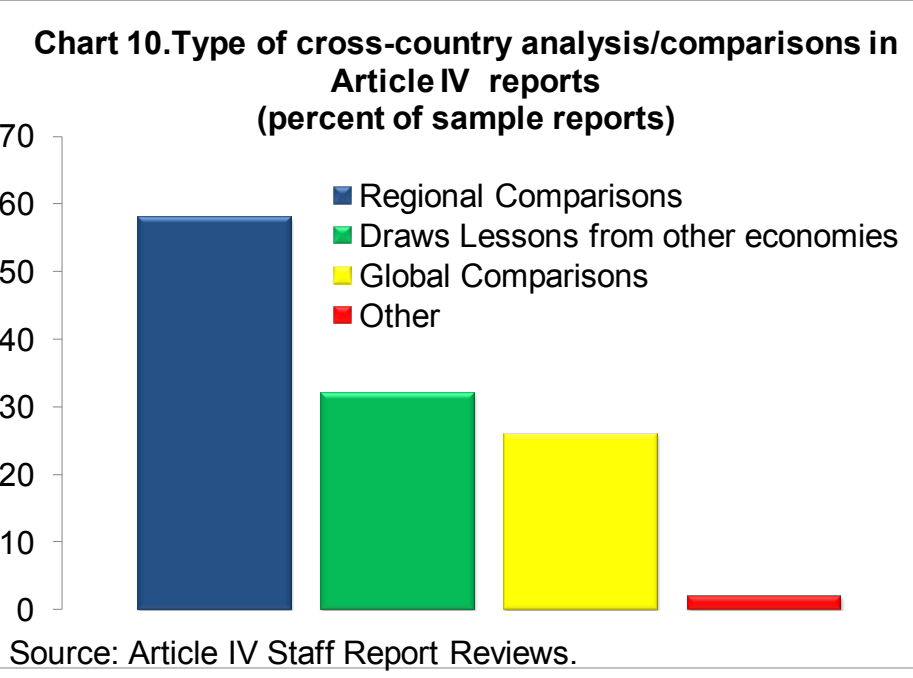

review of 50 Article IV reports found that only a third of sample reports drew lessons from other countries' experiences - although interviews suggest this is the type of analysis country authorities would like, while about 80 percent of the sample reports used some form of crosscountry comparisons or analyses (Chart 10). The majority of cross-country analyses were in the form of comparisons of indicators over a peer group, similar to the findings of the 2008 TSR (Statistical Appendix I, Table 5). Interviews indicated that authorities would like greater emphasis on presenting and discussing international comparisons and experiences relevant to their countries.

25. Challenges to enhanced analyses. About a third of respondents to the mission chief survey saw scope to focus greater attention on inward spillovers in the future Article IV consultations to a large or very large extent, while almost half of them responded in the same way as to cross-country analyses. However, they pointed to resource and data limitations as constraints to routinely conducting spillover and cross-country analyses (Chart 11). These two factors were also raised by mission chiefs as major constraints in the 2008 TSR.

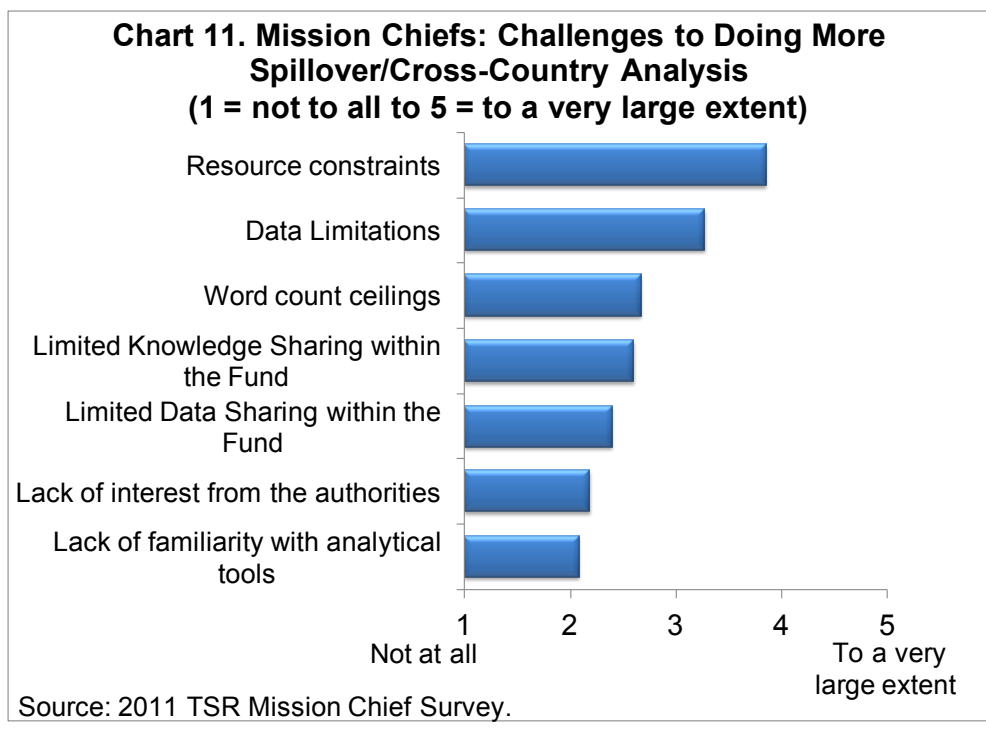




\section{Financial Sector Surveillance and Real-Financial Linkages}

26. The 2008 TSR reported that increased attention and resources allocated to financial sector issues in the Article IV consultations had paid off, but emphasized the need for further strengthening. It called for (i) greater integration of financial risks to real sector and vice versa; and (ii) more specificity of policy advice. This subsection provides an overview of findings. TSR Staff Background Studies, Chapter II Financial Sector Analysis in Bilateral Surveillance provides a detailed discussion on this issue.

27. Progress since $\mathbf{2 0 0 8}$ and room for improvement. The greatest progress since the 2008 TSR across policy issues is perceived in the area of financial sector analysis and advice (see Chart 6), although opinion varies across country groups. Advanced country authorities rated progress in this area less favorably than emerging market countries and LICs, while G20 authorities rated it less favorably than non-G-20 authorities. Across regions, Asian countries are the least convinced of progress in this area. Article IV staff report reviews found that, although about 70 percent of the sample reports provided rationale for the prioritization and composition of the proposed financial sector reforms, no prioritization was provided or reform proposals were too general to be useful in about a quarter of the sample. Furthermore, although the coverage of macro-financial issues has improved since the 2008 TSR, it remains uneven: less than half of the sample reports discussed the possible transmission of risks from financial to macro and just half of them discussed the transmission from macro to financial channels (see Chart 8). ${ }^{11,12}$ The mission chief survey indicated that data limitations and cross-departmental coordination were key constraints to making progress on financial sector analysis and recommendations (Chart 12).

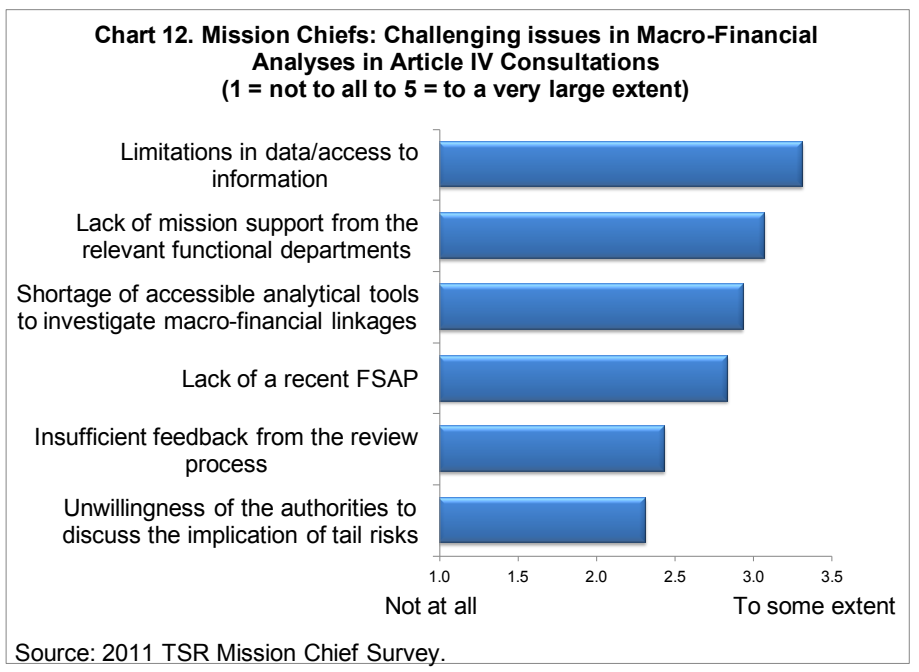

\footnotetext{
${ }^{11}$ In the Article IV staff report reviews in the 2008 TSR, staff found that only 30 percent of the sample reports clearly identified the macro-financial risk transmission channels.

${ }^{12}$ Even among the sample staff reports for advanced economies, where financial market developments could have significant economic impacts, a third did not cover financial to macro risk transmission channels.
} 


\section{Analysis of Exchange Rate and External Stability Risks}

28. The 2008 TSR reported that significant efforts had gone into improving the quality of exchange rate analysis, but called for further improvement. Specifically, it pointed to the need for (i) better integration of ER assessment and macro analysis; and (ii) greater transparency in the ER assessment. This subsection also only provides an overview of findings, while TSR Staff Background Studies, Chapter I Exchange Rate Assessments provides detailed discussion on this issue.

29. Progress in technical quality. The review of Article IV reports suggests that training and the use of CGER methods have improved the consistency of the Fund's exchange rate analysis. Compared with 2008, staff found more comprehensive use of CGER-based methods and more robust exchange rate analysis (Chart 13). However, 60 percent of the respondents to the mission chief survey reported that applicability of the standard CGER-based methods to a country posed a challenge in writing a staff report.

\section{Chart 13. Staff's Assessment of Article IV Reports: Progress on exchange rate assessment}

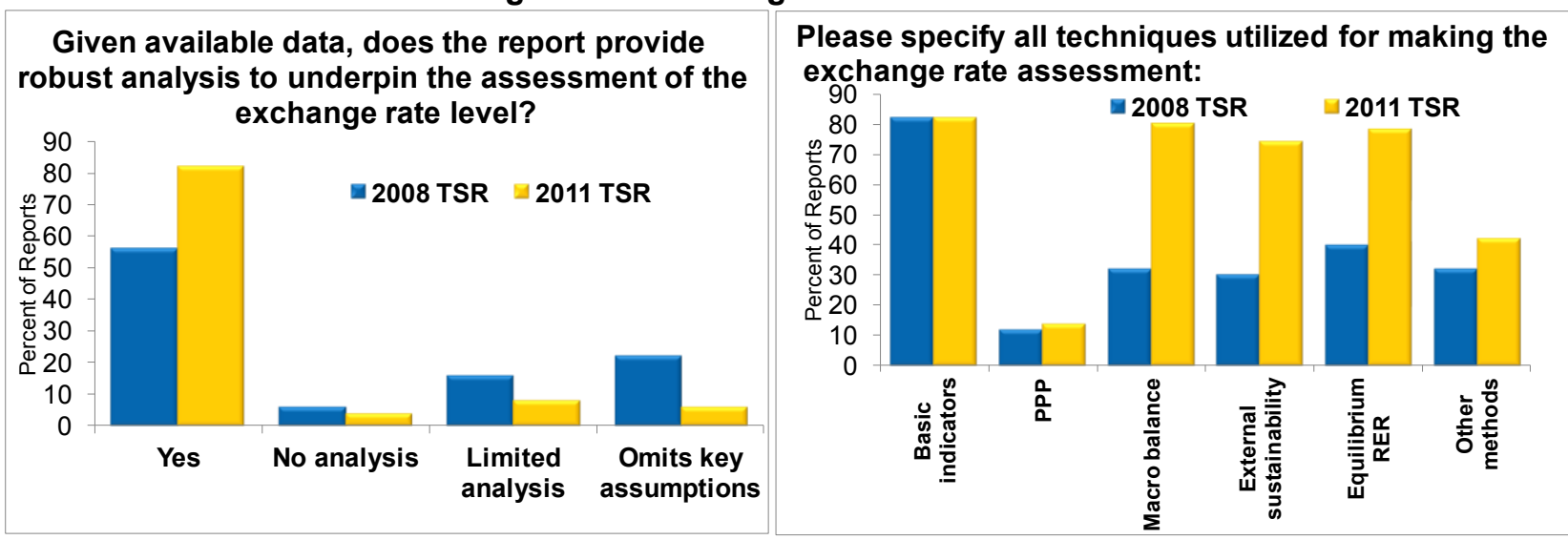

30. Perception on exchange rate analysis. According to country authorities, there has been limited improvement in exchange rate analysis since 2008 (see Chart 6). ${ }^{13} 40$ percent of Executive Director survey respondents representing advanced countries indicated that the government agencies with which they liaise did not rely on the Article IV staff report at all on this issue. This pattern is echoed by financial market participants - almost 60 percent of respondents saw no contribution to this issue in the Article IV reports for advanced countries. Moreover, the Executive Directors' perception of the quality of various aspects of exchange rate issues in the staff reports appears to have become less favorable compared with the 2008

\footnotetext{
${ }^{13}$ Although it is not surprising to see that European members, a large share of which are in the euro area, gave particularly unfavorable score on the value added and progress over the past few years of the Fund's surveillance for exchange rate policy, members in other regions also rated this issue less favorably compared with other policy areas.
} 
TSR. Less than 40 percent of them noted that various aspects of exchange rate assessments met their expectations in many/most/all reports in 2011, while more than 50 percent of them noted this to be the case in 2008 .

31. Perception versus technical progress. While the technical quality of exchange rate assessment has improved, stakeholders' perceptions on the quality of exchange rate policy advice are somewhat unfavorable. As pointed out in TSR Staff Background Studies, Chapter I Exchange Rate Assessments, a number of factors may explain less favorable perceptions: Article IV reports sometimes do not discuss details of exchange rate assessments, leading to questions regarding their integrity, while no multilateral publication allows for a comprehensive vision. The analysis of risks to external stability in many Article IV staff reports still focuses primary on exchange rate levels but insufficiently on risks arising from the capital and financial account. A number of those interviewed expressed dissatisfaction with the implementation of the 2007 Decision so far, noting it put too much focus on exchange rates at the expense of the broader range of issues relevant to external stability. Others indicated that they would like to see more work on global imbalances. Country authorities interviewed by external experts also argued that in some cases Fund advice on exchange rate policies was too generic, and was not sufficiently focused on policy implementation (TSR Staff Background Studies, Chapter I Exchange Rate Assessments).

\section{Other issues}

32. Capital flows. Although the Fund staff has recently increased its efforts and expanded its analytical framework, work is still in progress - and little progress in this area is perceived so far. More than half of the country authority survey respondents either did not see progress at all or only to a little extent in the analysis related to the management of capital flows compared with the pre-crisis period. Furthermore, more than 40 percent of respondents to the Executive Director survey reported that the coverage of capital flows in the Article IV reports was insufficient.

33. Reserve adequacy. Article IV staff report reviews found that discussions on reserve adequacy levels were either limited or unclear in about 60 percent of sample reports for countries which have their own national currency. Almost 40 percent of respondents to the Executive Director survey reported that the coverage of this issue in the Article IV reports was insufficient.

\section{Candor, "Silo" Mentality, ANd Evenhandedness}

34. Scope. This section examines several issues identified in the recent recommendations in the recent IEO report on the IMF performance in the run up to the crisis: (i) candor/encouraging a diversity of views; (ii) a "silo" mentality; and (iii) evenhandedness.

\section{Candor/Encouraging a diversity of views}

35. There are mixed perceptions about the degree of candor in surveillance reports. Similar to the 2008 TSR, almost all respondents to the country authority survey reported that 
the degree of candor in their Article IV reports was adequate. Almost half of the financial market survey respondents regarded candor as the strength of the Article IV reports.

However, media professionals rated candor less favorably as compared to other attributes of surveillance, such as timeliness, evenhandedness, clarity, and credibility.

\section{Mission chiefs'}

perception. About 60 percent of respondents to the mission chief survey reported that the authorities were largely/completely candid in their dialogue with the mission. More than 80 percent of them reported that the extent to which pressures from the authorities constrained the work of the mission was 'not at all' or 'to a little extent.' However, almost 20 percent of them reported pressures to 'some/large/very large' extent (Chart 14).

\section{Challenging the}

authorities' view. The 2011 IEO Report pointed out that IMF staff felt uncomfortable challenging the views of authorities in advanced economies on monetary and regulatory issues, given the authorities' greater access to banking data and knowledge of their financial markets, and the large numbers of highly qualified economists working in their central banks. However, a clear majority (about 80 percent) of respondents to the mission chief survey reported that they felt no, or little, difficulties in challenging the authorities because of their better knowledge, while the rest viewed this as a problem 'to some/large' extent (Chart 15). Article IV staff report reviews found that 70 percent of the sample reports clearly identified and explained dissenting views by the authorities (Statistical Appendix I, Table 7). Differences in the survey samples between the 2011 TSR and the IEO Report may have led to these different results, as the 2011 TSR focused solely on mission chiefs whereas the IEO report is based on interviews with economists as well as mission 
chiefs. This could indicate that there are different perceptions on this issue between mission chiefs and economists.

38. Expressing diversity of views among staff. The 2011 IEO

Report, based on interviews with economists as well as mission chiefs, had pointed out self censorship and difficulty to express a dissenting view as hampering the effectiveness of surveillance. Almost a quarter of the mission chief survey respondents saw self-censorship as a

factor inside the Fund that makes surveillance difficult at least some extent (Chart 16). As to pressure not to express different views (group-think), almost 40 percent of them thought it a constraining factor at least some extent. This ratio was higher among mission chiefs for G-20 and program countries than others.

\section{'Silo' mentality}

39. Mission chiefs' perception. More than 50 percent of respondents to the mission chief survey reported that difficulties working across departments and lack of knowledge sharing make surveillance work difficult at least to some extent. They perceived these factors to be one of the most serious internal factors constraining surveillance, next to only data limitations (see Chart 16). ${ }^{14}$ This finding is in line with that in the 2011 IEO Report. Country authority interviews indicated that there remained a perception that efforts to integrate multilateral and bilateral surveillance were stymied by the still existing "silo" mentality.

\footnotetext{
${ }^{14}$ As to future efforts in filling in data gaps, mission chiefs indicated different priorities. Sector balance sheet, cross-border exposure, and real estate price were ranked as the highest priority among mission chiefs for advanced and emerging market countries, while national account data was reported as the highest priority for LIC mission chiefs.
} 


\section{Evenhandedness}

\section{There are differences of} view on evenhandedness. In the country authority survey, only 38 percent of respondents agreed or strongly agreed with the sentence "the IMF is evenhanded in its policy advice," while almost 30 percent of respondents from advanced and emerging market countries and almost 60 percent from G-20 countries disagreed (Chart 17). ${ }^{15}$ Many written comments by country authorities indicated concern on evenhandedness, mostly of the "too soft on large systemic countries" variety. Country authorities echoed this perception in interviews. In the 2008 TSR, a similar concern was voiced by some Executive Directors in their written comments.

Perception among outside audiences on evenhandedness is more positive. 85 percent of respondents to the media survey rated evenhandedness of Article IV reports as very good or satisfactory (Chart 18).
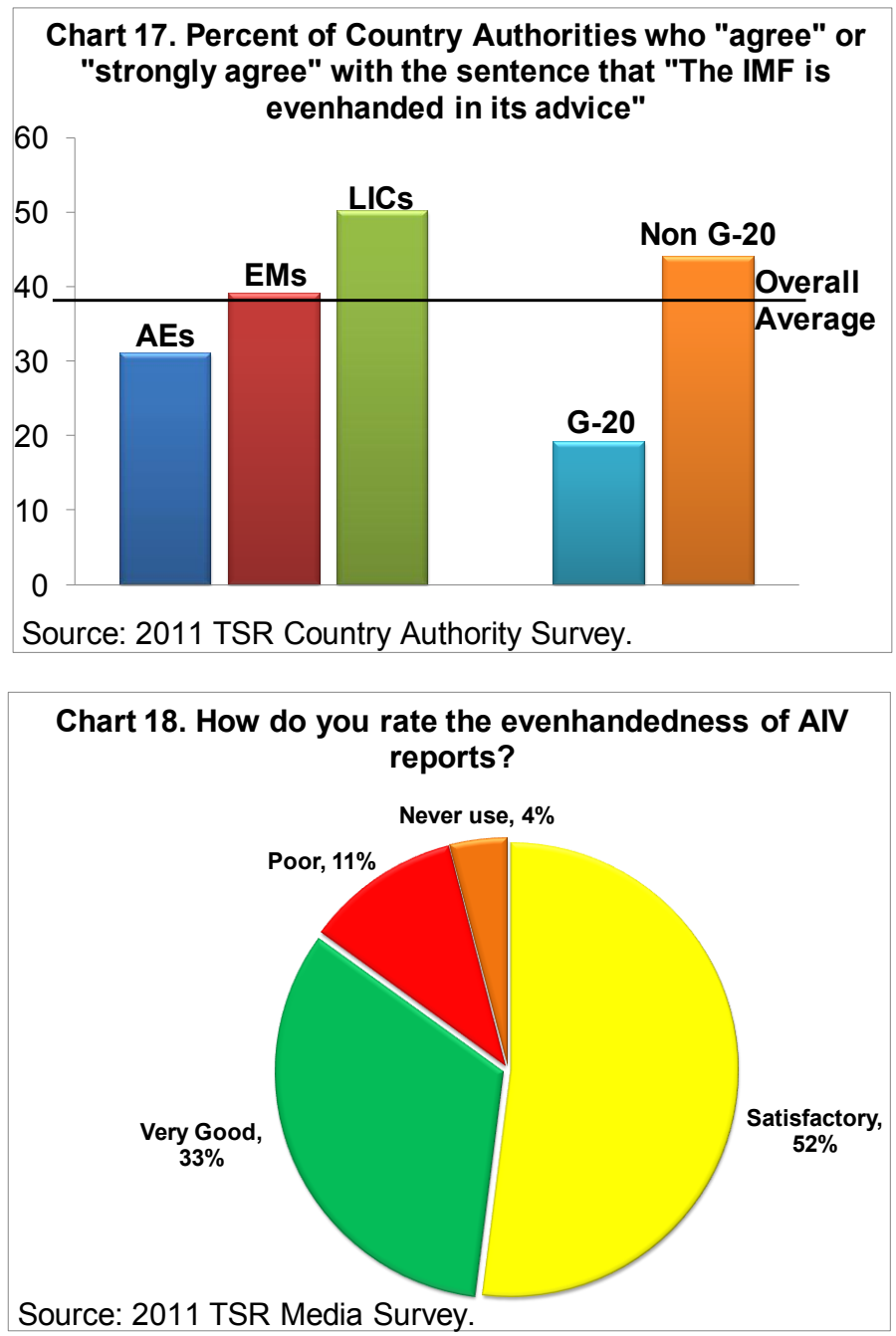

\section{Communication}

41. Communication. Around 70 percent of respondents to the media survey saw that the Fund's communication was much or somewhat better than that of other comparable international institutions or government agencies. 40 percent of respondents to the CSO Survey shared this view. The review of 50 Article IV staff reports found that reports were generally written in an accessible manner for readability by a wide audience (typically high school level) (Chart 19). ${ }^{16}$ However, Executive Directors and the country authorities saw

\footnotetext{
${ }^{15}$ This ratio was much lower among respondents from LICs (4 percent) and non-G-20 countries (12 percent).

${ }^{16}$ The Gunning Fog Index measures the readability of English writing. The index ranges from 6 to 20. It estimates the years of formal education needed to understand the text on a first reading. Texts for a wide audience generally require an index less than 12 .
} 
room for improvement in terms of the consistency of messages across various products. In their written comments, some Executive Directors pointed out the need to reduce overlaps and improve consistency and coherence of messages among various products. Some mission chiefs' written comments echoed this theme. By contrast, almost 90 percent of respondents to the financial market survey thought that the Fund's messages from various products were clear and coherent to a large or very large extent. TSR External Study-IMF Surveillance: Coverage, Consistency, and Coherence found that, although the review process seemed to be working effectively to prevent serious consistency problems among various products, there would be room for a consolidated overarching product with top-line messages across policy areas.

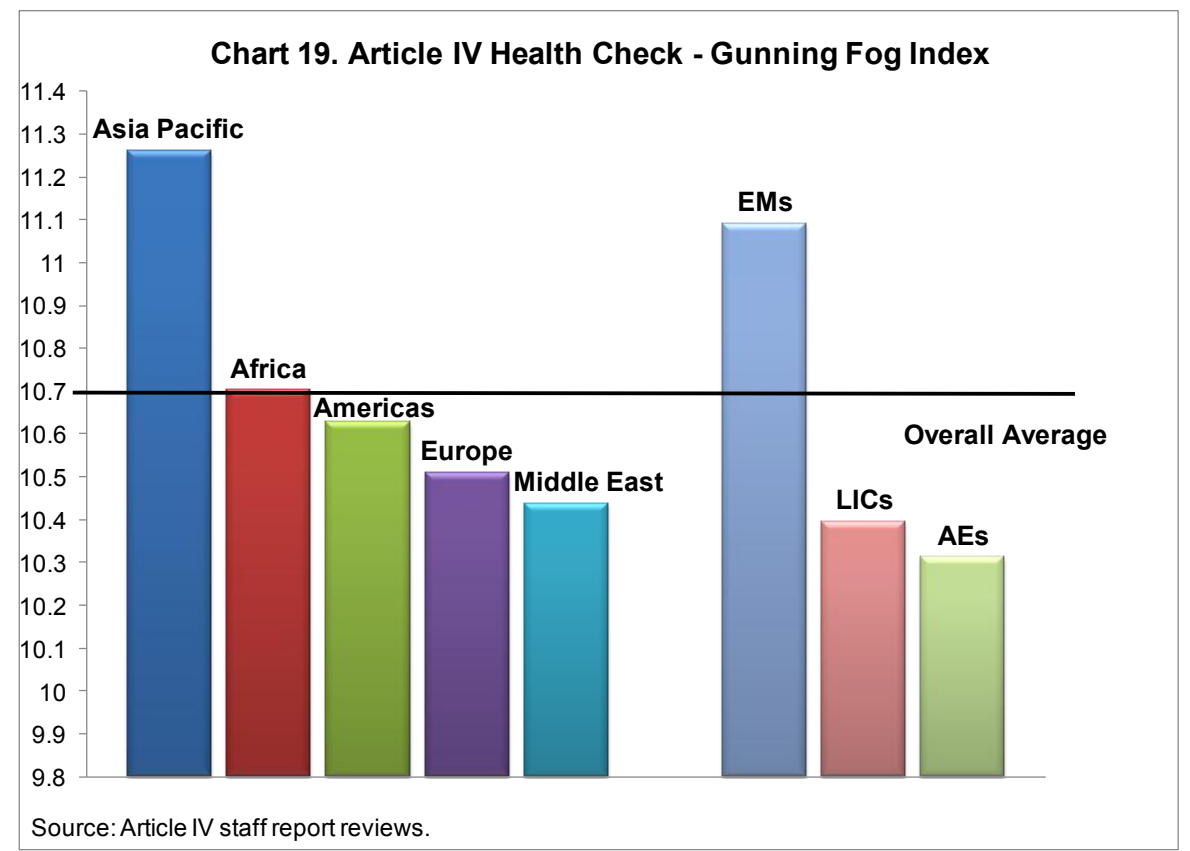




\section{Statistical Appendix I: Article IV Staff Report Reviews}

\section{Methodology}

42. A representative sample of Article IV reports was internally reviewed in order to collect standardized qualitative information across the main diagnostic questions.

The review was conducted by SPR economists. A sample of 50 reports/countries was reviewed, rather than the universe, to allow for more qualitative and in-depth review of staff reports. Detailed questionnaires corresponding to the main diagnostic questions were developed by the team to collect standardized qualitative information on the reports.

43. Several precautions were taken to maximize consistency across reviewers. As in the Article IV staff report reviews conducted for the 2008 Triennial Surveillance Review, pairs of economists from the review team reviewed each country and then met to compare their responses and exchange information about problems encountered and the solutions adopted. Any conflicting views between the two reviewers on a country's assessment were brought to the attention of a third reviewer to develop common understandings across the reviewers on how to interpret the questions. This helped implement the questionnaire uniformly for staff reports reflecting a range of country and operational circumstances, and helped ensure consistency of assessment across reviewers. Furthermore, when the internal review was completed, the team member responsible for Health Check Chapter checked the results across the 50-country sample for accuracy and consistency. Countries were divided up among reviewers in a way that ensured that each reviewer reviewed a group of countries that was diverse in terms of area departments, income level, and Fund program status.

44. One difference in methodology in the Article IV Staff Report Reviews in 2011 compared to the 2008 TSR was the use of the Gunning Fog index ${ }^{17}$ to automatically measure the readability of writing in staff reports in the 2011 TSR by a computer software. In 2008, Research Assistants in the Strategy, Policy and Review Department reviewed the staff reports to assess the readability of reports and the clarity of key conclusions and provide the perspective of "an average college-educated reader."

45. The following selection process resulted in the 50-country sample of staff reports listed in Table A:

\footnotetext{
17 The Gunning Fog index estimates the years of formal education needed to understand the text on a first reading. The index has a scale of 6 to 12 to estimate the years of formal education needed to understand the text on a first reading. Texts for a wide audience generally need a fog index less than 12 . Texts requiring nearuniversal understanding generally need an index less than 8. A fog index of 12 requires the reading level of a U.S. high school senior (around 18 years old).
} 
- $\quad$ The sample universe includes 148 Article IV consultation staff reports discussed by the Board between January 1, 2010 and April 30, 2011. In case a country has had two Article IV consultations completed during this period, only the latest one is included in the sample universe.

- $\quad$ The membership was stratified by income group (advanced, emerging, and developing/low-income) and by region ( 5 regions according to area department), and percentages of the membership within each strata calculated. The sample universe was similarly stratified, and a target number of countries was specified (based on a total of 50 staff reports) to match the percentage of the membership within each strata. In each strata, a random number ranging from 0 to 1 was assigned to each country, and then countries with the highest score within each strata were drawn to match the target number as closely possible, within the constraints of the available universe (Table B).

- Definition of income group classification is as follows: (i) Advanced: advanced economies according to the WEO classification in October 2010; (ii) Emerging markets: countries that fall into neither of advanced nor developing/low-income; and (iii) Developing/low-income: all PRGT-eligible countries. They are listed in the Appendix I of the Board paper Emerging from the Global Crisis: Macroeconomic Challenges Facing Low-Income Countries.

46. The sample includes 12 program countries (see Table A).

\section{Results}

Results are summarized Tables 1 through 7 of this Statistical Appendix I. 
Table A. List of 50 Countries for the Review of Staff Reports

\begin{tabular}{|c|c|c|c|c|c|c|c|c|}
\hline \multicolumn{3}{|c|}{ AFR } & \multicolumn{3}{|c|}{ APD } & \multicolumn{3}{|c|}{ EUR } \\
\hline \multirow[t]{10}{*}{$\mathrm{ADV}$} & EMG & DEV/LIC & $\mathrm{ADV}$ & EMG & DEV/LIC & $\mathrm{ADV}$ & EMG & DEV/LIC \\
\hline & Botswana & Burundi(*) & Singapore & China & Bangladesh & Austria & Croatia & \\
\hline & Seychelles(*) & Cameroon & & Indonesia & Cambodia & Cyprus & Lithuania & \\
\hline & South Africa & Chad & & Malaysia & Maldives $\left({ }^{*}\right)$ & Finland & Russia & \\
\hline & & Ethiopia(*) & & Micronesia & Timor Leste & Germany & San Marino & \\
\hline & & Lesotho & & & & Italy & Turkey & \\
\hline & & Malawi $\left({ }^{*}\right)$ & & & & Israel & & \\
\hline & & Nigeria & & & & Switzerland & & \\
\hline & & Sierra Leone $\left(^{*}\right)$ & & & & & & \\
\hline & & Senegal( $\left.{ }^{*}\right)$ & & & & & & \\
\hline
\end{tabular}

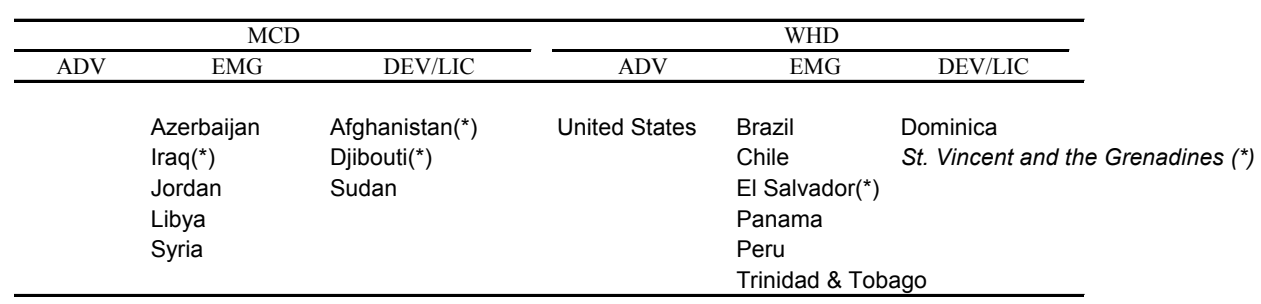

Notes

1. (*) denotes program countries.

2. Italic denotes members of currency unions or exchange arrangements with no separate legal tender.

Table B. Sample and membership strata by region and income level

\begin{tabular}{|c|c|c|c|c|c|c|c|c|c|c|c|c|c|c|c|c|}
\hline & \multicolumn{3}{|c|}{ AFR } & \multicolumn{3}{|c|}{ APD } & \multicolumn{3}{|c|}{ EUR } & \multicolumn{3}{|c|}{ MCD } & \multicolumn{3}{|c|}{ WHD } & \multirow[t]{3}{*}{ Total } \\
\hline & \multirow[b]{2}{*}{ ADV } & \multicolumn{2}{|r|}{$\overline{\mathrm{DEV} /}$} & \multirow[b]{2}{*}{$\mathrm{ADV}$} & \multicolumn{2}{|c|}{$\mathrm{DEV} /$} & \multicolumn{3}{|r|}{$\overline{\mathrm{DEV} /}$} & \multicolumn{3}{|r|}{$\overline{\mathrm{DEV} /}$} & \multicolumn{3}{|r|}{$\overline{\mathrm{DEV} /}$} & \\
\hline & & EMG & LIC & & EMG & LIC & ADV & EMG & LIC & ADV & EMG & LIC & ADV & EMG & LIC & \\
\hline \multicolumn{17}{|l|}{ In percent } \\
\hline Membership (benchmark) & 0 & 5 & 18 & 3 & 7 & 9 & 13 & 10 & 1 & 0 & 11 & 6 & 1 & 12 & 5 & 100 \\
\hline Sample of 50 & 0 & 6 & 18 & 2 & 8 & 8 & 14 & 10 & 0 & 0 & 10 & 6 & 2 & 12 & 4 & 100 \\
\hline \multicolumn{17}{|l|}{ In numbers } \\
\hline Membership (benchmark) & 0 & 10 & 34 & 5 & 13 & 16 & 24 & 19 & 1 & 0 & 20 & 11 & 2 & 23 & 9 & 187 \\
\hline Sample of 50 & 0 & 3 & 9 & 1 & 4 & 4 & 7 & 5 & 0 & 0 & 5 & 3 & 1 & 6 & 2 & 50 \\
\hline
\end{tabular}




\section{Appendix I, Table 1. Summary of Article IV Staff Report Review - Basic Macro Issues}

\begin{tabular}{|c|c|c|c|c|c|c|c|c|c|c|c|c|}
\hline \multirow{3}{*}{ Question } & \multirow{2}{*}{ Answers } & \multirow{2}{*}{ Aggregate } & \multirow{3}{*}{ AFR } & \multirow{3}{*}{$\mathrm{APD}$} & \multirow{2}{*}{$\begin{array}{ll}\text { Region } \\
\text { EUR } \\
\end{array}$} & \multirow{2}{*}{$\mathrm{MCD}$} & \multirow{2}{*}{ WHD } & \multicolumn{3}{|c|}{ Income Level } & \multirow{2}{*}{\multicolumn{2}{|c|}{ Program? }} \\
\hline & & & & & & & & ADV & EMG & LIC & & \\
\hline & & & & & (In perce & entage $\mathrm{c}$ & of applic & able sar & mple) & & & \\
\hline \multirow{3}{*}{$\begin{array}{l}\text { 1. Is the baseline scenario clearly identified and is there } \\
\text { a discussion of the key medium-term challenges? }\end{array}$} & $\begin{array}{l}\text { Yes, non-program country and the discussion extends to the medium- } \\
\text { term. }\end{array}$ & 76 & 50 & 89 & 100 & 63 & 78 & 100 & 87 & 50 & 0 & 100 \\
\hline & $\begin{array}{l}\text { Yes, program country and the discussion extends beyond the program } \\
\text { period to the medium-term. }\end{array}$ & 24 & 50 & 11 & 0 & 38 & 22 & 0 & 13 & 50 & 100 & 0 \\
\hline & No & 0 & 0 & 0 & 0 & 0 & 0 & 0 & 0 & 0 & 0 & \\
\hline \multirow[t]{2}{*}{$\begin{array}{l}\text { 2. Is the description of the baseline (and alternative } \\
\text { scenario where applicable) consistent with the numerical } \\
\text { presentation in the Staff Report? }\end{array}$} & $\begin{array}{l}\text { Yes } \\
\text { No because the presentation is not a fair representation of the numerical } \\
\text { presentation (e.g. the discussion plays down the vulnerabilities } \\
\text { demonstrated by the numbers excessively or the discussion is } \\
\text { excessively hedged-i.e. no clear bottom line a lot of use of on the one } \\
\text { hand/on the other hand). }\end{array}$ & 98 & 100 & 100 & 100 & 100 & 89 & 0 & 100 & 100 & 100 & 97 \\
\hline & No because there is too little discussion of the baseline. & 2 & 0 & 0 & 0 & 0 & 11 & 11 & 0 & 0 & 0 & \\
\hline \multirow{4}{*}{$\begin{array}{l}\text { 3. Are the recommended medium-term and short-term } \\
\text { fiscal policy objectives clearly artiuluated and sufficiently } \\
\text { detailed? Are the envisaged short-term fiscal measures put } \\
\text { in a clear medium-term fiscal road map? }\end{array}$} & Yes & 88 & 83 & 89 & 92 & 75 & 100 & 100 & 83 & 89 & 83 & 89 \\
\hline & $\begin{array}{l}\text { No because the discussion of medium-term fiscal obje } \\
\text { inadequate. }\end{array}$ & 10 & 17 & 11 & 8 & 13 & 0 & 0 & 13 & 11 & 17 & 8 \\
\hline & No because the discussion of short-term fiscal objectives is inadequate. & 2 & 0 & 0 & 0 & 13 & 0 & 0 & 4 & 0 & 0 & 3 \\
\hline & $\begin{array}{l}\text { No because the envisaged short-term fiscal measures are not put in } \\
\text { clear medium-term fiscal road map. }\end{array}$ & 0 & 0 & 0 & 0 & 0 & 0 & 0 & 0 & 0 & 0 & 0 \\
\hline \multirow{4}{*}{$\begin{array}{l}\text { 4. If fiscal adjustment (tightening or loosening) is } \\
\text { recommended over the next two years, does the report } \\
\text { provide sufficient rationale for the magnitude, pace and } \\
\text { composition of proposed fiscal change? (Check all that } \\
\text { apply) }\end{array}$} & $\begin{array}{l}\text { N/A: no fiscal adjustment is recommended (the recommendation is to } \\
\text { leave the fiscal stance unchanged). }\end{array}$ & 0 & 0 & 0 & 0 & 0 & 0 & 0 & 0 & 0 & 0 & 0 \\
\hline & The recommended magnitute of fiscal change is well justified. & 86 & 92 & 67 & 83 & 88 & 100 & 89 & 78 & 94 & 92 & 84 \\
\hline & The recommended pace of fiscal change is well justified. & 82 & 75 & 78 & 75 & 88 & 100 & 89 & 78 & 83 & 83 & 82 \\
\hline & The recommended composition of fiscal change is $\mathrm{w}$ & 88 & 83 & 89 & 75 & 100 & 100 & 89 & 91 & 83 & 92 & 87 \\
\hline \multirow{2}{*}{ 5. Does this country have its own national currency? } & Yes & 70 & 75 & 78 & 50 & 100 & 56 & 44 & 83 & 67 & 75 & 68 \\
\hline & ig four questions. & 30 & 25 & 22 & 50 & 0 & 44 & 56 & 17 & 33 & 25 & \\
\hline \multirow{4}{*}{$\begin{array}{l}\text { 6. Does the report provide an adequate and clear } \\
\text { assessment of the monetary policy stance? }\end{array}$} & N/A: $n$ & 30 & 25 & 22 & 50 & & 44 & 56 & 17 & 33 & 25 & 32 \\
\hline & the monetary policys & 70 & 75 & 78 & 50 & 100 & 56 & 44 & 83 & 67 & 75 & 68 \\
\hline & insufficient/unclea & 0 & 0 & 0 & 0 & 0 & 0 & 0 & 0 & 0 & 0 & 0 \\
\hline & $\begin{array}{l}\text { No because the staff's assessment of the monetary policy stance is } \\
\text { missing. }\end{array}$ & 0 & 0 & 0 & 0 & 0 & 0 & 0 & 0 & 0 & 0 & 0 \\
\hline \multirow{5}{*}{$\begin{array}{l}\text { 7. If monetary policy adjustment (tightening or } \\
\text { loosening) is recommended, does the staff provide a } \\
\text { justification for the proposed changes in the monetary } \\
\text { policy stance, and possible risks? }\end{array}$} & N/A: no national currency & 30 & 25 & 22 & 50 & 0 & 44 & 56 & 17 & 33 & 25 & 32 \\
\hline & $\begin{array}{l}\text { N/A: no monetary policy adjustment is recommended (the } \\
\text { recommendation is to leave monetary policy stance unchanged). }\end{array}$ & 36 & 42 & 33 & 17 & 88 & 11 & 33 & 39 & 33 & 42 & 34 \\
\hline & Yes & 34 & 33 & 44 & 33 & 13 & 44 & 11 & 43 & 33 & 33 & 34 \\
\hline & $\begin{array}{l}\text { No because there is no justification for the recommended monetary policy } \\
\text { adjustment. }\end{array}$ & 0 & 0 & 0 & 0 & 0 & 0 & 0 & 0 & 0 & 0 & 0 \\
\hline & $\begin{array}{l}\text { No because there is no discussion of risks of recommended policy } \\
\text { adjustment (e.g., possible balance-sheet effects, impact on the financial } \\
\text { sector). }\end{array}$ & 0 & 0 & 0 & 0 & 0 & 0 & 0 & 0 & 0 & 0 & 0 \\
\hline \multirow{6}{*}{$\begin{array}{l}\text { 8. Does the report appropriately discuss reserve } \\
\text { adequacy/level? }\end{array}$} & & 2 & 0 & 0 & 0 & 0 & 11 & 11 & 0 & 0 & 0 & \\
\hline & 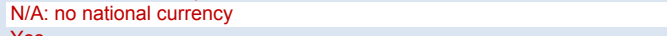 & 30 & 25 & 22 & 50 & 0 & 44 & 56 & 17 & 33 & 25 & 32 \\
\hline & Yes & 26 & 50 & 22 & 17 & 25 & 11 & 22 & 26 & 28 & 25 & 26 \\
\hline & No limi & 38 & 25 & 44 & 25 & 75 & 33 & 11 & 48 & 39 & 50 & 34 \\
\hline & & & & 11 & & 0 & & & & & & \\
\hline & No & 2 & 0 & 0 & 8 & 0 & 0 & 0 & 4 & & 0 & 3 \\
\hline \multirow{7}{*}{$\begin{array}{l}\text { 9. What metrics were used to assess reserve adequacy } \\
\text { (check all that apply)? }\end{array}$} & & 60 & 83 & 56 & 33 & 100 & 33 & 33 & 61 & 72 & 67 & 58 \\
\hline & & 20 & 8 & 11 & 33 & 13 & 33 & 11 & 39 & 0 & 0 & 26 \\
\hline & $\begin{array}{l}\text { Reserve to monetary aggregates (e.g., M2, M3, or other metrics using } \\
\text { financial sector variables) ratio. }\end{array}$ & 20 & 8 & 22 & 25 & 25 & 22 & 11 & 22 & 22 & 25 & 18 \\
\hline & alysis. & 6 & 0 & 11 & 8 & 13 & 0 & 11 & 4 & & 8 & 5 \\
\hline & Cor & 10 & 17 & 11 & 0 & 13 & 11 & 0 & 17 & & & 13 \\
\hline & $M$ & 4 & 0 & 0 & 0 & 13 & 11 & 0 & 9 & 0 & 0 & 5 \\
\hline & None & 4 & 8 & 11 & 0 & 0 & 0 & 0 & 9 & 0 & 8 & 3 \\
\hline
\end{tabular}


Appendix I, Table 1. Summary of Article IV Staff Report Review - Basic Macro Issues

\begin{tabular}{|c|c|c|c|c|c|c|c|c|c|c|c|c|}
\hline \multirow{3}{*}{$\begin{array}{r}\text { Question } \\
\end{array}$} & \multirow[b]{2}{*}{ Answers } & \multirow[t]{2}{*}{ Aggregate } & \multicolumn{5}{|c|}{ Region } & \multicolumn{3}{|c|}{ Income Level } & \multicolumn{2}{|c|}{ Program? } \\
\hline & & & AFR & APD & EUR & MCD & WHD & ADV & EMG & LIC & Yes & No \\
\hline & & \multicolumn{11}{|c|}{ (In percentage of applicable sample) } \\
\hline $\begin{array}{l}\text { 10. Where staff are recommending fiscal and/or } \\
\end{array}$ & Availability of sufficient fiscal financing/ market tensions. & 38 & 33 & 44 & 42 & 38 & 33 & 44 & 30 & 44 & 42 & 37 \\
\hline monetary policy adjustment (tightening or loosening) over & Sustainability of debt. & 68 & 83 & 56 & 75 & 63 & 56 & 67 & 57 & 83 & 83 & 63 \\
\hline the next two years, which factors are discussed to assess & Inflation outlook. & 44 & 50 & 44 & 42 & 38 & 44 & 56 & 48 & 33 & 17 & 53 \\
\hline whether this policy is appropriate? (Check all that apply) & Other considerations (please specify). & 24 & 25 & 44 & 8 & 0 & 44 & 11 & 35 & 17 & 17 & 26 \\
\hline \multirow{3}{*}{$\begin{array}{l}\text { 11. Where fiscal and/or monetary policy loosening is } \\
\text { described in the Staff report as having been implemented in } \\
2009 \text { or } 2010 \text { (including the impact of automatic stabilizers), } \\
\text { does the Article IV report adequately elaborate on a fiscal } \\
\text { and/or monetary policy exit strategy, including timing? }\end{array}$} & N/A. The country did not loosen fiscal or monetary policy in 2009 or 2010. & 16 & 25 & 11 & 25 & 13 & 0 & 0 & 17 & 22 & 33 & 11 \\
\hline & Yes & 70 & 58 & 56 & 75 & 75 & 89 & 100 & 65 & 61 & 58 & 74 \\
\hline & No & 14 & 17 & 33 & 0 & 13 & 11 & 0 & 17 & 17 & 8 & 16 \\
\hline \multirow{3}{*}{$\begin{array}{l}\text { 12. If fiscal or monetary exit strategies are elaborated in } \\
\text { the Article IV report (including from extraordinary financial } \\
\text { sector support measures), does the report discuss potential } \\
\text { implications of these on: (Check all that apply) }\end{array}$} & Financial stability. & 34 & 8 & 44 & 50 & 38 & 33 & 44 & 43 & 17 & 8 & 42 \\
\hline & Growth. & 38 & 33 & 44 & 33 & 13 & 67 & 44 & 43 & 28 & 25 & 42 \\
\hline & Employment. & 10 & 8 & 0 & 25 & 0 & 11 & 44 & 4 & 0 & 0 & 13 \\
\hline
\end{tabular}


Appendix I, Table 2. Summary of Article IV Staff Report Review - Financial Sector Issues

\begin{tabular}{|c|c|c|c|c|c|c|c|c|c|c|c|c|}
\hline \multirow{2}{*}{ Question } & \multirow[b]{2}{*}{ Answers } & \multirow[t]{2}{*}{ Aggregate } & \multicolumn{5}{|c|}{ Region } & \multicolumn{3}{|c|}{ Income Level } & \multicolumn{2}{|c|}{ Program? } \\
\hline & & & AFR & APD & EUR & MCD & WHD & ADV & EMG & LIC & Yes & No \\
\hline & & \multicolumn{11}{|c|}{ (In percentage of applicable sample) } \\
\hline \multirow{3}{*}{$\begin{array}{l}\text { 13. In discussing financial stability issues which } \\
\text { sectors did the report cover? (Check all that apply) }\end{array}$} & Banks & 98 & 92 & 100 & 100 & 100 & 100 & 100 & 100 & 94 & 92 & 100 \\
\hline & Non banks & 50 & 25 & 56 & 58 & 38 & 78 & 89 & 52 & 28 & 17 & 61 \\
\hline & Markets & 42 & 8 & 56 & 67 & 50 & 33 & 78 & 52 & 11 & 0 & 55 \\
\hline \multirow{3}{*}{$\begin{array}{l}14 . \quad \text { Is there an adequate coverage of all core FS } \\
\text { issues? (Indicate Yes, No, Not appropriate for each } \\
\text { category) }\end{array}$} & i. Identification of key risks/vulnerabilities & 94 & 92 & 89 & 100 & 88 & 100 & 100 & 96 & 89 & 92 & 95 \\
\hline & ii. Contagion risks and cross-border spillovers. & 44 & 17 & 44 & 67 & 25 & 67 & 78 & 52 & 17 & 25 & 50 \\
\hline & iii. Regulation and supervision framework. & 90 & 75 & 100 & 92 & 88 & 100 & 100 & 91 & 83 & 75 & 95 \\
\hline \multirow{10}{*}{$\begin{array}{l}\text { 15. What tools/information are used to assess FS } \\
\text { vulnerabilities? (Check all that apply) }\end{array}$} & Quantitative Analysis: Financial soundness indicators (FSIs). & 90 & 100 & 78 & 92 & 75 & 100 & 100 & 83 & 94 & 92 & 89 \\
\hline & $\begin{array}{l}\text { Quantitative Analysis: Other market indicators (e.g. equity prices, CDS } \\
\text { spreads). }\end{array}$ & 38 & 17 & 44 & 58 & 13 & 56 & 67 & 57 & 0 & 0 & 50 \\
\hline & $\begin{array}{l}\text { Quantitative analysis: Other types of quantitative analysis (e.g. BSA, } \\
\text { CCA, stress test, scenarios; transmission channels/feedback loops; } \\
\text { network analysis). }\end{array}$ & 44 & 42 & 22 & 67 & 13 & 67 & 67 & 57 & 17 & 33 & 47 \\
\hline & $\begin{array}{l}\text { Qualitative Analysis: Weaknesses in the FS structure or infrastructure } \\
\text { (e.g., legal framework, governance, payments)/FS supervisions and } \\
\text { regulation. }\end{array}$ & 90 & 75 & 100 & 92 & 88 & 100 & 89 & 96 & 83 & 75 & 95 \\
\hline & $\begin{array}{l}\text { Qualitative Analysis: Analysis of contagion risks and cross-border } \\
\text { spillover risks/vulnerabilities. }\end{array}$ & 38 & 8 & 44 & 67 & 13 & 56 & 78 & 43 & 11 & 8 & 47 \\
\hline & Qualitative Analysis: Other. & 6 & 8 & 0 & 0 & 0 & 22 & 11 & 9 & 0 & 8 & 5 \\
\hline & Information Sources: References to SIP and/or previous staff analysis & 28 & 8 & 22 & 42 & 13 & 56 & 33 & 43 & 6 & 8 & 34 \\
\hline & $\begin{array}{l}\text { Information Sources: Discussions with market participants and/or } \\
\text { credit rating agencies. }\end{array}$ & 10 & 0 & 11 & 8 & 13 & 22 & 22 & 13 & 0 & 0 & 13 \\
\hline & Information Sources: Reference to a previous FSAP/FSAP update & 40 & 42 & 33 & 50 & 38 & 33 & 44 & 39 & 39 & 42 & 39 \\
\hline & Information Sources: WEO/GFSR/EWE/VEA/VEE. & 10 & 8 & 0 & 25 & 0 & 11 & 33 & 4 & 6 & 8 & 11 \\
\hline \multirow{4}{*}{$\begin{array}{l}\text { 16. Does the report provide a clear assessment of } \\
\text { FS risks and vulnerabilities? }\end{array}$} & $\begin{array}{l}\text { Yes. If the discussion of FS risks and vulnerabilities is very good } \\
\text { please provide page references. }\end{array}$ & 76 & 83 & 78 & 100 & 38 & 67 & 89 & 83 & 61 & 58 & 82 \\
\hline & No because there is no assessment of FS vulnerabilities & 6 & 17 & 11 & 0 & 0 & 0 & 0 & 0 & 17 & 8 & 5 \\
\hline & $\begin{array}{l}\text { No because insufficient quantitative/qualitative analysis (none/few of } \\
\text { the tools listed in the previous question are used). }\end{array}$ & 14 & 0 & 11 & 0 & 63 & 11 & 0 & 13 & 22 & 33 & 8 \\
\hline & $\begin{array}{l}\text { No because the assessment is too hedged (there is no clear bottom } \\
\text { line) }\end{array}$ & 4 & 0 & 0 & 0 & 0 & 22 & 11 & 4 & 0 & 0 & 5 \\
\hline \multirow{6}{*}{$\begin{array}{l}\text { 17. Does the report provide clearly justified policy } \\
\text { recommendations in the following areas? (Check all } \\
\text { that apply) }\end{array}$} & Monitoring (e.g. stress testing). & 36 & 25 & 44 & 50 & 13 & 44 & 67 & 43 & 11 & 17 & 42 \\
\hline & Strengthening supervision/ supervisory framework. & 80 & 67 & 89 & 83 & 75 & 89 & 89 & 83 & 72 & 75 & 82 \\
\hline & $\begin{array}{l}\text { Crisis management (including capital injections and deposit insurance } \\
\text { guarantees)//exit from extraordinary measures }\end{array}$ & 42 & 8 & 56 & 58 & 0 & 89 & 78 & 43 & 22 & 25 & 47 \\
\hline & Supporting macroeconomic policy measures. & 40 & 25 & 22 & 50 & 38 & 67 & 44 & 52 & 22 & 42 & 39 \\
\hline & How to address concerns with regard to FS development. & 58 & 50 & 89 & 33 & 88 & 44 & 22 & 61 & 72 & 58 & 58 \\
\hline & No policy recommendations are made on FS issues. & 2 & 8 & 0 & 0 & 0 & 0 & 0 & 0 & 6 & 0 & 3 \\
\hline \multirow{4}{*}{$\begin{array}{l}\text { 18. Two-way transmission channels_-financial to } \\
\text { macro. Are financial sector issues discussed as a } \\
\text { potential source of macroeconomic or external } \\
\text { instability (e.g. effect on fiscal cost/debt } \\
\text { level/growth/employment)? }\end{array}$} & Yes & 40 & 17 & 44 & 58 & 0 & 78 & 67 & 39 & 28 & 25 & 45 \\
\hline & No because not covered. & 22 & 33 & 22 & 8 & 50 & 0 & 11 & 17 & 33 & 33 & 18 \\
\hline & No because the analysis is unclear. & 8 & 0 & 0 & 17 & 25 & 0 & 11 & 13 & 0 & 0 & 11 \\
\hline & $\begin{array}{l}\text { No because the financial sector is not seen as a source of potential } \\
\text { risk for macroeconomic/ external stability. }\end{array}$ & 30 & 50 & 33 & 17 & 25 & 22 & 11 & 30 & 39 & 42 & 26 \\
\hline
\end{tabular}


Appendix I, Table 2. Summary of Article IV Staff Report Review - Financial Sector Issues

\begin{tabular}{|c|c|c|c|c|c|c|c|c|c|c|c|c|}
\hline \multirow[b]{2}{*}{ Question } & \multirow{3}{*}{ Answers } & \multirow[t]{2}{*}{ Aggregate } & \multicolumn{5}{|c|}{ Region } & \multicolumn{3}{|c|}{ Income Level } & \multicolumn{2}{|c|}{ Program? } \\
\hline & & & AFR & APD & EUR & MCD & WHD & $\mathrm{ADV}$ & EMG & LIC & Yes & No \\
\hline & & \multicolumn{11}{|c|}{ (In percentage of applicable sample) } \\
\hline Two-way transmission channels-macro to & Yes & 50 & 50 & 44 & 75 & 13 & 56 & 89 & 52 & 28 & 33 & 55 \\
\hline financial. Does the report provide a clear analysis of & No because not covered. & 30 & 25 & 33 & 8 & 63 & 33 & 11 & 22 & 50 & 50 & 24 \\
\hline the risk factors that could trigger FS instability (e.g. & No because the analysis is unclear. & 10 & 8 & 11 & 8 & 25 & 0 & 0 & 13 & 11 & 0 & 13 \\
\hline $\begin{array}{l}\text { liquidity risks/credit risks/interest rate risk/maturity } \\
\text { mismatch/repricing risk, contagion risk or spillovers)? }\end{array}$ & $\begin{array}{l}\text { The macroeconomic situation is not seen as a source of potential risk } \\
\text { for the financial sector. }\end{array}$ & 10 & 17 & 11 & 8 & 0 & 11 & 0 & 13 & 11 & 17 & 8 \\
\hline \multirow{4}{*}{$\begin{array}{l}\text { 20. If financial sector reforms are recommended, } \\
\text { does the report provide sufficient rationale for the } \\
\text { prioritization and composition of the proposed } \\
\text { reforms? }\end{array}$} & Yes & 72 & 58 & 78 & 83 & 63 & 78 & 100 & 74 & 56 & 67 & 74 \\
\hline & \multirow{2}{*}{$\begin{array}{l}\text { No because no prioritization for reform is mentioned } \\
\text { The description of the composition of financial sector reform is too } \\
\text { general to be useful. }\end{array}$} & 12 & 0 & 11 & 17 & 13 & 22 & 0 & 17 & 11 & 0 & 16 \\
\hline & & 10 & 25 & 0 & 0 & 25 & 0 & 0 & 4 & 22 & 25 & 5 \\
\hline & N/A (no reforms are recommended) & 6 & 17 & 11 & 0 & 0 & 0 & 0 & 4 & 11 & 8 & 5 \\
\hline \multirow{4}{*}{$\begin{array}{l}\text { 21. For countries where an FSAP has been } \\
\text { completed since end-2009, are FSAP findings well } \\
\text { integrated into the assessment? }\end{array}$} & N/A (No FSAP in period) & 80 & 100 & 78 & 67 & 75 & 78 & 67 & 74 & 94 & 92 & 76 \\
\hline & $\begin{array}{l}\text { Yes (well integrated, e.g. includes findings from risk-assessment } \\
\text { matrix (RAM)). }\end{array}$ & 14 & 0 & 22 & 17 & 13 & 22 & 11 & 22 & 6 & 8 & 16 \\
\hline & \multirow{2}{*}{$\begin{array}{l}\text { No, there is no discussion of the FSAP findings in the report. } \\
\text { No FSAP findings are discussed, but policy implications are not clearly } \\
\text { drawn. }\end{array}$} & 4 & 0 & 0 & 17 & 0 & 0 & 22 & 0 & 0 & 0 & 5 \\
\hline & & 2 & 0 & 0 & 0 & 13 & 0 & 0 & 4 & 0 & 0 & 3 \\
\hline \multirow{3}{*}{$\begin{array}{l}\text { 22. } \\
\text { years (but countries with an FSAP within the last } 5 \\
\text { there reference to follow-up on FSAP findings? }\end{array}$} & N/A (No FSAP in the last five years) & 60 & 50 & 67 & 33 & 63 & 100 & 56 & 65 & 56 & 75 & 55 \\
\hline & Yes & 32 & 33 & 33 & 50 & 38 & 0 & 22 & 30 & 39 & 25 & 34 \\
\hline & No & 8 & 17 & 0 & 17 & 0 & 0 & 22 & 4 & 6 & 0 & 11 \\
\hline
\end{tabular}




\begin{tabular}{|c|c|c|c|c|c|c|c|c|c|c|c|c|}
\hline \multirow[b]{2}{*}{ Question } & \multirow[b]{2}{*}{ Answers } & \multirow[t]{2}{*}{ Aggregate } & \multicolumn{5}{|c|}{ Region } & \multicolumn{3}{|c|}{ Income Level } & \multicolumn{2}{|c|}{ Program? } \\
\hline & & & AFR & APD & EUR & MCD & WHD & ADV & EMG & LIC & Yes & No \\
\hline & & \multicolumn{11}{|c|}{ (In percentage of applicable sample) } \\
\hline \multirow{5}{*}{$\begin{array}{l}\text { 23. For countries with exchange rate } \\
\text { policies (i.e. not pure floaters), does the report } \\
\text { provide a reasoned appraisal of the member's } \\
\text { policies with respect to the exchange rate? }\end{array}$} & N/A & 26 & 33 & 0 & 50 & 0 & 33 & 67 & 9 & 28 & 17 & 29 \\
\hline & Yes & 66 & 67 & 78 & 42 & 100 & 56 & 33 & 78 & 67 & 83 & 61 \\
\hline & $\begin{array}{l}\text { No because the report does not describe policies that relate to the exchange rate } \\
\text { clearly. }\end{array}$ & 2 & 0 & 11 & 0 & 0 & 0 & 0 & 0 & 6 & 0 & 3 \\
\hline & $\begin{array}{l}\text { No because the report describes policies that relate to the exchange rate but does } \\
\text { not give a view on their appropriateness for the member. }\end{array}$ & 2 & 0 & 0 & 0 & 0 & 11 & 0 & 4 & 0 & 0 & 3 \\
\hline & No because the depth of analysis is too shallow. & 4 & 0 & 11 & 8 & 0 & 0 & 0 & 9 & 0 & 0 & $\underline{5}$ \\
\hline \multirow{3}{*}{$\begin{array}{l}24 . \quad \text { Does the report provide a clear } \\
\text { assessment of the exchange rate level? }\end{array}$} & Yes & 92 & 100 & 78 & 83 & 100 & 100 & 89 & 91 & 94 & 100 & 89 \\
\hline & No & 8 & 0 & 22 & 17 & 0 & 0 & 11 & 9 & 6 & 0 & 11 \\
\hline & Yes & 82 & 100 & 67 & 75 & 100 & 67 & 78 & 83 & 83 & 92 & 79 \\
\hline \multirow{4}{*}{$\begin{array}{l}\text { 25. Given available data, does the report } \\
\text { provide robust analysis to underpin the } \\
\text { assessment of the exchange rate level? }\end{array}$} & No because no analysis presented & 4 & 0 & 0 & 8 & 0 & 11 & 11 & 4 & 0 & 0 & 5 \\
\hline & No because sophistication/ depth of analysis is limited. & 8 & 0 & 22 & 8 & 0 & 11 & 11 & 9 & 6 & 0 & 11 \\
\hline & $\begin{array}{l}\text { No because critical features of methodologies and/or key assumptions are not } \\
\text { disclosed or, presented in a "black box" way. }\end{array}$ & 6 & 0 & 11 & 8 & 0 & 11 & 0 & 4 & 11 & 8 & 5 \\
\hline & $\begin{array}{l}\text { No because analysis/conclusions appear to be either not taking into account all } \\
\text { important factors or internally inconsistent (at odds with other facts presented in the } \\
\text { report). }\end{array}$ & 0 & 0 & 0 & 0 & 0 & 0 & 0 & 0 & 0 & 0 & 0 \\
\hline \multirow{7}{*}{$\begin{array}{l}\text { 26. Please specify all techniques utilized for } \\
\text { making the exchange rate assessment: } \\
\text { (Check all that apply) }\end{array}$} & a. Basic indicators (e.g. REER, market shares, export growth, unit labor costs, etc) & 82 & 75 & 100 & 75 & 75 & 89 & 67 & 87 & 83 & 83 & 82 \\
\hline & b. PPP approaches (e.g. weighted average relative prices, WAR & 14 & 8 & 22 & 8 & 13 & 22 & 11 & 9 & 22 & 8 & 16 \\
\hline & c. Macro economic balance approach & 80 & 92 & 78 & 83 & 63 & 78 & 89 & 74 & 83 & 75 & 82 \\
\hline & d. External sustainability approach & 74 & 92 & 67 & 83 & 63 & 56 & 89 & 83 & 56 & 67 & 76 \\
\hline & e. Equilibrium real exchange rate approach & 78 & 92 & 56 & 75 & 75 & 89 & 89 & 78 & 72 & 75 & 79 \\
\hline & $\begin{array}{l}\text { f. External vulnerabilities (discussion of effects of capital inflows, capital restrictions, } \\
\text { FX intervention or changes in reserves) }\end{array}$ & 28 & 25 & 33 & 33 & 38 & 11 & 0 & 43 & 22 & 17 & 32 \\
\hline & g. Other (please specify): & 20 & 8 & 44 & 8 & 38 & 11 & 0 & 22 & 28 & 50 & 11 \\
\hline \multirow{3}{*}{$\begin{array}{l}27 . \quad \text { In assessing the exchange rate, does } \\
\text { the analysis make allowances for member } \\
\text { specific circumstances? In your judgment, are } \\
\text { these allowances appropriate or excessive? }\end{array}$} & No clear adjustments for member specific circumstances & 52 & 50 & 67 & 67 & 13 & 56 & 67 & 57 & 39 & 58 & 50 \\
\hline & Allowances made for member circumstances and are clearly justified & 40 & 33 & 33 & 25 & 88 & 33 & 33 & 39 & 44 & 33 & 42 \\
\hline & Allowances made for member circumstances and are unclear & 8 & 17 & 0 & 8 & 0 & 11 & 0 & 4 & 17 & 8 & 8 \\
\hline
\end{tabular}


Appendix I, Table 4. Summary of Article IV Staff Report Review - Risk Assessment

\begin{tabular}{|c|c|c|c|c|c|c|c|c|c|c|c|c|}
\hline \multirow{2}{*}{$\begin{array}{l}\text { Question } \\
\end{array}$} & \multirow[b]{2}{*}{ Answers } & \multirow[t]{2}{*}{ Aggregate } & \multicolumn{5}{|c|}{ Region } & \multicolumn{3}{|c|}{ Income Level } & \multicolumn{2}{|c|}{ Program? } \\
\hline & & & AFR & APD & EUR & $\mathrm{MCD}$ & WHD & ADV & EMG & LIC & Yes & No \\
\hline & & \multicolumn{11}{|c|}{ (In percentage of applicable sample) } \\
\hline \multirow{2}{*}{ Does the staff report discuss tail risks? } & Yes & 16 & 17 & 11 & 8 & 25 & 22 & 22 & 4 & 28 & 33 & 11 \\
\hline & No & 84 & 83 & 89 & 92 & 75 & 78 & 78 & 96 & 72 & 67 & 89 \\
\hline \multirow{3}{*}{$\begin{array}{l}\text { 29. Are the major risks to baseline MT/LT scenario } \\
\text { taken into account in the policy messages of the SR? }\end{array}$} & Yes & 78 & 75 & 78 & 83 & 88 & 67 & 78 & 78 & 78 & 83 & 76 \\
\hline & $\begin{array}{l}\text { No because only some of the major risks to baseline MT/LT scenario } \\
\text { appear to be appropriately incorporated in the bottom-line messages. }\end{array}$ & 20 & 25 & 22 & 8 & 13 & 33 & 22 & 17 & 22 & 17 & 21 \\
\hline & $\begin{array}{l}\text { No because no policy advice stemming from identified risks appear to } \\
\text { have been incorporated in the bottom-line messages of the SR. }\end{array}$ & 2 & 0 & 0 & 8 & 0 & 0 & 0 & 4 & 0 & 0 & 3 \\
\hline
\end{tabular}


Appendix I, Table 5. Summary of Article IV Staff Report Review - Multilateral Perspective

\begin{tabular}{|c|c|c|c|c|c|c|c|c|c|c|c|c|}
\hline \multirow{2}{*}{ Question } & \multirow[b]{2}{*}{ Answers } & \multirow{2}{*}{ Aggregate } & \multicolumn{5}{|c|}{ Region } & \multicolumn{3}{|c|}{ Income Level } & \multicolumn{2}{|c|}{ Program? } \\
\hline & & & AFR & APD & EUR & $\mathrm{MCD}$ & WHD & ADV & EMG & LIC & Yes & No \\
\hline & & \multicolumn{11}{|c|}{ (In percentage of applicable sample) } \\
\hline \multirow{4}{*}{$\begin{array}{l}\text { 30. Are the impacts of global economic and financial } \\
\text { developments or policies of other countries (systemic } \\
\text { countries or trading partners) discussed in the report? }\end{array}$} & Yes. Passing reference (acknowledging effects and risks in general terms). & 46 & 42 & 67 & 17 & 50 & 67 & 11 & 57 & 50 & 58 & 42 \\
\hline & Yes. More than passing reference, with some analysis. & 14 & 17 & 0 & 25 & 0 & 22 & 22 & 13 & 11 & 8 & 16 \\
\hline & $\begin{array}{l}\text { Yes. Extensive substantive analysis (e.g. possible scenarios and } \\
\text { transmission mechanisms to show size of problem and policy implications). }\end{array}$ & 20 & 8 & 11 & 50 & 13 & 11 & 56 & 17 & 6 & 0 & 26 \\
\hline & No & 20 & 33 & 22 & 8 & 38 & 0 & 11 & 13 & 33 & 33 & 16 \\
\hline \multirow{3}{*}{$\begin{array}{l}\text { 31. How extensive is the use of cross-country analysis } \\
\text { in the Staff Report? }\end{array}$} & No use of cross-country analysis. & 22 & 17 & 11 & 17 & 50 & 22 & 22 & 26 & 17 & 42 & 16 \\
\hline & Some use of cross-country analysis & 44 & 58 & 44 & 25 & 38 & 56 & 0 & 39 & 72 & 58 & 39 \\
\hline & Extensive use of cross-country analysis & 34 & 25 & 44 & 58 & 13 & 22 & 78 & 35 & 11 & 0 & 45 \\
\hline \multirow{4}{*}{$\begin{array}{l}\text { 32. If cross-country analysis is used in the Staff } \\
\text { Report, what type of analysis is it? (check all that apply.) }\end{array}$} & Comparison of indicators over a peer group & 76 & 83 & 89 & 75 & 50 & 78 & 67 & 74 & 83 & 58 & 82 \\
\hline & Narrative illustrating experience of one or several other countries & 26 & 25 & 33 & 42 & 13 & 11 & 56 & 22 & 17 & 17 & 29 \\
\hline & Econometric analysis seeking to assess appropriateness of policy & 6 & 0 & 0 & 17 & 13 & 0 & 22 & 4 & 0 & 0 & 8 \\
\hline & Other & 6 & 0 & 0 & 25 & 0 & 0 & 33 & 0 & 0 & 0 & 8 \\
\hline \multirow{4}{*}{$\begin{array}{l}\text { 33. If cross-country analysis is used in the Staff } \\
\text { Report, what topics are covered? (check all that apply) }\end{array}$} & Regional trends & 58 & 50 & 44 & 83 & 38 & 67 & 78 & 48 & 61 & 42 & 63 \\
\hline & Global trends & 26 & 33 & 11 & 42 & 0 & 33 & 33 & 35 & 11 & 8 & 32 \\
\hline & Drawing relevant policy lessons from similarly-placed economies & 32 & 42 & 56 & 25 & 13 & 22 & 33 & 35 & 28 & 17 & 37 \\
\hline & Other & 2 & 0 & 11 & 0 & 0 & 0 & 0 & 0 & 6 & 0 & 3 \\
\hline
\end{tabular}


Appendix I, Table 6. Summary of Article IV Staff Report Review - Statistical Issues

\begin{tabular}{|c|c|c|c|c|c|c|c|c|c|c|c|c|}
\hline \multirow{2}{*}{$\begin{array}{l}\text { Question } \\
\end{array}$} & \multirow[b]{2}{*}{ Answers } & \multirow{2}{*}{ Aggregate } & \multicolumn{4}{|c|}{ Region } & & \multicolumn{3}{|c|}{ Income Level } & \multicolumn{2}{|c|}{ Program? } \\
\hline & & & AFR & APD & EUR & MCD & WHD & $\mathrm{ADV}$ & EMG & LIC & Yes & No \\
\hline & & & & & In perce & ntage $o$ & f applic & able san & ple) & & & \\
\hline \multirow{4}{*}{$\begin{array}{l}\text { 34. Where the Statistical Appendix highlights significant } \\
\text { data weaknesses are these discussed adequately in the } \\
\text { Article IV staff report? (Please use the Statistical Annex to } \\
\text { identify data weaknesses and look to see if these are } \\
\text { mentioned in the text of the Staff Report.) }\end{array}$} & N/A & 44 & 17 & 44 & 83 & 0 & 67 & 100 & 43 & 17 & 33 & 47 \\
\hline & $\begin{array}{l}\text { Yes. Data deficiencies are discussed but no remedial actions or TA } \\
\text { proposed. }\end{array}$ & 10 & 0 & 0 & 8 & 50 & 0 & 0 & 17 & 6 & 8 & 11 \\
\hline & Yes. Data deficiencies are discussed and remedial action/TA is proposed. & 32 & 42 & 44 & 8 & 38 & 33 & 0 & 22 & 61 & 42 & 29 \\
\hline & 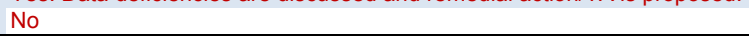 & 14 & 42 & 11 & 0 & 13 & 0 & 0 & 17 & 17 & 17 & 13 \\
\hline \multirow{2}{*}{$\begin{array}{l}35 . \quad \text { Does the Staff Report explain whether financial } \\
\text { sector data are adequate or inadequate to make an } \\
\text { assessment of key financial sector risks/vulnerabilities? }\end{array}$} & Yes & 10 & 0 & 22 & 0 & 13 & 22 & 0 & 17 & 6 & 0 & 13 \\
\hline & No & 90 & 100 & 78 & 100 & 88 & 78 & 100 & 83 & 94 & 100 & 87 \\
\hline
\end{tabular}


Appendix I, Table 7. Summary of Article IV Staff Report Review - Candor and Communication

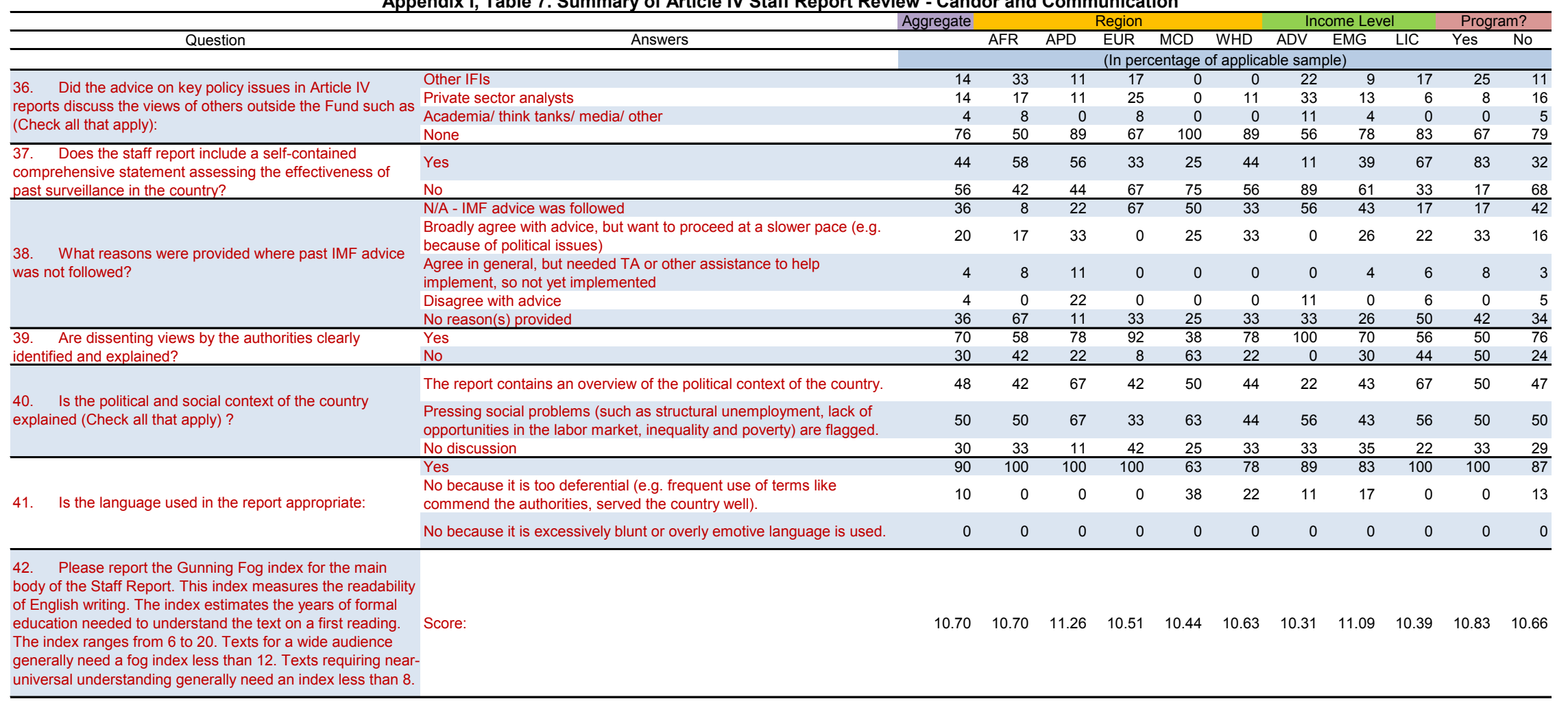




\section{Appendix II: Stakeholder Surveys}

\section{Methodology}

47. Several surveys were conducted for the 2011 Triennial Surveillance Review (TSR), to gather views across different groups of stakeholders on various aspects of surveillance. ${ }^{18}$ Anonymous surveys were conducted for member country authorities (to gauge their views of surveillance, largely focused on surveillance of their country); IMF Executive Directors (to gather their views as proxy for "the international community" on surveillance of countries other than the one (s) they represent, as well as their views on the countries they represent); Article IV IMF mission chiefs (as "producers" of bilateral surveillance); and the public, including financial market participants, media, civil society organizations, and think tanks.

48. The surveys posed questions relevant for each TSR theme, varying in emphasis depending on the audience, with the aim of capturing each audience's unique perspective of surveillance. To maximize response rates, the questions were phrased at a relatively general level.

- $\quad$ The thematic areas included (i) value-added of surveillance; (ii) four operational priorities set out in the 2008 TSR (risk assessment; multilateral perspective; financial sector surveillance and real-financial linkages; and exchange rate and external stability); (iii) issues critical to the effectiveness of surveillance (candor and encouraging a diversity of views, evenhandedness, taking into account the political and social context, and communication).

- $\quad$ The survey of country authorities and Executive Directors were similar in content and structure, focusing more on the quality of coverage in thematic areas.

- The mission chiefs' survey focused more on the difficulties in further improving the quality of surveillance and to make surveillance more effective. Mission chiefs who conducted Article IV consultations from September 2008 to February 2011 were sent the survey. Mission chiefs who covered more than one country during that period were asked to complete the survey based on their experience with the country that had a full consultation cycle since September 2008.

\footnotetext{
${ }^{18}$ The 2011 surveys build on the methodology used for the 2008 TSR, with some key differences including (i) the 2011 surveys reflects broader coverage of issues and more forward looking questions; and (ii) country authority surveys were sent to both the central bank/financial supervision agency and the ministry of finance/treasury of each member country in 2011, while one survey was sent to each member country in the 2008 surveys.
} 
- $\quad$ The surveys of financial market participants, think tanks, and civil society also focused on the quality of coverage in thematic areas, with questions to assess the effectiveness of communication. In thematic areas, respondents were asked to compare the quality of the Fund's analysis to other institutions doing similar analysis.

- A survey of the media focused on the effectiveness of communications.

49. For all audiences, efforts were made to include as many respondents as possible. The table below summarizes the universe of possible respondents and response rates. All responses were anonymous. Questions were included to help stratify the results by various categories, including, income level, size (G-20 as a proxy for a large country), region, program or non-program country, and the type of institution as relevant (e.g., finance ministry, central bank or regulatory/supervisory authority for country authorities; the type of bank or company for market participants).

50. Problems encountered. Response rate for the survey of think tanks was so low (241 think tanks contacted yielded a 5 percent response rate) that feedback from this type of audiences was not incorporated in the 2011 TSR. ${ }^{19}$ A more general point is that, ex post, the sample of respondents to a survey may not be fully representative of the original population targeted. While efforts were made to correct this imbalance, participation is voluntary. For transparency purposes, results are made available by relevant subsets.

\footnotetext{
${ }^{19}$ In the 2008 TSR, surveys for CSOs and Think Tanks were not incorporated due to very low response rates.
} 
Stakeholder Survey Sample Universe and Response Rates

\begin{tabular}{|c|c|c|c|c|c|c|c|c|}
\hline \multirow[t]{2}{*}{ Survey Audience } & \multicolumn{5}{|c|}{2011} & \multicolumn{3}{|c|}{2008} \\
\hline & $\begin{array}{c}\text { Number of } \\
\text { Respondents }^{3 /}\end{array}$ & $\begin{array}{c}\text { Number of } \\
\text { surveys sent }\end{array}$ & $\begin{array}{c}\text { Participation } \\
\text { Rate in } \% \\
\end{array}$ & $\begin{array}{l}\text { Regional Share of } \\
\text { Total } \\
\text { (Respondents) }^{3 /}\end{array}$ & $\begin{array}{l}\text { Regional Share } \\
\text { of Total (Sent) }\end{array}$ & $\begin{array}{c}\text { Number of } \\
\text { Respondents }\end{array}$ & $\begin{array}{c}\text { Number of } \\
\text { surveys sent }\end{array}$ & $\%$ \\
\hline Country Authorities $^{1 /}$ & 121 & 368 & $32.9 \%$ & & & 63 & 185 & $34.1 \%$ \\
\hline Africa & 10 & 66 & $15.2 \%$ & $8.3 \%$ & $17.9 \%$ & & & \\
\hline Asia Pacific & 19 & 58 & $32.8 \%$ & $15.7 \%$ & $15.8 \%$ & & & \\
\hline Europe & 56 & 114 & $49.1 \%$ & $46.3 \%$ & $31.0 \%$ & & & \\
\hline Middle East & 14 & 53 & $26.4 \%$ & $11.6 \%$ & $14.4 \%$ & & & \\
\hline Americas & 18 & 77 & $23.4 \%$ & $14.9 \%$ & $20.9 \%$ & & & \\
\hline Executive Directors & 18 & 24 & $75.0 \%$ & & & 14 & 24 & $58.3 \%$ \\
\hline Mission Chiefs & 95 & 154 & $61.7 \%$ & & & 55 & 83 & $66.3 \%$ \\
\hline Africa & 22 & 39 & $56.4 \%$ & $23.2 \%$ & $25.3 \%$ & & & \\
\hline Asia Pacific & 19 & 28 & $67.9 \%$ & $20.0 \%$ & $18.2 \%$ & & & \\
\hline Europe & 27 & 38 & $71.1 \%$ & $28.4 \%$ & $24.7 \%$ & & & \\
\hline Middle East & 12 & 22 & $54.5 \%$ & $12.6 \%$ & $14.3 \%$ & & & \\
\hline Americas & 14 & 27 & $51.9 \%$ & $14.7 \%$ & $17.5 \%$ & & & \\
\hline Financial Markets & 41 & 300 & $13.7 \%$ & & & 96 & 453 & $21.2 \%$ \\
\hline Media & 28 & 87 & $32.2 \%$ & & & 15 & 40 & $37.5 \%$ \\
\hline $\mathrm{CSOs}^{2 /}$ & 17 & 45 & $37.8 \%$ & - & - & insufficient & - & - \\
\hline \begin{tabular}{|l|} 
Think Tanks \\
\end{tabular} & 12 & 241 & $5.0 \%$ & - & - & insufficient & - & - \\
\hline
\end{tabular}

1/ In 2011, Country Authority surveys were surveys were sent to both the central bank/financial supervision agency and the ministry of finance/treasury of each member country. There were 121 respondents out of 368 survey recipients. The 121 respondents in 2011 are estimated to represent about 86 countries ( $46 \%$ of 187 member countries), compared to participation in 2008 of 63 countries ( $34 \%$ of 185 member countries).

2/ In addition to the online survey, surveys were also distributed to CSOs during an informational session at the IMF-World Bank Spring Meetings in April 2011. 3 / As some country authorities and mission chiefs did not identify their regional classifications, the sum of total repondents by region is less than the total number of respondents for the country authorities' and mission chiefs' surveys.

\section{Results of Stakeholders Surveys}

Tables 1 to 6 of this Statistical Appendix II report the results of the stakeholder surveys. The survey results are presented at an aggregate level, as well as by certain classificationsincluding regional, income, and IMF-supported program status-where relevant. Written comments for the stakeholders are presented in Tables 7 to 12 . 
Appendix II, Table 1. TSR Country Authorities' Survey Results ${ }^{1 /}$

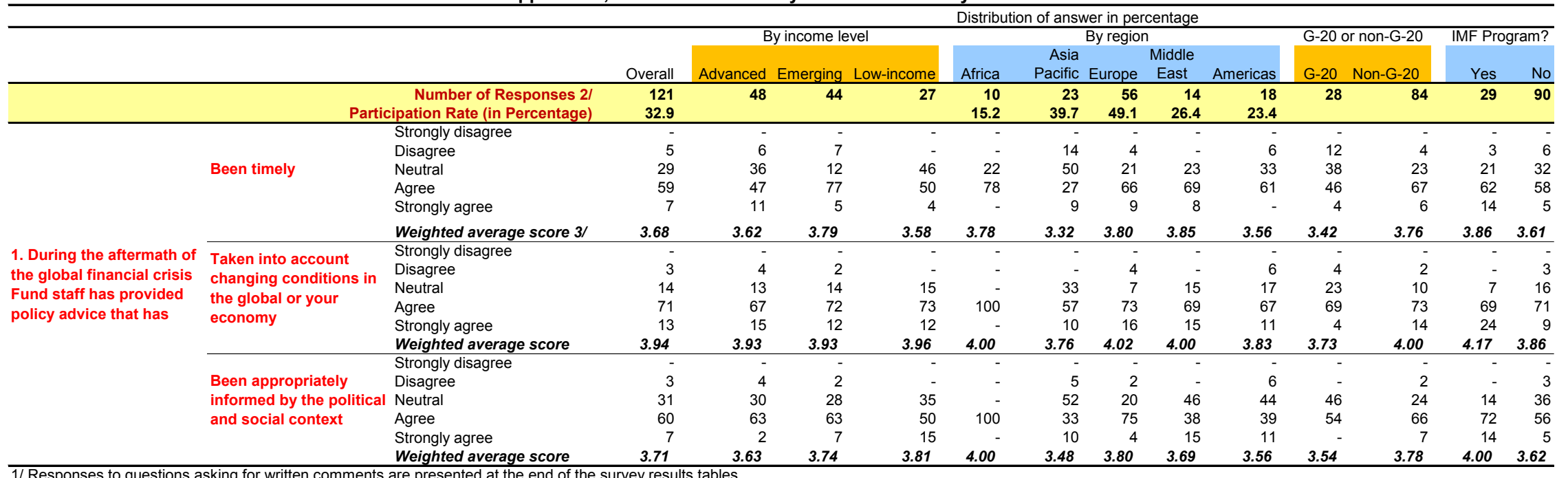

$1 /$ Responses to questions asking for written comments are presented at the end of the survey results tabs.

2/ Country authority surveys were sent to both the central bank/financial supervision agency and the ministry of finance/treasury of each member country.

3/ A weighted average was used to convert the responses to questions to select one from four or five answer choices to a 5-point scale to make the responses more comparable across questions. The higher

the score, the more positive the response was. 
Appendix II, Table 1. TSR Country Authorities' Survey Results

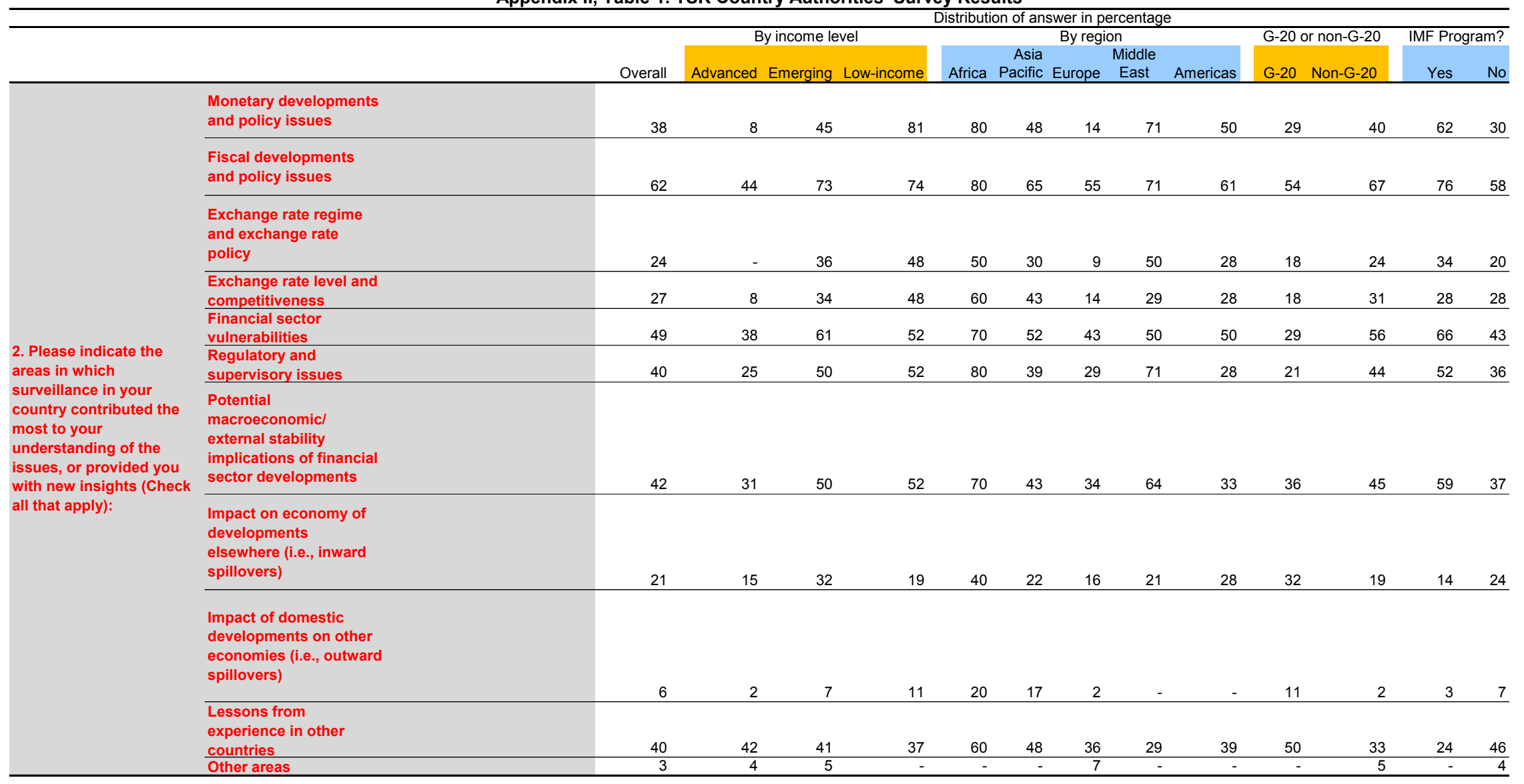


Appendix II, Table 1. TSR Country Authorities' Survey Results

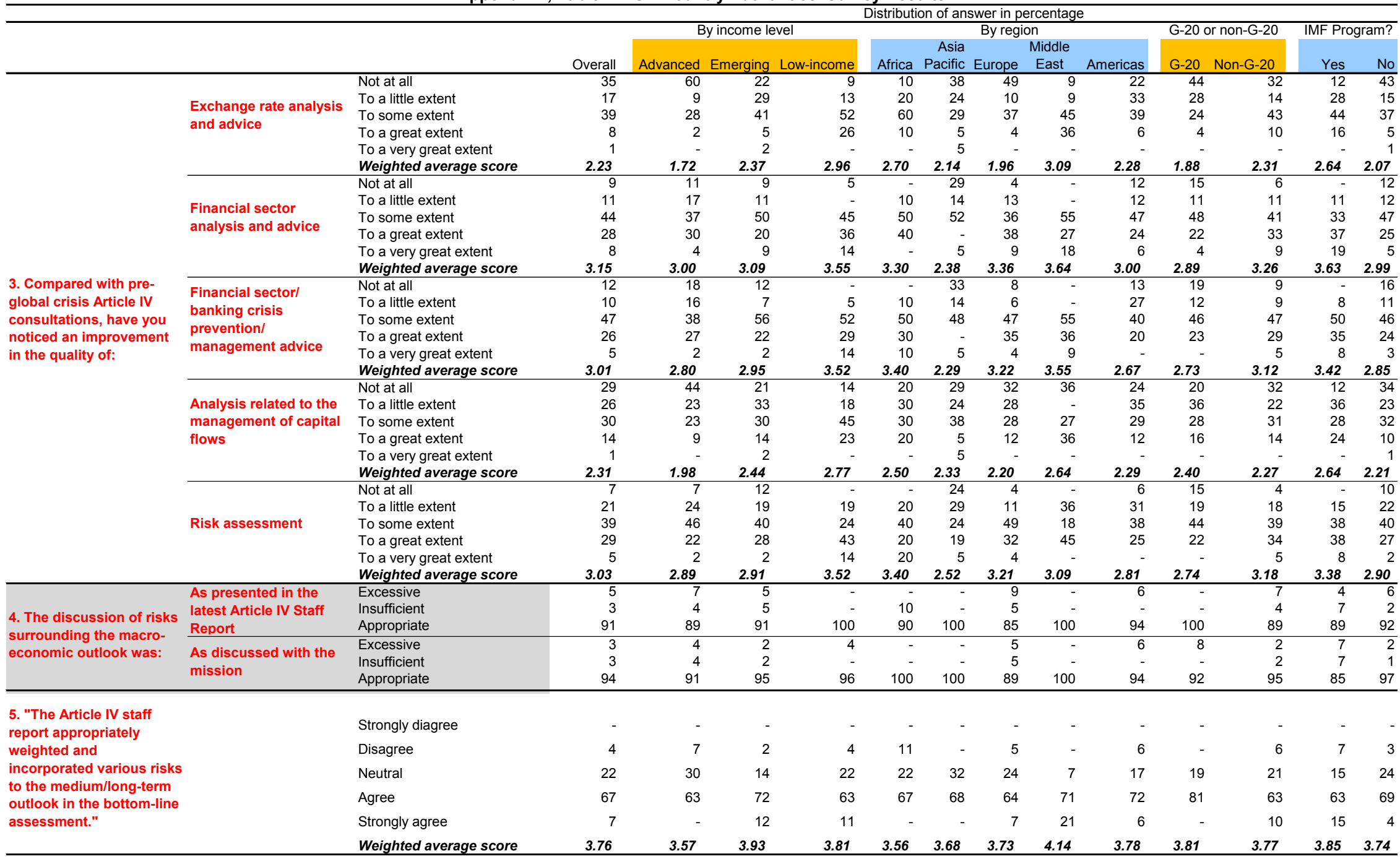


Appendix II, Table 1. TSR Country Authorities' Survey Results

\begin{tabular}{|c|c|c|c|c|c|c|c|c|c|c|c|c|c|c|c|}
\hline & \multicolumn{13}{|c|}{ Distribution of answer in percentage } \\
\hline & & & \multirow{2}{*}{\multicolumn{4}{|c|}{ By income level }} & \multicolumn{5}{|c|}{ By region } & \multirow{2}{*}{\multicolumn{2}{|c|}{ G-20 or non-G-20 }} & \multicolumn{2}{|c|}{ IMF Program? } \\
\hline & & & & & & & & Asia & & Middle & & & & & \\
\hline & & & Overall & Advanced & Emerging & Low-income & Africa & Pacific & Europe & East & Americas & G-20 & Non-G-20 & Yes & No \\
\hline \multirow{6}{*}{$\begin{array}{l}\text { 6. Do you think that Fund } \\
\text { advice signals risks: }\end{array}$} & & Too infrequently & 9 & 7 & 14 & 8 & 10 & 18 & 9 & & 6 & $\frac{5-40}{7}$ & 8 & 19 & 7 \\
\hline & For your country & With the adequate frequency & 86 & 87 & 84 & 85 & 90 & 82 & 84 & 85 & 94 & 85 & 87 & 74 & 89 \\
\hline & & Too frequently & 5 & 7 & 2 & 8 & - & & 7 & 15 & - & 7 & 5 & 7 & 4 \\
\hline & & Too infrequently & 38 & 37 & 43 & 25 & 22 & 43 & 38 & 23 & 50 & 50 & 34 & 22 & 43 \\
\hline & For other countries & With the adequate frequency & 59 & 61 & 58 & 63 & 56 & 57 & 60 & 77 & 44 & 50 & 61 & 74 & 54 \\
\hline & & Too frequently & 4 & 2 & - & 13 & 22 & - & 2 & - & 6 & - & 5 & 4 & 2 \\
\hline \multirow{12}{*}{$\begin{array}{l}\text { 7. Please indicate areas } \\
\text { which should be improved } \\
\text { in order to strengthen the } \\
\text { Fund's surveillance, from } \\
\text { the list below (several } \\
\text { answers possible): }\end{array}$} & Quality of analysis & & 42 & 46 & 41 & 41 & 50 & 48 & 36 & 50 & 44 & 64 & 35 & 34 & 44 \\
\hline & $\begin{array}{l}\text { Greater use of cross- } \\
\text { country comparisons }\end{array}$ & & 48 & 46 & 48 & 52 & 60 & 30 & 52 & 50 & 50 & 57 & 45 & 52 & 46 \\
\hline & Consistency of policy & & & & & & & & & & & & & & \\
\hline & advice across countries & & 40 & 35 & 41 & 44 & 50 & 26 & 41 & 21 & 61 & 57 & 37 & 31 & 42 \\
\hline & $\begin{array}{l}\text { Tailoring policy advice } \\
\text { to country }\end{array}$ & & & & & & & & & & & & & & \\
\hline & circumstances & & 62 & 56 & 68 & 63 & 80 & 74 & 57 & 64 & 50 & 61 & 60 & 55 & 63 \\
\hline & Timing of missions & & 16 & 10 & 16 & 26 & 20 & 9 & 11 & 50 & 11 & 11 & 18 & 38 & 9 \\
\hline & Staff's interaction with & & & & & & & & & & & & & & \\
\hline & the authorities & & 23 & 25 & 14 & 37 & 40 & 30 & 16 & 36 & 17 & 29 & 19 & 28 & 21 \\
\hline & Clarity of messages in & & & & & & & & & & & & & & \\
\hline & surveillance products & & 31 & 31 & 30 & 33 & 50 & 26 & 34 & 14 & 28 & 39 & 29 & 34 & 30 \\
\hline & Other & & 5 & 6 & - & 11 & - & 9 & 5 & - & 6 & 4 & 6 & 3 & 6 \\
\hline \multirow{12}{*}{$\begin{array}{l}\text { 8. To what extent did Fund } \\
\text { policy advice given in the } \\
\text { context of the most recent } \\
\text { Article IV consultation } \\
\text { help: }\end{array}$} & & Not at all & 6 & 7 & 9 & - & - & 9 & 2 & & 22 & 15 & 4 & & 8 \\
\hline & & To a little extent & 21 & 36 & 19 & - & 11 & 23 & 25 & 14 & 17 & 15 & 20 & 7 & 24 \\
\hline & Generate policy debate? & To some extent & 45 & 52 & 37 & 46 & 44 & 55 & 48 & 43 & 28 & 52 & 44 & 48 & 45 \\
\hline & & To a great extent & 27 & 5 & 35 & 50 & 44 & 14 & 23 & 43 & 33 & 19 & 30 & 41 & 23 \\
\hline & & To a very great ext & 1 & - & - & 4 & - & . & 2 & - & - & . & 1 & 4 & \\
\hline & & Weighted average score & 2.96 & 2.55 & 2.98 & 3.58 & 3.33 & 2.73 & 2.98 & 3.29 & 2.72 & 2.74 & 3.05 & 3.41 & 2.83 \\
\hline & & Not at all & 12 & 14 & 17 & - & - & 23 & 6 & - & 28 & 19 & 8 & - & 15 \\
\hline & & To a little extent & 27 & 50 & 17 & 4 & 11 & 32 & 32 & 14 & 22 & 33 & 23 & 7 & 32 \\
\hline & Foster appropriate & To some extent & 43 & 30 & 46 & 58 & 56 & 32 & 48 & 50 & 33 & 37 & 48 & 48 & 42 \\
\hline & policy change? & To a great extent & 16 & 7 & 20 & 27 & 22 & 14 & 12 & 29 & 17 & 11 & 17 & 33 & 11 \\
\hline & & To a very great exte & 3 & & & 12 & 11 & & 2 & 7 & - & . & 4 & 11 & \\
\hline & & Weighted average score & 2.72 & 2.30 & 2.68 & 3.46 & 3.33 & 2.36 & 2.72 & 3.29 & 2.39 & 2.41 & 2.86 & 3.48 & 2.48 \\
\hline \multirow{3}{*}{$\begin{array}{l}\text { 9. Was a press conferen } \\
\text { held at the end of the } \\
\text { most recent Article IV } \\
\text { consultation? }\end{array}$} & & & & & & & & & & & & & & & \\
\hline & & No & 35 & 32 & 45 & 27 & 33 & 57 & 24 & 43 & 39 & 50 & 28 & 21 & 39 \\
\hline & & Yes & 65 & 68 & 55 & 73 & 67 & 43 & 76 & 57 & 61 & 50 & 72 & 79 & 61 \\
\hline
\end{tabular}


Appendix II, Table 1. TSR Country Authorities' Survey Results

\begin{tabular}{|c|c|c|c|c|c|c|c|c|c|c|c|c|c|c|c|}
\hline & & & \multicolumn{13}{|c|}{ Distribution of answer in percentage } \\
\hline & & & \multicolumn{4}{|c|}{ By income level } & \multicolumn{5}{|c|}{ By region } & \multicolumn{2}{|c|}{ G-20 or non-G-20 } & \multicolumn{2}{|c|}{ IMF Program? } \\
\hline & & & Overall & Advanced & Emerging & Low-income & Africa & $\begin{array}{r}\text { Asia } \\
\text { Pacific }\end{array}$ & Europe & $\begin{array}{c}\text { Middle } \\
\text { East }\end{array}$ & Americas & G-20 & Non-G-20 & Yes & No \\
\hline \multirow{3}{*}{$\begin{array}{l}\text { 10. The degree of candor } \\
\text { in the most recent Article } \\
\text { IV staff report for my } \\
\text { country has been: }\end{array}$} & & Excessive & 2 & 4 & - & - & - & - & 4 & - & - & 4 & 1 & 4 & 1 \\
\hline & & Insufficient & 2 & 4 & - & - & - & - & 4 & - & - & - & 1 & 4 & 1 \\
\hline & & Appropriate & 97 & 91 & 100 & 100 & 100 & 100 & 93 & 100 & 100 & 96 & 98 & 93 & 98 \\
\hline \multirow{2}{*}{$\begin{array}{l}\text { 11. More candid messages } \\
\text { were delivered separately, } \\
\text { rather than in the staff } \\
\text { report: }\end{array}$} & & No & 66 & 64 & 67 & 65 & 67 & 64 & 72 & 57 & 61 & 73 & 65 & 61 & 69 \\
\hline & & Yes & 34 & 36 & 33 & 35 & 33 & 36 & 28 & 43 & 39 & 27 & 35 & 39 & 31 \\
\hline \multirow{3}{*}{ 12. If yes, how? } & Orally & & 74 & 85 & 62 & 75 & 33 & 83 & 79 & 80 & 67 & 60 & 72 & 45 & 86 \\
\hline & Concluding statement & & 18 & - & 31 & 25 & 67 & 17 & - & 20 & 33 & 20 & 20 & 36 & 9 \\
\hline & Other & & 9 & 15 & 8 & - & - & - & 21 & - & - & 20 & 8 & 18 & 5 \\
\hline & & Strongly disagree & 2 & 2 & 2 & - & - & 5 & 2 & & & 4 & & & 2 \\
\hline 13. "The IMF is & & Disagree & 21 & 27 & 27 & 4 & 11 & 18 & 24 & 14 & 28 & 54 & 12 & 11 & 25 \\
\hline evenhanded in its policy & & Neutral & 39 & 40 & 32 & 46 & 44 & 41 & 43 & 21 & 39 & 23 & 44 & 39 & 40 \\
\hline \multirow{3}{*}{ advice." } & & Agree & 35 & 29 & 39 & 42 & 44 & 36 & 30 & 50 & 33 & 19 & 40 & 43 & 32 \\
\hline & & Strongly agree & 3 & 2 & & 8 & - & & 2 & 14 & - & - & 4 & 7 & 1 \\
\hline & & Weighted average score & 3.15 & 3.02 & 3.07 & 3.54 & 3.33 & 3.09 & 3.06 & 3.64 & 3.06 & 2.58 & 3.35 & 3.46 & 3.05 \\
\hline \multirow{6}{*}{$\begin{array}{l}\text { 14. Do you feel that Fund } \\
\text { advice is: }\end{array}$} & & Too precise & 5 & & 9 & 8 & - & & 2 & 14 & 17 & & 7 & 14 & 2 \\
\hline & For your country & Adequately precise & 88 & 96 & 82 & 85 & 100 & 91 & 91 & 79 & 78 & 92 & 88 & 71 & 93 \\
\hline & & Insufficiently precise & 7 & 4 & 9 & 8 & - & 9 & 7 & 7 & 6 & 8 & 5 & 14 & 5 \\
\hline & & Too precise & 5 & 2 & 5 & 9 & - & 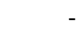 & 2 & 7 & 20 & 4 & 5 & 7 & 4 \\
\hline & For other countries & Adequately precise & 71 & 80 & 58 & 74 & 63 & 74 & 75 & 79 & 53 & 50 & 79 & 75 & 70 \\
\hline & & Insufficiently precise & 24 & 18 & 37 & 17 & 38 & 26 & 23 & 14 & 27 & 46 & 16 & 18 & 27 \\
\hline $\begin{array}{l}\text { 15. Do you feel there are } \\
\text { differences across the } \\
\text { membership in the } \\
\text { precision of policy advice }\end{array}$ & & No & 49 & 51 & 44 & 54 & 33 & 52 & 50 & 85 & 24 & 28 & 54 & 59 & 45 \\
\hline provided? & & Yes & 51 & 49 & 56 & 46 & 67 & 48 & 50 & 15 & 76 & 72 & 46 & 41 & 55 \\
\hline
\end{tabular}


Appendix II, Table 1. TSR Country Authorities' Survey Results

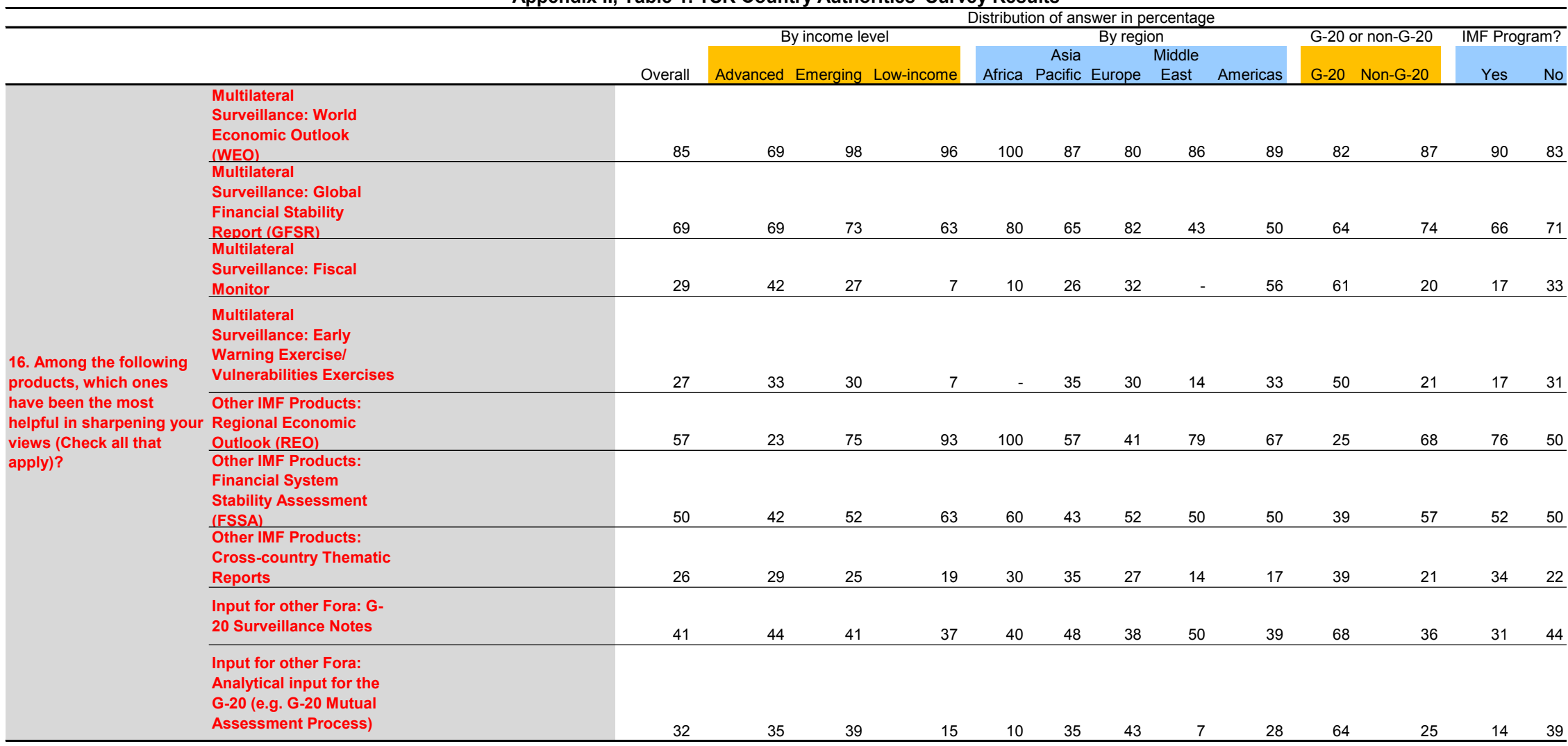


Appendix II, Table 2. TSR Executive Directors' Survey Results

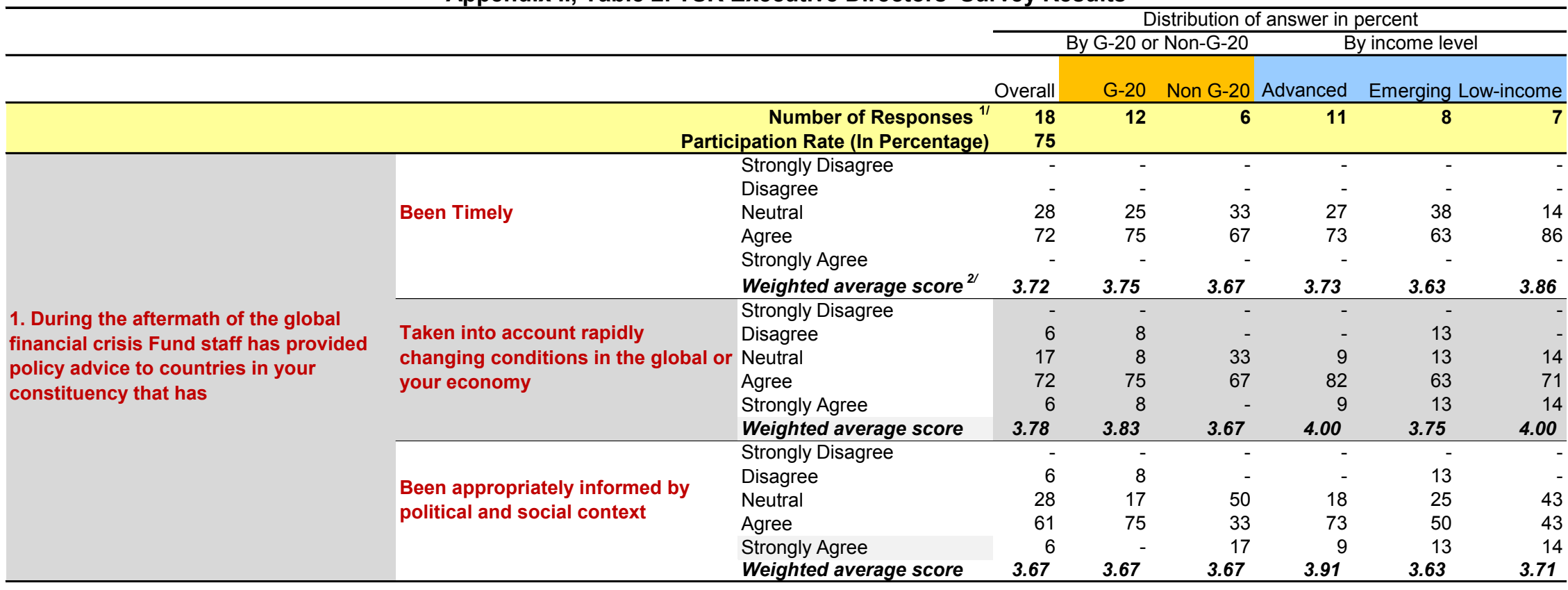

$1 /$ Number of respondents classified by income level add up to more than the number of overall respondents. This is because when a respondent's constituency includes more than two type of income levels (e.g., advanced and emerging market), the respondent is classified into both income level groups.

2/ A weighted average was used to convert the responses to questions to select one from four or five answer choices to a 5-point scale to make the responses more comparable across questions. The higher the score, the more positive the response was. 


\section{Appendix II, Table 2. TSR Executive Directors' Survey Results}

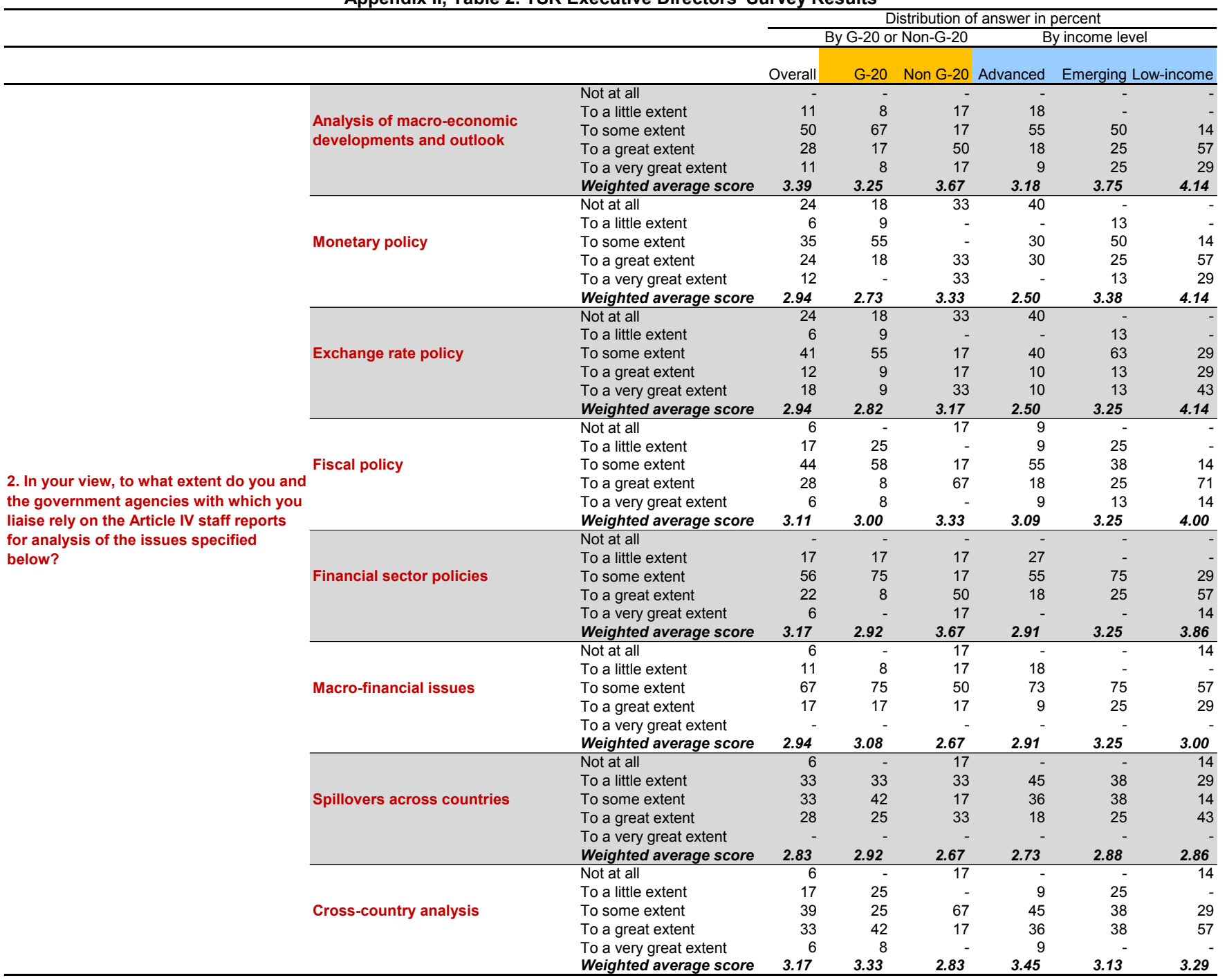


Appendix II, Table 2. TSR Executive Directors' Survey Results

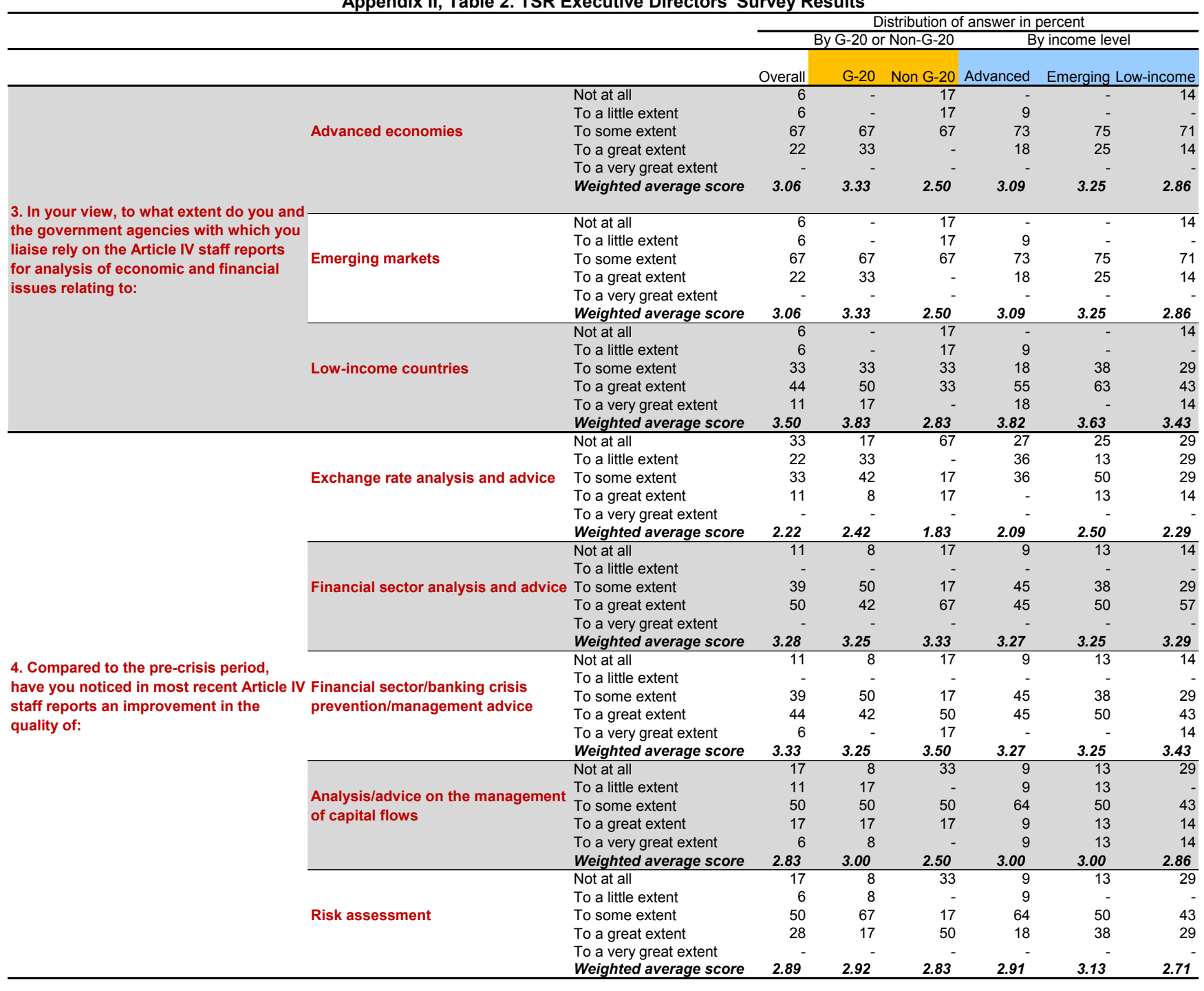




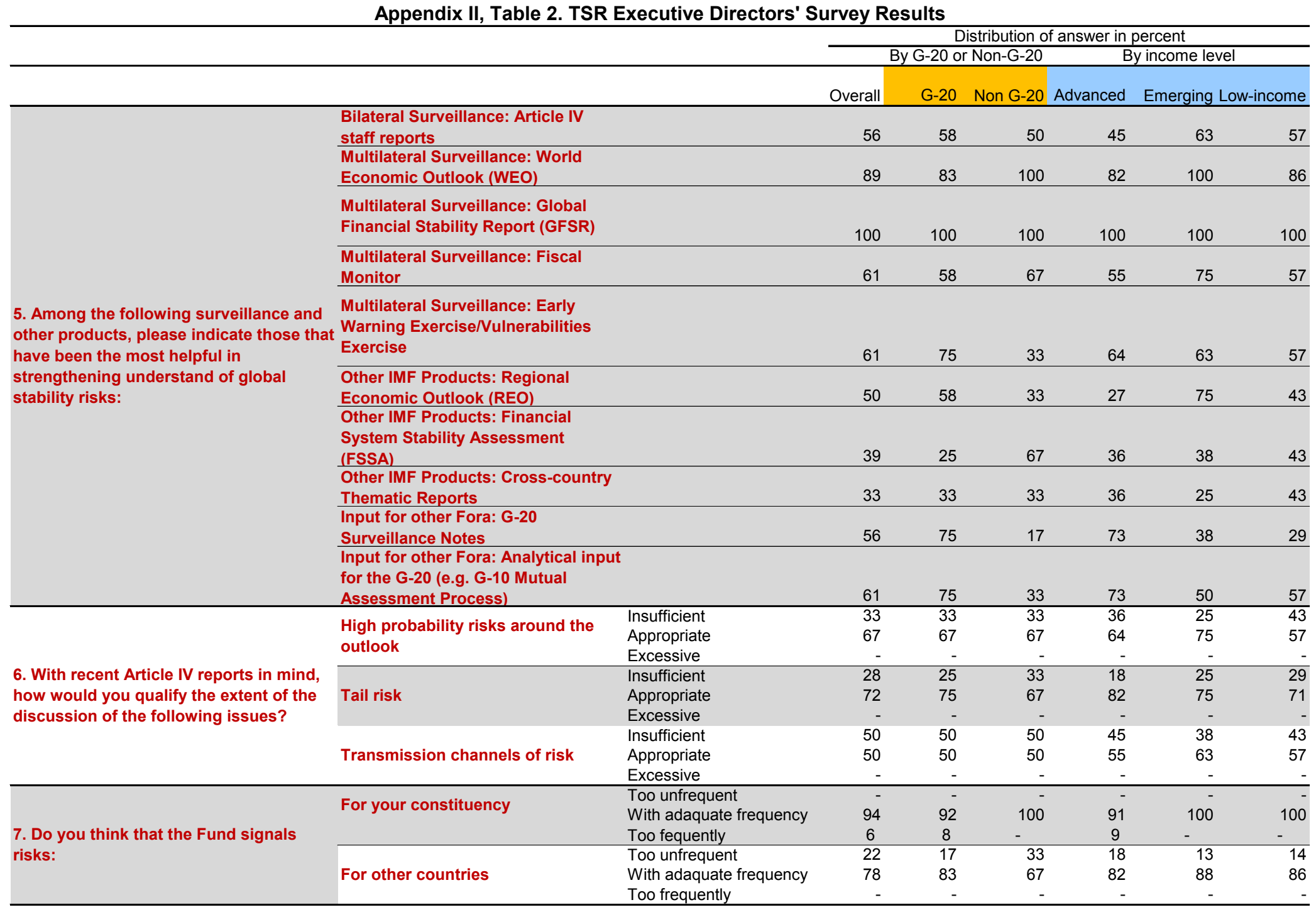


Appendix II, Table 2. TSR Executive Directors' Survey Results

\begin{tabular}{|c|c|c|c|c|c|c|c|c|}
\hline & & & \multicolumn{6}{|c|}{ Distribution of answer in percent } \\
\hline & & & \multicolumn{3}{|c|}{ By G-20 or Non-G-20 } & \multicolumn{3}{|c|}{ By income level } \\
\hline & & & Overall & $\mathrm{G}-20$ & Non G-20 & Advanced & Emerging $\mathrm{L}$ & Low-income \\
\hline \multirow{18}{*}{$\begin{array}{l}\text { 8. "Article IV staff reports appropriately } \\
\text { weight and incorporate various risks to } \\
\text { the medium/long-term outlook in the } \\
\text { bottom-line assessment:" }\end{array}$} & \multirow{5}{*}{ Overall } & Strongly Disagree & - & - & - & - & - & \\
\hline & & Disagree to Some Extent & 6 & - & 20 & 10 & - & \\
\hline & & Agree to Some Extent & 88 & 91 & 80 & 80 & 100 & 100 \\
\hline & & Strongly Agree & 6 & 9 & - & 10 & - & - \\
\hline & & Weighted average score & 3.67 & 3.79 & 3.40 & 3.67 & 3.67 & 3.67 \\
\hline & \multirow{5}{*}{ Advanced economies } & Strongly Disagree & - & - & - & - & - & \\
\hline & & Disagree to Some Extent & 35 & 36 & 33 & 20 & 38 & 14 \\
\hline & & Agree to Some Extent & 65 & 64 & 67 & 80 & 63 & 86 \\
\hline & & Strongly Agree & - & - & - & - & - & - \\
\hline & & Weighted average score & 3.20 & 3.18 & 3.22 & 3.40 & 3.17 & 3.48 \\
\hline & \multirow{5}{*}{ Emerging Markets } & Strongly Disagree & - & - & - & - & - & - \\
\hline & & Disagree to Some Extent & 18 & 9 & 33 & 30 & 13 & 29 \\
\hline & & Agree to Some Extent & 76 & 82 & 67 & 60 & 88 & 71 \\
\hline & & Strongly Agree & 6 & 9 & - & 10 & - & - \\
\hline & & Weighted average score & 3.51 & 3.67 & 3.22 & 3.40 & 3.50 & 3.29 \\
\hline & \multirow{3}{*}{ Low-income economies } & Strongly Disagree & - & - & - & - & - & \\
\hline & & Disagree to Some Extent & 6 & - & 17 & 10 & - & - \\
\hline & & Weighted average score & 3.82 & 3.79 & 3.89 & 3.80 & 3.83 & 4.05 \\
\hline \multirow{17}{*}{$\begin{array}{l}\text { 9. In the analysis of financial sector and } \\
\text { macro-financial issues, please indicate } \\
\text { whether Article IV reports discussed in } \\
\text { the past year have met your expectations } \\
\text { in describing how financial sector } \\
\text { developments could potentially impact } \\
\text { domestic or external stability: }\end{array}$} & \multirow{6}{*}{ Advanced economies } & In very few cases & - & - & - & - & - & \\
\hline & & In some cases & 17 & 8 & 33 & 27 & - & \\
\hline & & In many cases & 50 & 58 & 33 & 45 & 50 & 57 \\
\hline & & In most cases & 33 & 33 & 33 & 27 & 50 & 43 \\
\hline & & $\begin{array}{l}\text { Always } \\
\text { als }\end{array}$ & & & - & & 250 & \\
\hline & & $\begin{array}{l}\text { Weighted average score } \\
\text { In very few cases }\end{array}$ & $\begin{aligned} 3.17 \\
-\end{aligned}$ & $\begin{array}{r}3.25 \\
-\end{array}$ & $\begin{array}{r}3.00 \\
-\end{array}$ & $\begin{array}{r}3.00 \\
-\end{array}$ & $\begin{array}{r}3.50 \\
-\end{array}$ & $\frac{3.43}{-}$ \\
\hline & \multirow{5}{*}{ Emerging markets } & In some cases & 33 & 33 & 33 & 45 & 13 & 14 \\
\hline & & In many cases & 50 & 50 & 50 & 45 & 63 & 57 \\
\hline & & In most cases & 17 & 17 & 17 & 9 & 25 & 29 \\
\hline & & Always & - & 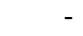 & - & - & - & - \\
\hline & & Weighted average score & 2.83 & 2.83 & 2.83 & 2.64 & 3.13 & 3.14 \\
\hline & \multirow{6}{*}{ Low-income countries } & In very few cases & 11 & 8 & 17 & 18 & - & - \\
\hline & & In some cases & 39 & 42 & 33 & 45 & 38 & 29 \\
\hline & & In many cases & 22 & 33 & - & 27 & 25 & 29 \\
\hline & & In most cases & 28 & 17 & 50 & 9 & 38 & 43 \\
\hline & & Always & - & - & - & - & - & - \\
\hline & & Weighted average score & 2.67 & 2.58 & 2.83 & 2.27 & 3.00 & 3.14 \\
\hline
\end{tabular}


Appendix II, Table 2. TSR Executive Directors' Survey Results

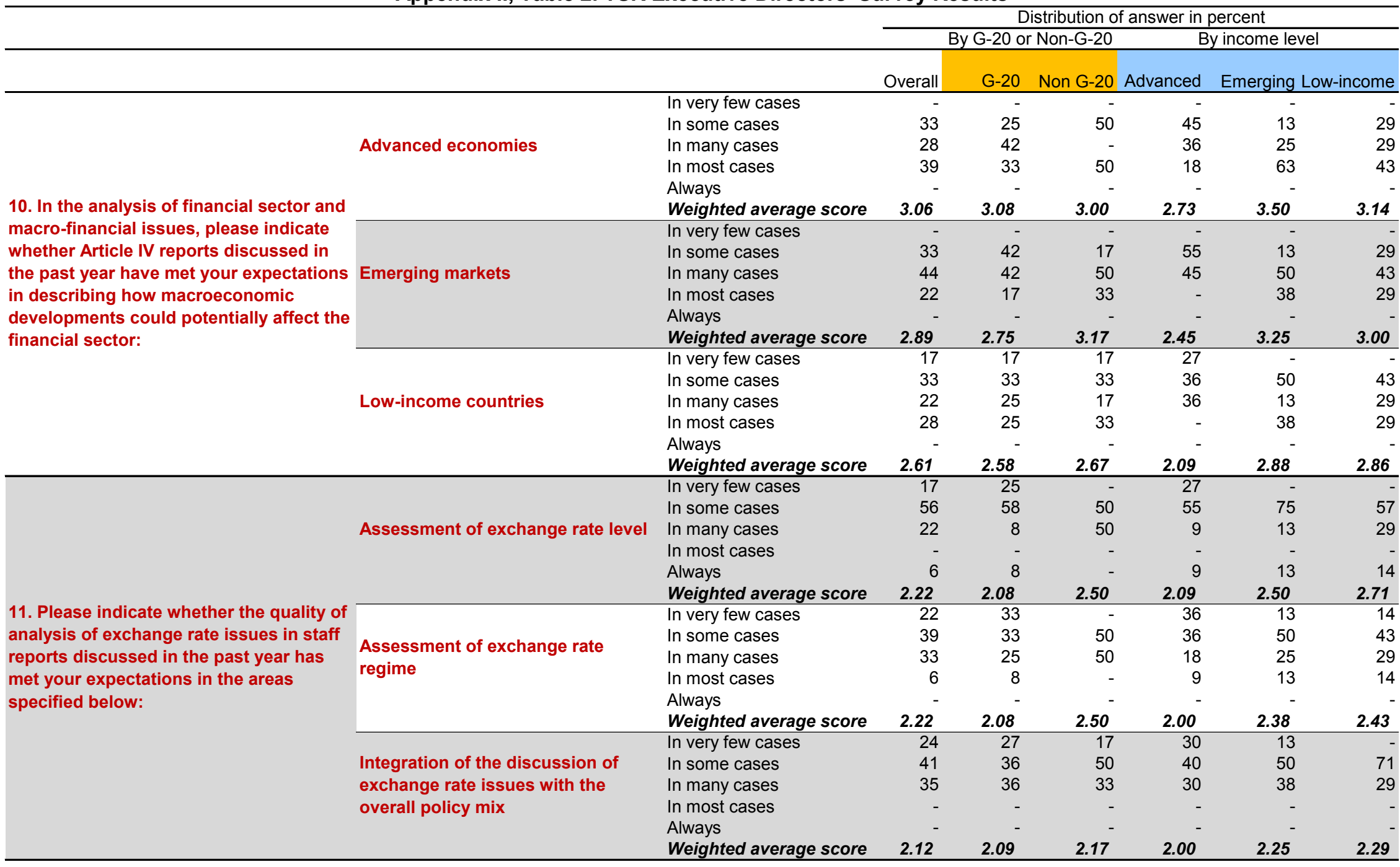


Appendix II, Table 2. TSR Executive Directors' Survey Results

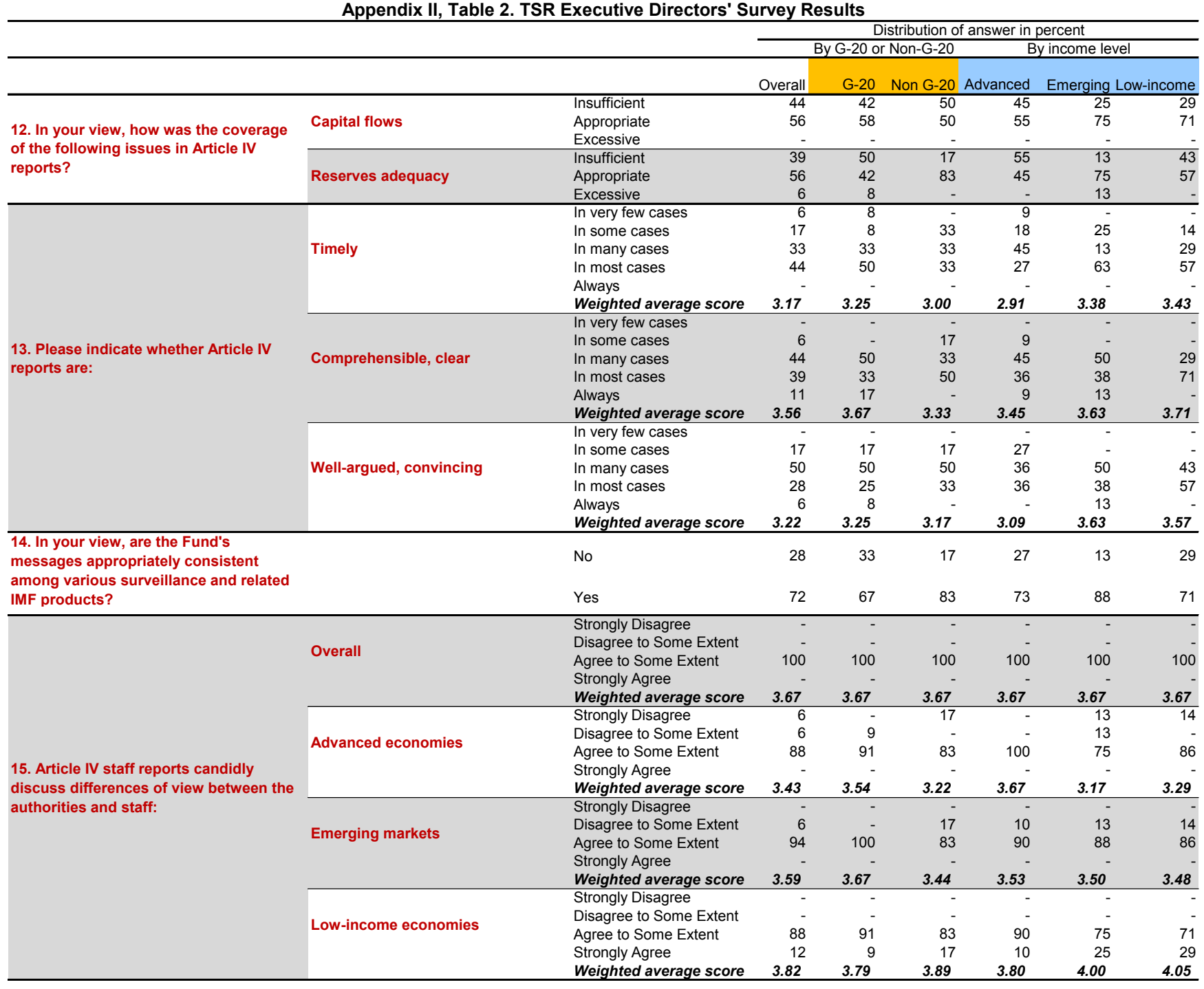




\section{Appendix II, Table 2. TSR Executive Directors' Survey Results}

\begin{tabular}{|c|c|c|c|c|c|c|c|c|}
\hline & & & \multicolumn{6}{|c|}{ Distribution of answer in percent } \\
\hline & & & \multicolumn{3}{|c|}{ By G-20 or Non-G-20 } & \multicolumn{3}{|c|}{ By income level } \\
\hline & & & Overall & $\mathrm{G}-20$ & Non G-20 & Advanced & Emerging L & come \\
\hline \multirow{6}{*}{\multicolumn{2}{|c|}{$\begin{array}{l}\text { 16. In your view, to what extent is the } \\
\text { policy advice in IMF Article IV staff } \\
\text { reports evenhanded across countries? }\end{array}$}} & Not at all & 6 & 8 & - & - & 13 & \\
\hline & & To a little extent & 17 & 8 & 33 & - & 25 & 29 \\
\hline & & To some extent & 44 & 42 & 50 & 45 & 38 & 43 \\
\hline & & To a great extent & 28 & 42 & - & 45 & 25 & 29 \\
\hline & & To a very great extent & 6 & - & 17 & 9 & - & - \\
\hline & & Weighted average score & 3.06 & 3.08 & 3.00 & 3.64 & 2.63 & 3.00 \\
\hline \multirow{12}{*}{$\begin{array}{l}\text { 17. To what extent did Fund policy advice } \\
\text { given in the context of recent Article IV } \\
\text { consultations in your constituency help: }\end{array}$} & \multirow{6}{*}{ Generate policy debate } & Not at all & 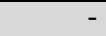 & - & - & - & - & \\
\hline & & To a little extent & 17 & 8 & 33 & 18 & - & 14 \\
\hline & & To some extent & 61 & 75 & 33 & 55 & 63 & 29 \\
\hline & & To a great extent & 22 & 17 & 33 & 27 & 38 & 57 \\
\hline & & To a very great extent & - & - & - & - & - & - \\
\hline & & Weighted average score & 3.06 & 3.08 & 3.00 & 3.09 & 3.38 & 3.43 \\
\hline & \multirow{6}{*}{ Foster appropriate policy change } & Not at all & - & - & - & - & - & - \\
\hline & & To a little extent & 28 & 33 & 17 & 45 & - & - \\
\hline & & To some extent & 56 & 58 & 50 & 36 & 63 & 57 \\
\hline & & To a great extent & 11 & 8 & 17 & 9 & 25 & 29 \\
\hline & & To a very great extent & 6 & - & 17 & 9 & 13 & 14 \\
\hline & & Weighted average score & 2.94 & 2.75 & 3.33 & 2.82 & 3.50 & 3.57 \\
\hline
\end{tabular}


Appendix II, Table 3. TSR Mission Chiefs' Survey Results

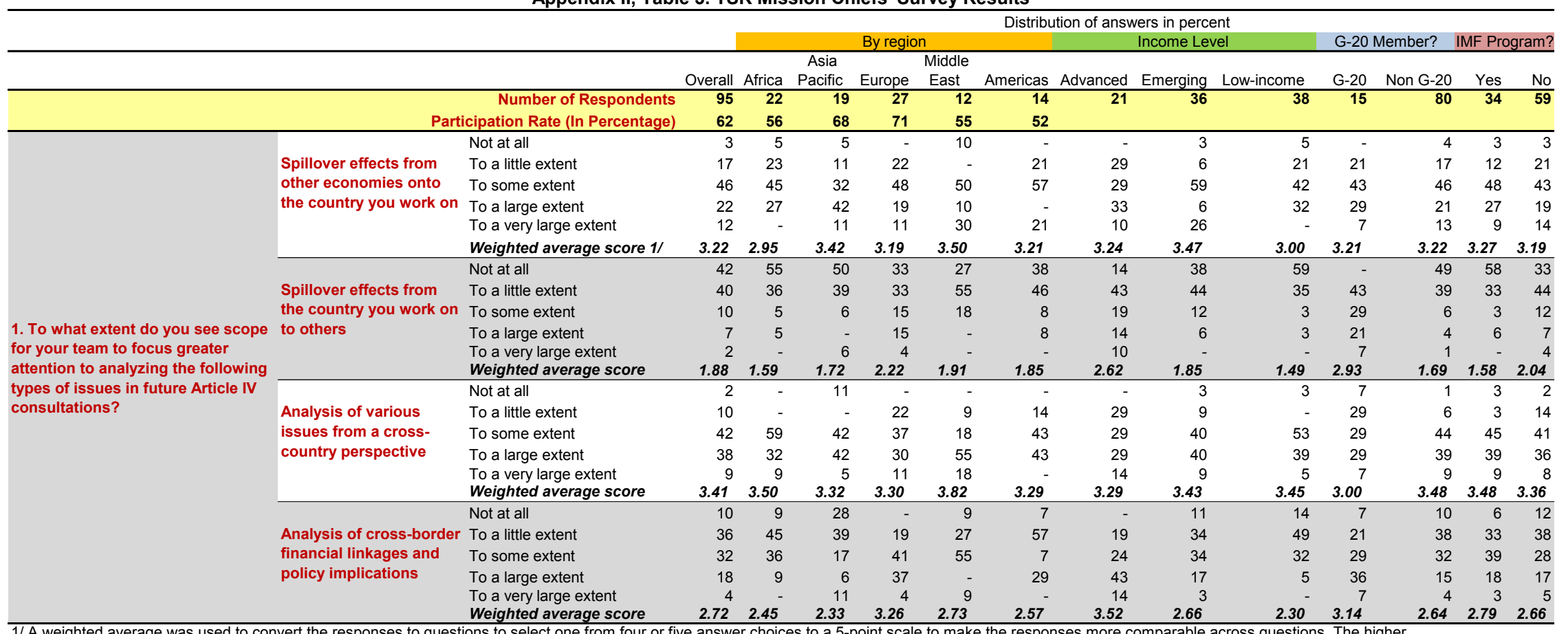

the score, the more positive the response was.
the 
Appendix II, Table 3. TSR Mission Chiefs' Survey Results

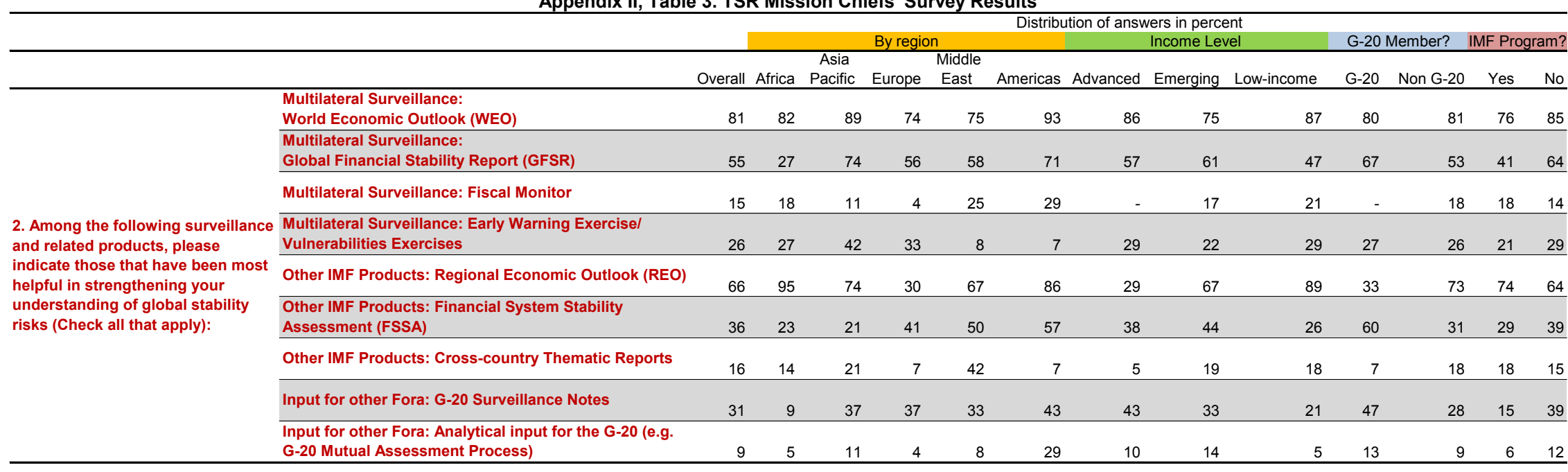




\section{Appendix II, Table 3. TSR Mission Chiefs' Survey Results}

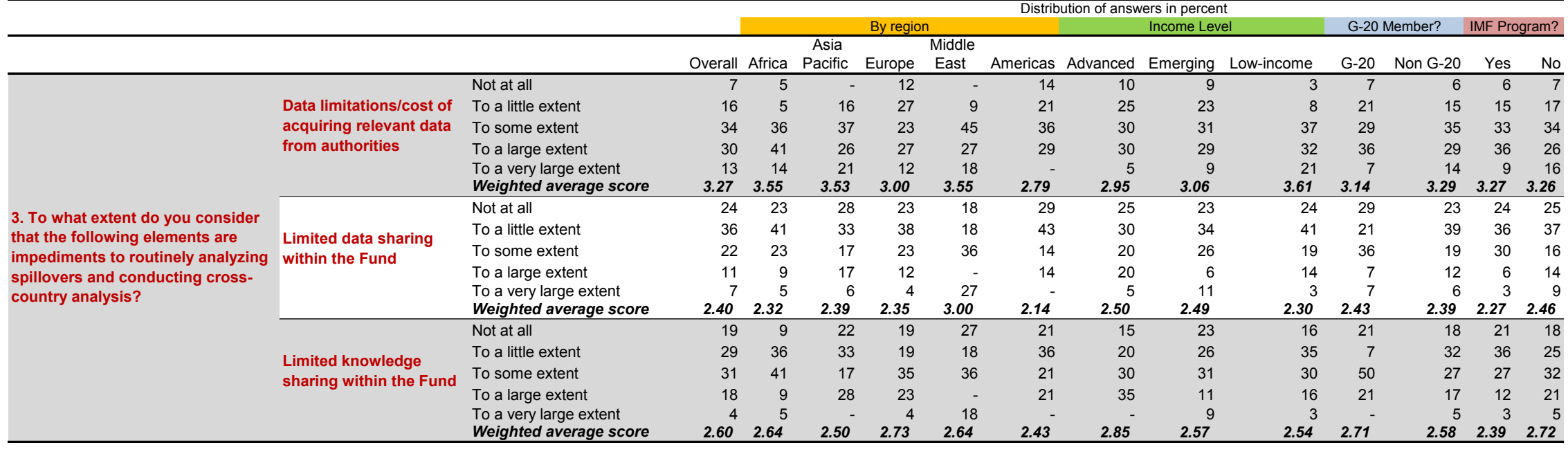


Appendix II, Table 3. TSR Mission Chiefs' Survey Results

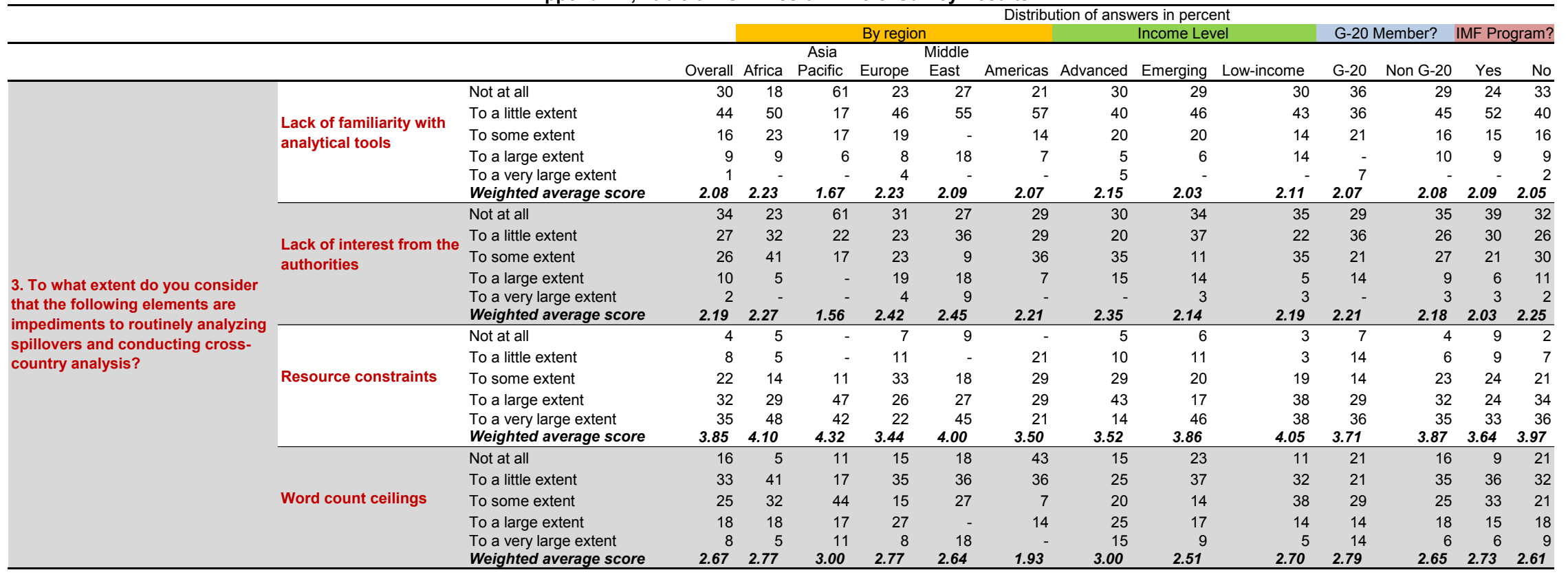




\section{Appendix II, Table 3. TSR Mission Chiefs' Survey Results}

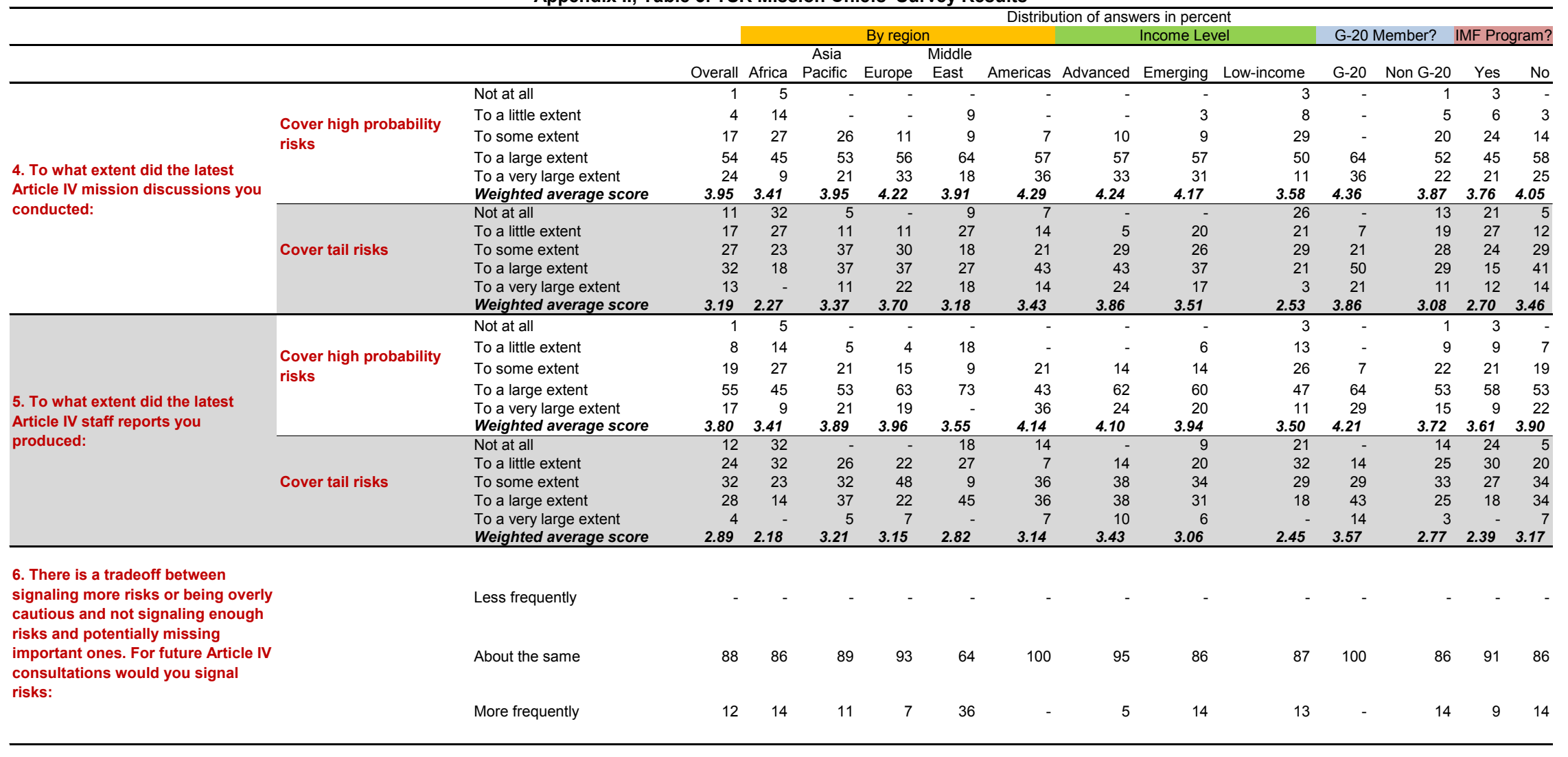


Appendix II, Table 3. TSR Mission Chiefs' Survey Results

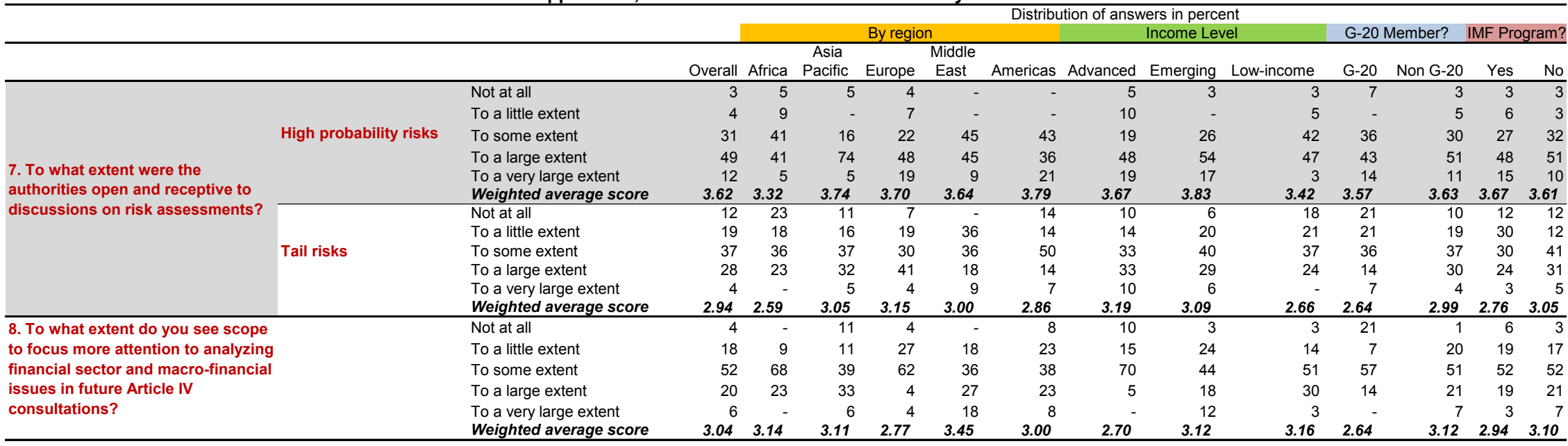


Appendix II, Table 3. TSR Mission Chiefs' Survey Results

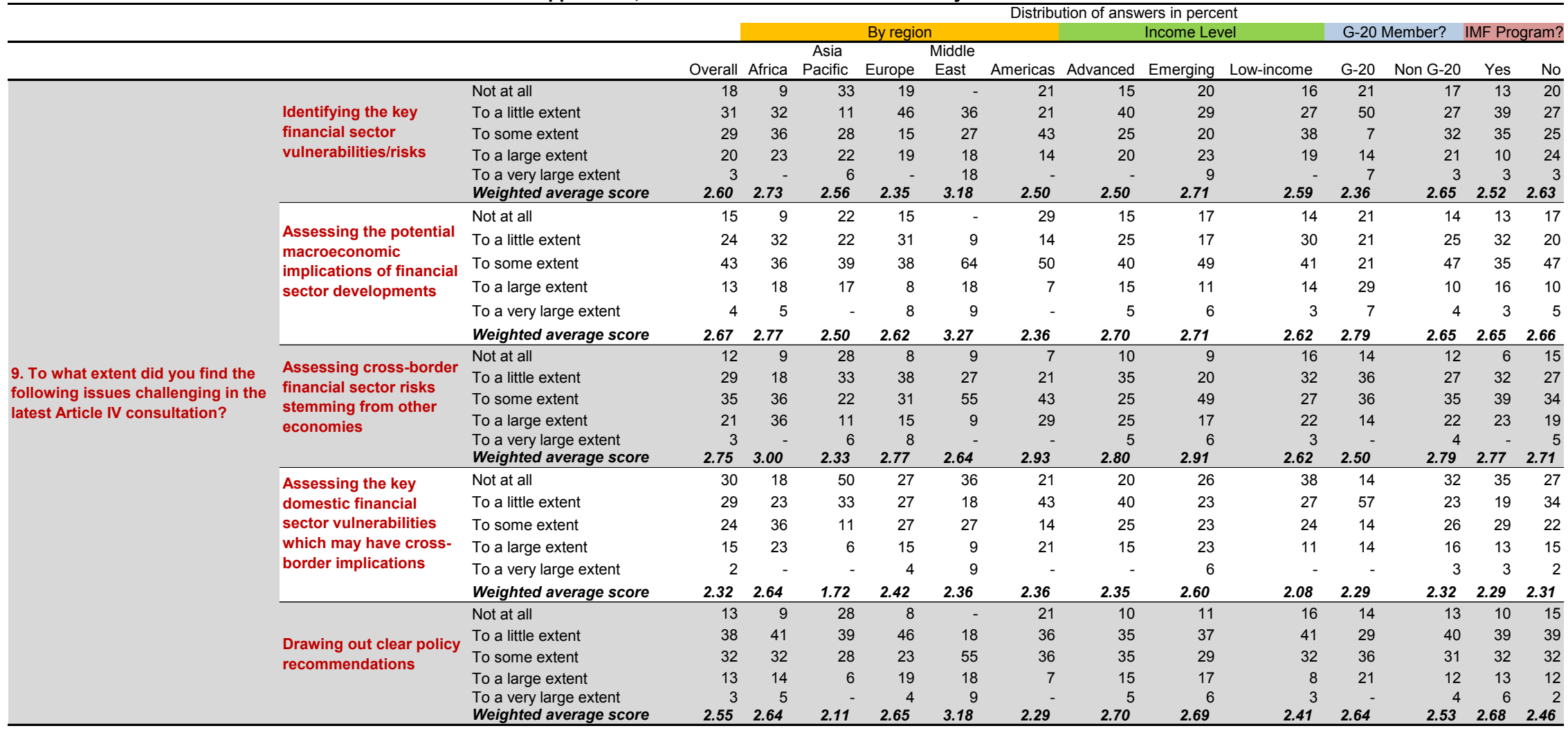


Appendix II, Table 3. TSR Mission Chiefs' Survey Results

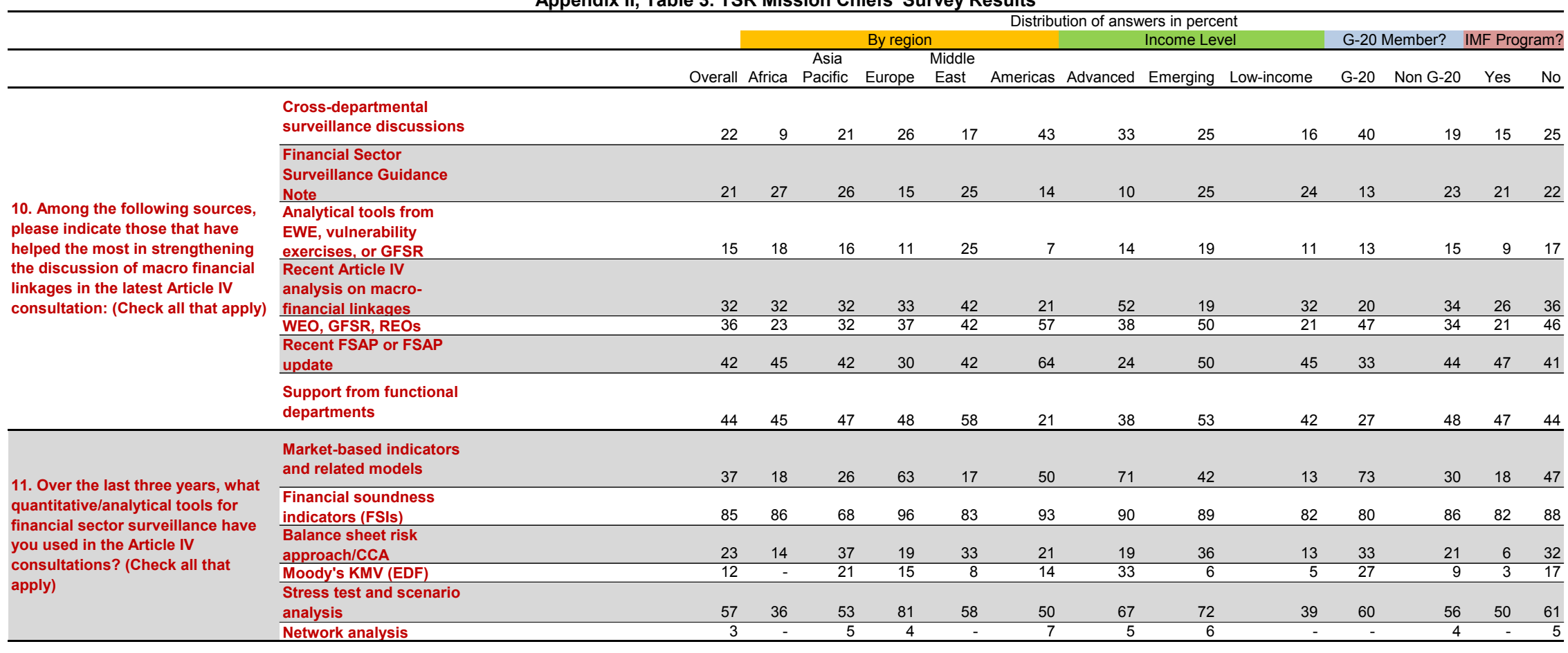


Appendix II, Table 3. TSR Mission Chiefs' Survey Results

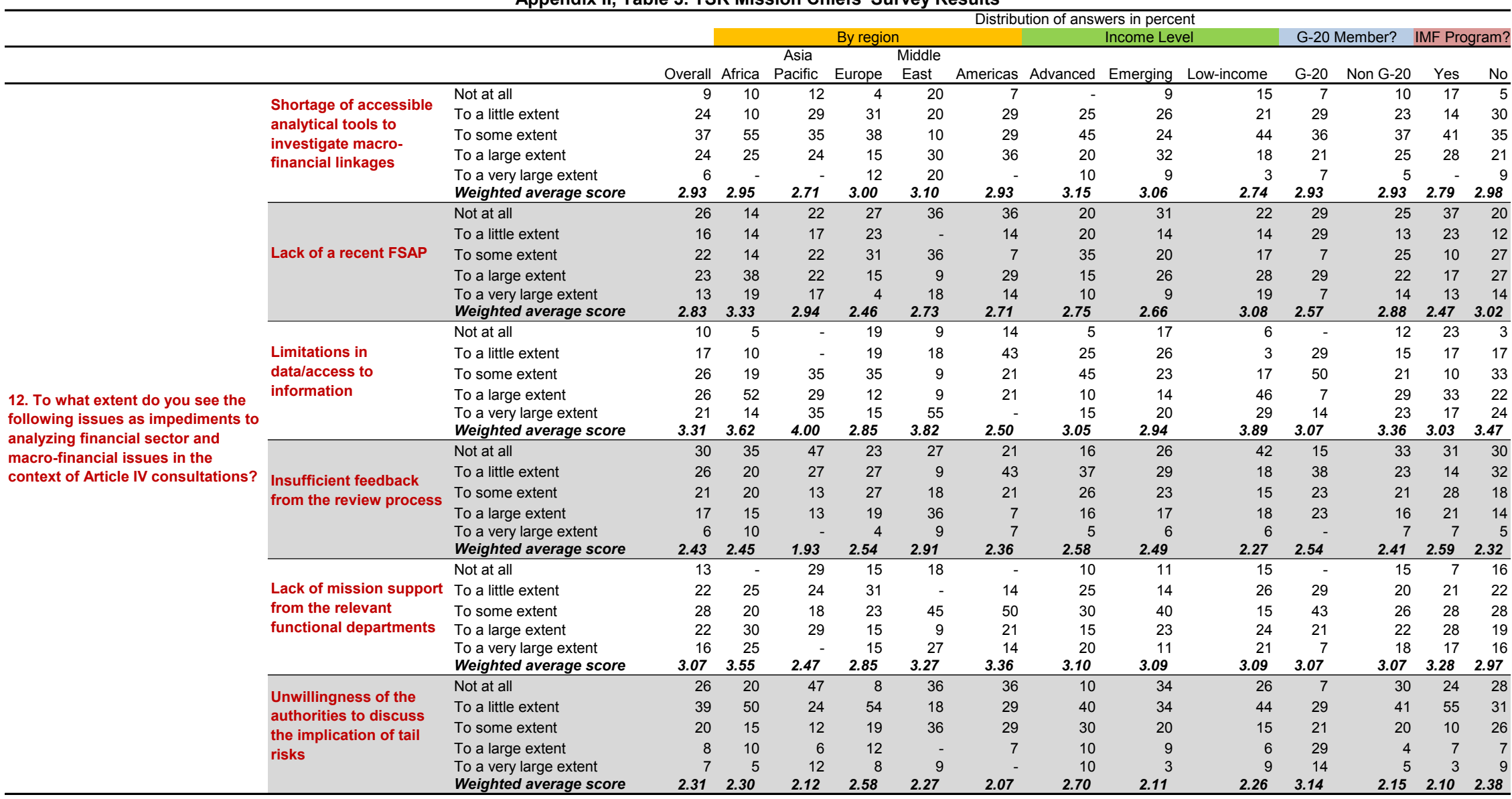


Appendix II, Table 3. TSR Mission Chiefs' Survey Results

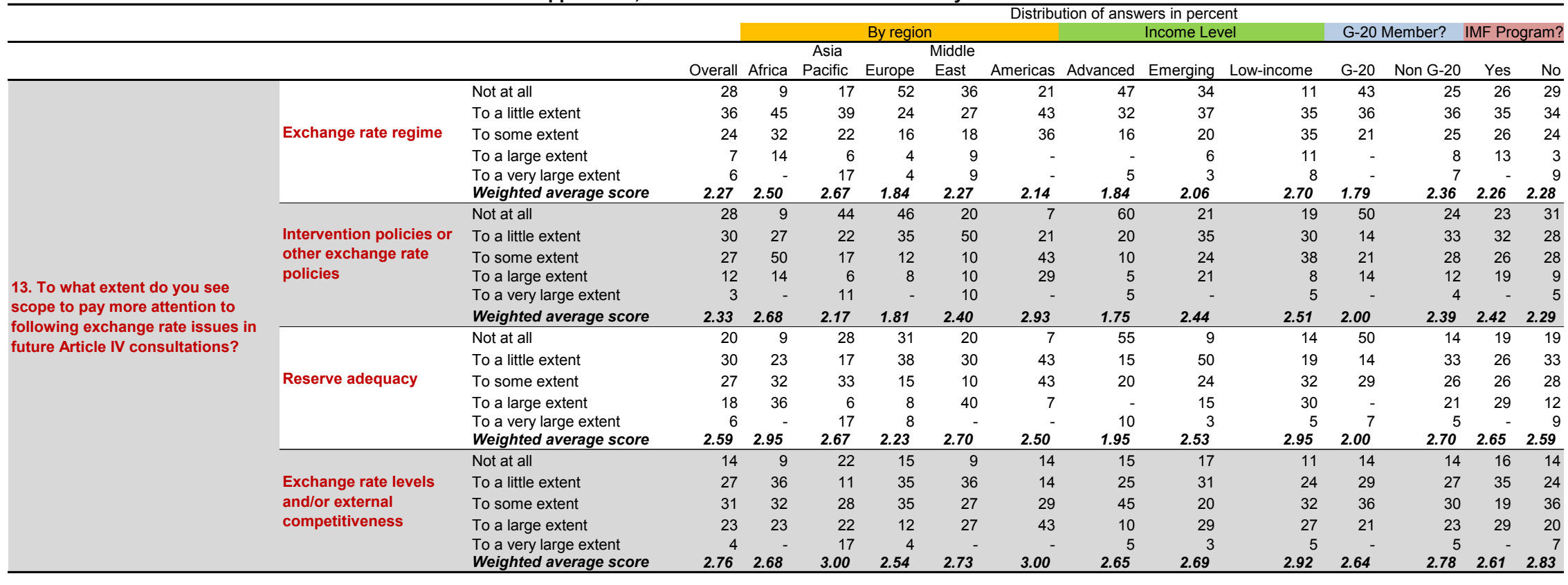


Appendix II, Table 3. TSR Mission Chiefs' Survey Results

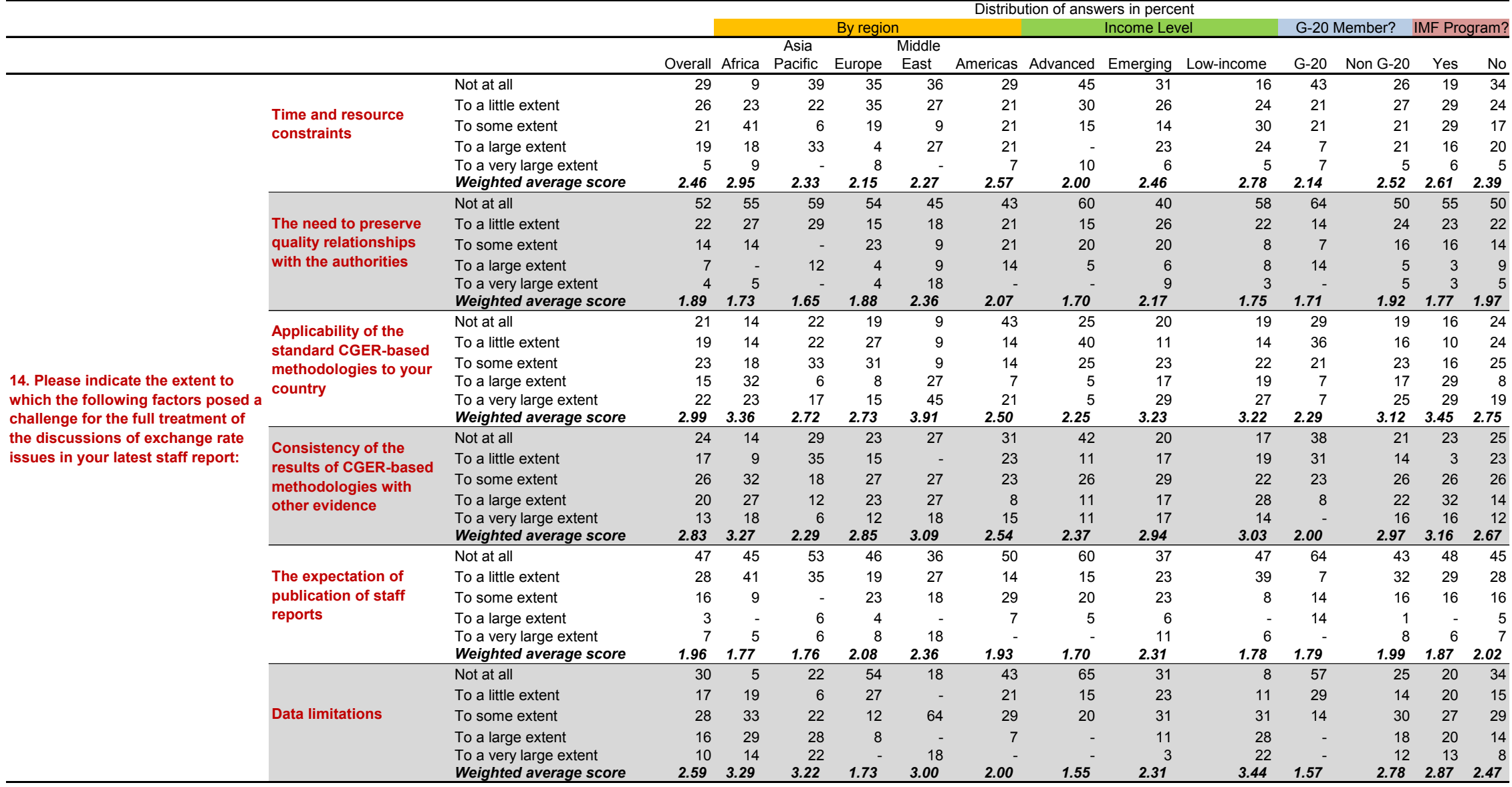


Appendix II, Table 3. TSR Mission Chiefs' Survey Results

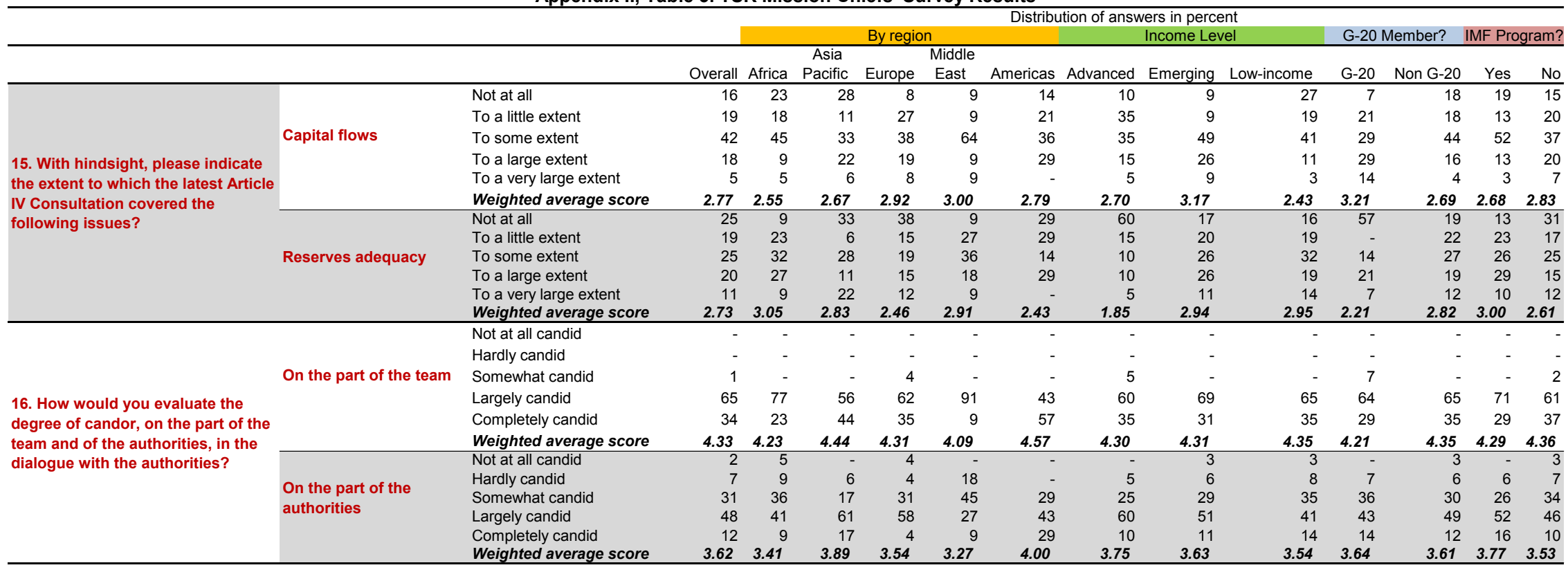


Appendix II, Table 3. TSR Mission Chiefs' Survey Results

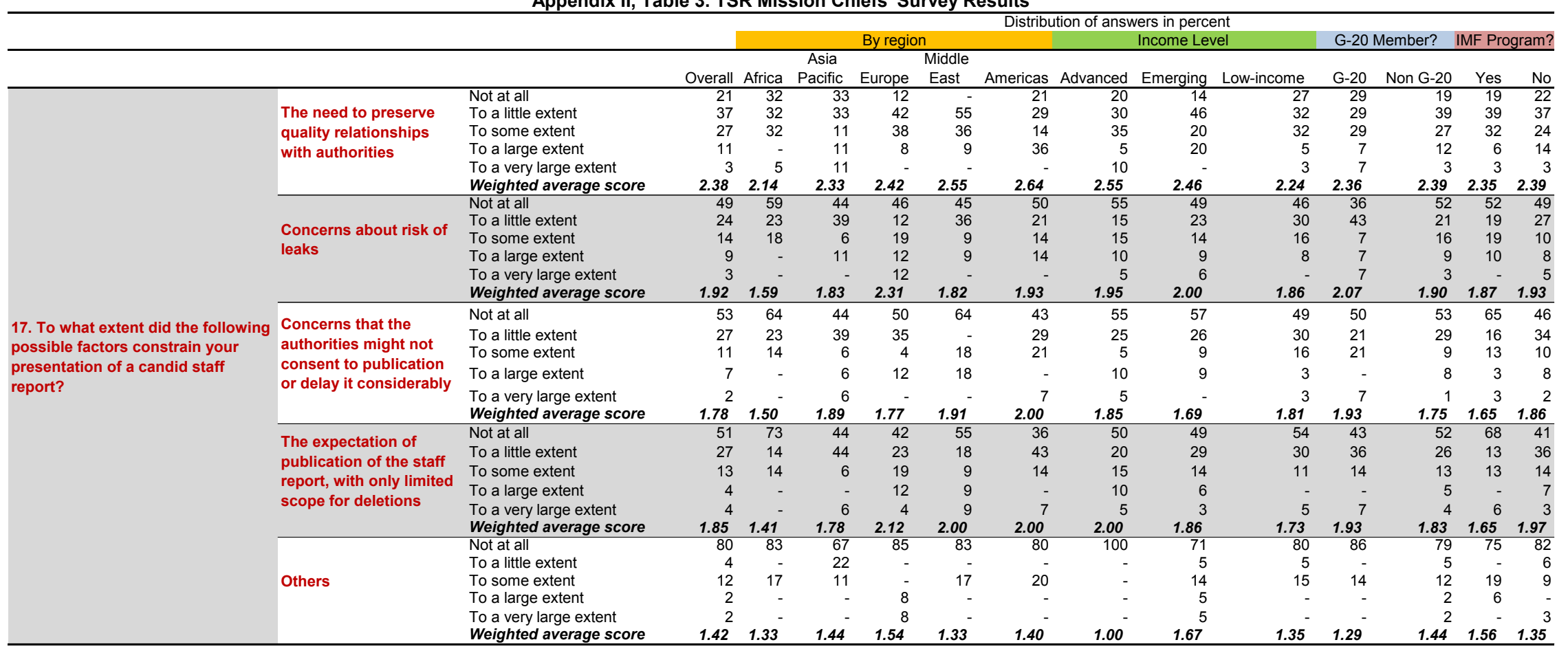


Appendix II, Table 3. TSR Mission Chiefs' Survey Results

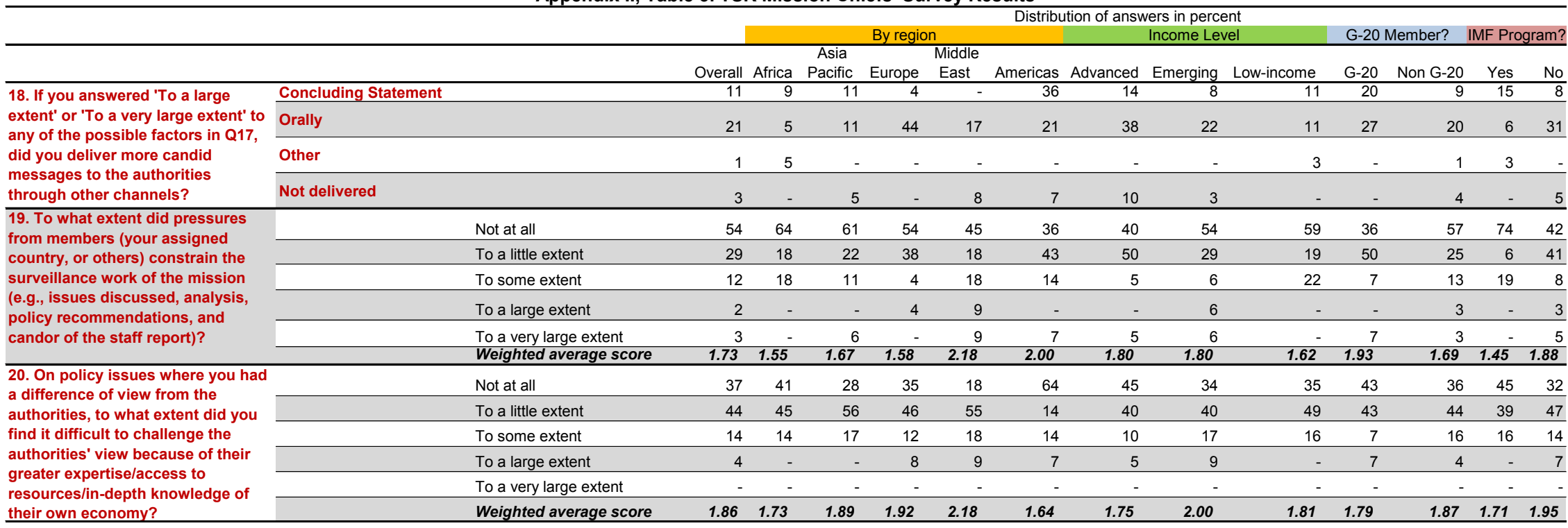


Appendix II, Table 3. TSR Mission Chiefs' Survey Results

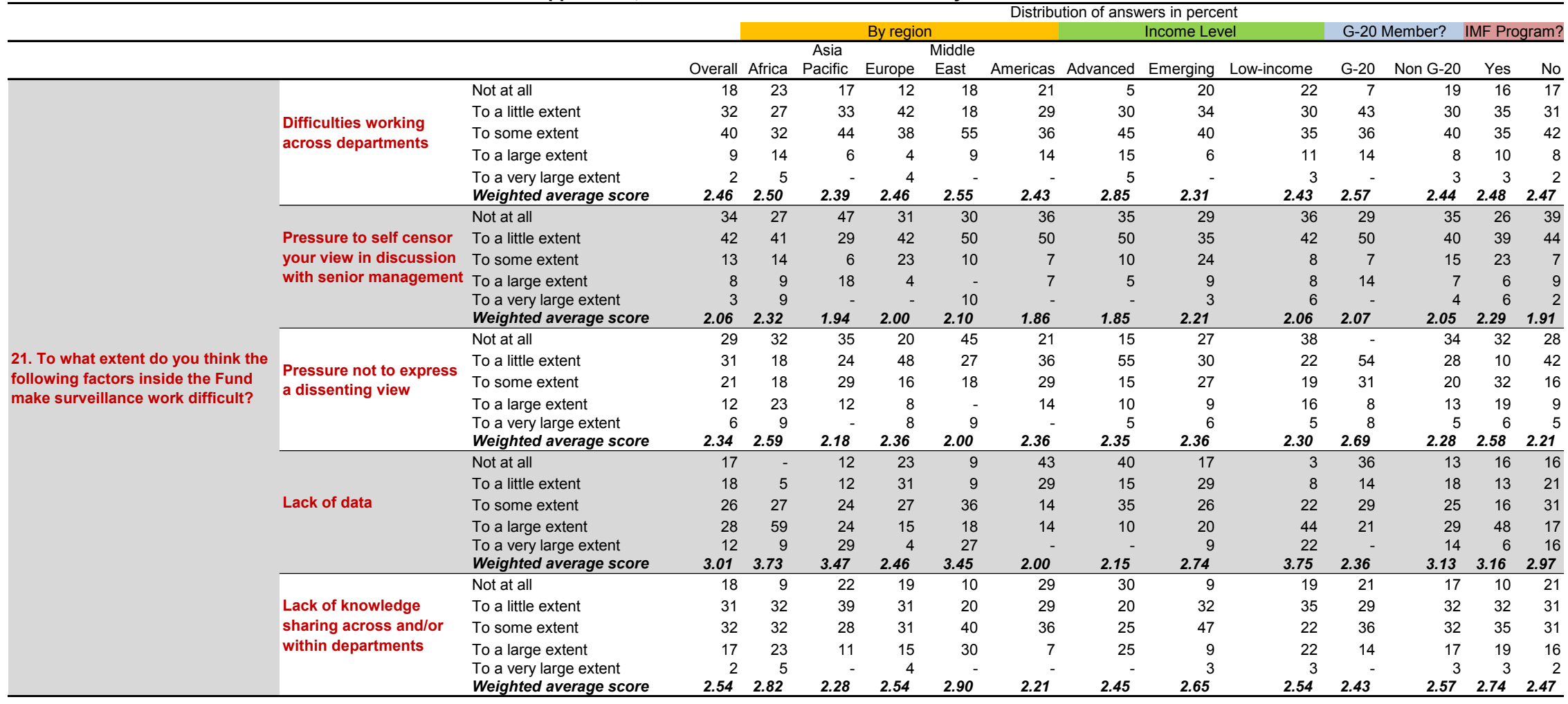


Appendix II, Table 3. TSR Mission Chiefs' Survey Results

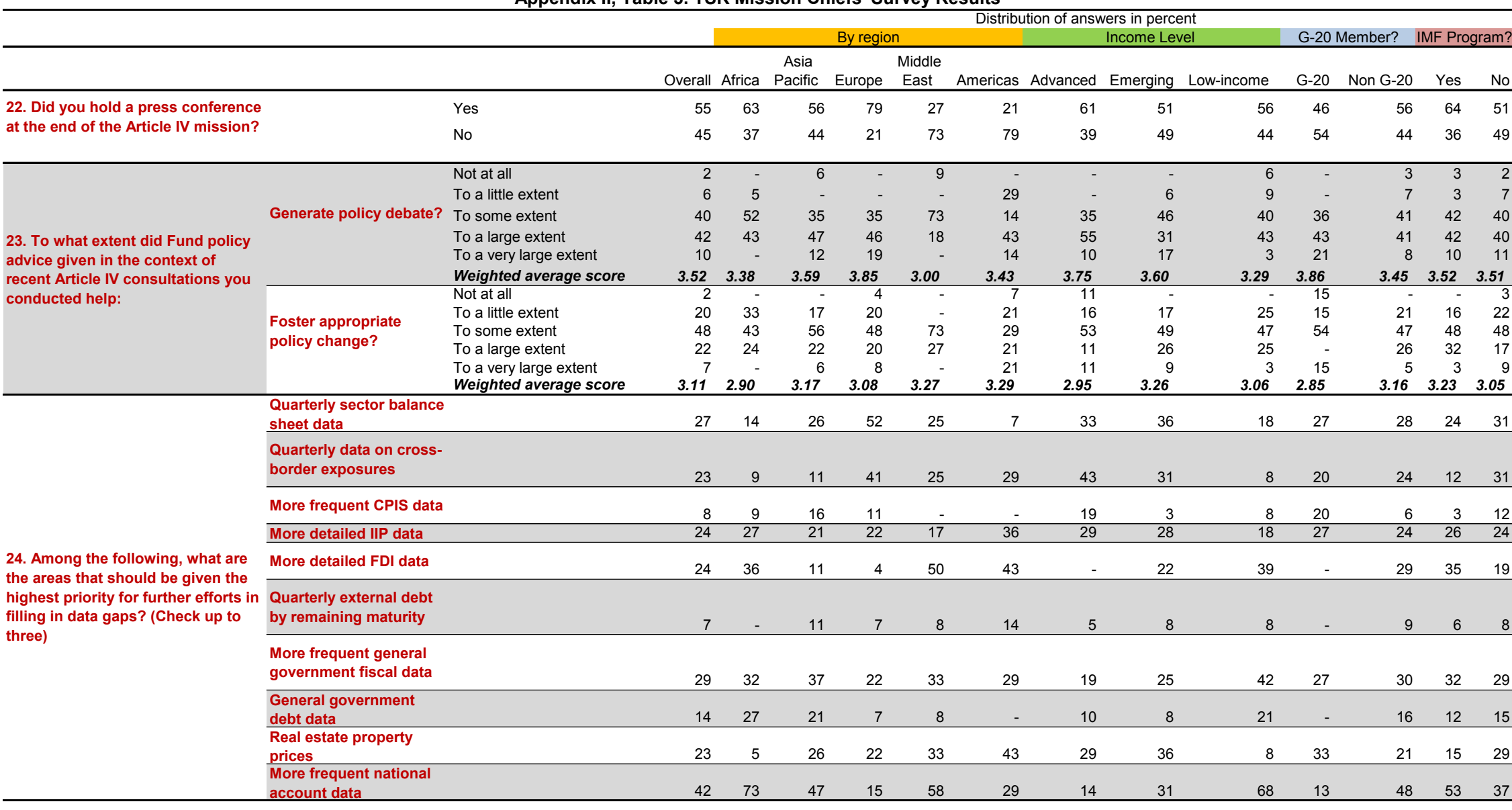


Appendix II, Table 4. TSR Financial Markets Survey Results

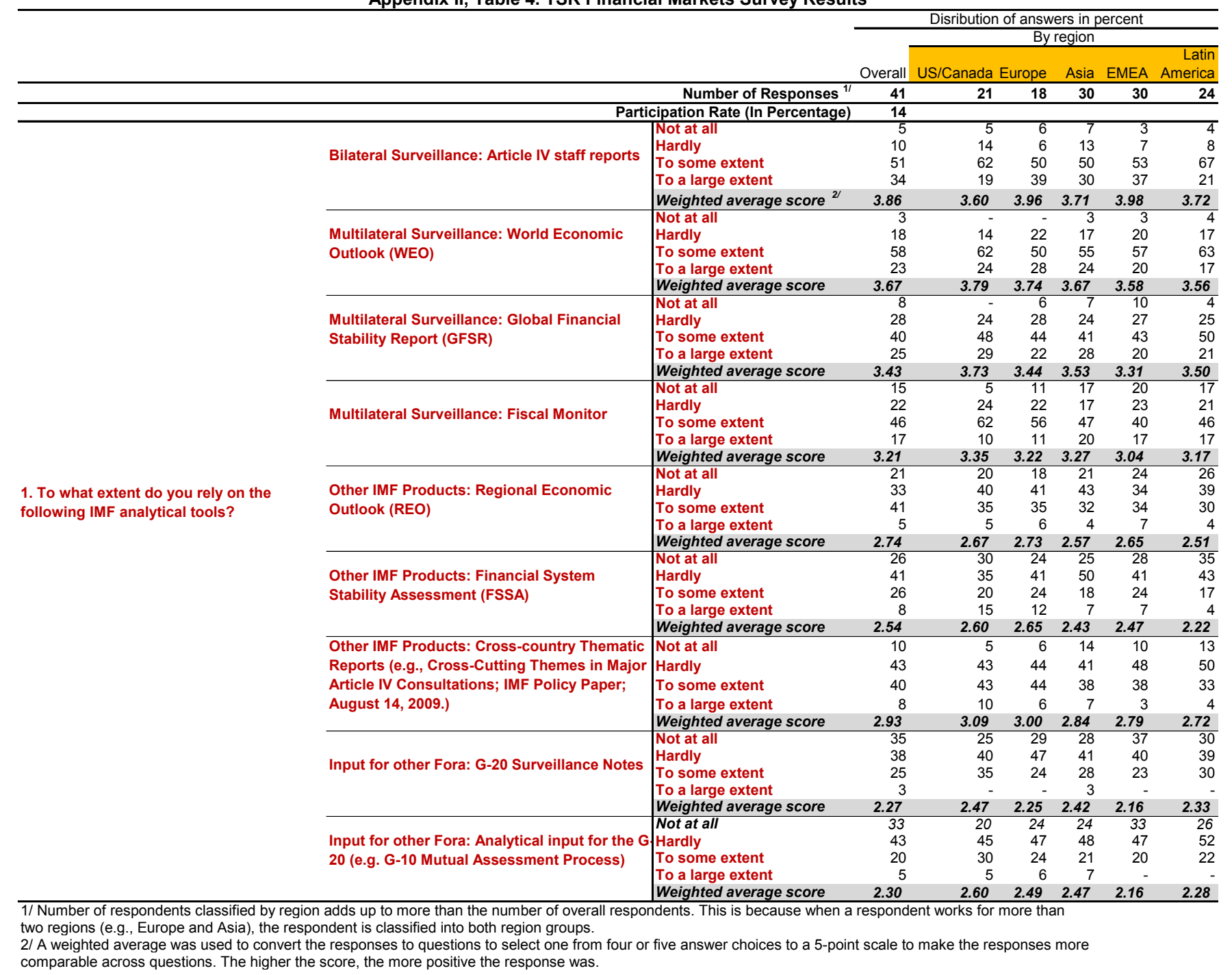




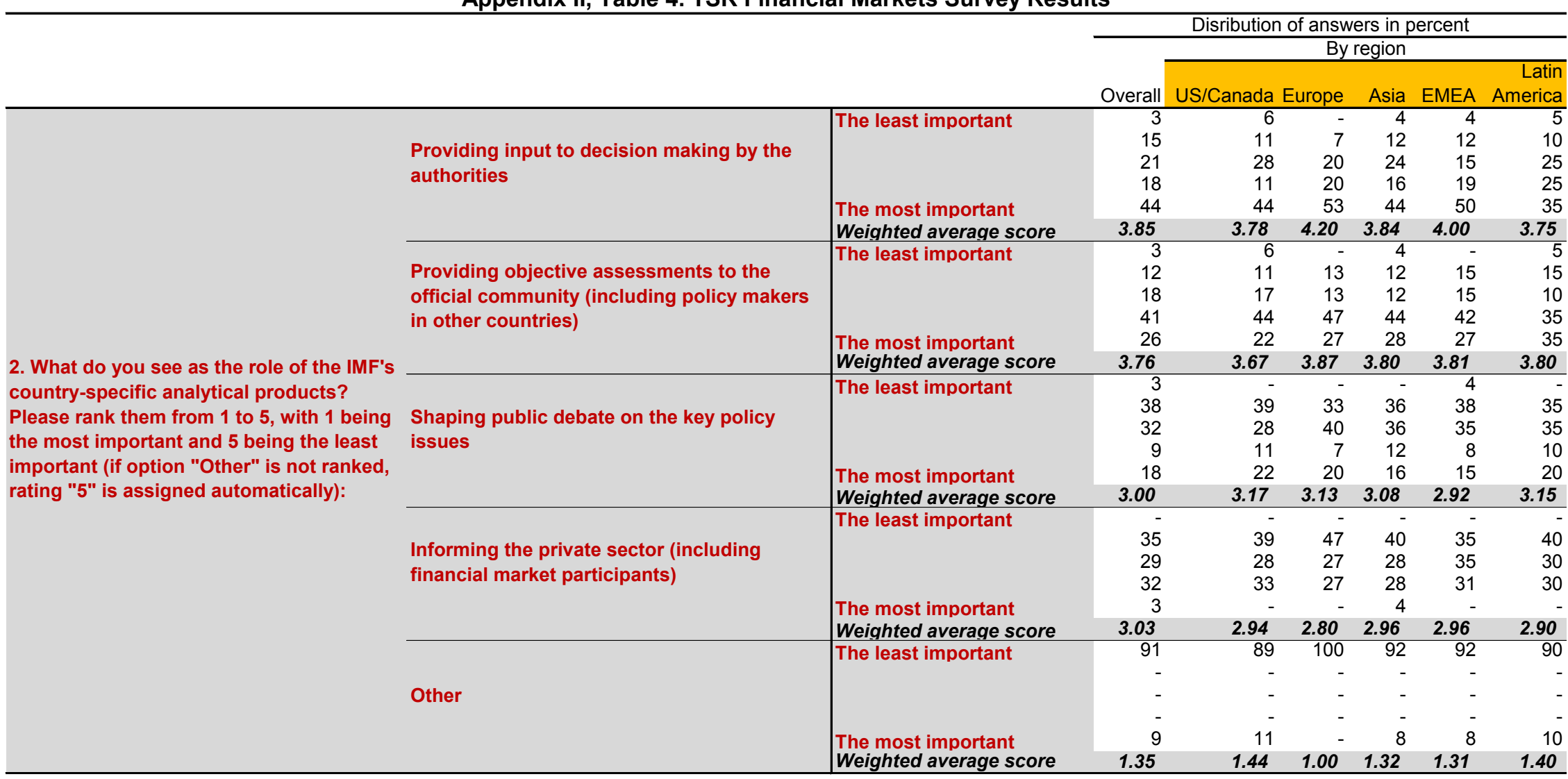




\begin{tabular}{|c|c|c|c|c|c|c|c|c|}
\hline \multicolumn{9}{|c|}{ Disribution of answers in percent } \\
\hline & & & \multirow[b]{2}{*}{ Overall } & \multicolumn{5}{|c|}{ By region } \\
\hline & & & & US/Canada & Europe & Asia & EMEA & America \\
\hline \multirow{28}{*}{$\begin{array}{l}\text { 3. What features of IMF country reports } \\
\text { (Art. IV consultations) do you consider as } \\
\text { their main strengths/weaknesses? Please } \\
\text { mark each feature as either a strength or a } \\
\text { weakness: }\end{array}$} & \multirow[b]{2}{*}{ Timeliness } & Weakness & 67 & 71 & 73 & 64 & 65 & 70 \\
\hline & & Neither & 27 & 24 & 27 & 32 & 27 & $\begin{array}{r}25 \\
5\end{array}$ \\
\hline & \multirow{3}{*}{ Candor } & Weakness & 24 & 35 & 40 & 24 & 27 & 30 \\
\hline & & Neither & 30 & 29 & 33 & 28 & 27 & 35 \\
\hline & & Strength & 45 & 35 & 27 & 48 & 46 & 35 \\
\hline & \multirow{2}{*}{ Evenhandedness } & $\begin{array}{l}\text { Weakness } \\
\text { Neither }\end{array}$ & $\begin{array}{l}16 \\
38\end{array}$ & $\begin{array}{l}19 \\
38\end{array}$ & $\begin{array}{l}21 \\
36\end{array}$ & $\begin{array}{l}17 \\
33\end{array}$ & $\begin{array}{l}20 \\
32\end{array}$ & $\begin{array}{l}21 \\
21\end{array}$ \\
\hline & & Strength & 47 & 44 & 43 & 50 & 48 & 58 \\
\hline & Comprehensiveness & $\begin{array}{l}\text { Weakness } \\
\text { Neither } \\
\text { Strength }\end{array}$ & $\begin{array}{r}- \\
6 \\
94\end{array}$ & $\begin{array}{r}- \\
6 \\
94\end{array}$ & $\begin{aligned}- \\
100\end{aligned}$ & $\begin{array}{r}- \\
8 \\
92\end{array}$ & $\begin{array}{r}- \\
8 \\
92\end{array}$ & $\begin{array}{l}10 \\
90\end{array}$ \\
\hline & \multirow{3}{*}{ Analytical depth } & Weakness & - & - & - & - & - & \\
\hline & & Neither & 9 & $\overline{-}^{-}$ & 7 & 8 & 12 & $\begin{array}{r}5 \\
95\end{array}$ \\
\hline & & Strength & 91 & 100 & 93 & 92 & 88 & $\frac{95}{6}$ \\
\hline & \multirow[t]{2}{*}{ Policy orientation } & $\begin{array}{l}\text { Weakness } \\
\text { Neither }\end{array}$ & $\begin{array}{r}3 \\
19\end{array}$ & 20 & 15 & $\begin{array}{r}4 \\
13\end{array}$ & $\begin{array}{r}4 \\
16\end{array}$ & $\begin{array}{r}6 \\
11\end{array}$ \\
\hline & & Strength & 77 & 80 & 85 & 83 & 80 & 83 \\
\hline & \multirow{3}{*}{ Objectivity } & Weakness & 6 & 6 & 7 & 8 & 4 & 10 \\
\hline & & Neither & 21 & 18 & 20 & 24 & 15 & 10 \\
\hline & & Strength & 73 & 76 & 73 & 68 & 81 & 80 \\
\hline & \multirow[b]{2}{*}{ Innovative techniques } & Weakness & 6 & & & 8 & 8 & $\begin{array}{l}10 \\
70\end{array}$ \\
\hline & & $\begin{array}{l}\text { Neither } \\
\text { Strength }\end{array}$ & $\begin{array}{l}79 \\
15\end{array}$ & $\begin{array}{l}82 \\
18\end{array}$ & $\begin{array}{r}93 \\
7\end{array}$ & $\begin{array}{l}72 \\
20\end{array}$ & $\begin{array}{l}81 \\
12\end{array}$ & $\begin{array}{l}70 \\
20\end{array}$ \\
\hline & \multirow{3}{*}{ New insights } & Weakness & 9 & 12 & 13 & 12 & 8 & 15 \\
\hline & & Neither & 55 & 41 & 53 & 52 & 58 & 55 \\
\hline & & Strength & 36 & 47 & 33 & 36 & 35 & 30 \\
\hline & \multirow{3}{*}{ Reflect access to privileged information } & Weakness & 6 & 6 & 7 & 8 & 4 & 10 \\
\hline & & Neither & 44 & 56 & 57 & 50 & 42 & 50 \\
\hline & & Strength & 50 & 38 & 36 & 42 & 54 & 40 \\
\hline & \multirow{2}{*}{$\begin{array}{l}\text { Presents authorities' views in addition to } \\
\text { views of IMF staff }\end{array}$} & $\begin{array}{l}\text { Weakness } \\
\text { Neither }\end{array}$ & 42 & 35 & 40 & 44 & 38 & 45 \\
\hline & & Strength & 58 & 65 & 60 & 56 & 62 & 55 \\
\hline & \multirow[t]{2}{*}{ Other } & $\begin{array}{l}\text { Weakness } \\
\text { Neither }\end{array}$ & 100 & 100 & 100 & 100 & 100 & 100 \\
\hline & & Strength & 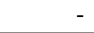 & - & - & - & - & \\
\hline \multirow{7}{*}{$\begin{array}{l}\text { 4. With recent Article IV reports in mind, } \\
\text { how would you qualify the extent of the } \\
\text { discussion of the following issues? }\end{array}$} & \multirow{2}{*}{ High probability risks around the outlook } & Insufficient & 3 & 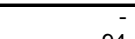 & 7 & $=-$ & 4 & \\
\hline & & Appropriate & $\begin{array}{r}91 \\
6\end{array}$ & $\begin{array}{r}94 \\
6\end{array}$ & 93 & $\begin{array}{r}96 \\
4\end{array}$ & 92 & $\begin{array}{r}95 \\
5\end{array}$ \\
\hline & \multirow{3}{*}{ Tail risk } & Insufficient & 25 & 19 & 20 & 17 & 20 & 16 \\
\hline & & Appropriate & 75 & 81 & 80 & 83 & 80 & 84 \\
\hline & & Excessive & 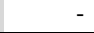 & & - & & & \\
\hline & \multirow{2}{*}{ Transmission channels of risk } & Insufficient & 31 & 38 & 33 & 29 & 24 & 26 \\
\hline & & $\begin{array}{l}\text { Appropriate } \\
\text { Excessive }\end{array}$ & 69 & 63 & 67 & 71 & 76 & 74 \\
\hline
\end{tabular}




\section{Appendix II, Table 4. TSR Financial Markets Survey Results}

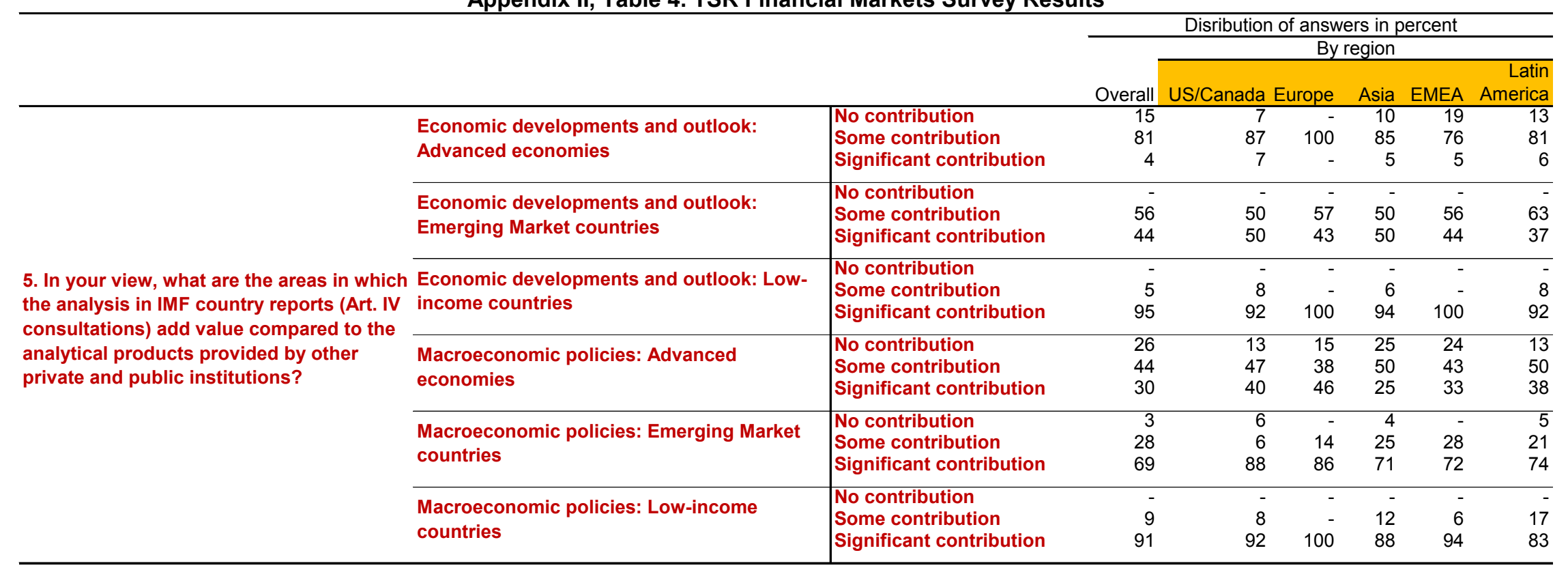




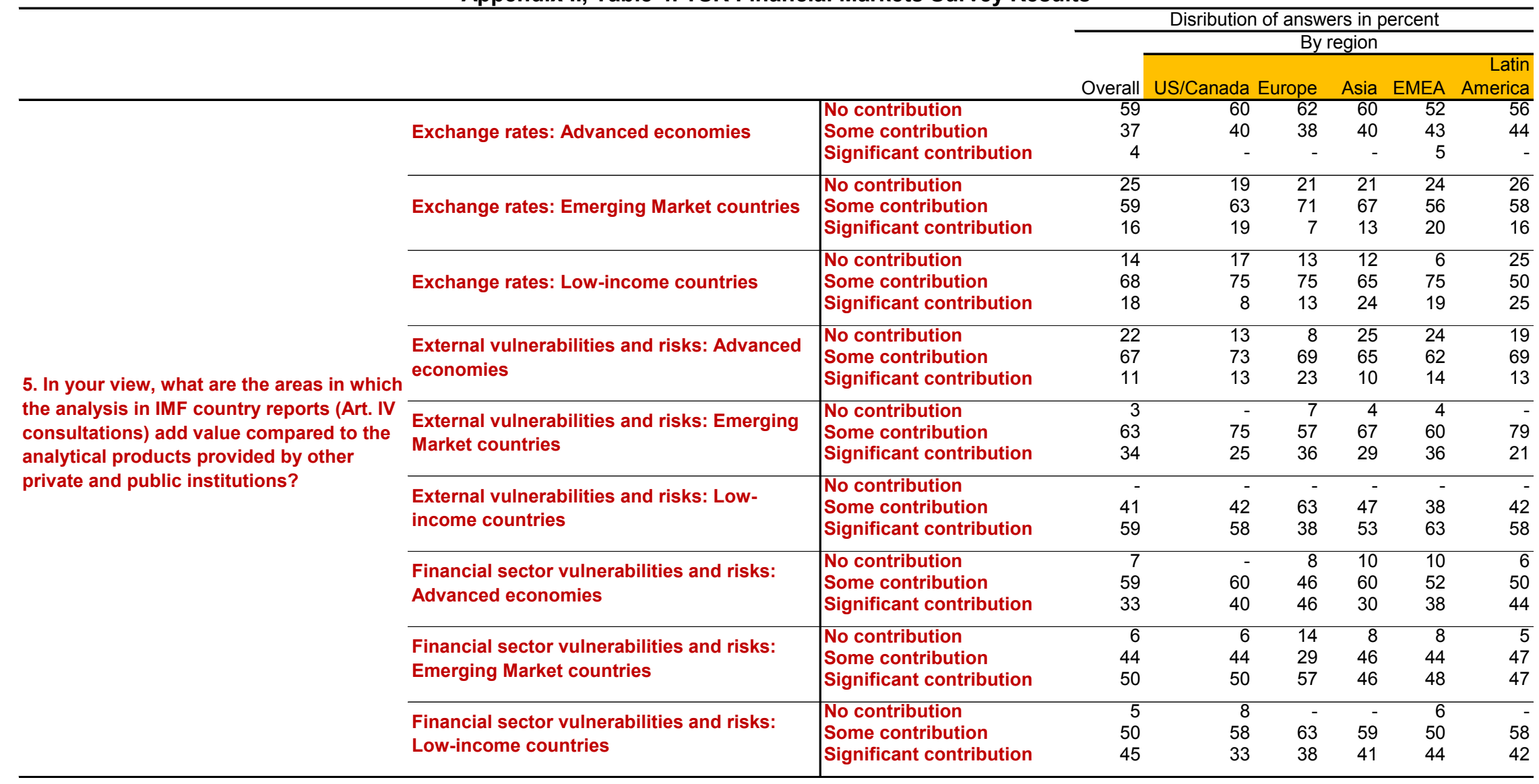


Appendix II, Table 4. TSR Financial Markets Survey Results

\begin{tabular}{|c|c|c|c|c|c|c|c|c|}
\hline \multicolumn{9}{|c|}{ Disribution of answers in percent } \\
\hline & & & \multirow[b]{2}{*}{ Overall } & \multicolumn{5}{|c|}{ By region } \\
\hline & & & & US/Canada & Europe & Asia & EMEA & $\begin{array}{r}\text { Latin } \\
\text { America } \\
\end{array}$ \\
\hline \multirow{10}{*}{$\begin{array}{l}\text { 5. In your view, what are the areas in which } \\
\text { the analysis in IMF country reports (Art. IV } \\
\text { consultations) add value compared to the } \\
\text { analytical products provided by other } \\
\text { private and public institutions? }\end{array}$} & \multirow{2}{*}{$\begin{array}{l}\text { Risk transmission between the financial } \\
\text { sector and the real economy: Advanced } \\
\text { economies }\end{array}$} & No contribution & $\begin{array}{l}19 \\
67\end{array}$ & $\begin{array}{l}13 \\
67\end{array}$ & $\begin{array}{l}15 \\
54\end{array}$ & $\begin{array}{l}25 \\
55\end{array}$ & $\begin{array}{l}14 \\
67\end{array}$ & $\begin{array}{l}19 \\
63\end{array}$ \\
\hline & & $\begin{array}{l}\text { Some contribution } \\
\text { Significant contribution }\end{array}$ & $\begin{array}{l}67 \\
15\end{array}$ & $\begin{array}{l}67 \\
20\end{array}$ & $\begin{array}{l}54 \\
31\end{array}$ & $\begin{array}{l}55 \\
20\end{array}$ & $\begin{array}{l}6 / \\
19\end{array}$ & $\begin{array}{l}63 \\
19\end{array}$ \\
\hline & \multirow{2}{*}{$\begin{array}{l}\text { Risk transmission between the financial } \\
\text { sector and the real economy: Emerging } \\
\text { Market countries }\end{array}$} & $\begin{array}{l}\text { No contribution } \\
\text { Some contribution }\end{array}$ & $\begin{array}{r}9 \\
56\end{array}$ & $\begin{array}{l}19 \\
56\end{array}$ & $\begin{array}{l}14 \\
50\end{array}$ & $\begin{array}{l}13 \\
54\end{array}$ & $\begin{array}{r}8 \\
60\end{array}$ & $\begin{array}{l}16 \\
58\end{array}$ \\
\hline & & Significant contribution & 34 & 25 & 36 & 33 & 32 & 26 \\
\hline & \multirow{2}{*}{$\begin{array}{l}\text { Risk transmission between the financial } \\
\text { sector and the real economy: Low-income } \\
\text { countries }\end{array}$} & $\begin{array}{l}\text { No contribution } \\
\text { Some contribution }\end{array}$ & $\begin{array}{l}14 \\
50\end{array}$ & $\begin{array}{l}17 \\
67\end{array}$ & $\begin{array}{l}13 \\
63\end{array}$ & $\begin{array}{r}6 \\
59\end{array}$ & $\begin{array}{l}19 \\
50\end{array}$ & $\begin{array}{r}8 \\
67\end{array}$ \\
\hline & & Significant contribution & 36 & 17 & 25 & 35 & 31 & 25 \\
\hline & \multirow[b]{2}{*}{$\begin{array}{l}\text { Cross-border risk transmission: Advanced } \\
\text { economies }\end{array}$} & No contribution & 23 & 13 & 17 & 21 & 25 & 25 \\
\hline & & $\begin{array}{l}\text { Some contribution } \\
\text { Significant contribution }\end{array}$ & $\begin{array}{l}62 \\
15\end{array}$ & $\begin{array}{l}67 \\
20\end{array}$ & $\begin{array}{l}67 \\
17\end{array}$ & $\begin{array}{l}58 \\
21\end{array}$ & $\begin{array}{l}65 \\
10\end{array}$ & $\begin{array}{l}56 \\
19\end{array}$ \\
\hline & $\begin{array}{l}\text { Cross-border risk transmission: Emerging } \\
\text { Market countries }\end{array}$ & $\begin{array}{l}\text { No contribution } \\
\text { Some contribution } \\
\text { Significant contribution }\end{array}$ & $\begin{array}{l}10 \\
68 \\
23\end{array}$ & $\begin{array}{l}13 \\
63 \\
25\end{array}$ & $\begin{array}{l}15 \\
62 \\
23\end{array}$ & $\begin{array}{r}9 \\
65 \\
26\end{array}$ & $\begin{array}{r}8 \\
75 \\
17\end{array}$ & $\begin{array}{l}11 \\
68 \\
21\end{array}$ \\
\hline & $\begin{array}{l}\text { Cross-border risk transmission: Low-income } \\
\text { countries }\end{array}$ & $\begin{array}{l}\text { No contribution } \\
\text { Some contribution } \\
\text { Significant contribution }\end{array}$ & $\begin{array}{l}10 \\
62 \\
29\end{array}$ & $\begin{array}{r}- \\
75 \\
25\end{array}$ & $\begin{array}{r}- \\
71 \\
29\end{array}$ & $\begin{array}{r}- \\
63 \\
38\end{array}$ & $\begin{array}{l}13 \\
67 \\
20\end{array}$ & $\begin{array}{l}67 \\
33\end{array}$ \\
\hline
\end{tabular}




\begin{tabular}{|c|c|c|c|c|c|c|c|c|}
\hline \multicolumn{9}{|c|}{ Disribution of answers in percent } \\
\hline & & & \multirow[b]{2}{*}{ Overall } & \multicolumn{5}{|c|}{ By region } \\
\hline & & & & US/Canada & Europe & Asia & EMEA & $\begin{array}{r}\text { Latin } \\
\text { America }\end{array}$ \\
\hline \multirow{12}{*}{$\begin{array}{l}\text { 5. In your view, what are the areas in which } \\
\text { the analysis in IMF country reports (Art. IV } \\
\text { consultations) add value compared to the } \\
\text { analytical products provided by other } \\
\text { private and public institutions? }\end{array}$} & \multirow{2}{*}{$\begin{array}{l}\text { Structural issues and policies (labor/product } \\
\text { market reforms): Advanced economies }\end{array}$} & $\begin{array}{l}\text { No contribution } \\
\text { Some contribution }\end{array}$ & $\begin{array}{l}30 \\
41\end{array}$ & $\begin{array}{r}27 \\
33\end{array}$ & $\begin{array}{l}23 \\
46\end{array}$ & 30 & $\begin{array}{l}29 \\
48\end{array}$ & $\begin{array}{l}25 \\
38\end{array}$ \\
\hline & & Significant contribution & 30 & 40 & 31 & 30 & 24 & 38 \\
\hline & $\begin{array}{l}\text { Structural issues and policies (labor/product } \\
\text { market reforms): Emerging Market countries }\end{array}$ & $\begin{array}{l}\text { No contribution } \\
\text { Some contribution } \\
\text { Significant contribution }\end{array}$ & $\begin{array}{r}3 \\
47 \\
50\end{array}$ & $\begin{array}{r}6 \\
31 \\
63\end{array}$ & $\begin{array}{r}- \\
50 \\
50\end{array}$ & $\begin{array}{r}4 \\
50 \\
46\end{array}$ & $\begin{array}{l}52 \\
48\end{array}$ & $\begin{array}{r}5 \\
42 \\
53\end{array}$ \\
\hline & $\begin{array}{l}\text { Structural issues and policies (labor/product } \\
\text { market reforms): Low-income countries }\end{array}$ & $\begin{array}{l}\text { No contribution } \\
\text { Some contribution } \\
\text { Significant contribution }\end{array}$ & $\begin{array}{r}5 \\
41 \\
55\end{array}$ & $\begin{array}{r}- \\
42 \\
58\end{array}$ & $\begin{array}{r}- \\
63 \\
38\end{array}$ & $\begin{array}{r}6 \\
41 \\
53\end{array}$ & $\begin{array}{r}6 \\
44 \\
50\end{array}$ & $\begin{array}{r}8 \\
33 \\
58\end{array}$ \\
\hline & $\begin{array}{l}\text { Cross-country analysis (i.e., that brings in } \\
\text { experience of other countries): Advanced } \\
\text { economies }\end{array}$ & $\begin{array}{l}\text { No contribution } \\
\text { Some contribution } \\
\text { Significant contribution }\end{array}$ & $\begin{array}{l}19 \\
59 \\
22\end{array}$ & $\begin{array}{l}13 \\
67 \\
20\end{array}$ & $\begin{array}{r}8 \\
77 \\
15\end{array}$ & $\begin{array}{l}10 \\
65 \\
25\end{array}$ & $\begin{array}{l}19 \\
67 \\
14\end{array}$ & $\begin{array}{l}19 \\
63 \\
19\end{array}$ \\
\hline & \multirow{2}{*}{$\begin{array}{l}\text { Cross-country analysis (i.e., that brings in } \\
\text { experience of other countries): Emerging } \\
\text { Market countries }\end{array}$} & $\begin{array}{l}\text { No contribution } \\
\text { Some contribution }\end{array}$ & $\begin{array}{r}6 \\
53\end{array}$ & $\begin{array}{r}6 \\
50\end{array}$ & $\begin{array}{r}7 \\
50\end{array}$ & 54 & $\begin{array}{r}4 \\
56\end{array}$ & $\begin{array}{r}5 \\
47\end{array}$ \\
\hline & & Significant contribution & 41 & 44 & 43 & 46 & 40 & 47 \\
\hline & \multirow{2}{*}{$\begin{array}{l}\text { Cross-country analysis (i.e., that brings in } \\
\text { experience of other countries): Low-income } \\
\text { countries }\end{array}$} & $\begin{array}{l}\text { No contribution } \\
\text { Some contribution }\end{array}$ & $\begin{array}{r}5 \\
41\end{array}$ & $\begin{array}{r}8 \\
50\end{array}$ & 38 & 29 & $5 \overline{0}$ & $\begin{array}{r}8 \\
33\end{array}$ \\
\hline & & Significant contribution & 55 & 42 & 63 & 71 & 50 & 58 \\
\hline & Other: Advanced economies & $\begin{array}{l}\text { No contribution } \\
\text { Some contribution } \\
\text { Significant contribution }\end{array}$ & $\begin{array}{r}50 \\
50 \\
-\end{array}$ & $\begin{array}{r}50 \\
50 \\
-\end{array}$ & $\begin{array}{r}50 \\
50 \\
-\end{array}$ & $\begin{array}{r}43 \\
57 \\
-\end{array}$ & $\begin{array}{r}50 \\
50 \\
-\end{array}$ & $\begin{array}{r}40 \\
60 \\
-\end{array}$ \\
\hline & Other: Emerging Market countries & $\begin{array}{l}\text { No contribution } \\
\text { Some contribution } \\
\text { Significant contribution }\end{array}$ & $\begin{array}{r}42 \\
58 \\
-\end{array}$ & $\begin{array}{r}60 \\
40 \\
-\end{array}$ & $\begin{array}{r}67 \\
33 \\
-\end{array}$ & $\begin{array}{r}40 \\
60 \\
-\end{array}$ & $\begin{array}{r}40 \\
60 \\
-\end{array}$ & $\begin{array}{l}38 \\
63\end{array}$ \\
\hline & Other: Low-income countries & $\begin{array}{l}\text { No contribution } \\
\text { Some contribution } \\
\text { Significant contribution }\end{array}$ & $\begin{array}{l}38 \\
50 \\
13\end{array}$ & $\begin{array}{r}50 \\
50 \\
-\end{array}$ & $\begin{array}{r}50 \\
50 \\
-\end{array}$ & $\begin{array}{l}29 \\
57 \\
14\end{array}$ & $\begin{array}{l}33 \\
50 \\
17\end{array}$ & $\begin{array}{l}20 \\
60 \\
20\end{array}$ \\
\hline
\end{tabular}


Appendix II, Table 4. TSR Financial Markets Survey Results

\begin{tabular}{|c|c|c|c|c|c|c|c|c|}
\hline \multicolumn{8}{|c|}{ Disribution of answers in percent } & \\
\hline & & & \multirow[b]{2}{*}{ Overall } & \multicolumn{5}{|c|}{ By region } \\
\hline & & & & US/Canada & Europe & Asia & EMEA & $\begin{array}{r}\text { Latin } \\
\text { America }\end{array}$ \\
\hline \multirow{36}{*}{$\begin{array}{l}\text { 6. Compared to an average quality of } \\
\text { similar type of analyses produced by other } \\
\text { public and private institutions, how would } \\
\text { you assess the overall quality in the IMF's } \\
\text { country reports (Art. IV consultations) of: }\end{array}$} & \multirow{6}{*}{ Cross-country analysis } & Much worse than average & - & - & - & - & - & \\
\hline & & Worse than average & 12 & 18 & - & 8 & 12 & 16 \\
\hline & & Average & 18 & 12 & 14 & 21 & 20 & 16 \\
\hline & & Better than average & 52 & 47 & 64 & 54 & 48 & 53 \\
\hline & & Much better than average & 18 & 24 & 21 & 17 & 20 & 16 \\
\hline & & Weighted average score & 3.76 & 3.76 & 4.07 & 3.79 & 3.76 & 3.68 \\
\hline & \multirow{6}{*}{ Analysis of cross-border risk transmission } & Much worse than average & - & - & - & - & - & \\
\hline & & Worse than average & 6 & 6 & - & 4 & 8 & 6 \\
\hline & & Average & 31 & 25 & 29 & 33 & 36 & 33 \\
\hline & & Better than average & 50 & 44 & 50 & 46 & 44 & 44 \\
\hline & & Much better than average & 13 & 25 & 21 & 17 & 12 & 17 \\
\hline & & Weighted average score & 3.69 & 3.88 & 3.93 & 3.75 & 3.60 & 3.72 \\
\hline & \multirow{6}{*}{$\begin{array}{l}\text { Analysis of financial sector risks and } \\
\text { vulnerabilities }\end{array}$} & Much worse than average & - & - & - & - & - & - \\
\hline & & Worse than average & - & - & - & - & - & - \\
\hline & & Average & 27 & 29 & 21 & 33 & 24 & 37 \\
\hline & & Better than average & 48 & 47 & 50 & 42 & 48 & 37 \\
\hline & & Much better than average & 24 & 24 & 29 & 25 & 28 & 26 \\
\hline & & Weighted average score & 3.97 & 3.94 & 4.07 & 3.92 & 4.04 & 3.89 \\
\hline & \multirow{6}{*}{$\begin{array}{l}\text { Two way analysis of risk transmission } \\
\text { between the financial sector and the real } \\
\text { economy }\end{array}$} & Much worse than average & - & - & - & - & - & \\
\hline & & Worse than average & 3 & - & - & 4 & 4 & 5 \\
\hline & & Average & 22 & 19 & 21 & 29 & 16 & 26 \\
\hline & & Better than average & 66 & 63 & 64 & 54 & 68 & 53 \\
\hline & & Much better than average & 9 & 19 & 14 & 13 & 12 & 16 \\
\hline & & Weighted average score & 3.81 & 4.00 & 3.93 & 3.75 & 3.88 & 3.79 \\
\hline & \multirow{6}{*}{ Analysis of exchange rate issues } & Much worse than average & - & - & - & - & - & \\
\hline & & Worse than average & 3 & 6 & 7 & 4 & - & 5 \\
\hline & & Average & 53 & 50 & 57 & 50 & 56 & 58 \\
\hline & & Better than average & 41 & 44 & 36 & 46 & 40 & 37 \\
\hline & & Much better than average & 3 & - & - & - & 4 & - \\
\hline & & Weighted average score & 3.44 & 3.38 & 3.29 & 3.42 & 3.48 & 3.32 \\
\hline & \multirow{6}{*}{ Analysis of external stability/vulnerability } & Much worse than average & - & - & - & - & - & \\
\hline & & Worse than average & - & - & - & - & - & - \\
\hline & & Average & 15 & 6 & 7 & 17 & 12 & 11 \\
\hline & & Better than average & 52 & 47 & 57 & 58 & 64 & 63 \\
\hline & & Much better than average & 33 & 47 & 36 & 25 & 24 & 26 \\
\hline & & Weighted average score & 4.18 & 4.41 & 4.29 & 4.08 & 4.12 & 4.16 \\
\hline
\end{tabular}




\section{Appendix II, Table 4. TSR Financial Markets Survey Results}

\begin{tabular}{|c|c|c|c|c|c|c|c|}
\hline & & \multicolumn{6}{|c|}{ Disribution of answers in percent } \\
\hline & & \multirow[b]{2}{*}{ Overall } & \multicolumn{5}{|c|}{ By region } \\
\hline & & & US/Canada & Europe & Asia & EMEA & $\begin{array}{r}\text { Latin } \\
\text { America } \\
\end{array}$ \\
\hline \multirow{8}{*}{$\begin{array}{l}\text { 7. Among the following products, which } \\
\text { ones have been the most helpful in } \\
\text { sharpening your views? (Check all that } \\
\text { apply) }\end{array}$} & Multilateral Surveillance: World Economic Outlook (WEO) & 59 & 67 & 61 & 60 & 60 & 63 \\
\hline & Multilateral Surveillance: Global Financial Stability Report (GFSR) & 44 & 48 & 44 & 43 & 47 & 42 \\
\hline & Multilateral Surveillance: Fiscal Monitor & 34 & 38 & 39 & 37 & 30 & 33 \\
\hline & Other IMF Products: Regional Economic Outlook (REO) & 22 & 14 & 11 & 17 & 23 & 13 \\
\hline & Other IMF Products: Financial System Stability Assessment (FSSA) & 22 & 24 & 33 & 17 & 23 & 17 \\
\hline & $\begin{array}{l}\text { Other IMF Products: Cross-country Thematic Reports (e.g., Cross-Cutting } \\
\text { Themes in Major Article IV Consultations; IMF Policy Paper; August 14, } \\
\text { 2009.) }\end{array}$ & 22 & 29 & 28 & 17 & 20 & 17 \\
\hline & Input for other Fora: G-20 Surveillance Notes & 10 & 14 & 11 & 13 & 13 & 17 \\
\hline & $\begin{array}{l}\text { Input for other Fora: Analytical input for the G-20 (e.g. G-10 Mutual } \\
\text { Assessment Process) }\end{array}$ & 15 & 19 & 22 & 20 & 10 & 17 \\
\hline
\end{tabular}




\begin{tabular}{|c|c|c|c|c|c|c|c|c|}
\hline & & & \multicolumn{6}{|c|}{ Disribution of answers in percent } \\
\hline & & & \multirow[b]{2}{*}{ Overall } & \multicolumn{5}{|c|}{ By region } \\
\hline & & & & US/Canada & Europe & Asia & EMEA & $\begin{array}{r}\text { Latin } \\
\text { America }\end{array}$ \\
\hline \multirow{30}{*}{$\begin{array}{l}\text { 8. What features of IMF global/regional } \\
\text { reports do you find most useful (please } \\
\text { rank the features from } 1 \text { to } 5 \text {, with } 1 \text { being } \\
\text { the least useful and } 5 \text { being the most } \\
\text { useful)? }\end{array}$} & & The least useful & 23 & 24 & 29 & 23 & 26 & 24 \\
\hline & & & 35 & 24 & 36 & 41 & 35 & 29 \\
\hline & Timeliness & & 29 & 41 & 29 & 23 & 26 & 35 \\
\hline & & & 3 & 6 & - & 5 & 4 & 6 \\
\hline & & The most useful & 10 & 6 & 7 & 9 & 9 & 6 \\
\hline & & Weighted average score & 2.42 & 2.47 & 2.21 & 2.36 & 2.35 & 2.41 \\
\hline & & The least useful & 3 & 6 & - & 5 & 4 & 6 \\
\hline & & & 3 & - & - & 5 & - & - \\
\hline & Comprehensiveness & & 10 & 12 & 14 & 14 & 13 & 12 \\
\hline & & & 48 & 53 & 50 & 50 & 52 & 53 \\
\hline & & The most useful & 35 & 29 & 36 & 27 & 30 & 29 \\
\hline & & Weighted average score & 4.10 & 4.00 & 4.21 & 3.91 & 4.04 & 4.00 \\
\hline & & The least useful & 3 & 6 & - & 5 & 4 & 6 \\
\hline & & & 6 & - & - & 9 & 4 & - \\
\hline & Analytical depth & & 10 & - & 7 & 14 & 9 & 6 \\
\hline & & & 39 & 47 & 29 & 27 & 35 & 35 \\
\hline & & The most useful & 42 & 47 & 64 & 45 & 48 & 53 \\
\hline & & Weighted average score & 4.10 & 4.29 & 4.57 & 4.00 & 4.17 & 4.29 \\
\hline & & The least useful & 3 & 6 & - & 5 & 4 & 6 \\
\hline & & & 6 & 6 & - & 5 & 9 & 6 \\
\hline & New insights & & 26 & 29 & 36 & 23 & 30 & 24 \\
\hline & & & 48 & 35 & 29 & 50 & 35 & 41 \\
\hline & & The most useful & 16 & 24 & 36 & 18 & 22 & 24 \\
\hline & & Weighted average score & 3.68 & 3.65 & 4.00 & 3.73 & 3.61 & 3.71 \\
\hline & & The least useful & 16 & 12 & 7 & 18 & 13 & 6 \\
\hline & & & 16 & 18 & 14 & 18 & 22 & 24 \\
\hline & Access to privileged information & & 32 & 29 & 36 & 18 & 35 & 24 \\
\hline & & & 26 & 35 & 36 & 32 & 26 & 35 \\
\hline & & The most useful & 10 & 6 & 7 & 14 & 4 & 12 \\
\hline & & Weighted average score & 2.97 & 3.06 & 3.21 & 3.05 & 2.87 & 3.24 \\
\hline \multirow{6}{*}{$\begin{array}{l}\text { 9. In your view, are the IMF's messages } \\
\text { from the various products listed above } \\
\text { clear and coherent? }\end{array}$} & & Not at all & - & - & - & - & - & - \\
\hline & & To a little extent & - & - & - & - & - & - \\
\hline & & To some extent & 13 & 18 & 14 & 18 & 4 & 18 \\
\hline & & To a large extent & 71 & 65 & 71 & 64 & 83 & 71 \\
\hline & & To a very large extent & 16 & 18 & 14 & 18 & 13 & 12 \\
\hline & & Weighted average score & 4.03 & 4.00 & 4.00 & 4.00 & 4.09 & 3.94 \\
\hline
\end{tabular}


Appendix II, Table 5. TSR Media Survey Results

\begin{tabular}{|c|c|c|c|c|c|c|}
\hline & & & \multicolumn{4}{|c|}{ Distribution of answers in percent } \\
\hline & & & \multirow[b]{2}{*}{ Overall } & \multicolumn{3}{|c|}{ By region } \\
\hline & & & & Asia & Europe & $\begin{array}{l}\text { USA and } \\
\text { Canada }\end{array}$ \\
\hline & & $\begin{array}{l}\text { Number of Respondents } \\
\text { Participation Rate (In Percentage) }\end{array}$ & $\begin{array}{l}28 \\
32\end{array}$ & 4 & 18 & 5 \\
\hline \multirow{3}{*}{\multicolumn{2}{|c|}{$\begin{array}{l}\text { 1. Do you cover IMF } \\
\text { surveillance and/or economic } \\
\text { or financial news? }\end{array}$}} & Rarely & 4 & - & 6 & - \\
\hline & & Sometimes & 14 & 50 & 6 & 20 \\
\hline & & Frequently & 82 & 50 & 89 & 80 \\
\hline & \multirow{5}{*}{$\begin{array}{l}\text { 2. If you cover IMF surveillance, } \\
\text { roughly what share of your total } \\
\text { coverage would you } \\
\text { characterize as: } \\
\text { (Please insert a percentage in } \\
\text { the bracket marks, so that the } \\
\text { column of percentages total } 100 \\
\text { percent) }\end{array}$} & Country-specific (please specify below) & 38 & 15 & 41 & 22 \\
\hline & & $\begin{array}{l}\text { Cross-country or regional (please } \\
\text { specify below) }\end{array}$ & 11 & 13 & 8 & 16 \\
\hline & & Global economic matters & 30 & 44 & 24 & 34 \\
\hline & & Global financial matters & 21 & 29 & 16 & 28 \\
\hline & & Other (please specify below) & 0 & - & 1 & - \\
\hline \multirow{40}{*}{$\begin{array}{l}\text { 3. How often do you use or } \\
\text { report on the following specific } \\
\text { instruments that the IMF uses } \\
\text { to communicate surveillance } \\
\text { information? }\end{array}$} & \multirow{5}{*}{$\begin{array}{l}\text { Multilateral } \\
\text { Surveillance: World } \\
\text { Economic Outlook }\end{array}$} & Not familiar with this instrument & - & - & - & - \\
\hline & & Rarely or Never & - & - & - & - \\
\hline & & Sometimes & 20 & 75 & 13 & - \\
\hline & & Frequently & 80 & 25 & 88 & 100 \\
\hline & & Weighted average score $^{1 /}$ & 4.73 & 4.00 & 4.83 & 5.00 \\
\hline & \multirow{5}{*}{$\begin{array}{l}\text { Multilateral } \\
\text { Surveillance: } \\
\text { Global Financial } \\
\text { Stability Report }\end{array}$} & Not familiar with this instrument & - & - & - & - \\
\hline & & Rarely or Never & 8 & - & 13 & - \\
\hline & & Sometimes & 32 & 75 & 31 & - \\
\hline & & Frequently & 60 & 25 & 56 & 100 \\
\hline & & Weighted average score & 4.36 & 4.00 & 4.25 & 5.00 \\
\hline & \multirow{5}{*}{$\begin{array}{l}\text { Multilateral } \\
\text { Surveillance: Fiscal } \\
\text { Monitor }\end{array}$} & Not familiar with this instrument & 16 & 25 & 19 & - \\
\hline & & Rarely or Never & 20 & 50 & 19 & - \\
\hline & & Sometimes & 36 & 25 & 38 & 40 \\
\hline & & Frequently & 28 & - & 25 & 60 \\
\hline & & Weighted average score & 3.35 & 2.33 & 3.25 & 4.47 \\
\hline & \multirow{5}{*}{$\begin{array}{l}\text { Other IMF } \\
\text { products: Financial } \\
\text { System Stability } \\
\text { Assessments } \\
\text { (FSSA) }\end{array}$} & Not familiar with this instrument & 15 & - & 24 & - \\
\hline & & Rarely or Never & 30 & 25 & 35 & 20 \\
\hline & & Sometimes & 37 & 50 & 29 & 40 \\
\hline & & Frequently & 19 & 25 & 12 & 40 \\
\hline & & Weighted average score & 3.12 & 3.67 & 2.73 & 3.93 \\
\hline & \multirow{5}{*}{$\begin{array}{l}\text { Other IMF } \\
\text { products: Regional } \\
\text { Economic Outlooks }\end{array}$} & Not familiar with this instrument & 4 & 25 & - & - \\
\hline & & Rarely or Never & 19 & - & 29 & - \\
\hline & & Sometimes & 54 & 75 & 47 & 75 \\
\hline & & Frequently & 23 & - & 24 & 25 \\
\hline & & Weighted average score & 3.61 & 3.00 & 3.59 & 4.00 \\
\hline & \multirow{5}{*}{$\begin{array}{l}\text { Other IMF } \\
\text { products: Cross- } \\
\text { country Thematic } \\
\text { Reports }\end{array}$} & Not familiar with this instrument & 12 & 25 & 13 & - \\
\hline & & Rarely or Never & 16 & - & 25 & - \\
\hline & & Sometimes & 60 & 50 & 50 & 100 \\
\hline & & Frequently & 12 & 25 & 13 & - \\
\hline & & Weighted average score & 3.29 & 3.33 & 3.17 & 3.67 \\
\hline & \multirow{5}{*}{$\begin{array}{l}\text { Input for Other } \\
\text { Fora: G-20 } \\
\text { Surveillance } \\
\text { Briefing Notes }\end{array}$} & Not familiar with this instrument & 7 & - & 12 & - \\
\hline & & Rarely or Never & 22 & - & 29 & - \\
\hline & & Sometimes & 22 & 50 & 24 & - \\
\hline & & Frequently & 48 & 50 & 35 & 100 \\
\hline & & Weighted average score & 3.81 & 4.33 & 3.43 & 5.00 \\
\hline & \multirow{5}{*}{$\begin{array}{l}\text { Input for Other } \\
\text { Fora: Analytical } \\
\text { input for the G-20 } \\
\text { (e.g. G-20 Mutual } \\
\text { Assessment }\end{array}$} & Not familiar with this instrument & 12 & - & 18 & - \\
\hline & & Rarely or Never & 15 & - & 24 & - \\
\hline & & Sometimes & 35 & 50 & 41 & - \\
\hline & & Frequently & 38 & 50 & 18 & 100 \\
\hline & & Weighted average score & 3.67 & 4.33 & 3.12 & 5.00 \\
\hline
\end{tabular}

1/ A weighted average was used to convert the responses to questions to select one from four or five answer choices to a 5-point scale to make the responses more comparable across questions. The higher the score, the more positive the response was. 
Appendix II, Table 5. TSR Media Survey Results

3. How often do you use or report on the following specific instruments that the IMF uses to communicate surveillance information?

\begin{tabular}{|c|c|c|c|c|c|}
\hline & & \multicolumn{4}{|c|}{ Distribution of answers in percent } \\
\hline & & \multirow[b]{2}{*}{ Overall } & \multicolumn{3}{|c|}{ By region } \\
\hline & & & Asia & Europe & $\begin{array}{l}\text { USA and } \\
\text { Canada }\end{array}$ \\
\hline Bilateral & Not familiar with this instrument & 4 & 25 & - & . \\
\hline Surveillance: & Rarely or Never & 26 & - & 35 & - \\
\hline \multirow{3}{*}{$\begin{array}{l}\text { Mission concluding } \\
\text { statements }\end{array}$} & Sometimes & 41 & 50 & 24 & 100 \\
\hline & Frequently & 30 & 25 & 41 & - \\
\hline & Weighted average score & 3.62 & 3.33 & 3.74 & 3.67 \\
\hline Bilateral & Not familiar with this instrument & 4 & 25 & - & - \\
\hline Surveillance: & Rarely or Never & 15 & - & 24 & - \\
\hline \multirow{3}{*}{$\begin{array}{l}\text { Country Article IV } \\
\text { reports }\end{array}$} & Sometimes & 30 & 25 & 12 & 80 \\
\hline & Frequently & 52 & 50 & 65 & 20 \\
\hline & Weighted average score & 4.06 & 3.67 & 4.22 & 3.93 \\
\hline Bilateral & Not familiar with this instrument & 4 & 25 & - & - \\
\hline Surveillance: Public & Rarely or Never & 19 & - & 24 & - \\
\hline Information & Sometimes & 52 & 50 & 47 & 80 \\
\hline \multirow[t]{2}{*}{ Notices/Press } & Frequently & 26 & 25 & 29 & 20 \\
\hline & Weighted average score & 3.67 & 3.33 & 3.74 & 3.93 \\
\hline Bilateral & Not familiar with this instrument & 11 & 25 & 12 & - \\
\hline Surveillance: & Rarely or Never & 22 & - & 29 & - \\
\hline Selected Issues & Sometimes & 63 & 75 & 59 & 80 \\
\hline \multirow[t]{2}{*}{ Papers (SIP) } & Frequently & 4 & - & - & 20 \\
\hline & Weighted average score & 3.12 & 3.00 & 2.96 & 3.93 \\
\hline \multirow{5}{*}{$\begin{array}{l}\text { Press Events: } \\
\text { Press briefings at } \\
\text { IMF Headquarters }\end{array}$} & Not familiar with this instrument & 8 & 25 & 6 & - \\
\hline & Rarely or Never & 13 & - & 19 & - \\
\hline & Sometimes & 50 & 25 & 56 & 50 \\
\hline & Frequently & 29 & 50 & 19 & 50 \\
\hline & Weighted average score & 3.67 & 3.67 & 3.50 & 4.33 \\
\hline \multirow{5}{*}{$\begin{array}{l}\text { Press Events: } \\
\text { Press briefings in } \\
\text { the field }\end{array}$} & Not familiar with this instrument & 4 & 25 & - & - \\
\hline & Rarely or Never & 35 & 25 & 40 & 25 \\
\hline & Sometimes & 35 & - & 40 & 50 \\
\hline & Frequently & 26 & 50 & 20 & 25 \\
\hline & Weighted average score & 3.43 & 3.33 & 3.40 & 3.67 \\
\hline \multirow{5}{*}{$\begin{array}{l}\text { Press Events: } \\
\text { Conference calls }\end{array}$} & Not familiar with this instrument & 12 & 25 & 6 & - \\
\hline & Rarely or Never & 31 & 50 & 29 & 25 \\
\hline & Sometimes & 42 & - & 59 & 25 \\
\hline & Frequently & 15 & 25 & 6 & 50 \\
\hline & Weighted average score & 3.15 & 2.67 & 3.20 & 4.00 \\
\hline \multirow{5}{*}{ Press Events: Other } & Not familiar with this instrument & 31 & 50 & 29 & - \\
\hline & Rarely or Never & 31 & - & 57 & - \\
\hline & Sometimes & 23 & 50 & 14 & - \\
\hline & Frequently & 15 & - & - & 100 \\
\hline & Weighted average score & 2.64 & 2.33 & 2.14 & 5.00 \\
\hline
\end{tabular}


Appendix II, Table 5. TSR Media Survey Results

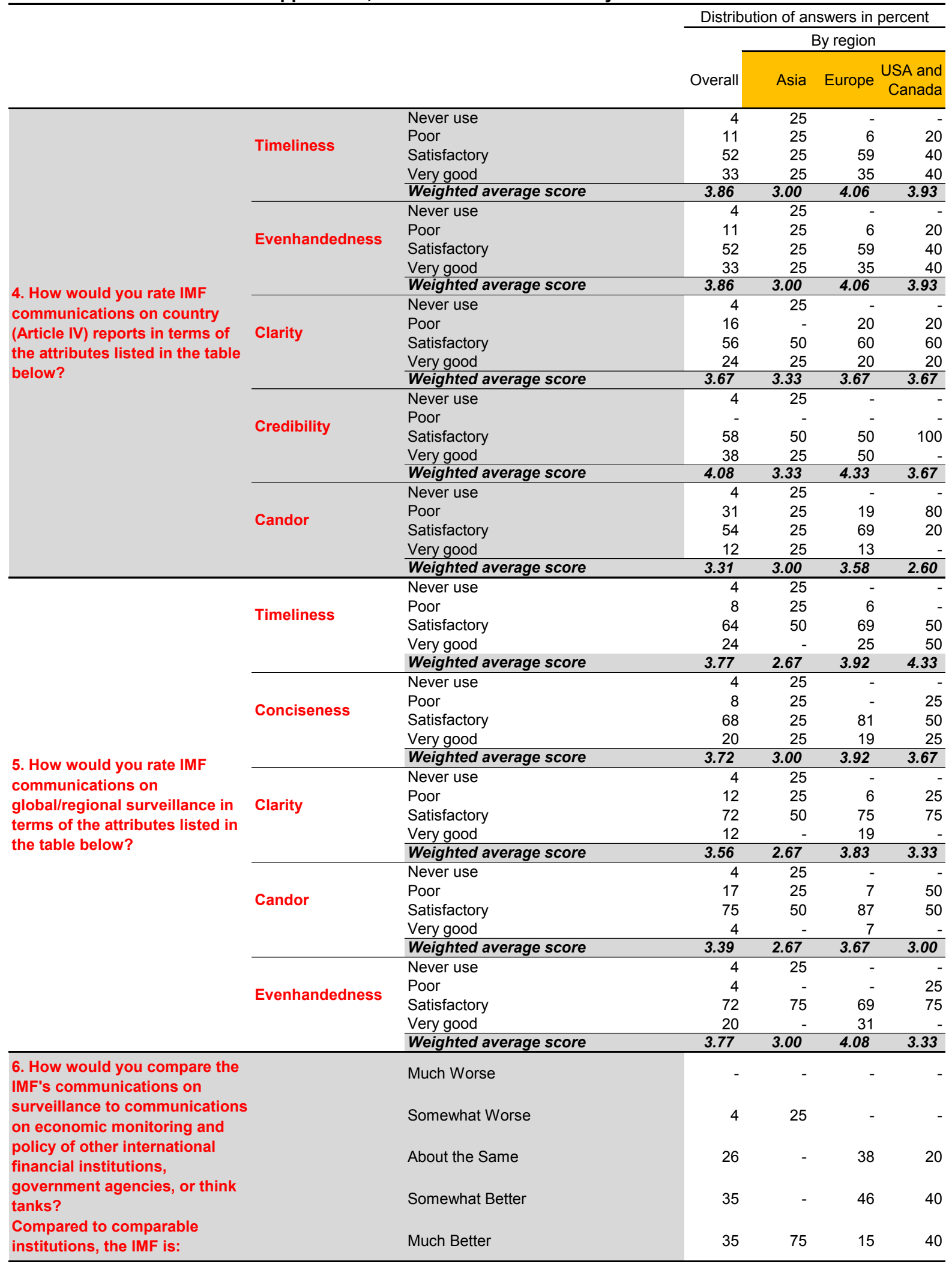


Appendix II, Table 6. TSR CSO Survey Results

\begin{tabular}{|c|c|c|c|}
\hline & & & $\begin{array}{c}\text { Overall } \\
\text { Number of } \\
\text { Responses }\end{array}$ \\
\hline & & Number of Responses & 17 \\
\hline & & Participation Rate (in Percentage) & 38 \\
\hline \multirow{6}{*}{$\begin{array}{l}\text { 1. Which region do you or your } \\
\text { organization focus on PCheck all } \\
\text { that apply): }\end{array}$} & Sub-Saharan Africa & & 6 \\
\hline & Asia & & 7 \\
\hline & Latin America or Caribbean & & 6 \\
\hline & Europe & & 5 \\
\hline & Middle East/North Africa & & 4 \\
\hline & USA and Canada & & 0 \\
\hline \multirow{6}{*}{ 2. Where is your organization based? } & USA or Canada based only & & 1 \\
\hline & other countries & & 1 \\
\hline & Western Europe based only & & 2 \\
\hline & $\begin{array}{l}\text { Western Europe, with branches in other } \\
\text { countries }\end{array}$ & & 2 \\
\hline & $\begin{array}{l}\text { In a Latin American or Caribbean / Middle } \\
\text { Eastern or African / Asian country, but } \\
\text { with a regional scope of work }\end{array}$ & & 6 \\
\hline & $\begin{array}{l}\text { In a Latin American or Caribbean / Middle } \\
\text { Eastern or African / Asian country, that } \\
\text { operates only in that country }\end{array}$ & & 3 \\
\hline \multirow{35}{*}{$\begin{array}{l}\text { 3. How familiar are you with the } \\
\text { following IMF surveillance products? }\end{array}$} & \multirow{5}{*}{ Individual country staff reports } & To a great extent & 5 \\
\hline & & To some extent & 4 \\
\hline & & To a little extent & 2 \\
\hline & & Not at all & 4 \\
\hline & & Weighted average score 1/ & 2.35 \\
\hline & \multirow{5}{*}{ World Economic Outlook (WEO) } & To a great extent & 3 \\
\hline & & To some extent & 6 \\
\hline & & To a little extent & 6 \\
\hline & & Not at all & 1 \\
\hline & & Weighted average score & 2.53 \\
\hline & \multirow{5}{*}{ Global Financial Stability Report (GFSR) } & To a great extent & 2 \\
\hline & & To some extent & 5 \\
\hline & & To a little extent & 4 \\
\hline & & Not at all & 4 \\
\hline & & Weighted average score & 2.06 \\
\hline & \multirow{5}{*}{ Fiscal Monitor } & To a great extent & 1 \\
\hline & & To some extent & 3 \\
\hline & & To a little extent & 5 \\
\hline & & Not at all & 5 \\
\hline & & Weighted average score & 1.65 \\
\hline & \multirow{5}{*}{ Regional Economic Outlook } & To a great extent & 2 \\
\hline & & To some extent & 5 \\
\hline & & To a little extent & 6 \\
\hline & & Not at all & 3 \\
\hline & & Weighted average score & 2.24 \\
\hline & \multirow{5}{*}{$\begin{array}{l}\text { Financial Sector Stability Assessment } \\
\text { (FSSA) }\end{array}$} & To a great extent & 0 \\
\hline & & To some extent & 6 \\
\hline & & To a little extent & 4 \\
\hline & & Not at all & 6 \\
\hline & & Weighted average score & 1.88 \\
\hline & \multirow{5}{*}{ G-20 Surveillance Notes } & To a great extent & 1 \\
\hline & & To some extent & 2 \\
\hline & & To a little extent & 5 \\
\hline & & Not at all & 7 \\
\hline & & Weighted average score & 1.59 \\
\hline
\end{tabular}

$1 / \mathrm{A}$ weighted average was used to convert the responses to questions to select one from four or five answer choices to a 5-point scale to make the responses more comparable across questions. The higher the score, the more positive the response was. 
Appendix II, Table 6. TSR CSO Survey Results

\begin{tabular}{|c|c|c|c|}
\hline \multirow{32}{*}{$\begin{array}{l}\text { 4. What aspects do you find most } \\
\text { valuable in IMF surveillance } \\
\text { products? } \\
\text { (Check all that apply) }\end{array}$} & \multirow{4}{*}{ Analysis of developments and outlook } & Find valuable & 12 \\
\hline & & Do not find valuable & 2 \\
\hline & & Not applicable & 1 \\
\hline & & Weighted average score & 1.53 \\
\hline & \multirow{4}{*}{ Monetary policy } & Find valuable & 8 \\
\hline & & Do not find valuable & 4 \\
\hline & & Not applicable & 1 \\
\hline & & Weighted average score & 1.18 \\
\hline & \multirow{4}{*}{ Exchange rate policy } & Find valuable & 8 \\
\hline & & Do not find valuable & 3 \\
\hline & & Not applicable & 2 \\
\hline & & Weighted average score & 1.12 \\
\hline & \multirow{4}{*}{ Fiscal policy } & Find valuable & 9 \\
\hline & & Do not find valuable & 3 \\
\hline & & Not applicable & 2 \\
\hline & & Weighted average score & 1.24 \\
\hline & \multirow{4}{*}{ Financial sector issues } & Find valuable & 10 \\
\hline & & Do not find valuable & 2 \\
\hline & & Not applicable & 3 \\
\hline & & Weighted average score & 1.29 \\
\hline & \multirow{4}{*}{ Economic contagion across countries } & Find valuable & 7 \\
\hline & & Do not find valuable & 3 \\
\hline & & Not applicable & 2 \\
\hline & & Weighted average score & 1.00 \\
\hline & \multirow{4}{*}{ Cross-country thematic analysis } & Find valuable & 9 \\
\hline & & Do not find valuable & 2 \\
\hline & & Not applicable & 2 \\
\hline & & Weighted average score & 1.18 \\
\hline & \multirow{4}{*}{ Other } & Find valuable & 2 \\
\hline & & Do not find valuable & 0 \\
\hline & & Not applicable & 3 \\
\hline & & Weighted average score & 0.24 \\
\hline \multirow{6}{*}{$\begin{array}{l}\text { 5. How would you compare the IMF's } \\
\text { communications on surveillance to } \\
\text { communications on economic } \\
\text { monitoring and policy of other } \\
\text { international financial institutions, } \\
\text { government agencies, or think tanks? } \\
\text { Compared to comparable institutions, } \\
\text { the IMF is: } \\
\text { (Please mark one choice) }\end{array}$} & \multicolumn{2}{|l|}{ Much better } & 2 \\
\hline & \multicolumn{2}{|l|}{ Somewhat better } & 4 \\
\hline & \multicolumn{2}{|l|}{ About the same } & 6 \\
\hline & \multicolumn{2}{|l|}{ Somewhat worse } & 2 \\
\hline & \multirow[t]{2}{*}{ Much worse } & & 1 \\
\hline & & Weighted average score & 2.88 \\
\hline
\end{tabular}




\section{Appendix II, Table 7. TSR Country Authorities Survey Comments}

\begin{tabular}{|l|}
\hline $\begin{array}{l}\text { 1. In reference to Question } 2 \text { on which areas in surveillance in your country contributed the most to your } \\
\text { understanding of the issues, or provided you with new insights, if you selected 'Other areas,' please } \\
\text { specify: }\end{array}$ \\
\hline $\begin{array}{l}\text { Labor market policy, structural reforms, investment attractiveness of the country, business environment, } \\
\text { regulatory framework }\end{array}$ \\
\hline Productivity and the labor market \\
\hline Internal governance federal vs. state level. \\
\hline $\begin{array}{l}\text { Labor market policy, structural reforms, investment attractiveness of the country, business environment, } \\
\text { regulatory framework }\end{array}$ \\
\hline
\end{tabular}

2. In reference to Question 7 on which areas should be improved in order to strengthen the Fund's surveillance, please comment on the areas you selected:

When projections are presented, their underlying assumptions and data (sources) should be provided to the authority in a timely manner.

Quality of analysis: While the quality of staff's analysis is very high in some areas (e.g. monetary/fiscal policy and has improved on financial regulation) it has been lacking in others, most notably, macroprudential policy. In the most recent Article IV mission, there was no macroprudential policy expert on the IMF team, even though this is currently a big issue for our country.

Timing of missions: Over the past year, our country has participated in an Article IV consultation, an FSAP and a spillover report, and within a further few months we will begin preparing for another Article IV consultation. This creates some scope for "IMF fatigue" which could be avoided with better coordination. For example, some of our staff have been asked same questions from IMF staff working on the FSAP and the spillover report.

Staff's interaction with authorities: The process for drafting the Article IV papers could be improved by allowing country authorities to comment on issues of FACT at an earlier stage of the drafting process. Country comments are currently sought 'at the last minute', which typically does not leave sufficient time for factual errors to be corrected- instead, time pressures often mean that when errors are found at a late stage, the analysis is dropped from the report altogether.

Greater use of cross-country comparisons: The Fund's key comparative advantage in the surveillance of advanced economies is in conducting cross-country comparisons and analyzing spillovers across countries (policymakers in advanced economies are typically well-equipped to analyze their own economies). This is an area where Fund surveillance can add the most value to our own analysis, and we would encourage a greater focus on this type of analysis.

Improvement in the tick-marked areas will certainly strengthen the Fund's surveillance and thereby enable it to make proper policy prescriptions for sustained economic growth.

All systemically important economies should be appropriately covered by Fund's surveillance, with due followup monitoring.

As Article IV Mission staff change from year to year there is the possibility that they would fail to really understand the unique characteristics of particular countries and so their assessment of developments in the particular country may not be quite correct.

Comparison with neighboring or similar countries is very important to understand the current status in our country.

The IMF staff should obtain a full understanding of the country's central bank view, models and forecasts in order to achieve a convergence of general macroeconomic development assessment.

Need of more regional and cross border surveillance. Externalities or spillover effects should be more used in the Article IV. 


\section{Appendix II, Table 7. TSR Country Authorities Survey Comments}

\section{In reference to Question 7 on which areas should be improved in order to strengthen the Fund's} surveillance, please comment on the areas you selected:

We welcome the spillover reports to be prepared by IMF and FSAP reports for systematically important countries.

In particular, taking into account balance of payments specificities of small open economies.

Even-handedness important.

Use of cross-country comparisons has improved but the Fund (and the OECD for that matter) still tends to struggle to find the right comparators and to make sense of the similarities and differences. Cross-country comparative insights should be perhaps the key strength of Fund surveillance, given the universal membership etc, but it still is not. I recall highlighting this when I was on the Board, but I still get the sense that it is a bit of an optional extra, at least where the comparators aren't immediately obvious (it doesn't help that most of our comparators are not with the region that covers our country in the IMF).

On the quality of analysis, it is not that the analysis is bad, simply that it rarely sheds fresh insights that we learn much from. To some extent that shouldn't surprise - our central bank and Treasury, while small, have more people than the Fund's country team — but the Fund should be employing really smart policy/analytical people who, by virtue of their experience and international perspectives and ability to stand outside our country, can help cut through some of the trickier issues.

We sometimes have the feeling that the 'top down approach', i.e. that some policy messages are 'non-negotiable', not in the least because of consistency reasons with for example the 'euro area advice', limits the quality of the policy assessment as for some countries the policy message in question is not applicable/very relevant at that point in time. Although, on the whole, the quality of the Article IV mission is high, an even more country specific approach could be beneficial.

The answers to the question on the extent to improvement in the quality of advice compared to pre-crisis times reflect the fact that the quality of the Fund's bilateral surveillance of our country was already high in the precrisis period, such that we did not notice a marked change post crisis. We want to emphasize that we have always found the IMF mission staff very competent.

For the question on assessing Fund policy advice in the most recent Article IV in terms of generating policy debate and fostering policy change, most of the analysis carried out by the Staff is generally covered in greater depth by our national authorities, such that the mission, despite the quality of its surveillance, did not stimulate much additional policy debate.

As there are other international bodies that are more specialized in financial stability, the IMF could maybe best contribute by focusing on cross-country comparison of general economic conditions, a field in which the fund might have a comparative advantage.

Improving the above mentioned areas could increase efficiency of programs implementation processes, which in turn contributes to strengthening the IMF's surveillance.

- A remaining gap in surveillance is the lack of impact analysis of domestic developments on other economies and of inward spillovers

- The mandatory FSAPs are a positive development. Their periodicity should be increased to 3 years to ensure an [NOTE: respondent did not finish comment]

Mission interactions are heavily influenced by the quality of the head of mission. A fuller contribution from the entire team would add weight to policy interactions.

Quality of analysis: care needs to be taken that new format of surveillance reports to not negatively impact on quality. In-depth selected issues papers are, for instance, no longer the norm.

Although there are many differences, there are also many similarities among the countries, especial those in the neighborhood.

When projections are presented, their underlying assumptions and data (sources) should be provided to the authority in a timely manner. 


\section{Appendix II, Table 7. TSR Country Authorities Survey Comments}

2. In reference to Question 7 on which areas should be improved in order to strengthen the Fund's surveillance, please comment on the areas you selected:

Some staff papers can be made more succinct and accessible.

A deeper appreciation of the unique circumstances affecting policymaking in individual countries is useful to ensure usefulness and relevance of staff reports.

Staff's consultations with other stake holders' groups should be increased

We think that Staff reports should bring into comparison peers' performance in the common policy areas in order to give more incentive to countries to do better in their performance areas. Policies should also be tailored to reflect country circumstances. For instance, in reporting compliance to certain performance standards such as level of NPLs, performance of countries who apply Islamic accounting standards should be tied to the Islamic Accounting requirements rather than the International standards. IMF visiting missions also need to interact more with policy makers on the ground in order to foster sense of ownership of the findings.

The categories are balanced/well determined

1. More proactive missions. Most missions come too late in the process, i.e., long after the problem has reached a critical level, or waiting for some prior action.

2. Over the years there has been improvement in tailoring policy advice to country circumstances but much more can be done.

Previous Resident Mission (based in-country) assisted with quality research and analysis

Visits to be after March, allow for year-end data to be finalized, including fiscal numbers and the Central Bank's March monetary policy statement to be available.

It would be useful to formulate more adequate policy advice on the basis of cross-country comparison-more detailed analysis of comparison and similarities between different countries could be useful.

The Fund could facilitate early detection of financial sector vulnerabilities and identification of financial sector development needs and consider to even recommend institutional changes.

More clarity

Financial sector analysis and advice improved notably but bank recapitalization needs and restructuring were not emphasized enough.

The Fund should be more definite and candid with its views.

1) Not enough impact analysis of domestic developments on other economies and vice versa.

2) We welcome the newly mandatory FSAPs for systemic countries and support the forthcoming spillover reports ( 5 systemic countries report, EWE).

3) Still remain problem of traction of IMF's recommendations.

Fund advice would be better tailored if it paid more attention to the broader legal, regulatory and institutional environment of the individual countries which it monitors. The Fund's tendency to use standard templates or frameworks for analysis may at times lead to an inaccurate assessment of risks or to misleading comparisons between countries that differ in fundamental respects.

Also, while Fund surveillance publications are generally comprehensive in identifying possible risks, they could devote more attention to assessing the probability or potential severity of the risks identified. This would help improve the consistency of policy advice across countries.

Staff's consultations with other stake holders' groups should be increased.

We welcome the spillover reports to be prepared by IMF and FSAP reports for systematically important countries.

Economic orthodoxy is flawed. It's not a problem peculiar to the Fund. 


\section{Appendix II, Table 7. TSR Country Authorities Survey Comments}

\section{In reference to Question 7 on which areas should be improved in order to strengthen the Fund's} surveillance, please comment on the areas you selected:

We sometimes have the feeling that the 'top-down approach', i.e. that some policy messages are 'nonnegotiable', not in the least because of consistency reasons with for example the 'euro area advise' limits the quality of the policy assessment as for some countries the policy message is not very relevant at that point of time. Although on the whole, the quality of the Article IV mission is high, an even more country-specific approach could be beneficial.

In particular, taking into account balance of payments specificities of small open economies.

Consistency of policy advice across countries: We have the impression that small countries are generally subject to stricter surveillance than bigger countries; moreover, we have sometimes the perception that the IMF's view on continental Europe is generally more critical containing more downside risks than on the US. At least for the financial sector policies, reasons behind the lack of evenhandedness appear to result also from the IMF culture of thinking: IMF staff is too caught up in its preferred economic models.

Tailoring policy advice to country circumstances: Here we feel that Fund surveillance does not sufficiently take into account the fact that a country is a member of EMU. This is particularly true for the Fund's exchange rate analysis in the context of the CGER exercise.

Constant changes in mission chiefs and in team members have meant little in-depth knowledge of our country's economy and institutions, resulting in shortcomings in quality of analysis. Also, need experts (say from functional departments, e.g., FAD), rather than generalists to do better work and surveillance in specialized areas and to have more meaningful interaction with the authorities.

It may be useful to reiterate that there is no all-encompassing panacea or quick fix solution to financial/macroeconomic distress as the circumstances surrounding the said distress is distinct to a country. Thus, policy prescriptions may vary across countries. This is one important lesson of the 1997 crisis where the IMF's prescription of high interest regime further aggravated the economic conditions of Asian countries affected by the crisis.

3. In reference to Question 9 on whether or not a press conference was held at the end of the most recent Article IV consultation, if no press conference was held, please indicate the reasons for not holding one:

It was felt that the release to the media of the Mission's concluding statement was sufficient, particularly as there were no major issues of contention in it.

This is the staff's report and we do not want to show any interference.

Ample press coverage is undertaken when the Report of the Article IV Consultation is published.

Relatively low level of general public interest in article IV consultations in our country.

A formal press conference has never been carried out in our country. The mission chief did, however, conduct a media briefing.

Normally a press release is issued at the end of negotiations.

A press release was issued as discussed with the authorities

There was no Press Release but the newspapers reported on the recent Article IV Mission.

Normally a press release is issued at the end of negotiations

A press release sufficed. There were no issues of divergence of views.

In the past, no need was seen to hold a press conference.

Ministry of Finance chose to keep the findings internal.

4. In reference to Question 11 on if more candid messages were delivered separately, rather than in the staff report, if you answered 'Yes,' please explain how. If you answered 'Other," please specify:

In Selected Issues.

Yes but could have been even stronger.

Closed door meeting between authorities and staff team. 


\section{Appendix II, Table 7. TSR Country Authorities Survey Comments}

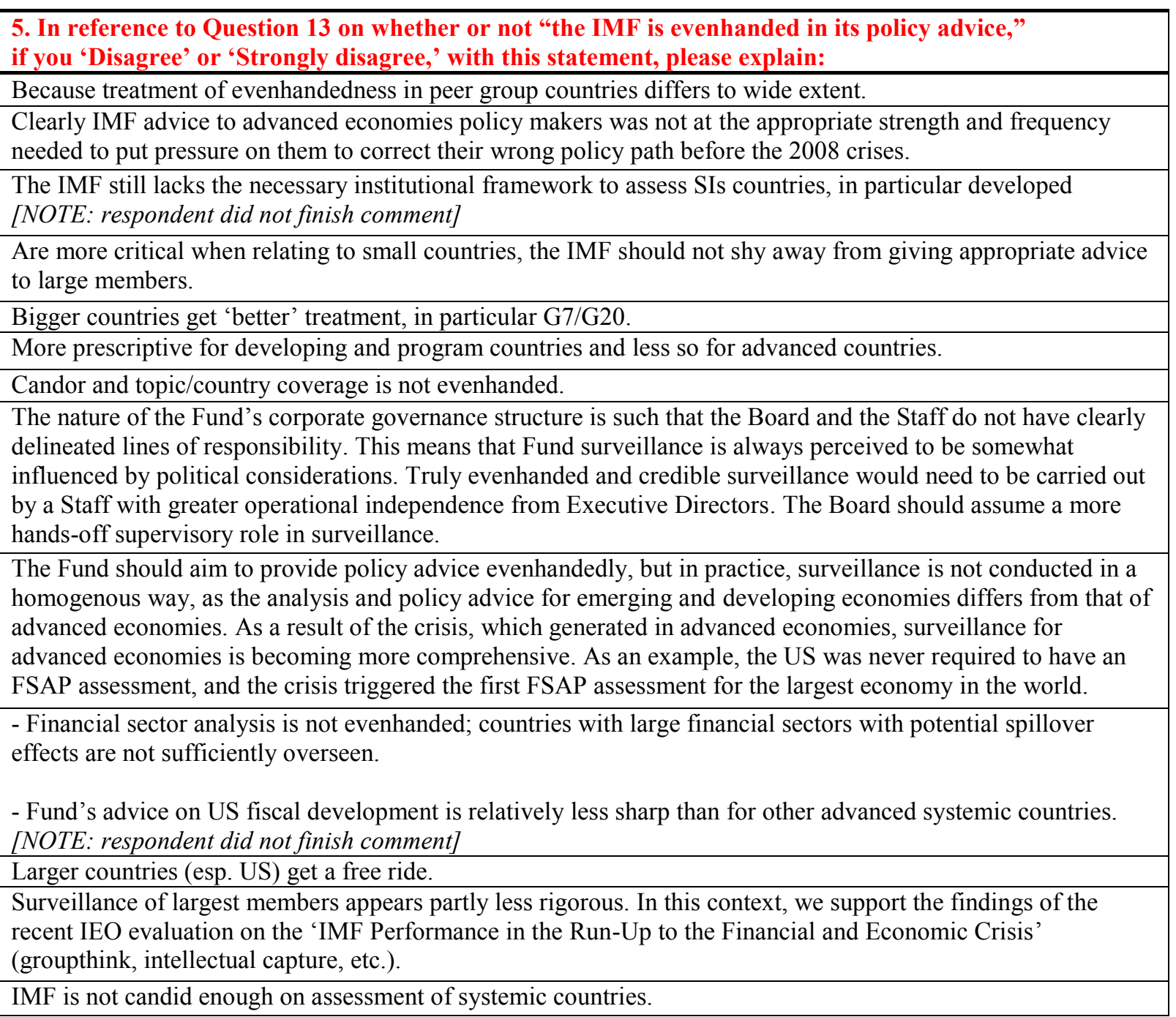

6. In reference to Question 15 on whether you feel there are differences across the membership in the precision of policy advice provided, please explain:

Risk assessment and policy advice in peer group countries in particular large advanced countries differ to wide extent.

Our sense is that Mission teams are evenhanded in their direct interactions with policymakers across the membership, but this may not necessarily be reflected in the final published surveillance product. Overall, the published policy advice for systemic countries tends to be less precise than for non-systemic economies. These differences may reflect tailoring policy advice to local circumstances.

E.g. Difference between large and smaller economies.

The policy advice to advanced countries seems to be too broad in issues that are particularly relevant for the domestic debate. The impact of the IMF's policy advice is greater in emerging markets than in developed countries. The coverage from the press and the messages delivered are very often more precise for developing or emerging markets compared to developed countries. 


\section{Appendix II, Table 7. TSR Country Authorities Survey Comments}

\section{In reference to Question 15 on whether you feel there are differences across the membership in the} precision of policy advice provided, please explain:

Largely, I suspect, a reflection of the research resource the Fund can/does throw at big country issues, compared with what is realistic for a small country. There is a difficult balance: the Fund devotes more to the US survey, since the US matters more, but it is competing in a pool with lots of researchers and analysts and the chances of making much difference to policy is limited. In a small country, with few other researchers, the chances of making a difference should be greater.

It all depends on the quality and expertise of the staff working on your country.

The Fund often hints at large members - but names small.

There is clearly a large difference with respect to exchange rate analysis. The 2007 Surveillance Decision is not being fully implemented, especially with respect to large reserve accumulators. The Fund need to be more forceful in its analysis of currency manipulation and exchange rate misalignment - it must call out when countries are not respecting the Articles and the Decision.

Policy advice is more detailed for emerging and developing economies, while for advanced economies policy advice is more general in nature.

Less advanced economies are given more precise advice, which makes sense.

We have noticed differences of precision of countries with similar characteristics (advanced/ emerging).

There is a difference between larger and smaller countries.

In the papers published (staff reports, working papers) we see different approaches to similar problems and consequently differences in the policy advices, although we feel that the similarities are more than the differences.

Similar policy advice to both low income and developed countries, for instance policy advice packages for European Countries with domestic debt crises, content and precision of policy advice has been the same as for as for developing low income countries.

Identifying differences in the scale, depth, degree and context of the problems the fund's policy advice provided became different across the members.

IMF records show instances where IMF staff advice led some countries to the wrong direction. Further, there are cases where countries' actual performance contradicted IMF projections.

If more thorough analyses of developments in major economies had been made, much of the difficulties that spilled over to other countries could have been avoided

The more developed countries ...less precision

Contingent on depth and coverage of data availability

This has mainly to do with the quality of statistics available.

This difference is explained by different attitude of the authorities.

The international agenda is set by G-20 in their interests. The Fund has so far been unable to counter this.

Precision of policy advise relates in large measure to country circumstances

Not applicable.

Depending on team members of the mission.

7. Do you see any gaps in coverage and/or unnecessary duplication among the various IMF surveillance and related products? If so, please indicate the most notable examples (if not, please leave blank):

WEO and GFSR are duplicated especially in a financial market area. They should be integrated to a single report.

There continue to be analytical inconsistencies between the WEO and the GFSR (notwithstanding the fact that the GFSR is intended to focus more on tail risks). For example, the draft Spring 2011 WEO and GFSR contain somewhat conflicting messages about the consequences of US monetary policy for capital flows to EMEs.

The key messages from many of the surveillance products (including the WEO and the GFSR) need to be brought out more clearly, through more concise summaries. This extends to the analytical chapters. We would encourage staff to write more concisely, and to focus their analysis on the most relevant points. 


\section{Appendix II, Table 7. TSR Country Authorities Survey Comments}

7. Do you see any gaps in coverage and/or unnecessary duplication among the various IMF surveillance and related products? If so, please indicate the most notable examples (if not, please leave blank):

-IMF surveillance could recognize/further enhance cross-sectoral as well as risk based approach;

-to adequately delineate roles between the IMF and other fora involved in surveillance (e.g. G20) and to keep the major role of the IMF on issues of Fund's c

[NOTE: respondent did not finish comment]

Gaps: Linkages between financial sector risk and the real economy (second round effects).

Cross country operational issues related to capital flows.

We welcome the MDs statement with key messages on the WEO and the GFSR, as the IEO report indicates lack of a clear key message from the WEO and the GFSR.

We also welcome the integration of the financial stability assessments in the Article IVs.

We would like to see more cross-country reports.

Too many publications with too little bite.

There is a gap in surveillance of external stability including exchange rate developments, reserve accumulation, and progress towards reducing imbalances.

The WEO and especially the GFSR are too long. They could be considerably sharpened and shortened. The emphasis should be on multilateral dimensions (e.g. spillovers) that are not readily available to private sector economists.

The discussion of surveillance related to capital flows is a perfect example of duplication. While SPR worked on that paper, MCM worked on a different one regarding macro prudential policies. The overlap is totally evident, especially once SPR decided to create a new category of tools: CFMs that are not residency-based. Lack of evenhandedness also is apparent, with the SPR paper suggestive of surveillance (assuming issues of capital flows are for EM), while the MCM paper on macroprudential skims the issue of surveillance.

Duplications with other international bodies could be addressed.

Gaps in coverage:

- cross-border capital flows (multilateral and bilateral perspective)/both for recipient and source countries;

- Global liquidity analysis and surveillance;

- Systemic stability perspective/analysis of spillovers.

Yes, there are gaps in the macro-financial analysis; there is a need to better analyze risks in the financial sector that may spill over to the macroeconomy (real sector).

WEO and GFSR are duplicated especially in a financial market area. They should be integrated to a single report.

More interlinking of global and country surveillance required.

Gaps: (1) Financial assessment of most systemic countries (so far);

(2) links between macroeconomy and financial sector

(3) Assessment of the impact of national policies on others' economies and outward spillovers \& associated risks

(4) Policy transparency \& accountability liability ('data gap')

Data published by the IMF in its various publications (Article IV, WEO, GFSR) have often been found to be inconsistent. 


\section{Appendix II, Table 7. TSR Country Authorities Survey Comments}

7. Do you see any gaps in coverage and/or unnecessary duplication among the various IMF surveillance and related products? If so, please indicate the most notable examples (if not, please leave blank):

In order for multilateral surveillance products to influence the decisions of policy makers, a clear and concise message is required. The key messages of important flagship publications like the WEO, GFSR and Fiscal Monitor can be obscured by the high volume of material included in these publications, including detailed technical material which at times can overshadow the main points.

The consistency of the Fund's message is also important. We welcome efforts by the Fund to integrate the flagship publications (and potentially the forthcoming spillover reports) by ensuring that the main messages are consistent, and by cross-referencing across publications to minimize overlap.

Regional Economic Outlook and WEO.

Cross country operational issues related to capital flows.

Messages should be more coherent.

There is some overlap between the WEO and GFSR.

There is a gap in surveillance of external stability including exchange rate developments, reserve accumulation and progress towards reducing imbalances.

The FSB is usurping the legitimate functions of the IMF.

Going forward, we see little need to introduce new multilateral surveillance products. Actually, the Fund needs to be careful not to confuse readers by establishing too many publications dealing with multilateral surveillance issues. Instead, the analysis of multilateral developments, including spillovers and cross country linkages, should be enhanced within the framework of existing surveillance products. Moreover, we see limited value added of REOs in terms of raising effectiveness of regional surveillance and interlinking bilateral and multilateral surveillance.

More voting rights should be vested on emerging market economies, although there are steps being adopted by the IMF in this regard.

8. We would welcome any general comments on what the IMF could do to enhance the overall effectiveness of surveillance, or provide specific follow up referencing the question numbers as appropriate:

In order to enhance the effectiveness of surveillance, Articles of Agreement of IMF should be amended to include financial stability in the formal purpose of IMF.

Overall it is balanced and appropriate 


\section{Appendix II, Table 7. TSR Country Authorities Survey Comments}

8. We would welcome any general comments on what the IMF could do to enhance the overall effectiveness of surveillance, or provide specific follow up referencing the question numbers as appropriate:

General comments:

The Fund should focus its surveillance on its areas of comparative advantage, in particular, on macrofinancial and cross-country linkages. An important element of this is ensuring that multilateral and bilateral surveillance products are linked up.

We think the Fund is in the best position to carry out surveillance of cross-border capital flows, but that its ability to do so is hampered by inadequate data. We would strongly encourage further progress on the work already underway at the IMF and the BIS. This should include more detailed information on the capital flows to and from countries for which we already have some data, and extending the sample of countries (in particular, to capture better flows between emerging markets).

For systemic economies, the effectiveness of surveillance could be enhanced by ensuring that national policymakers are able to engage with IMF Staff/external consultants with a commensurate degree of seniority.

Comments on specific questions:

Question on assessing Fund policy advice in the most recent Article IV in terms of generating policy debate and fostering policy change: Fund advice has been helpful in generating policy debate in relation to banking sector regulatory issues, but it has had minimal impact on the monetary policy debate.

Question on which multilateral surveillance products have been the most helpful: The GFSR contains useful analysis, but is an unwieldy document. It could be improved by increasing the focus on the key risks, and ensuring consistent messaging with the WEO. The EWE/Vulnerabilities exercise is a secretive process, which detracts from its ability to inform policy (except perhaps at the most senior level).

Question on which other IMF products have been the most helpful: the FSSA is too long. We would suggest producing a summary containing key charts and tables. Cross-cutting thematic reports are a step in the right direction. We would encourage staff to ensure that the focus remains on drawing out key lessons from these exercises.

We are very satisfied with the IMF's surveillance and assistance on specific subjects, which has been very helpful in facing the 2008-2010 crisis, as well as current situations in our country.

Personnel changes of the IMF staff members should be kept to a minimum. There might be room for further involvement of the OAP during the IMF mission.

To enhance the overall effectiveness of surveillance, the IMF should improve the quality of analysis, provide detailed but appropriate policy prescriptions and follow up by conducting implementation reviews and assessing their impact on the economy.

The IMF could be even more candid in its policy advice, in particular telling the 'truth' when a country's policies are too lax, bound to lead to financing difficulties when adverse situations materialize. Should pay more attention to risks of too large external financing positions (leverage e.g. private sector balance sheet in relation to GNP, public sector/fiscal sustainability)

How come IMF failed to warn on Iceland debt build-up or the same for Ireland?

- to aim at improving the follow-up and implementation of Fund's policy advice;

- to further emphasize the role of systemically important economies

High risk for future duplication of surveillance, in particular in Europe (IMF/EBA/ESRB/FSB/BCBS...).

Follow IEO recommendations.

We encourage the IMF to prepare general guidelines or principles for managing capital inflows/outflows, further elaboration of metrics for reserve adequacy and inclusion of these metrics to IMF surveillance. 


\section{Appendix II, Table 7. TSR Country Authorities Survey Comments}

8. We would welcome any general comments on what the IMF could do to enhance the overall effectiveness of surveillance, or provide specific follow up referencing the question numbers as appropriate:

- organize regional consultations with national authorities

- make presentation of surveillance documents after the Board discussion

- have closer interaction with the authorities before the Article IV mission

A refinement of the CGER methodology would be welcome. It should allow a better assessment of the exchange rate situation, in particular of small open economies.

- Greater transparency on assumptions used for macroeconomic forecasts

-Greater transparency on country specific models for macroeconomic forecasts

-Greater reactivity on current economic developments, at least for small advanced countries.

The Fund teams really need to know the country, and the ethos of its bureaucracy and policymakers. In some countries, candor and searching challenge won't be very welcome. We tend to crave challenge and welldeveloped alternative perspectives. In countries with that sort of culture, really top-notch analytical leaders are likely to have the most impact - relationship management etc is relatively less important than when the issue is getting heard at all.

This is not a recipe though for shying away from hard challenges in unreceptive countries. In my experience at the Board the Fund's surveillance too often failed from not posing hard enough questions and challenges, and being too willing to go along with conventional wisdoms (e.g. the euro area), than from being the boy who cried wolf.

We see a role for the IMFC as a medium through which members apply peer review and pressure and address cross border spillovers of domestic policies.

IMF shall adjust its focus of surveillance, paying more attention to the macroeconomic policies of major reserve currency issuing economies, the financial sector and the cross-border capital flows.

Follow a policy of more evenhandedness.

We support increased transparency of surveillance products, including mandatory publication of Article IV reports and publication of CGER analysis. Stronger discussion of capital flows and stronger analysis of reserve adequacy, incorporating the Fund's new metric, is also needed in bilateral surveillance. Reforms to the IMF organizational structure may be required to help promote greater consistency and candor of surveillance across countries. Staff should move forward in incorporating the recommendations of the recent IEO report on surveillance. More generally, the Fund should reflect on its value added in surveillance of advanced economies and emerging markets given the large amount of academic and investment bank analysis and surveillance. 


\section{Appendix II, Table 7. TSR Country Authorities Survey Comments}

8. We would welcome any general comments on what the IMF could do to enhance the overall effectiveness of surveillance, or provide specific follow up referencing the question numbers as appropriate:

For us, corporate governance reforms are the next and necessary step in the evolution of IMF surveillance. We would recommend the full implementation of the IEO recommendations on corporate governance reforms to enhance accountability, delineate lines of responsibility, enhance ministerial involvement and augment the Board's role in terms of Staff supervision (rather than direct Board involvement) and in setting the strategic direction of the Fund (and its surveillance). By providing the Staff with greater operational independence (though still accountable to the Board periodically), the credibility and traction of the Fund's advice would improve notably. We would recommend:

- more work in terms of pushing ahead with the IMFB

- a greater role of independent evaluation in the TSR (less staff self-assessment).

- stricter implementation of the 2007 surveillance Decision

- better use and expansion of the Statement of Surveillance Priorities, to act as a means of getting countries to re-affirm their Article IV commitments.

The IMF should work more strongly in tailoring their policy recommendations according to a country's specific circumstances.

We think the IMF can enhance the effectiveness of surveillance by providing equal policy advance and assistance across on the membership economies.

- The legal framework of IMF surveillance should be reviewed to ensure that IMF is equipped to deal relevantly with today's economic and financial realities: systemic stability and spillovers, capital account management, macro-financial stability. To thi

[NOTE: respondent did not finish comment]

We believe that completion of the governance reform will be critical component of effective IMF surveillance for providing emerging markets with a greater sense of ownership and for fostering global policy coordination.

More independent analysis and candid policy assessments, in particular of systemically important countries.

The regional and subregional reports should be updated more frequently.

In order to enhance the effectiveness of surveillance, Articles of Agreement of IMF should be amended to include financial stability in the formal purpose of IMF.

-Greater transparency on assumptions used for macroeconomic forecasts

-Greater transparency on country specific models for macroeconomic forecasts

-Greater reactivity on current economic developments, at least for small advanced countries

The staff reviews should be made public and not depend upon the approval of authorities. This is an important document for the purposes of accountability and transparency and withholding this report to be seen by a select few creates inequality to access of information and could be used for personal benefit.

Access to information like BOP, Debt database and monthly and annual bulliton be enhanced.

We think that IMF should do more to share with the local Authorities the knowledge pertaining to the techniques IMF staff adopt on their assessment missions; we think that this matter will facilitate understanding and ownership of IMF recommendations by local authorities.

As indicated earlier, the IMF could do better in analyzing developments in more advanced economies. Certain developing countries have been frequently advised to modernize their financial system, whereas it was poorly recognized that the modernization could make them more vulnerable to malfunction of international financial markets. Indeed, some developing countries have suffered from international financial investment by their institutions / residents. 


\section{Appendix II, Table 7. TSR Country Authorities Survey Comments}

8. We would welcome any general comments on what the IMF could do to enhance the overall effectiveness of surveillance, or provide specific follow up referencing the question numbers as appropriate:

Transfer of knowledge between persons coming to work on a country and the one leaving. Too much time is spent going over the same issues with each change of personnel.

More country specific research...could be joint with the authorities.

- FSAPs on a more formal and regular basis, interlinked with the Article IV process, is a major step forward in addressing concerns expressed in earlier answers.

- Early Warning Exercise is also welcome.

- The IMF database is very useful and its expa

[NOTE: respondent did not finish comment]

1) We would welcome institutional measures that bring more traction from the members;

2) We welcome the proposed review of the surveillance legal framework in order to clarify \& enhance the IMF's role in global financial stability and in particular capital flows management. We think that all possible options for reform should be considered (such as a review of the 2007 Decision and multilateral surveillance decision or amendment of the Articles of Agreement); 3) The Fund's potential role in monitoring capital flows should be enhanced; 4) We welcome the developments of tools and databases relative to multilateral surveillance but have to contemplate every information tools.

IMF should adjust its focus of surveillance, paying more attention to the macroeconomic policies of major reserve currency issuing economies, the financial sector and the cross-border capital flows.

We welcome the Fund's recent work on financial stability issues, as well as its attempts to develop analytical underpinnings for its surveillance (e.g. the recent paper on capital flows). We encourage this work to continue.

We encourage the Fund to continue working closely with the G-20 and coordinate closely with other bodies. This will help enhance the traction of Fund surveillance.

While recent publications have been very comprehensive in their listing of potential vulnerabilities, greater assessment of the likelihood and severity of the various risks identified could increase their usefulness for decision makers and improve the clarity of the message.

Bilateral surveillance should continue to have a cornerstone role in Fund surveillance as it remains the most direct way for the Fund to communicate policy advice to country authorities, and it provides a valuable opportunity for candid and confidential discussions. While the Fund's efforts to develop its multilateral surveillance are useful, these efforts should not come at the expense of its bilateral surveillance work.

Access to information like BOP, Debt database and, Monthly and Annual Bulletin be enhanced

The turnaround of staff work in the country has an impact on the dialogue with the authorities. Any team working on a given country should be stable for at least 2 years. This will help improve the understanding the country's specificities, thus limiting the communication gap and improving the dialogue with the authorities.

We encourage the IMF to prepare general guidelines or principles for managing capital inflows/outflows, further elaboration of metrics for reserve adequacy and inclusion of these metrics to IMF surveillance.

We support increased transparency of surveillance products, including mandatory publication of Article IV reports and publication of CGER analysis. Stronger discussion of capital flows and stronger analysis of reserve adequacy, incorporating the Fund's new metric, is also needed in bilateral surveillance. Reforms to the IMF organizational structure may be required to help promote greater consistency and candor of surveillance across countries. Staff should move forward in incorporating the recommendations of the recent IEO report on surveillance. More generally, the Fund should reflect on its value added in surveillance of advanced economies and emerging markets given the large amount of academic and investment bank analysis and surveillance.

We are quite pleased with Fund surveillance. We see no need for significant change. 


\section{Appendix II, Table 7. TSR Country Authorities Survey Comments}

8. We would welcome any general comments on what the IMF could do to enhance the overall effectiveness of surveillance, or provide specific follow up referencing the question numbers as appropriate:

- MD's statements with key messages on the WEO \& GFSR are important, as they will force the IMF to come with one message.

- We also welcome the integration of the financial stability assessment in the Article IVs.

- We would like to see more cross-count

[NOTE: respondent did not finish comment]

A refinement of the CGER methodology would be welcome. It should allow a better assessment of the exchange rate situation, in particular of small open economies.

In our view, it will be paramount to further enhance the Fund's analytical capabilities in the field of macrofinancial surveillance even beyond the progress that has been made recently. Generally speaking, we believe that efforts to strengthen surveillance should primarily focus on issues of substance and less on procedures.

Some degree of co-ordination and follow-up between Surveillance exercises will help in the preparation of forthcoming missions. Sometimes the policy advice is only reviewed in the consultation that follows.

To improve IMF surveillance (especially the preventive aspect) competent IMF staff should be assigned more in a sustained manner to smaller IMF non-operational members. This surveillance should be backed by experts (from functional departments, e.g., fiscal expert and BOP statistics expert included in missions to our country). Quality of staff needs to be improved with recruitment of experienced personnel from Central Bank Supervision departments and Government Treasury departments, rather than from academia and the European Commission and the Inter American Development Bank. Surveillance for smaller economies at least should concentrate on an assessment of vulnerabilities in specific areas that have serious macroeconomic consequences and/or systemic repercussions.

We emphasize that the Fund should modify incentives for the Fund's staff to speak truth and to overcome the hurdles which have led to a lack of evenhandedness in the Fund's treatment of its members. The Art. IV mission team should be diversified in its expertise; to incorporate staff with some experiences on policy making apart from existing bright economists. Furthermore, this undertaking will be more effective with a sufficient preparation in advance of the mission.

Surveillance can be improved through pointing out clearly the emerging risks, providing a comprehensive explanation of policy options to minimize exposures, and preparing ways to respond if some of the risks materialized. The Fund and staff should remain supportive of country's needs for capacity building and technical assistance; and TAs should be provided on a timely and effective manner. 


\section{Appendix II, Table 8. TSR Executive Directors' Survey Comments}

1. Do you see any gaps in the coverage and/or unnecessary duplication among the various IMF surveillance and related products? If so, please indicate the most notable examples (if not, please leave blank):

Most notable overlaps are in the fiscal area with area departments, FAD, RES and MCM all doing very similar work, leading to seeming contradictions in IMF analysis and muddying the message.

The consistency of key messages in the WEO and the GFSR has improved and continued efforts will be essential.

REO vs. WEO, Article IV, and Cross country thematic reports. REOs may be viewed as redundant. Too early to gauge on thematic reports.

Analysis of the implications of the policies of the systemically important countries (especially the United States) for the global monetary and financial stability and for the macro-economic management in the emerging market economies has remained very weak, particularly in the bilateral surveillance exercise. The relative importance of risks identified in the multilateral surveillance (through early warning, WEO, GFSR, fiscal monitor report) has not been allowed to affect the allocation of Fund surveillance attention and staff resources. The institutional surveillance framework (esp. the 2007 Decision) fails to capture the key risks to international monetary and financial stability. Ad hoc improvement in surveillance practice cannot substitute an urgently needed reform of surveillance framework.

WEO, GFSR, and Fiscal Monitor.

The REO reports do not always cover the relevant groupings of countries and their impact on policy making is questionable.

There is a risk that numerous products could blunt the key messages. A single short and succinct multilateral product that is more than a synthesis would be required as accompaniment to the various products.

I see some overlaps between the Fiscal Monitor and the WEO/GFSR. The frequency of the Fiscal Monitor could be reduced.

Not much duplication, but I have noticed an effort to harmonize the WEO and GFSR reports, and I encourage staff to continue these efforts.

Much of the WEO, GFSR (and to some extent the Fiscal Monitor) covers overlapping territory: analysis and policy messages around the need to tackle vulnerabilities and the financial sector and fiscal consolidation. Parallel publications convey a sense that the publication strategy is being driven by Departmental structures, not by the messages that the Fund has to convey.

\section{In reference to Question 8 on whether or not Article IV staff reports appropriately weight and incorporate various risks to the medium/long-term outlook in the bottom-line assessment, if you marked "Strongly disagree" or "Disagree to some extent," please explain:}

A key shortcoming of Fund surveillance in advanced economies and systemic financial centers has been its failure to highlight relevant risks and vulnerabilities. Indeed, the mistake of not including advanced economies in the Vulnerability Exercise launched in 2001 was corrected only after the crisis.

Article IV Reports are the bread and butter of this institution. Important to provide frank assessments of macro-economic and macro-prudential policies. Greater responsibility should be placed on membership to comply with its obligations to undertake this surveillance and publish.

Staff policy advice on addressing the medium and long term risks in advanced economies has been vague (compared with that given to emerging market economies), often self-censored on the ground of perceived political constraints.

It seems to me that emerging market Article IVs, especially of highly dynamic countries, has been somewhat soft on policy advice and somewhat lacking in bringing out the impact of their policies on other countries (both emerging and advanced).

Article IV staff reports for several AEs remain coy about the full extent of risks these countries face. The Fund has been muted about risks of debt defaults in some European countries or bogged down fiscal consolidation plans in others.

Risks are generally incorporated, but less so for advanced economies, especially in the case of the U.S. 


\section{Appendix II, Table 8. TSR Executive Directors' Survey Comments}

\section{In reference to Question 14 on if, in your view, the Fund's messages are not appropriately} consistent among various surveillance and related IMF products, please explain:

Area department products frequently differ from multilateral surveillance products. For example, area departments will most likely find FX reserves accumulation to be appropriate while papers prepared by functional departments would signal excess reserves accumulation.

WEO, Fiscal Monitor, and Bilateral Surveillance often include mixed messaging and advice for countries.

1. On exchange rate assessment, staff reports focus too much on the short term. Although the assessment of the level is based on medium term projections of fundamentals, including current account balance, however, such projections are based on a constant exchange rate. This is self defeating. Furthermore, staff considers major reserve currencies' exchange rates are appropriate (with only one slightly away from equilibrium), while that of some major emerging market currencies are substantially undervalued. How can that happen if the latter is trading overwhelmingly with the former group?

2. On capital flows, staff reports do not see any recent surge in net flows from advance to emerging markets. However, much of their attention has been focused on developing guidelines on measures to deal with inflows. At the same time no attempt has been made to analyzing the implications of advanced economies' policies for global capital flows. On the policy choice for recipient countries, staff advice is to make macro policy adjustments before resort to capital controls, despite their recognition that the inflows are due to relatively better fundamentals in the recipient countries. Why adjust the policies of the countries with better fundamentals rather than those of the countries with weaker fundamentals?

Notwithstanding important efforts in recent years by staff to work together across the products, it is the differing emphases of the various products that undermine the consistency of the messages. To illustrate: the WEO will capture the strengthening recovery, but will gloss over the continuing weaknesses in financial balance sheets which in the medium term holds more risks to the outlook are best captured in the GFSR. Flagship publications (WEO, GFSR) give impression of having been reconciled at late stage in production process. Differences of emphasis still emerge. And area departments often have different perspective on individual countries.

4. Please indicate whether you see a systematic tendency for reports on certain types of countries, or
countries with certain types of issues, to be less candid than others. Please provide some examples:
IMF staff have tendency to accept many reasons for high forex reserves accumulation -- aging populations,
for example. Yet how can the many countries with aging populations all promote exports to generate higher
reserves?
AEs, and countries facing problems in arrears such as foreign exchange, banking, debts, and arrears.
I believe that the risks in emerging economy reports are downplayed.
I still see more convergence of views between authorities of AEs and staff, but a clearer reflection of
divergence of views with EMs and LICs.
We have noted in the past that Article IV reports were favorable regarding developments in many advanced
economies. After the crisis we find out that the reports were not very candid about weaknesses in certain
sectors. For example: Greece, Ireland.

5. In reference to Question 16 on, in your view, to what extent the policy advice in IMF Article IV staff reports is evenhanded across countries, please elaborate why you selected "Not at all" or "To a little extent:"

Article IV reports tend to more candid and critical of the current policies of the emerging market and developing countries than on the advanced economies, esp. major shareholders. They tend to be candid on the past policy mistakes of advanced members, but endorse their current policies and vague on the adjustments needed. On the need for structural reforms, the advice for the advanced economies has always been sketchy, and there is no progress monitoring anything similar to that over the emerging market and developing members. The latter group is being asked to share the disproportional burden of adjustments to the global excesses mainly caused by the policies of the advanced economies.

This is coming from lack of coordination on the part of the management and staff, and political considerations. 


\section{Appendix II, Table 8. TSR Executive Directors' Survey Comments}

5. In reference to Question 16 on, in your view, to what extent the policy advice in IMF Article IV staff reports is evenhanded across countries, please elaborate why you selected "Not at all" or "To a little extent:"

On low income countries, the reports do not hesitate to criticize policies and measures taken, but we do not see the same approach when it comes to advanced economies and some emerging countries whose policies many times have spillover effects. For example, there is little criticism of protectionist agricultural policies in advanced and emerging economies, but protectionist policies in low income countries are always criticized.

6. Are there differences in the traction of surveillance among the countries in your constituency? If so, please explain:

Difference between program and non-program countries

Clearly, Fund advice has more traction in small countries with limited domestic policy development capacity. In larger, more advanced countries, Fund advice can help test or affirm existing views. Public debate about Fund advice can be helpful at the margin, but may also be counterproductive, depending on the prevailing political dynamics.

There is a difference between program and non-program countries.

Traction is not surprisingly highest in program countries. Traction is relatively high in countries which want to maintain a good track record and which are vulnerable to changes in market sentiment.

Program countries tend to follow Fund advice more closely. By contrast non-program countries are remote and in some cases see Article IV consultation as a process to tick a box and wait for the next consultation.

LICs and small middle income countries are more likely to follow Fund recommendations and policy advice.

There is not much difference among the countries in my constituency.

Yes, stronger in program countries.

7. What steps could be taken to improve the traction of the Fund's surveillance?

Always address issues of key concern in member countries from the authorities' perspective including with policy options and arguments pros and cons, better use of cross-country relevant experiences across the Fund's membership, increase significantly share of staff with practical policy experience, focus more on diversity of thinking. Ensure that Article IV reports would explain why if recommendations are not followed.

Clearer public messaging.

Enhancing the traction of surveillance would depend in large part on the Fund's ability to gain the trust of the authorities. Indeed, convincing the authorities of the merits of Fund's advice is paramount to the implementation of such advice.

Systematically improve the Fund's policy advising; skills, as opposed to technical skills, and think more strategically about how to engage the authorities on sensitive issues.

Appropriate candor in assessments and advice, and the responsibility of membership to publish.

Greater candor and even-handedness, less political influence on the mission teams.

Mission chiefs need to be familiar with the issues at hand and take into account the political and social implications of their advice.

A more consistent monitoring of what happened to past Fund advice. More specificity in Fund advice. As ultimately most countries will exit Fund program, it is important for the Fund to identify more effective ways of engaging with authorities through products that appeal to all the membership.

More clear and concise messages on multilateral surveillance.

Elevate some surveillance discussions at the ministerial level. Incorporate in Article IV reports a Box on how the authorities did or did not follow-up on past recommendations. Strengthen the multilateral dimension of surveillance.

Just as is done now as regards press conference at the end of missions, staff could give conferences or seminars on important economic policies that are important for the country.

Greater ministerial involvement, guidance, and review 


\section{Appendix II, Table 8. TSR Executive Directors' Survey Comments}

7. What steps could be taken to improve the traction of the Fund's surveillance?

Demonstrate genuine value added to the authorities based on real expertise. The authorities look to the Fund for advice on how other countries have approached similar issues but it is not always forthcoming.

It is admittedly hard to do so on the basis of the current pattern of one/two week mission a year. This suggests there is a case for rethinking the surveillance model, and looking for more consistent and frequent but shorter engagement.

Seeking to improved traction through more media engagement would be a mistake. It puts the Fund in play in the media in a way that undermines the confidential advisor role.

8. We would welcome any general comments on what the IMF could do to enhance the overall effectiveness of surveillance, or specific comments referencing the question numbers as appropriate:

The Fund must be viewed by the authorities as an independent and trusted advisor to enhance acceptance of Fund's advice. Moreover, the Fund should be seen as evenhanded across countries and group of countries. Increasing the regional diversity of Fund staff is also important to strengthen the quality of surveillance. More adverse scenario testing of the baseline projections in every Article IV. Obligatory reserve adequacy assessment, exchange rate assessments in every Article IV report. Contribution to widening or closing global imbalance gap.

Overhaul of the surveillance framework is urgently needed to capture the changed dynamics of the global risks. It should at least assign equal attention to monetary, fiscal, financial sector policies as well as macrocritical structural policies to that of exchange rate.

Greater involvement of ministers in IMFC meetings on surveillance issues.

Whatever the number of surveillance products, which may be necessary for better targeting of the diverse membership, the key message must still come out and be remembered easily.

Surveillance must of course adequately cover countries specificities but some higher degree of standardization could be useful (inclusion of a Box on follow-up on past advice, more consistency in the analysis of the exchange rate, rigorous implementation of the newly established guidelines on capital flows...).

At a higher level of ambition, traction would be enhanced by ministerial discussion of some issues and more emphasis on the multilateral dimension (spillover analysis). This would increase interest in the product and this should not be done only for the systemic economies where a specific spillover report will be presented, but more generally. Another idea could be to better articulate surveillance and lending and use surveillance to qualify countries for different types of lending facilities. This would raise the stakes in surveillance discussions.

Finally, the fundamental issue is the legal framework of surveillance, which is outdated. Fund jurisdiction over the capital account seems necessary, under one form or another.

The so-called 'innovative format' for Article IV is not an improvement in my view. These reports tend to provide less substantive analysis and argumentation.

The present approach is broadly appropriate. However, we think that assessment of policies and their medium term and long term impact and also their effects on other countries should be spelled out. The views of authorities should be given more prominence, especially when these views differ from those of staff.

Keep improving financial sector expertise within staff.

The bilateral model of annual missions and little other engagement needs to be rethought.

Multilateral surveillance which highlights inter-relationships and spillovers deserves more emphasis overall, potentially opening scope for more traction and influence. But the suite of flagship multilateral products do not engage the authorities and are in urgent need of reform/consolidation.

The evidence of Departments failing to work together - but rather working in parallel - is very clear.

Arguably the biggest Management challenge in surveillance is to tackle this. 


\section{Appendix II, Table 9. Mission Chiefs' Survey Comments}

1. If relevant, please explain how you use the analytical inputs that you provide for the G-20 in the course of your other surveillance work:

The regular surveillance work and its analytical component are aligned broadly with the priorities and directions of the $\mathrm{G} 20$ as a whole, so the ongoing work readily translates into input that is also relevant to the G20. So analytical surveillance drives G20 contributions, not the other way around. This involves keeping close tabs on overall G20 deliberations and focus.

the $\mathrm{G} 20$ process has just been a cost to my work and had no benefit

Use of work of financial sector stability, lessons from the crisis, and addressing global imbalances assessing country and regional risks

If what is being asked is whether the work required in the context of G20 adds value to our bilateral surveillance, 'Not much' is the answer. Responding to G20-related work request is simply an additional workload we have to carry.

We use it as input into the staff report and SIPs that focus on medium-term challenges

As a means of assessing global economic developments and their impact on country in question; advising authorities of implications and these developments that might impact them

I am not sure if this note is referring to the G-20 MAP or to the G-20 surveillance notes or the fiscal monitor.

- If the former, we do not use at all the analytical inputs for the MAP in our other surveillance work. This is in part because the country that I cover is not well-covered in the MAP which relies on broad country groupings that do not really apply to this country.

- If the latter, we tend to use the analytical inputs for these exercises more in our bilateral surveillance work. We have shared information with the authorities on fiscal multipliers, automatic stabilizers, and putting the country in a global context using global economic developments, etc.

\begin{tabular}{|l|}
\hline 2. In reference to Question 7 on to what extent the authorities were open and receptive to discussions on \\
risk assessments, if you marked "Not at all" or "To a little extent," please indicate why: \\
\hline The authorities are very sensitive to any discussion of policies or institutional arrangements that are less than \\
perfect, for domestic political reasons. As a result, there is a serious disincentive to do candid risk assessments, \\
as the process becomes very onerous and combative all the way to the Board discussion, and individual team \\
members are singled out by the authorities for retribution and repeatedly asked to be replaced. Fortunately, our \\
Front Office has been very supportive, but it uses up a lot of our political capital to defend our work, even when \\
the risks have (and did) materialize subsequently. \\
\hline $\begin{array}{l}\text { I think some authorities perceive extensive discussions on low-probability risks as 'speculative' and not worth } \\
\text { their time. This is truer in the Ministry of Finance, where ST concerns dominate, than in the Central Bank. }\end{array}$ \\
\hline The authorities tend to dismiss the tail risks as irrelevant doom saying. \\
\hline The authorities regarded such discussions as too hypothetical. \\
\hline $\begin{array}{l}\text { The authorities were to a large extent focused on domestic political issues which distracted them from macro- } \\
\text { financial priorities. }\end{array}$ \\
\hline \begin{tabular}{l} 
The existing, high probability risks are pretty obvious, but less obvious is a thorough accounting of the potential \\
costs involved (quasi-fiscal, financial, or other) and the best way to go about resolving or mitigating these risks. \\
As policy-makers with limited time, the authorities are understandably focused on high probability risks, with \\
significantly less appetite for tail risks. \\
\hline They discounted the tail risks. \\
\hline Due to capacity constraints even the discussion of more standard risks is a luxury. \\
\hline Focus is on ensuring implementation of sound policies and main risks, which are plenty already. \\
\hline - In Country A I work one: \\
authorities unwilling to discuss risks of spillover from a European country in crisis to their banks- they have \\
little control over it and no tools to address it as their exchange rate arrangement precludes liquidity support. \\
-authorities see [NOTE: respondent did not finish comment]
\end{tabular} \\
\hline
\end{tabular}




\section{Appendix II, Table 9. Mission Chiefs' Survey Comments}

The high probability risks dominate the discussion

The country in question is not integrated regionally or globally. The main challenges it faces are internal. Authorities felt risks would not impact significantly the domestic economy.

In a low income country context, highlighting risks carries a lot of costs but little benefits as long as there is no option for additional financing--which is clearly the case now.

Small country far removed from financial market risks.

There are very well-identified high probability risks (oil price volatility, security), while tail risks are not well understood in this case.

The high probability risks were so important and potentially damaging that there was a need to focus on these and not dilute the discussions taking up less pressing issues.

(i) To avoid spooking markets; (ii) difficulty in defining the appropriate policy response to tail risks, especially if their impact is seen as uncertain.

We did not discuss tail risks and neither did the authorities bring them during the discussions.

Decided to focus on major risks.

3. In reference to Question 9 onto what extent you found the following issues challenging in the latest Article IV consultation: Identifying key financial sector vulnerabilities/risks; Assessing potential macroeconomic implications of financial sector developments; Assessing cross-border financial sector risks stemming from other economies; Assessing key domestic financial sector vulnerabilities which may have cross-border implications; and Drawing out clear policy recommendations, for the most challenging issue, please provide a short explanation setting out why:

The capacity of the regulatory authorities to collect and analyze data is very limited.

Many issues pertain to cross-border financial institutions and the policies should be developed in a broader context than bilateral surveillance.

Deciding how much of the difficulties in financial institutions were due to idiosyncratic factors (as claimed by the authorities) vs. systemic/regulatory weaknesses.

Information on the full risks from other countries is often not available in an easily digested format.

The authorities are unwilling to provide non-public data on banking and financial risks, and this is a significant constraint on our ability to identify such risks.

Lack of relevant data on cross-border exposures.

The situation in Europe--where most cross-border issues for my country come from--is very fluid and complex. Getting agreement on how to address concentration risk.

Financial sector vulnerabilities/risks are not out there for anyone to see. That is why, in the case of individual institutions, resource-intensive on-site examinations are necessary. The risk identification process is often hampered by the difficulty of determining appropriate (fundamentals-based) asset values against which each institution's and/or financial industry's asset quality has to be measured.

Once such vulnerabilities/risks are identified, drawing out policy recommendations that directly address them is not difficult. But their macro implications are not straightforward, not least because how people's sentiment and/or financial institutions' behavior are affected by a risk event is difficult to predict.

No particular challenges for any of them to the extent that the information was accurate.

Assessing the impact of a fall in house price on the banking sector and wider economy was the most difficult issue for the authorities politically. They resisted discussion of tail risks in this area.

The authorities initially were rather complacent and defensive. It took effort to get a serious discussion going about financial sector risks.

Why challenging? Because we don't have the resources, and since we are a LIC/non-systemic case, we don't get assistance from MCM, but instead have to rely on other IFIs.*

Difficult to assess the macroeconomic implications of realization of possible currency-induced credit risk. Also difficult to define (and recommend) the level of sustainable credit growth from both a macroeconomic and financial stability perspective.

Poor quality of financial sector data. Lack of data on cross-border financial flows.

*Edited for language. 


\section{Appendix II, Table 9. Mission Chiefs' Survey Comments}

3. In reference to Question 9 onto what extent you found the following issues challenging in the latest Article IV consultation: Identifying key financial sector vulnerabilities/risks; Assessing potential macroeconomic implications of financial sector developments; Assessing cross-border financial sector risks stemming from other economies; Assessing key domestic financial sector vulnerabilities which may have cross-border implications; and Drawing out clear policy recommendations, for the most challenging issue, please provide a short explanation setting out why:

Macro-financial linkages are very difficult to assess in quantitative terms. They depend on having complex models and significant amounts of data--neither of which are available to us. More broadly, data limitations make it very difficult to conduct analysis.

Of course, the biggest challenge is not drawing out the policy conclusions per se, but rather convincing the authorities to act.

An FSAP Update preceded the Article IV and financial sector vulnerabilities/risks were discussed intensively during the program.

The financial sector is under-developed. Central bank capacity is very weak and financial sector data are very weak as well.

- Authorities do not provide bank by bank supervisory data. This means staff cannot assess individual banks well and cannot run stress tests (using public data would require an RA to enter balance data for 30 banks over 5 years using quarterly statements.)

The risks are obvious--from very heavy directed lending and weak supervision capacity

Lack of reliable and up to date financial sector data make it difficult to determine the extent of risks in the sector.

Time constraints, lack of resources, lack of staff training

Official data and data from on-site inspections differ by a wide margin.

It is a low-income country with an undeveloped financial sector that is on the verge of an external crisis.

However, it is hard to assess market pressure accurately.

Little is known about actual the nature of financial sector vulnerabilities--this is why FSAP was recommended before next Article IV.

No framework or database exists for this analysis. (Note the banking system is well capitalized, diminishing many risks at least for the time being.)

Data limitations hamper analysis of macro-financial linkages.

Assessing cross border risks was hard because of lack of information on the operations of multi-country financial institutions.

The financial sector in the country I work on is small, and the macro implications of issues such as high NPLs for the broader macroeconomy are not straightforward.

4. In reference to Question 11 on what quantitative/analytical tools for financial sector surveillance you have used in the Article IV consultations over the last three years, if you used market-based-indicatorrelated models or models which are not listed, please specify:

We used CDS and spreads for example

A chapter in the SIP focused on market-based indicators to assess linkages between banks within the country and between local banks and banks abroad. 


\section{Appendix II, Table 9. Mission Chiefs' Survey Comments}

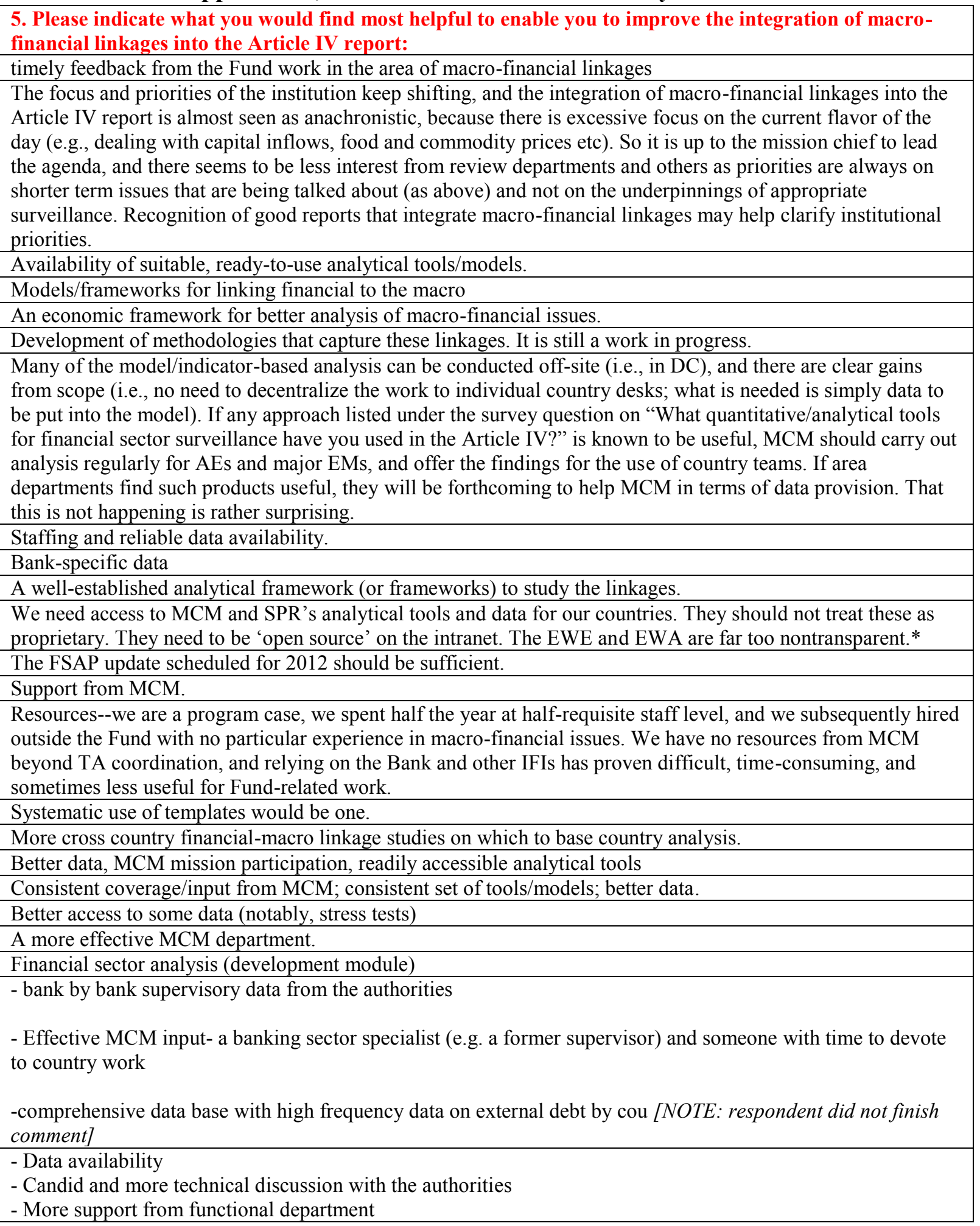

*Edited for language. 


\section{Appendix II, Table 9. Mission Chiefs' Survey Comments}

\begin{tabular}{|l|}
\hline $\begin{array}{l}\text { 5. Please indicate what you would find most helpful to enable you to improve the integration of macro- } \\
\text { financial linkages into the Article IV report: }\end{array}$ \\
\hline $\begin{array}{l}\text { MCM's current focus is on G-20 and other vulnerable economies. Getting them focused on other countries } \\
\text { requires a lot of persistence. MCM should create a unit serving as a backstopping center for all country teams, } \\
\text { so that we can all do our jobs in a more balanced way. }\end{array}$ \\
\hline More training. More time in the field. \\
\hline Macro-financial linkages are very limited due to the low level of financial development in the country. \\
\hline More support from qualified MCM economists. \\
\hline Having an FSAP done before next Article IV \\
\hline mission visits to major financial centers \\
\hline Assistance from functional dept. \\
\hline Support from experts who could look at financial issues with a macro perspective. \\
\hline
\end{tabular}

\footnotetext{
6. In reference to Question 14 on the extent to which the following factors posed a challenge for the full treatment of the discussions of exchange rate issues in your latest staff report, if you marked "To a large extent" or "To a very large extent" to any of the factors, please explain:
}

The authorities threatened to withhold publication of the staff report due to the discussion of exchange rate issues. Needed a lot of maneuvering and massaging the text to get their approval.

Mission team size an issue, as well as standard CGER not informative for a number of countries.

The CGER-based methodologies do not take into account all relevant country-specific factors; moreover, they do not seem applicable to small open economies.

CGER by itself is not much use - it needs to be put in context, e.g. it is not enough to stabilize NFA if NFA is very negative.

The expectation of publication and the desire to maintain good relations with the authorities act as powerful brakes on the presentation of issues in the staff report.

We have built our own set of models to analyze real exchange rate levels, closely inspired by the underlying models in CGER. Data sometimes were not so great, though.

CGER might be the best we can hope for at this point, but the best is not good enough to trust.

I work in resource rich fixed exchange rate regimes where the results of the models are highly sensitive to commodity prices and resources under the ground.

The authorities do not provide the timely data on the international reserves, and there is a small doubt about the data accuracy.

One issue is that WEO convention requires major economy country teams to assume constant real exchange rates. However, if the exchange rate is under or overvalued, this convention forces country teams to choose between (i) either making current account forecasts that are consistent with a constant real exchange rate but that they don't really believe in (because they think the exchange rate will eventually adjust), resulting in broader growth and macro scenarios that may not be their central scenario or (ii) projecting current account adjustment in the absence of exchange rate adjustment, which results in the CGER showing the exchange rate as being at its equilibrium value, when in fact that is not the case.

The factor explains itself -- applicability of CGER based methodologies to low income countries with high volatility and weak data.

Authorities have very opposite view of the exchange rate regime as of IMF, we agreed to disagree

CPI based REER provides only partial picture

There is a tradeoff between having a focused staff and report and one that touches briefly on many issues. We have favored the former, which has implied that less attention was paid to exchange-rate related issues in the last Article IV report (much attention had been paid before that, but the issue was whether to continue repeating the same message or to spend a bit more time on other issues).

The CGER process has become a major challenge with very little informational content or policy guidance, but a huge bureaucratic drag.*

We consider the exchange rate overvalued. This needed to be handled with sensitivity in the staff report.

CGER doesn't work well, but the real problem is that the 2007 decision is not implementable in practice.

*Edited for language. 


\section{Appendix II, Table 9. Mission Chiefs' Survey Comments}

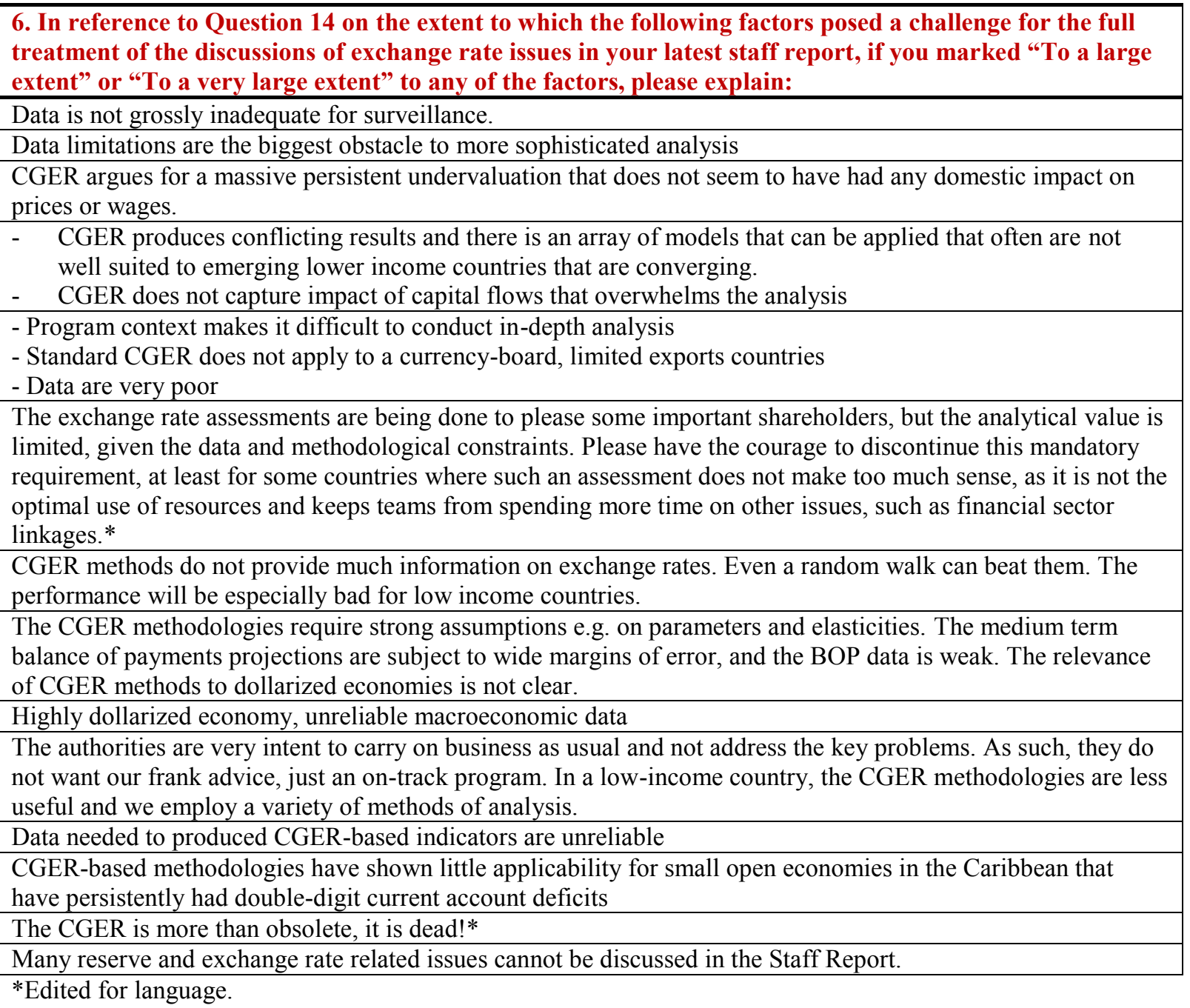

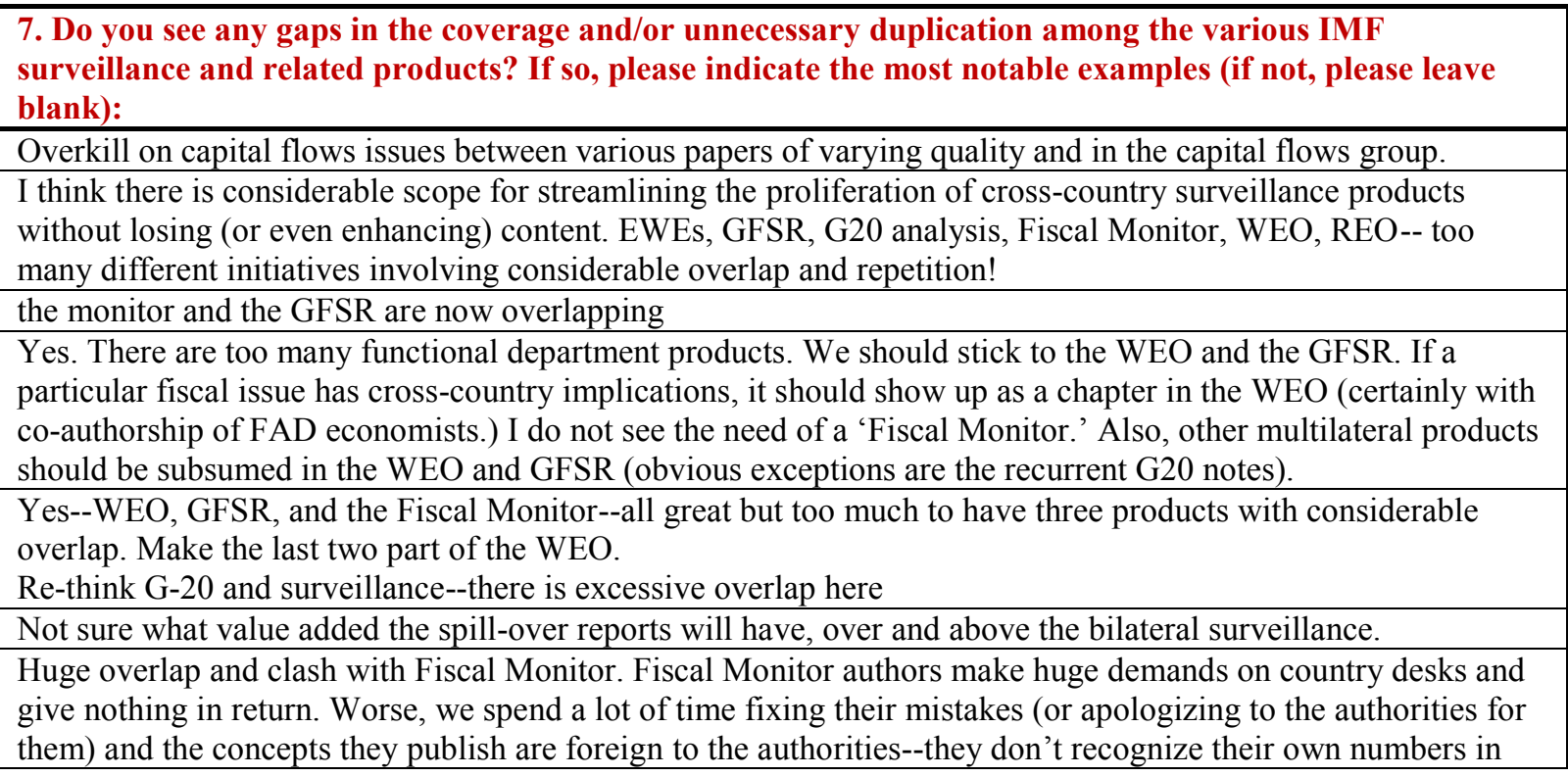




\section{Appendix II, Table 9. Mission Chiefs' Survey Comments}

7. Do you see any gaps in the coverage and/or unnecessary duplication among the various IMF surveillance and related products? If so, please indicate the most notable examples (if not, please leave blank):

the FM, which creates major communications problem.*

GFSR and WEO are too US and Euro centric with limited analysis of advanced countries in Asia.

The WEO and GFSR should be integrated. The Fiscal Monitor should be a chapter in the WEO.

Not sure the REOs have a large readership and could be shortened.

Yes, the WEO, GFSR, and Fiscal Monitor sometimes cover the same issues and not always consistently. For example, repetitive discussions of sovereign risks may occur in all three documents. It would be more efficient to combine these into one streamlined document that is something akin to an A4 staff report and Selected Issues paper for the whole world. RES could be in charge of the real sector part, MCM the financial sector part, and FAD the fiscal sector part. This would eliminate duplication, promote a more consistent and unified message, and make the Fund's messages more focused and prominent (rather than being lost in a sea of many publications).

REOs provide little value added over the WEO and the GFSR.

YES!!!!!!!!!!!!!!!!!!!!!!!!!!!!!!!!

There are far too many multilateral surveillance products.

- The EWE simply reflects risks that are mentioned in the WEO/GFSR and does not address tail risks at all.

- The fiscal monitor should be folded into the WEO. There is no need for such a long product.

- The GFSR has become far too long and unwieldy.

WEO, GFSR and regional surveys continue to significantly and unnecessarily overlap.

Fiscal monitor involves a lot of duplication with limited value added compared with WEO and GFSR

Focus of most of these products is mainly on advanced economies and major emerging markets.

REOs and WEO. Reo and country reports, especially on developments and outlook

WEO and the GFSR and the Fiscal Monitor- on fiscal policy and fiscal financing risks

The question of inclusive growth should feature more prominently in teams' analyses. Fortunately, the MD has a good sense for this becoming a key issue for many countries, but our surveillance efforts do not sufficiently focus on this and little guidance is available for teams to focus on this important question. Instead, we spend our time with exchange rate assessments, overly frequent debt sustainability assessments (will vulnerability really change that much in a year or two?), and the standard checklists for Art. IV missions. Let's have some courage and allow teams to focus on what they consider important for their respective country and do not follow cookiecutter approaches. Then questions of employment generation and social protection will automatically gain more traction in the Fund's analysis.*

Spillover reports largely overlap with A4 reports and with other surveillance products and have little clear value added;

Some of the cross-country papers recently done by SPR also appear to provide very little to no value, but use much staff time and travel funds.

Although I work on a low-income country, I don't find the vulnerability exercise to be useful. Our own assessment is more meaningful to me. Many IMF products are useful for emerging market and developed economies. I read them for interest but not usefulness to my own work at this time.

There are clear duplications between the GSFR and the WEO. The GFSR is difficult to read and does not have a wide audience in the institution. They are both written thinking to the outward audience, not as a tool to shape Fund policies.*

REOs and Chapter II of the WEO.

*Edited for language. 


\section{Appendix II, Table 9. Mission Chiefs' Survey Comments}

\section{In reference to Question 17 on to what extent the following possible factors constrained your presentation of a candid staff report, if you marked "Other," please explain:}

The 'need to preserve relationship with authorities' should be understood as a management issue in the Fund. I am not afraid to have disagreement with the authorities. But if the authorities were to complain to management I have very low expectation that management would back me up--even if the mission's view is exactly as laid out and agreed in the policy consultation note

If 'candor' means one's ability to speak his mind, it is often seriously, and these days increasingly, constrained from above, through EXR's instruction not to speak a word, or to say only certain things, on particular issues. And the reasons for such restrictions are usually not explained, except that one can vaguely feel that there must be some sensitivity.

The corrections and deletions policy needs to be amended. It focuses too much on the details and not sufficiently on fact that the image of the Fund can be damaged by such an inflexible policy. The constraints of the policy, alongside the ultra-strict implementation of SPR without regard to the broader context, will inherently make mission chiefs more conservative and unwilling to take risks in the staff report. This is not in the best interest of the institution.

Review process within the Fund, and a few attempted interferences from the ED's office.

It's difficult to be candid for your country when other staff reports for countries in the region are not candid.

The Fundese

Concern about market reaction on discussion of exchange rate and devaluation. Concern about triggering bank runs if weak banks are named or can be easily identified (possible in smaller banking systems in smaller countries)

Lack of hard evidence (e.g. data) to substantiate warning on risks without looking unduly alarming or undermining the relationship with authorities.

Message control in the review process. Certain things should not be said.

9. In reference to Question 20 on policy issues where you had a difference of view from the authorities, if you marked "To some extent," "To a large extent," or "To a very large extent" in how difficult you found it to challenge the authorities' view because of their greater expertise/access to resources/in-depth knowledge of their own economy, what could be done to overcome these difficulties?

Better quality staff and resources.

the authorities could take a less defensive attitude

Lower teams' rotation

Difference of opinion came up in regard to treatment of non-resident deposits, reflecting different appreciation of the risks. Again, access to cross country studies and evidence would have been useful.

Technical preparation/background. You cannot argue on technical ground if you have a master taken 20 years ago from an obscure university and the counterpart has $3 \mathrm{PhDs}$ from top universities. This is the reason why it is so key to keep an outstanding level of economists. The access to data is a secondary issue.

- sharing bank-by-bank supervisory data

-more in house expertise and resources to compile published financial sector data (quarterly balance sheets of banks)

More resources. Stronger local economists or stronger role for them.

More resources

10. In reference to Question 21 on to what extent you think the following factors inside the Fund make surveillance work difficult, if there are any factors inside the Fund, other than those listed in Question 21 which make surveillance work difficult, please explain:

It is not clear whether Management would support in practice candid surveillance when it may lead to a possible disagreement with authorities, given the emphasis on maintaining and improving good relations with the authorities at all costs.

the main problem is that if the authorities complain about me to my supervisor my career will suffer On certain issues, staff seem to have given up on forming their own views, and simply follow whatever Management says. This is even worse than self censoring mentioned above, because self censoring assumes that staff at least have their own views. 


\section{Appendix II, Table 9. Mission Chiefs' Survey Comments}

\section{In reference to Question 21 on to what extent you think the following factors inside the Fund make} surveillance work difficult, if there are any factors inside the Fund, other than those listed in Question 21 which make surveillance work difficult, please explain:

MCM speaks with many voices.

See above on MCM, SPR, Fiscal Monitor. Functional departments do not adequately help the country teams-they are a burden, making huge data demands, and producing absurd analyses that show a complete lack of knowledge of the country institutional framework, which we then have to try to fix (against their resistance). I remember fondly the days when the functional departments were helpful. Those days are over.* Our software systems for data sharing (SharePoint, DM5, Country Exchange, TAIMS, etc) are terrible. Smaller mission teams, infrequent contact with the authorities, and lack of other resources.

Ever-growing mandates, combined with nonsensical time constraints, without sufficient staff resources. Limited resources.

Lack of RAs;

Staffing issues: difficulties attracting high quality staff to positions on non-program smaller countries. Poor personnel management- senior management unwilling to authorize recruitment, forcing temporary solutions by taking team members away to fill gaps on other countries. High turnover on assignments so country detail and knowledge is lost and no relationship is built with counterparts where team members change too frequently MCM staffing and resource constraints, especially following the G-20 FSAP mandate are being born by the LIC countries, most regrettably on 'development' FSAPs. This is unfair to these members and pose unwelcome challenges for staff working on these countries

There is clearly a resource constraint on work from other department (especially functional departments) on smaller, less systemic countries. Collaboration in principle is good but the resource rationing makes it almost impossible in some cases. E.g., it is very difficult to have resources to work on the financial sector of a low income countries as they seem to be all devoted to G20/systemic countries.

Resource constraints are always underestimated. While macro challenges and requirements have risen, resources have remained stagnant or were even reduced. This leads to a more superficial analysis, with risks to the Fund's reputation.

An ever increasing amount of non-desk related work is piling up on desks - reviews, requests for inputs to various cross-country products and papers, response to journalist questions, etc. At the end, very little time is left to focus on the core bilateral surveillance.

Management's unwillingness to back staff in their message.

*Edited for language.

11. In reference to Question 22 on if you held a press conference at the end of the Article IV mission, if your answer is "No," please explain why:

There was no accessible media presence in the country.

Authorities requested that we not hold a press conference.

the authorities refuse

Our preliminary conclusions were covered in the press. In later and earlier visits, I gave interviews to the press.

We had a press release and then met with selected journalists for more in-depth discussion, and the res rep

followed up with other media.

Published the concluding statement.

The authorities do not allow us to have one

The authorities do not encourage it.

We issued a press statement instead, in this occasion.

The authorities forbid us to have one.

Authorities did not agree to it.

A press conference was planned by the mission ended early because and election was called. Instead, we held a conference call after the publication of the staff report 2 days after the board meeting.

Because of the recent unrest in the Middle East and Management decision to remain low key in the media.

However, I had bilateral interviews with international and local press.

Authorities not keen; we had a separate event on the REO which was very well received. Concluding statement 


\section{Appendix II, Table 9. Mission Chiefs' Survey Comments}

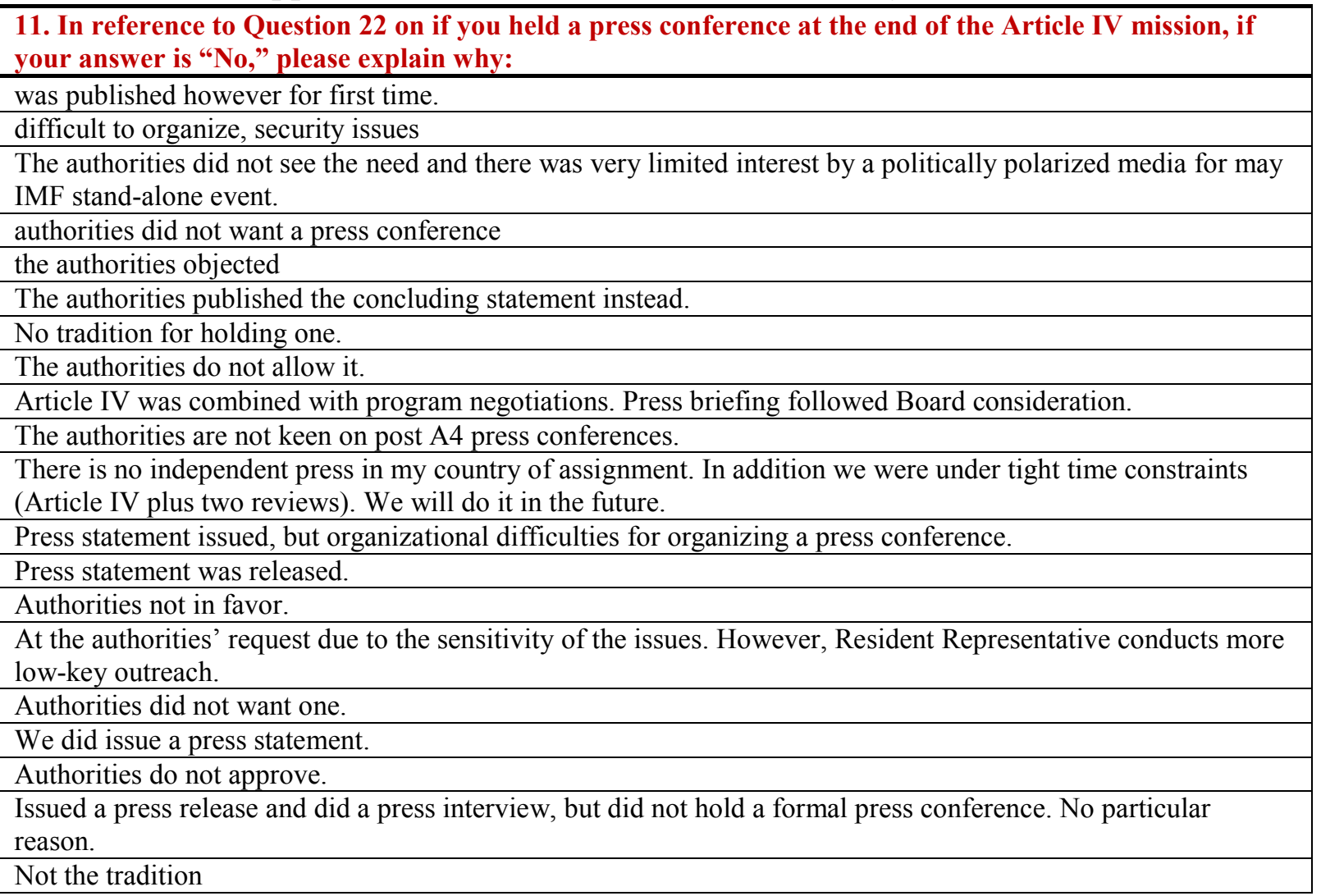

12. What could be done to improve the traction of Fund's surveillance?

To encourage the authorities to share the staff report more actively with the private sector.

Management needs to reinforce messages from Article IV candidly with authorities during high level meetings

with authorities so that it is not dismissed as the view of the mission team alone and not supported by the

Fund's overall staff and management.

be more candid and frank about problems/risks

Make the views of staff independent from those of the Board; allow for production and publication of staff reports without the need for Board approval, and hold Board discussion as an entirely separate process, with a different output (the summing up).

We got a lot of traction with the authorities enacting a set of measures that mirrored the team's suggestions (and they did not need to do so, as this was not a program mission.) This positive result was due to respectful, deep debates with the authorities.

The Fund should not worry so much about traction, and focus more on doing the best analysis and policy recommendations and then leave the rest to the authorities. Focus on traction should not lead to a situation where we give up on first-best recommendations in favor of second-best solutions 'given the real world'. The Fund of course needs to be mindful of political realities, but it should stay technocratic.

Additional work on the pros and cons of fiscal rules.

This question should best be asked to the authorities.

Not much, but continue to produce as good economics as possible

For the big countries--not much. They will chart their own courses. We need to continue with outreach though.

Importantly, if the functional departments were more of a help and less of a burden, we could do more of the analytical work that actually has some traction with countries.

Have a resident representative in the country.

Focus on the most important problems facing the country in a manner that fits in the local public debate on 


\section{Appendix II, Table 9. Mission Chiefs' Survey Comments}

12. What could be done to improve the traction of Fund's surveillance?

economic issues.

We were in basic agreement with the authorities.

Staff reports should be geared toward the public, not the Board. To make them punchier, readable, and succinct, the staff appraisal, which typically just repeats conclusions made in the main body of the report, should be dropped. The authorities' views should be drafted by the authorities themselves in an attached statement/BUFF rather than having to be detailed in the report. All reports should start with an Executive Summary, with key policy recommendations in bullets. This would result in much more streamlined reports.

Higher quality analysis -- which can only come from dedicated country work. In the current environment, with multiple departmental and extra-departmental initiatives to which we must respond, simply finding the time to do fundamental research and country-analysis is difficult -- this is one of the major corners we have cut as part of the downsizing process.

Improve the image of the Fund.

Allow more frequent staff visits and contacts with authorities. The most effective policy impact we have is when we give advice in a low-key and behind the scenes way, i.e., in a more advisory capacity.

Surveillance will always be an uphill battle, but more innovative and creative framing of a country's policy issues is needed and staff reports that look more modern as print products would also help.

A civilian and elected government with a broader mandate than the current military junta.

$=$ openness and buy-in by the authorities to seek fund advice.

More and better trained human resources devoted to country teams. We are beginning to be too short-staffed to be able to offer in depth and convincing analysis, especially vis-à-vis emerging markets or advanced economies. Allow for more in-between staff visits. We need to move away from the once-per-year visit to a member to maintain more direct and more frequent contact with member authorities. Especially in the current environment (where countries are seeking for policy responses to the many challenges they are facing), the Fund could provide more value-added. But the resource envelope is too tight for this.

Less rigidity. Provide more analysis and tools to authorities to help them deliver on their objectives rather than ours.

Article IV discussions should be separated from program reviews. And there may be scope to alter the composition of the team a little with functional specialists replacing area department generalists.

Improve the consistency of the policy message among key development partners.

Focus less on bureaucratic issues and more on substance.

13. In reference to Question 24 on the areas that should be given the highest priority for further efforts in filling in data gaps, if there are any other data priorities not listed in Question 24, please specify:

Some of the more basic data are missing, such as unemployment, capacity utilization, and reliable nation-wide CPI.

International reserves

The authorities publish external debt by remaining maturity, but more granular data by sector is needed to better understand the risks.

Better data on real estate property prices for the whole economy are needed to better inform judgments on risks. real sector indicators (labor market, wages, prices, economic activity, capacity utilization)

The move to GFSM 2001 for all countries take us in the opposite direction by forcing teams to use less-frequent (annual) data rather than more frequent (monthly) cash data. What are our priorities as an institution in terms of data--frequency or something different?

More reliable BOP data.

Financial sector data.

Bank balance sheet data, especially for the state-owned banks is highly suspect.

Employment and labor market data.

better BOP reporting of off-balance sheet transactions 


\section{Appendix II, Table 9. Mission Chiefs' Survey Comments}

14. We would welcome any general comments on what the IMF could do to enhance the overall effectiveness of surveillance, or provide specific follow up referencing the question numbers as appropriate:

It is interesting that nowhere in the questionnaire were we asked to give our views on the adequacy of surveillance or our coverage of macrofinancial issues, only on our 'scope for increasing'. 'Scope for increasing' is very different from desirability of increasing. In my country, there is certainly scope for increasing, but I would not do it, as we already give ample coverage to these issues. Seems like a design flaw in the survey questions to me.

We need to set a higher standard of independence from authorities to promote more candid surveillance. We should be more willing to speak out in public even if it means annoying the authorities.

We need to shift the focus back to bilateral surveillance, with functional departments supporting area departments in this effort.

Surveillance--bilateral for sure, but also multilateral--depends on the work by country teams. But country teams have been squeezed at the same time as the demands on country teams from multilateral surveillance products have increased. A rebalancing is needed. The various multilateral surveillance products--which have become the way for functional departments to brandish their name--should be streamlined. And more functional departments' resources should be devoted to support country teams.

Get the functional departments to support the area departments.

Management discipline the process--let's get everyone on the same page, not producing contradictory analyses that country teams have to scramble to fix.

Kill the Fiscal Monitor. Put the GFSR and WEO in one publication.

Get all the MCM and SPR data and analytical tools up on their website where country teams can use them (data and tools are not proprietary!!)

Management support of staff signaling risks is very important.

Fund needs more frequent presence in LICs and middle income where capacity is weak to develop policy responses. For many, Fund presence is the only opportunity to focus on macroeconomic issues at all.

The SPR papers providing cross-country comparisons of economic and policy reaction to the crisis provide useful in raising questions about relevant comparisons. More such studies (for instance from MCM on financial sector issues / monetary policy) would be helpful.

The culture of the institution must change and staff must be supported in providing views or analysis that the authorities may not agreed with or like. Until this is done, surveillance will remain muted and veiled in diplomatic language.

The 2007 decision doesn't work as a surveillance framework neither in theory nor in practice and needs to go back to the (drawing) Board.

It is a very welcome development that the Fund is now beginning to be able to have an impact on the policy of its largest members through the G-20 platform. This progress also raises the legitimacy of our work with other members.

The Fund has to decide whether it wants to be equipped to do high-level economic work on all its member countries or only a selected number. Universal high quality economic work requires much more human resources, or a quite different prioritization of work, than currently. The recent wave of programs in advanced countries is accelerating a process of decreasing competitiveness of the Fund in the field of economic surveillance which was already underway. The focus on cross-country analysis can only go so far without sound single-country analysis.

My concern is that soon we will no longer be looked at as a reference for economic analysis of EM and advanced country economic developments.

Find the right balance between mandatory work (exchange rate assessments, DSAs, standard Art. IV checklists etc) and empowering country teams or departments to determine priorities. The resource envelope is finite, so let's use those resources to the benefit of the member and not to satisfy institutional requirements.

In a low income post conflict country the main challenges that the authorities face are developmental in nature and they are less interested in analysis of prospective macroeconomic risks, spillovers and macro-financial 
Appendix II, Table 9. Mission Chiefs' Survey Comments

14. We would welcome any general comments on what the IMF could do to enhance the overall effectiveness of surveillance, or provide specific follow up referencing the question numbers as appropriate:

linkages. In this context the main objective of Fund surveillance is not greatly appreciated by the authorities.

Country teams should be encouraged to be candid and reassured about strong management support.

Ensure greater evenhandedness and uniformity of treatment in our diagnosis of economic issues and policy recommendations across countries with different political clout. This applies to macroeconomic surveillance (were differences across departments are stark) and to FSAPs.

More training for mission chiefs on surveillance.

Get rid of the CGER 


\section{Appendix II, Table 10. Financial Markets Survey Comments}

1. In reference to Question 2 on ranking (from 1 to 5 , with 1 being the most important and 5 being the least important) the role of the IMF's country-specific analytical products, if you have additional comments, please use the space below:

Poorly worded question. I think answers won't be useful.

'See' could mean what role should be or what I think it is right now. I have completely different answers depending on which it is!

I think the IMF should have a big role in terms of shaping debate etc, but it has always had its own axe to grind (e.g. Greece) so I take analysis in that spirit; i.e. not fully objective.

On country analysis, I find it usually fairly shallow on bigger countries, but extremely useful on smaller ones, where there is less coverage.

The rankings will depend upon the country in question. Also, I have treated the product as different from the process. For instance, the Article IV paper itself is just a reflection of discussion had with country authorities. So, while the discussions probably provide input into decision making the paper only reflects input already provided from the country authorities' perspective.

Data tables are incredibly important for the private sector so don't shorten/cut these. Also don't cut the length of Art.IV reports. There is a lot of sell-side research that is 'short and readable' but it lacks depth. The only fall-back the private sector has for more in depth analytical country reports is, in many cases, the Art.IV report. So an invaluable product.

The ordering in proposed is very much the traditional view. Over the last 20 years, the disclosure of the studies has been a much bigger boost to both public debate and market analysis. As the focus of the market has shifted to a wider array of IMF member countries, the value of the disclosure of the Staff work has risen commensurately.

THE TWO ON THE PUBLIC DEBATE REFLECTS WHERE THINGS ARE, NOT WHERE THEY OUGHT TO BE

2. In reference to Question 3 on what features of IMF country reports (Art. IV consultations) you consider as their main strengths/weaknesses, if you have additional comments, please use the following space:

You have missed out the best thing of all, which is the data, particularly for smaller, less well-covered countries. Presentation of debt, credit, vulnerabilities is excellent. I've therefore ticked comprehensiveness as a strength, though I think the written analysis has got a little bit thin recently. I'd like to see more selected issues.

I would put authorities' views in a separate document. I don't bother reading them normally.

The more candor the better. This has improved a lot for exchange rate assessments but there is still often self-censorship and a lack of bluntness or a lack of willingness to consider tail-risk scenarios. Baselines are generally intellectually boring, so useful to conduct scenario analysis and stress tests. I rely more on meetings with local IMF personnel, rather than the rather reports itself. Would once have regarded objectivity as a strength of IMF Article IV reports. However in my opinion the IMF has lost some of its objectivity since the onset of the global financial crisis, and is too accommodating of policy slippage by authorities, including in those countries with IMF programs - e.g. Sri Lanka.

3. In reference to Question 9 on whether or not, in your view, the IMF's messages from the various products listed in previous questions are clear and coherent, please explain why you selected 'Not at all' or 'To a little extent' in the space below:

NO COMMENTS PROVIDED 


\section{Appendix II, Table 10. Financial Markets Survey Comments}

4. Do you see any gaps in the coverage and/or unnecessary duplication among the various IMF
surveillance and related products? If so, please indicate the most notable examples (if not, please
leave blank):
I think your exchange rate analysis is inevitably poor since you get in to trouble with authorities for being
opinionated and wrong. I wouldn't bother if I were you!
The cross-country spillovers focus is worth a try though you have much further to go. It comes over as
being a bit formulaic.
There is an inherent overlap in WEO and the GFSR when financial dislocation is at the heart of economic
developments as it has been in the past few years
The access to privileged information, and new insights are IMF's best strengths from our perspective. The
current IMF country representative does a great job of disseminating IMF's point of view personally, and
his standing in the local markets is very high. However, I do think IMF should be doing more to
disseminate their reports in a more institutional manner.
More timely, perhaps shorter Article IV-style updates

\section{Please indicate any IMF analysis that you found particularly useful and/or types of analysis that} you would like to see more of (please explain why):

I particularly like the data on banking health in GFSR, and I like the increased emphasis on vulnerability indicators in country reports. I think you should make more emphasis to bring all reports up to best standards.

WEO/GFSF are great in depth think pieces (candor has greatly improved in recent years).

I find the new IMF staff position notes incredibly helpful.

There is enormous value in cross-country analysis/statistics. The fiscal monitor in this respect is one of the most important recent innovations.

The IMF should be more transparent in informing the public its implicit foreign exchange forecasts and reasoning behind.

The issue with IMF analysis is not its quality but the inherent constraints on discussing risks (due to the risk of sparking contagion) as well as the balance between maintaining access to policy makers/information and providing unwelcome advice

Personal meetings with the local IMF country rep always leave one with new insights- I have always taken international investors to meet IMF here, as that probably gives them the most balance picture of the country.

The table in the Fiscal Monitor that shows a cross-country comparison of the IMF's estimate of the debtstabilizing primary has been particularly useful for our work (first published as Appendix Table 5 in the July 2009 Fiscal Monitor). This is still the best comparison of fiscal risks available, and the IMF's analysis has had a strong impact on the pricing of sovereign risks in the market, as shown in Figure 1.6 of the April 2010 GFSR

However, the IMF has frequently changed the format and methodology of this analysis. Instead of coming up with new and innovative ways of telling the story, it would be preferable to get the data in exactly the same format every six months. This would allow us to check progress over time. Also, it would be more useful to just compare the structural PB and the debt-stabilizing PB, instead of deriving a 'needed' fiscal adjustment based on arbitrarily chosen targets (60\% for advanced economies and $40 \%$ for EM).

Analysis of public policy inc. fiscal policy, in particular e.g. analysis of impacts of policy vs. no-change counterfactuals. No other source provides this kind of analysis with the same comprehensiveness.

I think the overall suite of products is excellent, and superior to just about anything from the private sector. As a longtime user, I am also very heartened by the increased candor over time (e.g., recent European Article IVs are much more grounded in reality than comparable surveillance or MOUs of large clients like Argentina or Russia in the late 1990s). Given the analytical reach and the amount of data on hand, what would probably be most useful to me would be to expand things like the cross country fiscal monitor into cross country comparisons that include private sector debt, Net International Investment Positions, etc. I like the working papers. 


\section{Appendix II, Table 10. Financial Markets Survey Comments}

6. How do you think the IMF could best enhance the overall effectiveness of its surveillance?

Staff updates in between GFSR rounds. In many cases your staff will be right on top of new developments a month after AIV is published, but the world doesn't know about it for a year. You should allow staff updates that are light on views but include forecast for more variables than the WEO, and that don't require board approval.

1) reports need to be published; (2) would be great if there was a vehicle to have publication more than $1 \mathrm{x}$ per year (e.g. publish the macro-tables every quarter).

The biggest benefit would come from a greater willingness among major economies to surrender to sovereignty over questions of global policy coordination. Without that greater willingness, the effectiveness of the analysis is handicapped by the lack of country follow-through.

Article IV reports play a particularly valuable role in providing a definitive review of a large range of countries. In terms of quickly getting up to speed on a country, there are few better sources. They also provide a useful historical record. As such, I hope they remain (a) frequent (annual); and (b) comprehensive in their coverage of macroeconomic issues (not too much streamlining).

By changing the review policy for Article 4 reports to make them less diplomatic.

More timely updates on public policy impact.

Provide more data that is comparable across countries. The publication of fiscal data for EM countries in the WEO database was a very useful improvement. Why not publish more series? e.g. ToT for individual countries?

Find more ways to shame the G7, especially the US.

Timeliness. Some Article IVs are so late they lose usefulness.

Improve timeliness on smaller emerging markets and convince more governments to publish Article IV

reports. 


\section{Appendix II, Table 11. TSR Media Survey Comments}

\begin{tabular}{|l|}
\hline $\begin{array}{l}\text { 1. In reference to Question } 2 \text { on roughly what share of your total coverage of IMF surveillance you } \\
\text { would characterize as: Country-specific; Cross-country or regional; Global economic matters; } \\
\text { Global financial matters; or Other, please specify the relevant country or region name(s). If you } \\
\text { selected 'other,' please specify: }\end{array}$ \\
\hline All regions and virtually all countries. \\
\hline GREECE \\
\hline US, EU, China \\
\hline $\begin{array}{l}\text { I do cover economic news and last time reforms and sometimes IMF surveillance (Ukraine, country specific } \\
\text { with the focus on reforms).I am interested to improve my qualification so that to cover global IMF } \\
\text { surveillance. Also with regard to the latest event in the Middle East and Northern Africa I am interested in } \\
\text { additional information about IMF role in stabilization of situation in mentioned regions. }\end{array}$ \\
\hline Turkey \\
\hline Poland \\
\hline ECA \\
\hline Japan, East Asia \\
\hline all regions and an assortment of countries \\
\hline $\begin{array}{l}\text { We look at the big countries, including China and India, and also those countries which are in the news at } \\
\text { any particular time, so Greece, Ireland, euro troubled countries at the moment. }\end{array}$ \\
\hline Portugal \\
\hline ROMANIA, CENTRAL AND EAST EUROPEAN COUNTRIES, EU \\
\hline USA, Euro zone, Germany, Canada \\
\hline All regions--I cover most IMF releases \\
\hline USA \\
\hline USA, Europe (in particular Germany) \\
\hline Country-specific: $25 \%$ crisis countries; cross-country or regional: $25 \%$ China \\
\hline $\begin{array}{l}\text { country-specific: } 10 \text { (countries in the news at the moment); cross-country or regional: } 10 \text { (regions in the } \\
\text { news at the moment) }\end{array}$ \\
\hline Brazil, China, India, United States, EU countries, African countries \\
\hline Ireland, euro area, EU \\
\hline US, Europe, Japan, China, other major emerging economies, countries with IMF programs. \\
\hline
\end{tabular}

2. If you use or report on IMF communications on surveillance (for example, a country report (Article IV consultation report), Press Release, or a Public Information Notice), what information or elements are you mainly interested in? Are there certain parts of IMF communications that you find more or less useful?

I'm mainly interested in insights from the IMF management and staff, on various economic and financial issues, whether national or international. Sometimes they raise political or social questions which are of much interest for our audience. That's why my interest in the abundant IMF literature is very broad. Everything that may grasp people's attention is relevant.

I' $m$ always interested in those information elements which are relative with the process of fiscal adjustment program which is implemented in my country by IMF and EU.

Interested in global economic and financial information. The role of IMF in global economy.

Policy recommendations, economic forecasts, currency valuation, debt levels. The least useful has been currency, since that policy has been watered down.

Any is useful especially the informal communications that gives explanations on what is going on. Why IMF insist on fulfilling some point of IMF memorandum with certain governments? I would appreciate more direct information from IMF about communications between IMF and the government of the country I cover.

Article IV Consultation Country Report.

The economic outlook plays a key role in my coverage, e.g. the future trajectory of GDP, Inflation and employment, but also the IMF's policy recommendations are of interest 


\section{Appendix II, Table 11. TSR Media Survey Comments}

2. If you use or report on IMF communications on surveillance (for example, a country report (Article IV consultation report), Press Release, or a Public Information Notice), what information or elements are you mainly interested in? Are there certain parts of IMF communications that you find more or less useful?

Current statistics and commentary.

Board opinion in politicized issues.

I'm mainly interested in WEO and the country report.

Data and detailed narrative...less interested in prescriptive advice and more interested in what has happened and why.

Prefer to go to the direct report where possible. The press reports are often lacking, and would be improved by fact box of leading facts and figures. PINs are also not very reader friendly on the whole.

In a country report I'm interested in whether the agreement criteria were met, the recent macroeconomic developments in the country and across the region, economic outlooks, the state of the economic reforms etc.

Reports and Survey on world economic conditions released by IMF.

Mainly interested in analytical reports, especially staff reports.

As well as decisions on credit lines.

I would like to get these reports faster after they are completed (even though I know it's up to the countries, not the IMF).

I find there's too much jargon, in reports but also in press releases.

In the reports I am interested about the most recent elements, which are often put as an annex when something has been going on after the report completed and before it was released. I think it should be made clearer, it's often buried.

I'm mainly interested in the big picture for a general audience.

The general problem is the sheer volume of IMF publications. With the papers published before and during the spring and fall meetings, the various updates in between, discussion notes and fiscal monitors--it has become extremely difficult to handle. The biggest problem: It has got more and more difficult to understand what is really new information or simply a repetition of already well known material.

The Article IVs are useful in two ways: 1) when I'm covering crisis countries; 2) when I need to quickly get up to speed on a country that has no one covering it.*

I find the summaries of economic conditions in the Article IV PINs useful, particularly when I am trying to learn something about a country in a hurry. I often look at the old ones in such instances. I also often forward the emails announcing them to my colleagues overseas.

Forecasts, general outlook, consistence with stated policy objectives.

We are mainly interested in growth rates, fiscal policy data and inflation.

All.

IMF staff assessment of economic performance and outlook.

*Edited for language.

\begin{tabular}{l}
\hline 3. Please comment on whether you see any gaps in the coverage or unnecessary duplication and/or \\
inconsistent messages among the various IMF surveillance and related products? \\
\hline $\begin{array}{l}\text { The lack of consistency between messages has been obvious sometimes in my opinion between global } \\
\text { views and country reports. The tension between schools of thought may appear to the focused reader since } \\
\text { the arrival of Mr. Blanchard as economic counselor. It seems to me he has advocated for much more fiscal } \\
\text { stimulus than missions on the ground. }\end{array}$ \\
\hline The IMF is putting out way too many reports and updates - and so risks irrelevance of its information. \\
\hline There is far too little information about the Mutual Assessment Process or China. \\
\hline Sometimes overlapping occurs, but probably hard to avoid given the interconnection between areas. \\
\hline Breaking embargo in WEO often troubles me. \\
\hline $\begin{array}{l}\text { My main complaint is that the IMF does not flag its important communications. Input for the G20 is } \\
\text { especially bad. }\end{array}$
\end{tabular}




\title{
Appendix II, Table 11. TSR Media Survey Comments
}

\begin{tabular}{l}
\hline $\begin{array}{l}\text { 3. Please comment on whether you see any gaps in the coverage or unnecessary duplication and/or } \\
\text { inconsistent messages among the various IMF surveillance and related products? }\end{array}$ \\
\hline I can say that some macroeconomic figures, at national level, are out-of-date. \\
\hline WEO, GFSR and Fiscal Monitor belong in one publication. \\
Regional Economic Outlook could be covered by WEO. \\
\hline $\begin{array}{l}\text { There's too much of the same thing at times. For instance on the capital flow/capital controls issue, there } \\
\text { were and are too many reports from different departments. It feels like a sort of competition within the IMF } \\
\text { rather than an effort to come up with one consistent report. }\end{array}$ \\
\hline $\begin{array}{l}\text { As already indicated there are simply way too many reports put out by the IMF. It has become very time } \\
\text { consuming to distinguish new and valuable material from sheer repetition. Particularly irritating are the } \\
\text { updates in between the regular reports. }\end{array}$ \\
\hline $\begin{array}{l}\text { The inconsistencies are one way to see divisions within the IMF on subjects such as capital controls. So I } \\
\text { find them useful too. }\end{array}$ \\
\hline More visibility could be given for G-20 process; search engine on the website is a mess!!! \\
\hline
\end{tabular}

\begin{abstract}
4. Please comment on how relevant and how much impact on the public debate the messages in the IMF's communications on surveillance have (that is, the public debate on international, regional, and/or national economic and financial policies and developments):
\end{abstract}

It's very difficult to assess from my point of view. The impact in the financial press seems higher than in the policies of member countries, though.

Particularly in my country the messages which are sent by the IMF announcements or executive's statements have an unprecedented impact on the domestic public debate. And I should confess that the aid of IMF communication's team is very important because they are dealing with my request professionally and trying to do the best in order the messages which are being sent, to be specific, clarified and credible. Covering the IMF reporting since the last October, their collaboration with me has been proved effective and productive.

Very relevant.

I would say that huge impact when message concerns national economy.

Reports that are about the Global Financial Crisis and Country Consultation Note are effective and have impact on public debates.

Impact and presence is obviously higher during times of crises. But overall, the IMF's surveillance products present in my view an important and respected voice of expertise and guidance to the international economic debate.

We tend to take the IMF's messages very seriously. But there are too many internet-people who love conspiracy theory, such as IMF is a tool of US government to pursue their own interest.

Highly relevant; impact seems contingent on the circumstances -- higher in cases of smaller countries or ones over which the fund has leverage due to events; less so for larger countries or when the fund speaks on broader or more generic policy matters (i.e. the financial tax debate).

The IMF does not have as much impact as it should because in spite of a supposed new openness, the press office tries to guard its secrets. Having covered the IMF and World Bank for 35 years and having worked at the World Bank for two, the IMF press office has always been rather unhelpful. Covering annual meetings and spring meetings has become tedious. I understand security but journalists who have been cleared should be able to meet and tap into the Fund's founts of wisdom more easily. The question below is not very sensible. The knowledge and judgment within the IMF is often far better than outside think tanks etc, but it emerges in worse shape because of the challenges of the IMF press office. It is a great pity because your MD is witty and knowledgeable about the political and economic as well as financial implications and repercussions. *

IMF's messages are very relevant as long as they are accurate (and this quality is verified in time). Also, the public expects a candor and objective message regarding the economic perspectives, even if this message is not in line with those communicated by the public authorities.

*Edited for language. 


\section{Appendix II, Table 11. TSR Media Survey Comments}

\begin{tabular}{|c|}
\hline $\begin{array}{l}\text { MF's communications on surveillance have (that is, the public debate on international, regional, } \\
\text { ind/or national economic and financial policies and developments): }\end{array}$ \\
\hline Very influential. \\
\hline $\begin{array}{l}\text { IMF communicates too much with too many reports. That diminishes the impact on the public debate. WEO } \\
\text { has high impact, GSFR much less and fiscal monitor even more less. Financial system stability assessment } \\
\text { is important. Regional reports (except euro-zone) are not. G20 input is not important as process driven by } \\
\text { G20 and not by IMF. }\end{array}$ \\
\hline $\begin{array}{l}\text { I find there's too much jargon in IMF reports and it's not candid enough. I know it's very political and often } \\
\text { the result of a compromise but it's frustrating to try to guess what the message is sometimes. That also } \\
\text { undermines the impact the IMF can have. When the IMF gets out with a stronger, clearer message (for } \\
\text { example fiscal monitor or WEO on the US) then it has a real impact. }\end{array}$ \\
\hline $\begin{array}{l}\text { IMF comments are very relevant and since the financial crisis even more. Although using the IMF as a kind } \\
\text { of think tank to tap on while working on deadline is not a real option--it takes too long to get answers. }\end{array}$ \\
\hline $\begin{array}{l}\text { The IMF's role is getting larger and larger in terms of affecting public debate. Big issue is whether IMF } \\
\text { messages play any role in the US debate. }\end{array}$ \\
\hline Very relevant. \\
\hline at the impact on public debate has been decreasing in the last years. You $\mathrm{h}$ \\
\hline
\end{tabular}

5. The reasons why the communications of the IMF or other institutions are better or worse are: I think that the IMF communication team is more professional on dealing with issues as well as crises which sometimes are blowing up. They are always willing to respond to any question and to give the right and accurate perspectives of any issue.

The reason is how IMF officers are dealing with requests. For sure will be an answer even though it is a kind of refuse to comment the situation. But personally [NOTE: respondent did not finish comment] Because of the effective future expectations...

Less clear and more 'technical' than e.g. what I've seen from the OECD's communications; more precise, 'to the point' and tangible than e.g. the World Bank (which of course deals with a different realm).

Timely notice pre-release.

Pros: timeliness, responsiveness, thoroughness, accessibility on deadline has all been good.

Cons: Too much caution about speaking for the record; top officials often seem a bit scripted.

The press office distrusts the press.

There a clear effort to try to release more documents than in the past. But the timing is often complicated. The IMF dumped on us many dense documents in the week ahead of the Spring Meetings and there's no way that as journalists we could do a good job when there's so much arriving at the same time.

The IMF is good at making a lot of documents accessible. It still lags other organizations in giving us access to the staff that wrote these reports.

Again, if I compare the IMF with think tanks and from the perspective of a reporter working on deadline its worse. It takes too long to get answers and the answers are often very diplomatic. But is it fair to see the IMF as another kind of think tank or is he more of a government ministry?

1) the other institutions are really lousy at communicating; 2) you have a very good press team Easy to find on Web. Easy to get to the key actors and authors when I want to. Reliable quality. Clarity, methodology, authority, empirical database.

I cannot think of another institution that are so open on the data and analysis it produces. 


\section{Appendix II, Table 11. TSR Media Survey Comments}

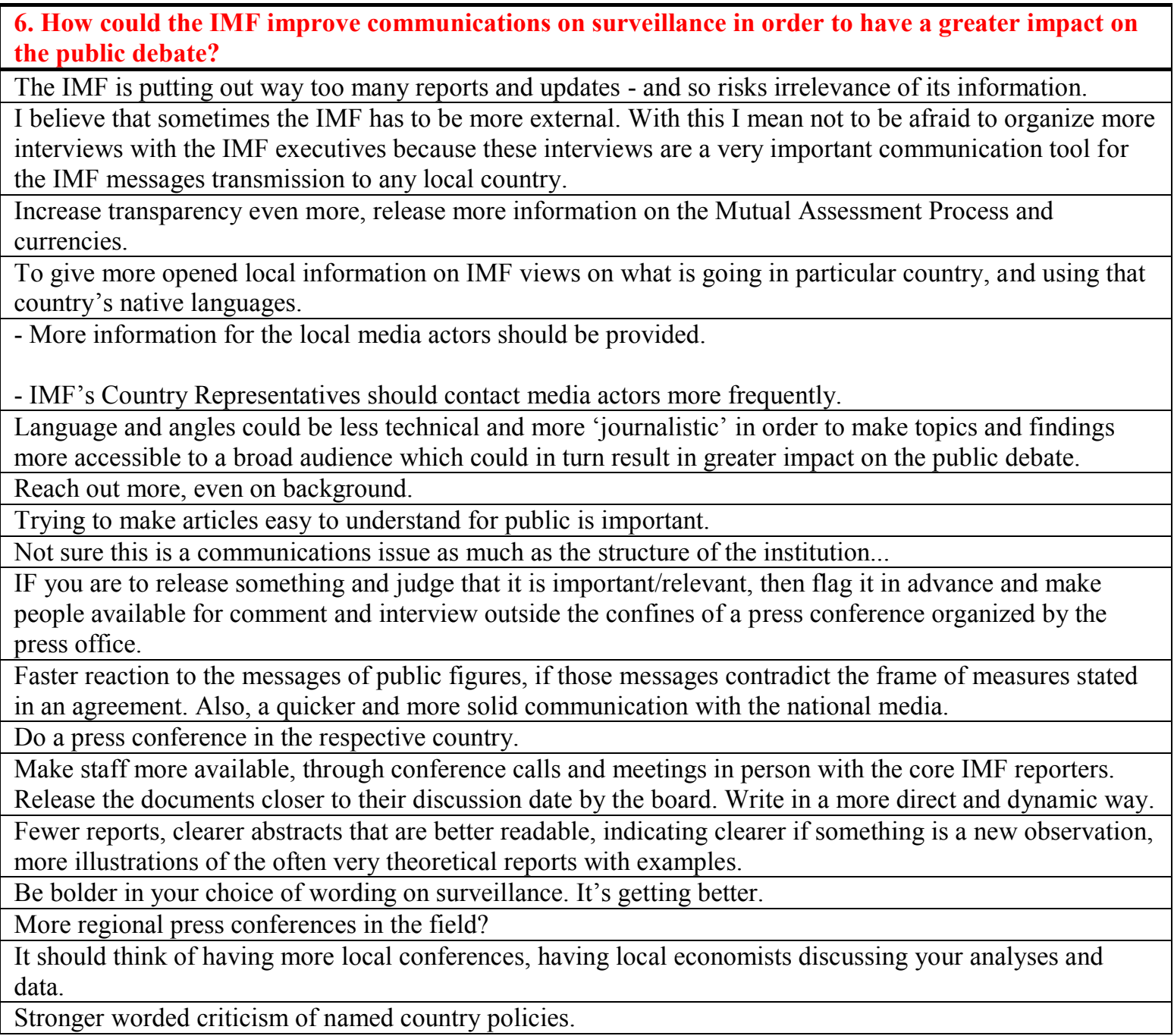




\section{Appendix II, Table 12. TSR CSO Survey Comments}

\begin{tabular}{l} 
1. The reasons why the communications of the IMF compared to other institutions are better or \\
worse are: \\
\hline Media Notifications. \\
\hline The communications are data-based and well analyzed. \\
Openness and willingness to incorporate views of new actors. \\
The IMF fails to take into account the views of many external stakeholders. Thus the views and \\
communications of the IMF are often one-sided. Additionally the failure to address the spillovers of \\
economic and international policy of systemically important countries means communication is ineffective \\
because it misses some of the most important issues. \\
\hline It reaches me now better than before; more easily obtainable. \\
The IMF is only recently opening up to wider society. It was always perceived as secretive and \\
unaccountable for its work, perhaps accountable to its Board. \\
\hline The people do not know the products. \\
We don't have an IMF office so I don't know about it so much. After coming here, communication is good \\
but there is room for improvement. \\
The only time the IMF and its publications are mentioned is when related to the MD. Compared with the \\
OECD and similar publications such as "Economic Outlook," the general belief--even inside IMF staff--is \\
that the OECD's studies are much more reliable. In this sense, their communication strategy is also more \\
extensive and more often quoted by governments and academia. \\
\hline $\begin{array}{l}\text { More in-depth and professional approach to analysis of issues and assessment of policies and their impact } \\
\text { on the economy. }\end{array}$ \\
\hline $\begin{array}{l}\text { I think IMF has been the global entity and also has influence to the member states. It also enjoys and } \\
\text { mobilizes the gigantic resources in the globe. }\end{array}$ \\
\hline Need to more details or information sharing at the national level; Need for more reporting. \\
IMF and IMF's work is not visible at all in the media and society. \\
\hline
\end{tabular}

\begin{tabular}{|l|}
\hline 2. What do you see as the main strength(s) of Fund surveillance? \\
\hline Very strong on depth of analysis. \\
\hline The strengths and weaknesses of the country's policies and programs. \\
\hline Knowledge generation. \\
\hline The fact that there is an independent voice overlooking some of the Fund's most powerful members. \\
\hline Providing data. \\
\hline It provides checks and balances and can provide early warning systems. \\
\hline The process wants to find the opinion of external independent experts. \\
\hline I think main Fund surveillance is economic outlook and cross-country analysis. \\
\hline Its country-specificity and financial-depth analysis. \\
\hline $\begin{array}{l}\text { It's precautionary and serves to alert officials of pending problems and/or provide assurances of outlook and } \\
\text { performance. }\end{array}$ \\
\hline Resource tabbing and also in strategic mobilization of the funds. \\
\hline Monitoring policies. \\
\hline Most independent and professional. \\
\hline
\end{tabular}




\section{Appendix II, Table 12. TSR CSO Survey Comments}

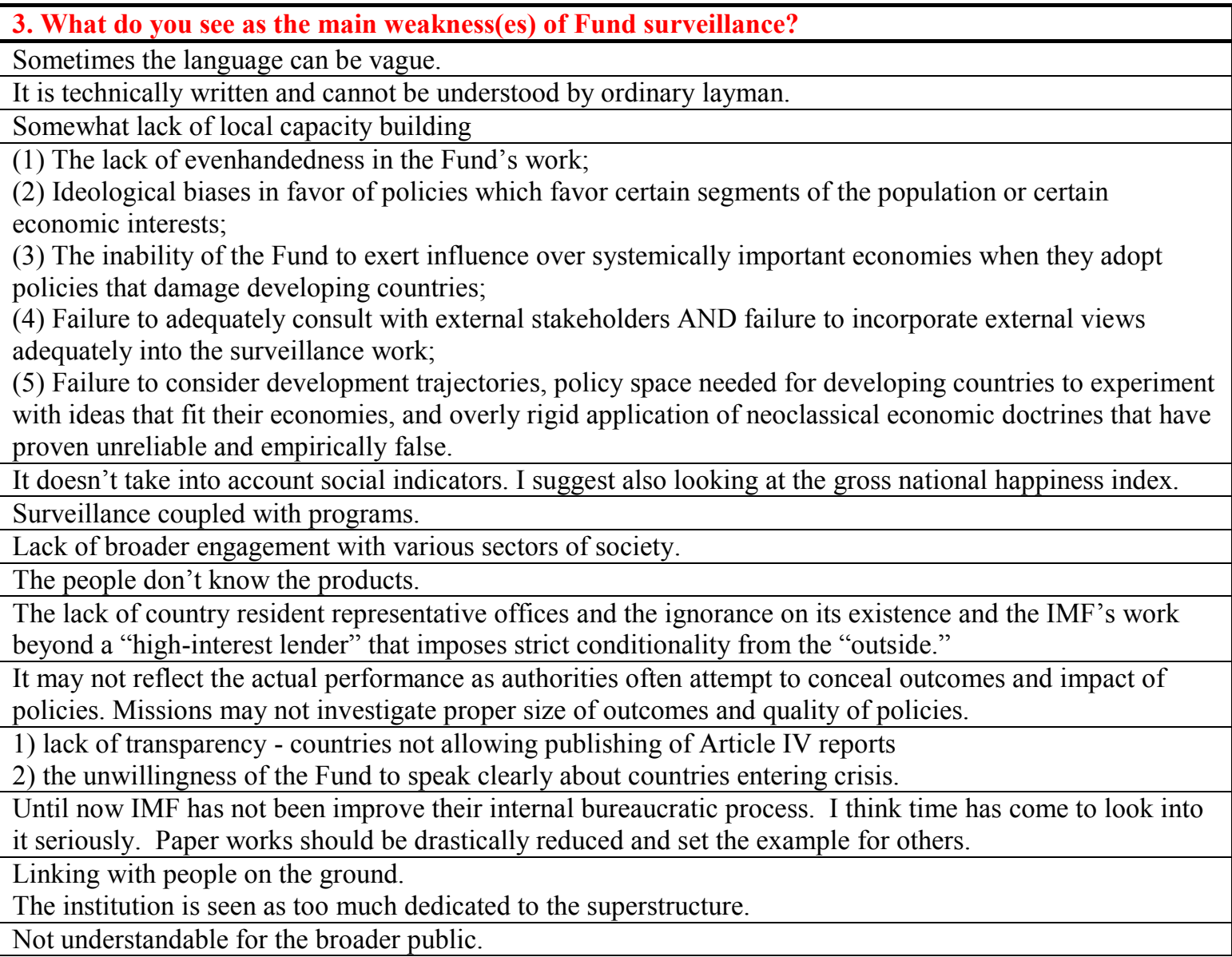

\section{Please use this space to offer any comments on how the IMF can make its surveillance more effective:}

Enhance dissemination of surveillance through presentation/discussion with CSOs.

The language can be simpler and shorter-like how Prof. Richard Bird writes.

Please read and incorporate the ideas in this briefing: http://www.brettonwoodsproject.org/art-566307

It needs to use technology like mobile internet and television to get more feedback from the masses.

Build expert think tanks in all member countries, exchange with them. Decouple from programs.

Communicate better and beyond its traditional audiences.

The IMF needs to do a campaign to help people know their products.

More consultation with diverse groups and make sure consultation ideas are put into action.

Associate with CSOs, not only governments. Also monitor and measure the efficiency and

representativeness of the IMF's own work. Would welcome students--especially economists--to participate in the review.

The IMF needs to deepen its analysis and become more doubtful of positive outlooks often displayed by authorities. Authorities often overrate and praise their performance by concealing actual performance or facts or by playing down the negatives. Authorities also may blame performance on external shocks or elements beyond their control while the reality is the opposite. Missions/economists need to assess quality of policies and variables such as investment and current spending.

Maybe in improving more communication of local offices with partners; regional approaches in reporting are also required.

Make reports that are understandable and user-friendly and advertise them among the people and media. CSOs can help doing this. 